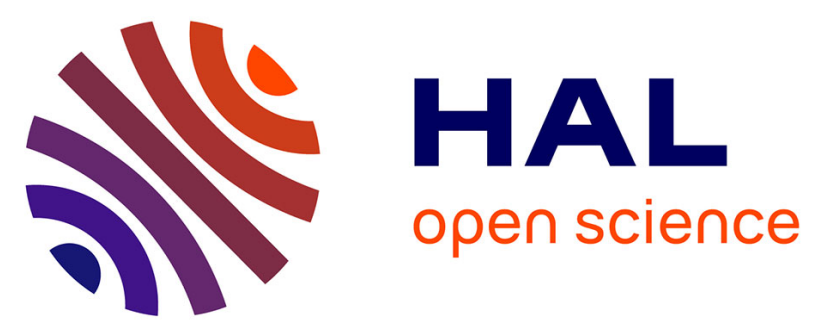

\title{
Revision of the genus [i]Neoseiulella[/i] Muma (Acari: Phytoseiidae). Re-description of species, synonymies assessment, biogeography, plant supports and key to adult females
}

Mohamad Kanouh, Serge Kreiter, Martial Douin, Marie-Stéphane Tixier

\section{To cite this version:}

Mohamad Kanouh, Serge Kreiter, Martial Douin, Marie-Stéphane Tixier. Revision of the genus [i]Neoseiulella[/i] Muma (Acari: Phytoseiidae). Re-description of species, synonymies assessment, biogeography, plant supports and key to adult females. Acarologia, 2012, 52 (3), pp.259-348. 10.1051/acarologia/20122048 . hal-01224019

\section{HAL Id: hal-01224019 \\ https://hal.science/hal-01224019}

Submitted on 3 Nov 2015

HAL is a multi-disciplinary open access archive for the deposit and dissemination of scientific research documents, whether they are published or not. The documents may come from teaching and research institutions in France or abroad, or from public or private research centers.
L'archive ouverte pluridisciplinaire HAL, est destinée au dépôt et à la diffusion de documents scientifiques de niveau recherche, publiés ou non, émanant des établissements d'enseignement et de recherche français ou étrangers, des laboratoires publics ou privés. 


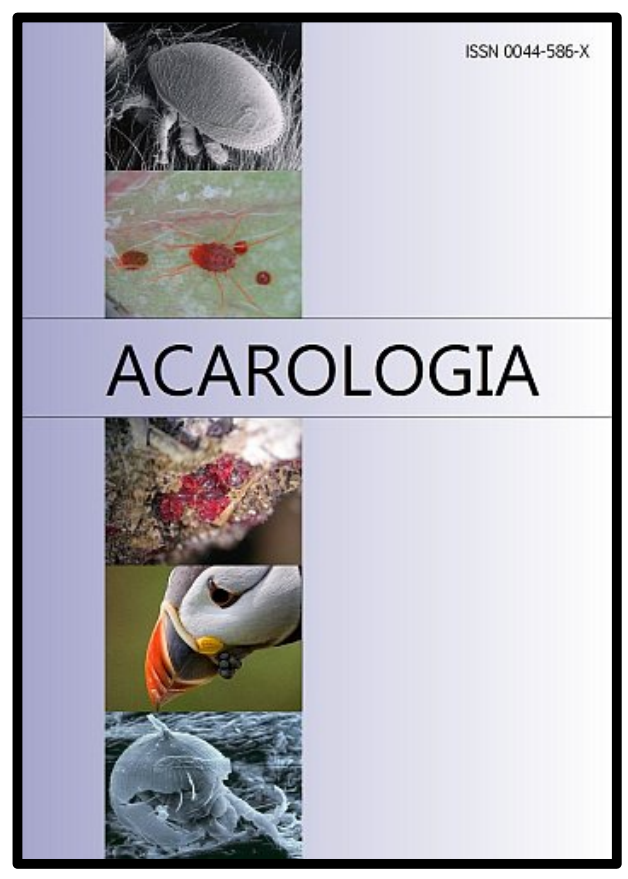

\section{ACAROLOGIA}

A quarterly journal of acarology, since 1959

Publishing on all aspects of the Acari

All information:

to http://www1.montpellier.inra.fr/CBGP/acarologia/ acarologia@supagro.inra.fr

\section{OPEN ACCESS}

\section{Acarologia is proudly non-profit, with no page charges and free open access}

Please help us maintain this system by encouraging your institutes to subscribe to the print version of the journal and by sending us your high quality research on the Acari.

Subscriptions: Year 2015 (Volume 55): $300 €$ http://www1.montpellier.inra.fr/CBGP/acarologia/subscribe.php

Previous volumes (2010-2014): $220 €$ / year (4 issues)

Acarologia, CBGP, CS 30016, 34988 MONTFERRIER-sur-LEZ Cedex, France

Acarologia is under free license and distributed under the terms of the

Creative Commons-BY-NC-ND which permits unrestricted non-commercial use, distribution, and reproduction in any medium, provided the original author and source are credited. 


\title{
REVISION OF THE GENUS NEOSEIULELLA MUMA (ACARI: PHYTOSEIIDAE). RE-DESCRIPTION OF SPECIES, SYNONYMY ASSESSMENT, BIOGEOGRAPHY, PLANT SUPPORTS AND KEY TO ADULT FEMALES
}

\author{
Mohamad Kanouh, Serge KREITER ${ }^{*}$, Martial DouIN and Marie-Stéphane TIXIER
}

(Received 05 December 2011; accepted 06 May 2012; published online 27 September 2012)

Montpellier SupAgro, Unité Mixte de Recherche Centre de Biologie pour la Gestion des Populations (CIRAD / INRA / IRD / SupAgro), Campus International de Baillarguet, CS 30 016, 34988 Montferrier-sur-Lez cedex, France. kreiter@supagro.inra.fr ( ${ }^{*}$ Corresponding author),douin@supagro.inra.fr, tixier@supagro.inra.fr

\begin{abstract}
Identification of species within the family Phytoseiidae is of primary importance for biological control programs. However, considerable disagreements between authors are often observed concerning the placement of species in genera. Moreover, considering the small number of available morphological characters and the poor knowledge of their reliability for species diagnostics, synonymies between several species could be questioned. This study aims to provide a taxonomic revision of a genus belonging to the sub-family Typhlodrominae: Neoseiulella Muma. Whereas the last revision of this genus (carried out in 1996) took into account 26 valid species, we propose now to include 47 species in the genus Neoseiulella based on type material observations. At first, three species (Neoseiulella eiko, N. eleglidus and N. schusteri) have been excluded from this genus, as their morphological attributes do not match the morphological characters which define the genus. Secondly, we also think that another species placed in the genus Typhlodromus (Anthoseius): T. (A.) elisae, has to be included in the genus Neoseiulella. Finally, several synonymies have been analysed and we conclude that: (i) $N$. aceri is a synonym of $N$. squamiger and provisionally of $N$. aceris (ii) $N$. tiliarum is a synonym of $N$. formosa, (iii) $N$. transitans is a synonym of N. prunus, and provisionally of N. vollsella, (iv) N. manukae is a synonym of N. glenfieldensis and (v) Neoseiulella tuberculata, N. sexapori and N. arutunjani are considered valid specific entities. A new synonymy between Neoseiulella nesbitti and N. armidalensis is also proposed. A standardised re-description of all the species of the genus is proposed and a key to the species for the adult females is provided. This study also gives an exhaustive compilation of all available information concerning the geographical distribution of species of Neoseiulella and their plant supports.
\end{abstract}

KEYWORDS - Taxonomy; morphology; identification; diagnoses

\section{INTRODUCTION}

Over the past fifty years, mites of the family Phytoseiidae Berlese (Acari: Mesostigmata) have been widely studied because of the ability of several species to control phytophagous mites and small insect pests in various crops worldwide (Kostiainen and Hoy 1996; McMurtry and Croft 1997). Tax- onomy studies, especially those dealing with diagnosis, are thus of first importance to ensure biological control program successes. Furthermore, knowledge of Phytoseiidae diversity can open new insights for the control of new pests. Chant and McMurtry $(1994,2007)$ recognized 2,280 species of Phytoseiidae dispatched in three sub-families (Amblyseiinae, Phytoseiinae, and Typhlodrominae) and 
84 genera. Species identification is mainly based on the morphological characters of females, as dorsal chaetotaxy, the shape and the setation of the ventral shields, the spermatheca shape, the setation of legs and the morphology and dentition of the chelicerae (Chant and McMurtry 2007). Identification of species is difficult, essentially because of the small number of available visible characters and of the poor knowledge on their reliability for species diagnostic. Thus, species validity (synonymy) is often questioned and disagreements between authors are noted in literature. Furthermore, as new taxa are discovered, as phylogenetic analyses are developped (Kanouh et al. 2010a), genera description and attributes could be modified, as well as the number of species belonging to them.

The aim of the present study is to provide an updated and complete revision of one genus belonging to the sub-family Typhlodrominae, tribe Typhlodromini: Neoseiulella Muma. The last revision of this genus carried out by Denmark and Rather in 1996 included 26 valid species, whereas in 2004, in the last world catalogue of the family Phytoseiidae, Moraes et al. reported 43 species, 35 being considered valid. In 2007, Chant and McMurtry in their world revision of the family have included 46 species and did not consider the previous synonymies. Furthermore, these latter authors did not take into account one additional species described in 2006. The genus Neoseiulella is thus currently assumed to include 46 species. However, doubts on some synonymies still exist as authors did not agree (Denmark and Rather 1984; Chant and YoshidaShaul 1989; Denmark and Rather 1996; Kolodochka 2009). The revision presently provides complete morphological descriptions of females based on the examination of type material and includes all the species reported in the genus Neoseiulella. Males are also described for some species for the first time. Moreorer, this paper presents an exhaustive compilation of all available information on geographical distribution of species of the genus and their plant supports. The present data set constitutes thus not only a taxonomic revision but also an actualised catalogue of the genus Neoseiulella.

The first part of the paper focuses on an histor- ical review of the genus Neoseiulella. The morphological characters defining the genus Neoseiulella, and validity of species presently included in this genus are consequently analysed. Six cases of synonymy within this genus are then studied and discussed. Finally, redescriptions of the species that we consider valid, and a key to adult females, are provided.

\section{HISTORICAL REVIEW OF THE GENUS Neoseiulella}

A summary of the complex history of the genus Neoseiulella is given in the Table 1.

Neoseiulella tiliarum (Oudemans 1930), initially included in the genus Typhlodromus Scheuten, was the first species described within the genus Neoseiulella. Two other species were described later and also assigned to the genus Typhlodromus: Neoseiulella nesbitti (Womersley 1954) and Neoseiulella aceri (Collyer 1957).

In 1959, Chant proposed the tiliarum species group in the genus Typhlodromus and included in it these three species. He characterized this species group by the presence of 11 pairs of lateral setae on the dorsal shield, and three or four pairs of preanal setae on the ventrianal shield.

In 1961, Muma proposed two new genera, Neoseiulella including $N$. nesbitti, and Typhloctonus including $N$. aceri and $N$. tiliarum. These two genera differed by the number of setae on the sternal shield, and by the occurrence of the preanal seta JV3 and macrosetae on the leg IV.

In 1962, Wainstein proposed two new subgenera differentiated according to the number of preanal setae: Nesbitteius including $N$. nesbitti and Kallistoseius including $N$. aceri and $N$. tiliarum. At the same time, Pritchard and Baker (1962) included these three species in the genus Typhlodromus (Seiulus) Berlese. In 1966, Ehara also used the sub-genus Typhlodromus (Seiulus) to designate the tiliarum species group.

In 1972, Abbasova placed N. tiliarum and N. aceri in the genus Seiulus. In 1975, Tseng proposed a monotypic genus, Shiehia, for Neoseiulella multispinosa (Tseng). Wainstein (1977) adopted the genus 
Typhloctonus proposed by Muma (1961) and divided it into three sub-genera: Typhloctonus (Typhloctonus), T. (Neoseiulellus) and T. (Tasmanidromus). Arutunjan (1977) and Kolodochka (1978) used the genus Typhloctonus for Neoseiulella squamiger (Wainstein), $N$. formosa (Wainstein) and N. tuberculata (Wainstein).
In 1981, Beglyarov used Typhloctonus as a subgenus in the genus Seiulus. Athias-Henriot and Fauvel (1981) proposed a new genus, Pegodromus, including in it Neoseiulella crassipilis (Athias-Henriot and Fauvel) and N. squamiger. Then, Lehman (1982) proposed a new monotypic genus, Heteroseiulus for

TABlE 1: A summary of the complex history of the genus Neoseiulella Muma

\begin{tabular}{|c|c|c|c|}
\hline Year & Combination of genera proposed by authors & $\begin{array}{l}\text { Considered species of the genus } \\
\text { Neoseiulella }\end{array}$ & Author \\
\hline 1930 & Typhlodromus & tiliarum & Oudemans \\
\hline 1954 & Typhlodromus & nesbitti & Womersley \\
\hline 1957 & Typhlodromus & aceri & Collyer \\
\hline 1959 & tiliarum group in the genus Typhlodromus & nesbitti, aceri, tiliarum & Chant \\
\hline \multirow[t]{2}{*}{1961} & I. Neoseiulella & I. nesbitti & Muma \\
\hline & II. Typhloctonus & II. tiliarum, aceri & \\
\hline \multirow[t]{2}{*}{1962} & I. Typhlodromus (Nesbitteius) section nesbitteius & I. nesbitti & Wainstein \\
\hline & II. Typhlodromus (Nesbitteius) section Kallistoseius & II. aceri, tiliarum & \\
\hline 1962 & Typhlodromus (Seiulus) & nesbitti, aceri, tiliarum & Pritchard and Baker \\
\hline 1966 & Typhlodromus (Seiulus) & nesbitti, formosa, tuberculata & Ehara \\
\hline 1972 & Seiulus & aceri, tiliarum & Abbasova \\
\hline 1974 & Typhloctonus & vollsella & Chaudhri et al. \\
\hline 1975 & Shiehia & multispinosa & Tseng \\
\hline \multirow[t]{3}{*}{1977} & I. Typhloctonus (Typhloctonus) & I. aceri, tiliarum & Wainstein \\
\hline & II. Typhloctonus (Neoseiulellus) & II. nesbitti & \\
\hline & III. Typhloctonus (Tasmanidromus) & III. cottieri & \\
\hline 1977 & Typhloctonus & formosa, tuberculata, squamiger & Arutunjan \\
\hline 1978 & Typhloctonus & formosa, squamiger & Kolodochka \\
\hline 1981 & Seiulus (Typhloctonus) & aceri, arutunjani, tiliarum, tuberculata & Beglyarov \\
\hline 1981 & Pegodromus & crassipilis, squamiger & Athias-Henriot and Fauvel \\
\hline 1982 & Heteroseiulus & aceris & Lehman \\
\hline \multirow[t]{2}{*}{1984} & Heteroseiulus = Typhloctonus; & aceri $=$ aceris & Denmark and Rather \\
\hline & Typhloctonus $\neq$ Neoseiulellus $\neq$ Tasmanidromus & & \\
\hline 1989 & $\begin{array}{l}\text { Neoseiulella, Typhloctonus, Shiehia, Pegodromus and } \\
\text { Heteroseiulus = Typhlodromus }\end{array}$ & $\begin{array}{l}26 \text { species in the tiliarum species } \\
\text { group }\end{array}$ & Chant and Yoshida-Shaul \\
\hline 1994 & Neoseiulella & $\begin{array}{l}\text { tiliarum species group, } \\
\text { cottieri species group }\end{array}$ & Chant and McMurtry \\
\hline \multirow[t]{3}{*}{1996} & I. Neoseiulella (Neoseiulella) & I. 9 species & Denmark and Rather \\
\hline & II. Neoseiulella (Typhloctona) & II. 17 species & \\
\hline & (Pegodromus $\neq$ Neoseiulella $)$ & & \\
\hline 2004 & Neoseiulella & 43 species (35 valid) & Moraes et al. \\
\hline 2007 & Neoseiulella & 46 species & Chant and McMurtry \\
\hline 2009 & Typhloctonus & tiliarum (type species) & Kolodochka \\
\hline
\end{tabular}


Kanouh M. et al.

Neoseiulella aceris (Lehman).

In 1984, Denmark and Rather considered valid the three sub-genera within the genus Typhloctonus proposed by Wainstein (1977), Typhloctonus, Neoseiulellus and Tasmanidromus. They also synonymised Heteroseiulus (Lehman) and Typhloctonus.

In 1989, in their revision of the tiliarum group within the genus Typhlodromus, Chant and YoshidaShaul considered 26 species and synonymised the genera Neoseiulella, Typhloctonus, Shiehia, Pegodromus, and Heteroseiulus.

Then in 1994, in the revision of the sub-families Phytoseiinae and Typhlodrominae, Chant and McMurtry divided the genus Neoseiulella in two species groups: the tiliarum species group (JV3 present) and the cottieri species group (JV3 absent).

In 1996, Denmark and Rather revised the genus Neoseiulella and also divided it into two sub-genera with three or four pairs of preanal setae: JV1, JV2, JV3 (present: N. [Neoseiulella], / absent: N. [Typhloctona]) and ZV2. Then, Kolodochka (2009) used the genus Typhloctonus for the species of the genus Neoseiulella occurring in Ukraine.

Still today, the definition of the genus Neoseiulella is not thus very clear, and species of the genus Neoseiulella could be included in other genera or in different sub-genera, depending on the author's opinions. In the present revision, as Chant and McMurtry $(1994,2007)$, we considered the genera Typhloctonus, Heteroseiulus, Pegodromus, and Shiehia junior synonyms of the genus Neoseiulella.

\section{DEFINITION OF THE GENUS Neoseiulella MUMA}

Neoseiulella Muma 1961: 295; Denmark and Rather 1996: 44; Chant and McMurtry 1994: 247; Moraes et al. 2004: 290; Chant and McMurtry 2007: 145. Typhloctonus Muma 1961: 299; Chaudhri et al. 1974: 231; Denmark and Rather 1984: 163; Kolodochka 2009: 484; Omeri 2009: 9 (Type species: Typhlodromus tiliarum Oudemans 1930a: 51). Typhlodromus (Nesbitteius) section Nesbitteius Wainstein 1962: 23 (Type species: Typhlodromus nesbitti Womersley
1954: 179).Typhlodromus (Nesbitteius) section Kallistoseius Wainstein 1962: 23 (Type species: Typhlodromus tiliarum Oudemans 1930: 51). Typhlodromus (Nesbitteius) (Wainstein) Arutunjan 1970: 19. Typhlodromus (Seiulus) Berlese, Pritchard and Baker 1962: 212-213; Ehara 1966: 16. Shiehia Tseng 1975: 48 (Type species: Shiehia multispinosa Tseng 1975: 48). Typhloctonus (Neoseiulellus) Muma, Wainstein 1977: 1416. Typhloctonus (Typhloctonus) Muma, Wainstein 1977: 1416. Typhloctonus (Tasmanidromus) Wainstein 1977: 1416. (Type species: Typhlodromus cottieri Collyer 1964: 640). Seiulus (Typhloctonus) Muma, Beglyarov 1981: 19; Karg 1983: 322. Pegodromus AthiasHenriot and Fauvel 1981: 71 (Type species: Pegodromus crassipilis Athias-Henriot and Fauvel 1981: 73). Heteroseiulus Lehman 1982: 236 (Type species: Heteroseiulus aceris Lehman 1982: 236). Neoseiulella (Neoseiulella) Denmark and Rather 1996: 44. Neoseiulella (Typhloctona) Denmark and Rather 1996: 44.

Type species: Typhlodromus nesbitti Womersley 1954: 179, by original designation.

Three genera are included in the tribe Typhlodromini within the sub-family Typhlodrominae: Neoseiulella, Typhlodromus and Typhloseiulus Chant and McMurtry. The genus Neoseiulella differs from the genus Typhlodromus by having both $\mathrm{Z} 1$ and S5 present. It differs from the genus Typhloseiulus essentially by the ventrianal shield, which is reduced (only one seta, JV2, inserted on the ventrianal shield) in Typhloseiulus (Chant and McMurtry 1994, 2007). In the present study, we consider the species of the genus Neoseiulella to have the following attributes:

Adult female with moderate to large body dimensions, dorsal shield varying from 260 to $480 \mu \mathrm{m}$ in length, and (160 to $310 \mu \mathrm{m})$ in width (at level of s4), and (140 to $260 \mu \mathrm{m})$ (at level of Z1).

Dorsal shield - Absence of $z 6$ together with the presence of z3, s6, Z1 and S5 (Chant and McMurtry $1994,2007)$. In some species, both or one of the sublateral setae $\mathrm{r} 3$ and $\mathrm{R} 1$ are inserted on the dorsal shield, but usually they are situated on the interscutal membrane. The dorsal shield bears usually 19 pairs of setae: j1, j3, j4, j5, j6, J2, J5, s4, s6, S2, S4, S5, z2, z3, z4, z5, Z1, Z4, Z5; dorsal setal pattern 12A: 9B (Chant and McMurtry 1994). Setae J1 
is present on three species (N. aceri but not visible on the drawing Fig 1, N. montforti, N. myopori); Chant and Yoshida-Shaul (1989) considered its presence as an "aberration" that does not affect the placement of such species. Usually, dorsal setae are smooth and Z4 and Z5 slightly serrated; but in some species all dorsal and sub-lateral setae are serrated. Dorsal shield bears one to seven pairs of solenostomes: gd1 (posterolateral to j3), gd2 (posteromediad to j4z4), gd4 (posterolateral to s4), gd5 (posteromediad to z5), gd6 (anteromediad to Z1), gd8 (anterior to $Z 4), g d 9$ (anterior to S5). The peritreme is short in few species (extending to level of $\mathrm{z} 4, \mathrm{z} 2$ or between $z 2-j 3$ ), but is usually long (extending to level of $j 1$, $\mathrm{j} 3$, or between $\mathrm{j} 1 \mathrm{j} 3$ ). It has a stippled surface, except for N. elongata (Ferragut and Pena-Estevez), that has a peritreme with an anterior surface striate. This latter characteristic is also found in the species of the genus Typhloseiulus but N. elongata differs from these species by the shape of the ventrianal shield (reduced in Typhloseiulus, not reduced in N. elongata) and the nature of dorsal setae (thorn-like in Typhloseiulus, simple in N. elongata).

Ventral shields - The female caudoventral pattern is JV: ZV; JV-3/ ZV; JV-3, 4/ ZV (Chant and McMurtry 1994). Sternal shield (35 to $95 \mu \mathrm{m}$ long; 50 to $100 \mu \mathrm{m}$ wide, at level of ST2), is smooth with two or three pairs of setae (ST1, ST2, ST3) and two pairs of poroids. A pair of metasternal setae (ST4) is inserted on separate platelets with a pair of small poroids. Genital shield smooth (95 to $170 \mu \mathrm{m}$ long; 40 to $90 \mu \mathrm{m}$ wide, at level of ST5), except for N. crassipilis that has genital shield distinctly reticulated. Three, four or six elongate platelets (for some authors genital sigilla in three pairs maximum) are situated between genital and ventrianal shields. For some species, these latter platelets or genital sigilla are fold under the genital shield. Ventrianal shield smooth, faintly striate, or reticulated (75 to $165 \mu \mathrm{m}$ long; 45 to $170 \mu \mathrm{m}$ wide, at level of ZV2), with three or four pairs of preanal setae: JV1, JV2, JV3 (present/ absent) and ZV2, usually with a pair of solenostomes $g v 3$. Four pairs of caudoventral setae (ZV1, ZV3, JV4, and JV5) are situated on the integument surrounding the ventrianal shield. The caudoventral seta JV4 is absent for one species, $N$. oleariae (Collyer). This absence is also found in the species of the tribes Typhloseiopsini and Metaseiulini in the sub-family Typhlodrominae (Chant and McMurtry 1994). However, N. oleariae differs from these species by the presence of both $\mathrm{Z} 1$ and $S 4$. The primary metapodal plate or inguinal sigilla for some authors (18 to $40 \mu \mathrm{m}$ long; 2 to $11 \mu \mathrm{m}$ wide) is elongate. The secondary metapodal plate (or inguinal sigilla) is of about $1 / 3$ as long as the primary one. Some poroids surround the ventrianal shield.

Spermatheca - The cervix ( 2 to $16 \mu \mathrm{m}$ long) has a cup- or U-shaped type, with atrium nodular to indistinct.

Chelicera - One to 13 teeth, without or usually with a pilus dentilis, are observed on the fixed digit of the chelicera. The movable digit (20 to 60 long) is edentate in some species but usually with 1 to 4 teeth.

Legs - The chaetotactic formulae of femorae, genuae, tibiae of legs I to IV are constant except for genu of leg II: femur I: 2-5/3-2; femur II: 2-5/2-1; femur III: 1-3/1-1; femur IV: 1-3/1-1; genu I: 2-2/1, 2/1-2; genu II: variable (see below); genu III: 1-2/1, 2/0-1; genu IV: 1-2/1, 2/0-1; tibia I: 2-2/1, 2/1-2; tibia II: 1-1/1, 2/1-1; tibia III: 1-1/1, 2/1-1; tibia IV: 1-1/1, 2/0-1. Except for Neoseiulella carmeli (Rivnay and Swirski) in which the genu II bears six setae (1$2 / 0,2 / 0-1)$, the genu II bears seven $(2 / 0-1,2-2 / 0)$ or eight $(2-2 / 1,2 / 0-1)$ setae. In some species, one or two macrosetae are present on the leg III, but usually no macroseta is observed on the legs I-III. In some species, macroseta is also absent on the leg IV, but usually leg IV bears at least one macroseta.

\section{MATERIAL AND METHODS}

Type materials of the species of the genus Neoseiulella have been examined (whenever possible) and measured with a phase and differential interference contrasts microscope (Leica DMLB, Leica Microsystèmes SAS, Rueil-Malmaison, France) (40x magnification). All the measurements are given in micrometers $(\mu \mathrm{m})$ and all measurements were performed with Perfect Image v. 7.6 software (Clara Vision). When more than one specimen was measured, mean and ranges (minimum - maximum) 
Kanouh M. et al.

TABLE 2: Morphological characteristics of Neoseiulella celtis (after Denmark and Rather 1996); N. compta (after Chant and Yoshida-Shaul 1989); N. multispinosa (after Tseng 1975); N. vollsella (after Denmark and Rather 1984)

\begin{tabular}{|c|c|c|c|c|}
\hline & N. celtis & N. compta & N. multispinosa & N. vollsella \\
\hline Dorsal Shield length & 369 & 286 & 313 & 326 \\
\hline Dorsal Shield width (at s4) & 185 & $?$ & 176 & 286 \\
\hline Dorsal Shield width (at Z1) & $?$ & 156 & $?$ & $?$ \\
\hline Dorsal Shield reticulation & reticulated & reticulated & reticulated & reticulated \\
\hline j1 length & 20 & 12 & 12.5 & 18 \\
\hline j3 length & 25 & 13 & 12.5 & 21 \\
\hline j4 length & 16 & 10 & 7.5 & 13 \\
\hline j5 length & 17 & 10 & 7.5 & 16 \\
\hline j6 length & 20 & 13 & 7.5 & 16 \\
\hline J2 length & 25 & 13 & 7.5 & 18 \\
\hline J5 length & 11 & 6 & 14 & 8 \\
\hline z2 length & 19 & 9 & 12.5 & 18 \\
\hline z3 length & 24 & 11 & 12.5 & 21 \\
\hline z4 length & 22 & 12 & 12.5 & 21 \\
\hline z5 length & 17 & 10 & 7.5 & 16 \\
\hline Z1 length & 20 & 13 & 10 & 23 \\
\hline Z4 length & 20 & 16 & 20 & 26 \\
\hline Z5 length & 47 & 17 & 15 & 39 \\
\hline s4 length & 24 & 10 & 12.5 & 26 \\
\hline s6 length & 28 & 12 & 12.5 & 18 \\
\hline S2 length & 32 & 12 & 12.5 & 26 \\
\hline S4 length & 32 & 15 & 12.5 & 26 \\
\hline S5 length & 26 & 17 & 15 & 18 \\
\hline r3 length & 28 & 11 & 10.5 & 23 \\
\hline R1 length & 25 & 11 & 12.5 & 18 \\
\hline gd1 presence & absent & absent & $?$ & $?$ \\
\hline gd2 presence & absent & absent & $?$ & $?$ \\
\hline gd4 presence & absent & absent & $?$ & $?$ \\
\hline gd5 presence & absent & absent & $?$ & $?$ \\
\hline gd6 presence & absent & absent & $?$ & $?$ \\
\hline gd8 presence & absent & present & $?$ & $?$ \\
\hline gd9 presence & present & absent & $?$ & $?$ \\
\hline Sternal Shield length & $?$ & $?$ & 67 & $?$ \\
\hline Sternal Shield width & $?$ & $?$ & 57.5 & $?$ \\
\hline ST3 on/off Sternal Shield & on & $?$ & on & on \\
\hline Genital Shield width & $?$ & $?$ & $?$ & $?$ \\
\hline Ventrianal Shield length & $?$ & 84 & 100 & $?$ \\
\hline Ventrianal Shield width & $?$ & 77 & 111 & $?$ \\
\hline Ventrianal Shield reticulation & smooth & smooth & reticulated & smooth \\
\hline
\end{tabular}

Measurements values of the different parts of the body are expressed in micrometers $(\mu \mathrm{m})$. 
TABLE 2: Continued.

\begin{tabular}{lcccc}
\hline & N. celtis & N. compta & N. multispinosa & N. vollsella \\
\hline JV3 presence/absence & present & present & present & present \\
Solenostomes / ventrianal shield & present & present & present & present \\
JV5 length & $?$ & 11 & $?$ & $?$ \\
Primary metapodal plate length & $?$ & $?$ & 37 & $?$ \\
Numbers of teeth on the fixed digit & 6 & 4 & 4 & 7 \\
pilus dentilis presence/absence & 0 & 1 & $?$ & $?$ \\
Numbers of teeth of movable digit dentation & 2 & 0 & 0 & 2 \\
Movable digit length & $?$ & 15 & $?$ & $?$ \\
Numbers of setae/ genu II & 7 & $?$ & $?$ & $?$ \\
Macrosetae on genu IV (length) & absent & absent & absent & present (16) \\
Macrosetae on tibia I (length) & absent & absent & absent & present (16) \\
Macrosetae on basitarsus IV (length) & present (41) & absent & absent & present (31) \\
Peritreme level & j1 & j1 & j1 & j1 \\
Spermatheca shaped & cup-shaped & $?$ & cup-shaped & $?$ \\
\hline
\end{tabular}

Measurements values of the different parts of the body are expressed in micrometers $(\mu \mathrm{m})$.

were provided. The kind of material (holotype, paratype, syntype, lectotype and/or paralectotype) and the institution or the museum where this material is deposited are provided in the redescription of each species. Setal nomenclature used in this paper follows Lindquist and Evans (1965) as adapted by Rowell et al. (1978) for the Phytoseiidae, with modifications for the caudal region as given by Lindquist (1994). Idiosomal gland nomenclature follows Athias-Henriot (1975) and Swirski et al. (1998).

The type materials of 41 species were examined. Despite repeated requests, it has been impossible to borrow the type materials of the four following species: N. celtis (Denmark and Rather) from India, N. compta (Corpuz-Raros) from Philippines, N. multispinosa (Tseng) from Taiwan, and N. vollsella (Chaudhri, Akbar and Rasool) from Pakistan. Detailed characteristics of these latter species were thus taken from the original descriptions and re-descriptions (Table 2). All other species were redescribed, even for synonyms in order to have objective arguments based on the real observation and study of morphological characters. This was done in order to establish synonymies on scientific bases and not on claimed bases.
Data on the geographical distribution and plant supports were mainly obtained from the world catalogue of the family Phytoseiidae (Moraes et al. 1986, 2004), from the original descriptions and from all the other publications reporting species of the genus Neoseiulella.

\section{RESULTS}

The result section is divided in five parts. The first part presents species that have been eliminated from the genus and those newly included. The second part presents a discussion on synonymies emphasized in literature. The third section deals with new suspected synonymies. The fourth part provides a re-description of the species we consider valid. Lastly, a key for female identification is proposed in the fifth part.

\section{The species considered as belonging to the genus Neoseiulella}

Are all the species presently known as Neoseiulella included into this genus?

Among the 46 species presently considered, three have been excluded from the genus Neoseiulella, as 
their attributes do not fit the morphological characters defining it. These species are N. schusteri, N. eiko and N. eleglidus.

\section{(i). Neoseiulella schusteri (Youssef and El-Brollosy)}

Typhlodromus schusteri Youssef and El-Brollosy in Zaher 1986: 129.

Neoseiulella schusteri (Youssef and El-Brollosy) Moraes et al. 2004: 295; Chant and McMurtry 2007: 147.

This species was not included in the genus Neoseiulella in the previous revisions of Chant and Yoshida-shaul (1989) and Denmark and Rather $(1984,1996)$. However, it was considered a member of the genus Neoseiulella in the last world catalogue of the family Phytoseiidae (Moraes et al. 2004), and then in the revision of the family (Chant and McMurtry 2007). As it has been impossible to borrow and thus to observe the type specimens (deposited in Plant Protection Department, Faculty of Agriculture, Cairo University, Egypt), an attentive examination of the dorsal chaetotaxy of the female, based on the original description, was carried out. We observe that the dorsal seta $\mathrm{z} 3$ is absent. This latter character with the presence of nine pairs of lateral setae on the dorsal shield (j3, z2, z4, s4, s6, S2, S4, $\mathrm{S} 5, \mathrm{Z5}$ ) keys to the species Cydnoseius negevi (Swirski and Amitai), tribe Galendromimini (sub-family Typhlodrominae). El-Brollosy (personal comm. 2008) confirmed that $N$. schusteri had been misidentified, and that it is a junior synonym of $C$. negevi.

\section{(ii). Neoseiulella eleglidus (Tseng)}

Typhlodromus (Typhlodromus) eleglidus Tseng 1983: 64-66. Typhlodromus eleglidus (Tseng) Wu et al. 1991: 82. Neoseiulella eleglidus (Tseng) Moraes et al. 2004: 293; Chant and McMurtry 2007: 147.

This species was not included in the genus Neoseiulella in the revisions of Chant and Yoshida-shaul (1989) and Denmark and Rather $(1984,1996)$. However, it was included in the genus Neoseiulella in the last world catalogue (Moraes et al. 2004), and then in the revision of the family (Chant and McMurtry 2007). It has been impossible to borrow and thus to observe the type specimens (deposited in
Plant Quarantine Laboratory, Tainan Branch, Bureau of Commodity Inspection and Quarantine, Tainan, Taiwan). However, the original description of this species shows 18 pairs of setae on the dorsal shield (j1, j3, j4, j5, j6, J2, J5, z2, z3, z4, z5, Z4, $\mathrm{Z} 5, \mathrm{~s} 4, \mathrm{~s} 6, \mathrm{~S} 2, \mathrm{S4}, \mathrm{S} 5)$ and 2 sub-lateral setae ( $\mathrm{r} 3$ and $\mathrm{R} 1)$. Because of the absence of seta $\mathrm{Z} 1$ and presence of seta 55 , this dorsal setal pattern (12A: 8B) keys to the genus Typhlodromus (Anthoseius) De Leon (tribe Typhlodromini, sub-family Typhlodrominae).

\section{(iii). Neoseiulella eiko Walter}

Neoseiulella eiko Walter 1997: 335; Moraes et al. 2004: 293; Chant and McMurtry 2007: 147.

The examination of the type materials of this species shows that $Z 1$ is absent, and $Z 2$ is present. These two characters with the presence of $z 3, s 6$ and S5, and the absence of z6 clearly constitute a new dorsal chaetotaxic pattern within the family Phytoseiidae. We therefore propose species to be included in a new genus in the tribe Typhlodromini (sub-family Typhlodrominae). The description of this new genus will be on the scope of another publication. Material examined. The female holotype and three female paratypes, collected by Walter (1995) on leaves of rainforest trees near the Boulders (Babinda, Queensland, Australia). Type materials are deposited in the UQIC, Department of Entomology, University of Queensland, St Lucia, Australia.

Are there species currently placed in other genera that in fact belong to the genus Neoseiulella?

Working on the genus Typhlodromus (Anthoseius), we observed that the species Typhlodromus (Anthoseius) elisae (Schicha and McMurtry 1986) might be included in the genus Neoseiulella. Schicha and McMurtry (1986), when described this species in the genus Typhlodromus, stated the absence of S5 on the dorsal shield. Furthermore, they drew nine pairs of ventrianal setae (4 preanals and 5 caudoventrals) whereas Phytoseiidae only could have eight (Chant and McMurtry 2007). As no species of Phytoseiidae presently described have the combination of characters beared by $T$. (A.) elisae: absence of S5, presence of both Z1 and S2, and five pairs of caudoventral setae, one of the hypotheses to explain such an 
aberration would be that one of the caudoventral setae might correspond to the seta S5. If S5 is effectively present, T. (A.) elisae would key to the genus Neoseiulella. Chant and Yoshida-Shaul (1989) also considered this hypothesis as they thought that S5 might be present (despite the poor conditions of the holotype). They thus included this later species in the tiliarum group. However, Denmark and Rather (1996) did not agree with this hypothesis, and consequently, excluded it from the genus Neoseiulella. This species was then cited in the sub-genus Typhlodromus (Anthoseius) De Leon in the world catalogue of the family Phytoseiidae (Moraes et al. 2004) and in the last revision of the family (Chant and McMurtry 2007). However, the examination of the holotype (Figure 1) clearly shows that S2 and Z1 (in the original description) are both present. This species thus does not belong to the genus Typhlodromus (Anthoseius) but to the genus Neoseiulella.

The questionements concerning T. (A.) elisae should alert us on the fact that in the literature other similar cases could exist, i.e. species placed in genera but clearly not belonging to them. In a further work, it would be worth to check for this.

\section{Neoseiulella elisae (Schicha and McMurtry) (Figure 1)}

Typhlodromus elisae Schicha and McMurtry 1986: 177; Chant and Yoshida-Shaul 1989: 1023-1024; Schicha 1987: 152, 154. Typhlodromus (Anthoseius) elisae Schicha and McMurtry Moraes, 2004: 322.

\section{Adult female (Figure 1a-d)}

Dorsal shield (Figure 1a) - Dorsal shield strongly reticulated, more heavily sclerotized on dorsocentral area of the shield: length 485 ; width 300 (at level of s4 and at level of Z1). Three pairs of solenostomes: gd5, gd8, and gd9 and 1 pair of poroids clearly visible. Sub-lateral setae ( $\mathrm{r} 3$ and R1) on the lateral margin. Bearing 19 pairs of setae, all dorsal and sub-lateral setae smooth: j1 22; j3 33; j4 18; j5 28; j6 42; J2 55; J5 18; z2 25; z3 25; z4 30; z5 30; Z1 43; Z4 60; Z5 55; s4 43; s6 50; S2 63; S4 55; S5 50; sub-lateral setae r3 38 and R1 40. Peritreme extending anteriorly to level of $\mathrm{j} 1$.

Ventral shields (Figure 1b) - Sternal shield lightly reticulated, 70 long and 50 wide (at level of ST2), with three pairs of setae (ST1, ST2 and ST3) and two pairs of small solenostomes. The fourth pairs, the metasternal setae (ST4) on separate platelets. A pair of small pores accompanying ST4. Genital shield lightly reticulated, 145 long and 70 wide (at level of ST5). Four elongate platelets or genital sigilla separating the genital and ventrianal shields not discernible on the specimen examined. One pair of poroids close to the genital shield (ST 5) and 4 pairs of poroids around the genital shield. Ventrianal shield subtriangular, distinctly reticulated throughout, 143 long and 133 wide (at level of ZV2), with four pairs of preanal setae (JV1, JV2, JV3 and ZV2), and a pair of small circular solenostomes gv3 posteromediad to JV3. Four pairs of caudoventral setae (ZV1, ZV3, JV4 and JV5) on the integument surrounding the ventrianal shield. JV5 50 long, smooth.

Spermatheca (Figure 1c) - Cervix 20 long, coneshaped.

Chelicera — Not visible.

Legs (Figure 1d) - Measurements of legs: leg I 356; leg II 270; leg III 288; leg IV 388. Seven setae $(2-2 / 0,2 / 0-1)$ on the genu II. Legs much shorter than the dorsal shield and macrosetae only on leg IV, SgeIV: 13, Sti IV: 40 with tip tapered, St IV: 28.

Material examined - The female holotype deposited in the New South Wales Department of Primary Industries, Agricultural Scientific Collections Unit (Acarology), Orange Agricultural Institute, Forest Road, Orange NSW 2800, Australia.

Adult male - The male of this species is unknown.

Previous reports - N. elisae is only known from Western Australia on Eucalyptus sp. (Myrtaceae).

We thus consider 44 valid species in the genus Neoseiulella in the followings parts of this paper.

\section{Are the synonyms previously suspected valid or not?}

Six synonymies (including 15 species) have been advanced by different authors (Denmark and Rather 1984; Chant and Yoshida-Shaul 1989; Denmark and Rather 1996; Moraes et al. 2004; Kolodochka 2009). In the present paper, we will 
Kanouh M. et al.
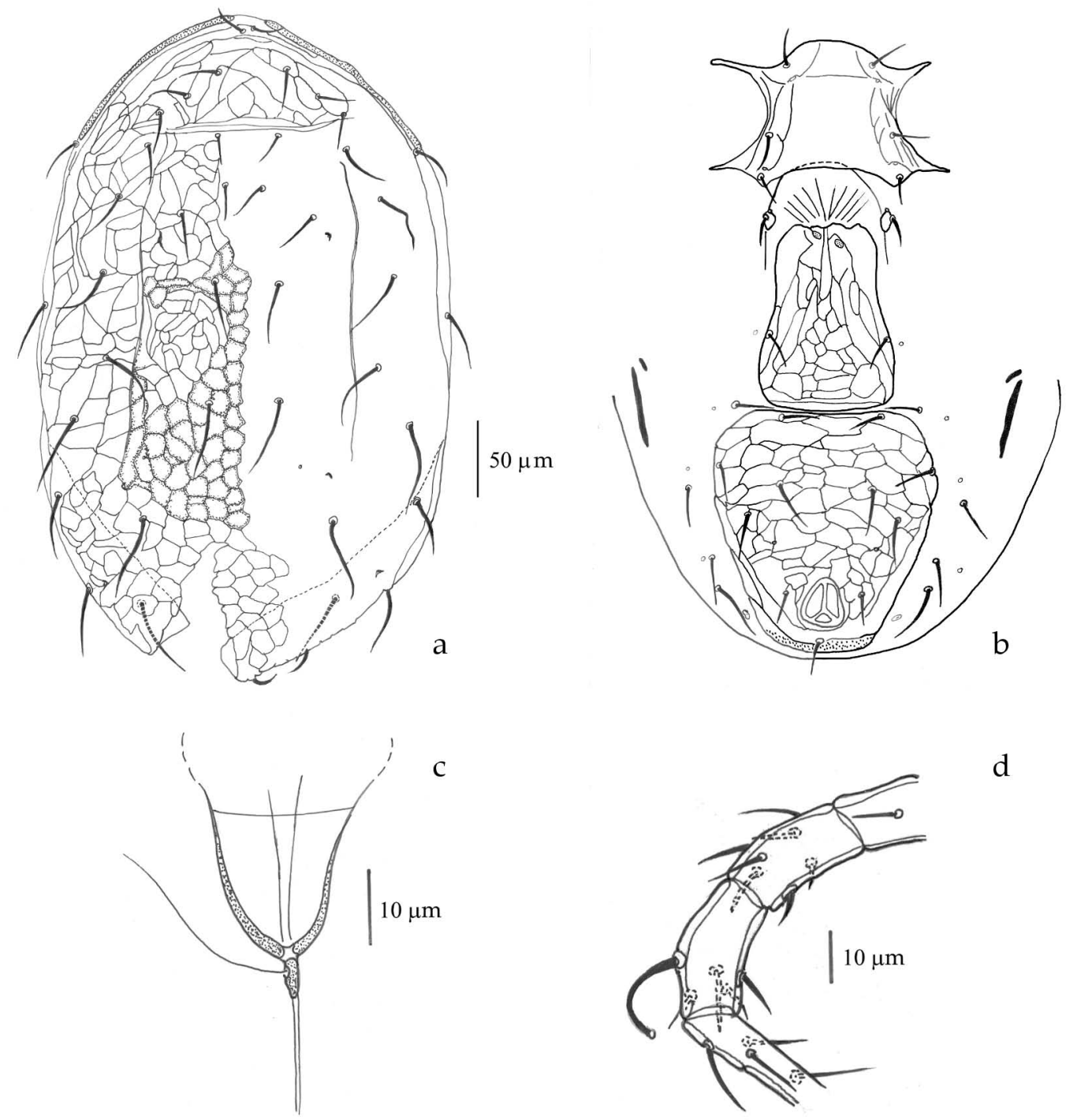

FIGURE 1: Neoseiulella elisae (Schicha and McMurtry). Female (holotype): a - dorsal shield; b - ventral shields; c - spermatheca; d chelicera. 
only focus on five of them, as it has been impossible to borrow and examine the type materials of Neoseiulella compta, N. multispinosa, and N. vollsella despite repeated requests during three years. For each synonymy, we present a complete description of the species based on the type materials.

\section{(i). Neoseiulella aceri (Collyer), N. squamiger (Wainstein) and N. aceris (Lehman)}

Neoseiulella squamiger was assumed to be a tentative junior synonym of $N$. aceri by Livshitz and Kuznetsov (1972) and Kolodochka (1986, 2009). Based on the examination of type materials, Denmark and Rather $(1984,1996)$ considered N. aceri to be different from both N. squamiger and N. aceris, and proposed that $N$. aceris as a junior synonym of N. squamiger, whereas Chant and YoshidaShaul (1989) considered that N. aceri was a senior synonym of both $N$. squamiger and $N$. aceris.

\section{Neoseiulella aceri (Collyer)} (Figure 2)

Typhlodromus aceri Collyer 1957: 199-200; Chant 1958: 626; Hirschmann 1962: 12; Livshitz and Kuznetsov 1972: 20; Chant and Yoshida-Shaul 1989: 1013. Typhlodromus (Typhlodromus) aceri (Collyer) Chant 1959: 65; Westerboer and Bernhard 1963: 565568. Typhloctonus aceri (Collyer) Muma 1961: 299; Denmark and Rather 1984: 166-167; Kolodochka 1986: 30-31; Moraes et al. 1986: 232; Kolodochka 2009: 486-487. Typhlodromus (Nesbitteius) aceri (Collyer) Wainstein 1962: 23. Seiulus aceri (Collyer) Abbasova 1972: 22; Karg and Edland 1987: 387; Steeghs et al. 1993: 24. Seiulus (Typhloctonus) aceri (Collyer) Beglyarov 1981: 19. Neoseiulella (Typhloctona) aceri (Collyer) Denmark and Rather 1996: 60. Neoseiulella aceri (Collyer) Moraes et al. 2004: 290; Chant and McMurtry 2007: 147.

\section{Adult female (Figure 2a-d)}

Dorsal shield (Figure 2a) - Dorsal shield distinctly reticulated throughout: length 318 (312 326), width 170 (166 - 174) (at level of s4) and 201 $(198$ - 207) (at level of Z1). Five pairs of small solenostomes on the dorsal shield: gd1, gd2, gd6, $\operatorname{gd} 8$, and gd9. No poroid visible. Sub-lateral setae (r3 and R1) on the lateral margin. Dorsal shield bearing 19 pairs of setae, all serrated: $\mathrm{j} 116(15-17)$; j3 $26(25-26)$; j4 18 (17 - 18); j5 18 (17 - 18); j6 24 (23 - 25); J2 31 (30 - 31); J5 14 (13 - 14); z2 21 (20 - 22); z3 26; z4 27; z5 16 (15 - 16); Z1 30 (28 - 31); Z4 35; Z5 38 (37 - 39); s4 31; s6 31 (30 - 31); S2 31; S4 26 (25 - 26); S5 14 (13 - 15); sub-lateral setae r3 21 (20 - 21) and R1 20. A pair of dorsal setae J1 (32) on one of the syntype females examined. Peritreme extending anteriorly to the level of $\mathrm{j} 3$ or between z2-j3.

Ventral shields (Figure 2b) - Sternal shield 37 $(34-40)$ long and $53(51-58)$ wide (at level of ST2), is smooth with three pairs of setae (ST1, ST2 and ST3) and two pairs of poroids (posterior to ST1; anterior to ST3). The pair of sternal setae ST3 on an elongate projection of the sternal shield. A pair of metasternal setae (ST4) on separate platelets with a pair of small poroids. Genital shield 126 (118 132) long and 60 (58-61) wide (at level of ST5), smooth. Four elongate platelets or genital sigilla between genital and ventrianal shields. One pair of poroids close to the genital shield (ST 5) and 4 pairs of poroids around the genital shield. Ventrianal shield subquadrate-shaped, 99 (96 - 101) long and 83 (82 - 86) wide (at level of ZV2), distinctly reticulated, with four pairs of preanal setae (JV1, JV2, JV3 and ZV2) and a pair of solenostomes gv3 posterior to JV3. Four pairs of caudoventral setae (ZV1, $\mathrm{ZV} 3$, JV4 and JV5) on the integument surrounding the ventrianal shield. JV5 $14(13-14)$ long, smooth. Primary metapodal plate or inguinal sigillum 30 (26 -31) long and $3(2-4)$ wide.

Spermatheca (Figure 2c) - Cervix $4(3-5)$ long, cup-shaped, with an enlarged atrium.

Chelicera (Figure 2d) - Two teeth and a pilus dentilis on the fixed digit. Movable digit $22(20-23)$ long, edentate. Legs. Measurements of legs: leg I 225 (210 - 231); leg II 204 (190 - 222); leg III 212 (190 - 225); leg IV 249 (233 - 270). Seven setae (2-2/0, $2 / 0-1)$ on the genu II. No macroseta on legs. Material examined. Four female syntypes deposited in the British Museum of Natural History $=\mathrm{BMNH}$, Cromwell Road, London, UK.

\section{Adult male (Figure 2e, f)}

Described by Collyer (1957), Chant (1958) and Denmark and Rather (1984, 1996). Dorsal shield chaetotaxy similar to the female. Ventrianal shield 


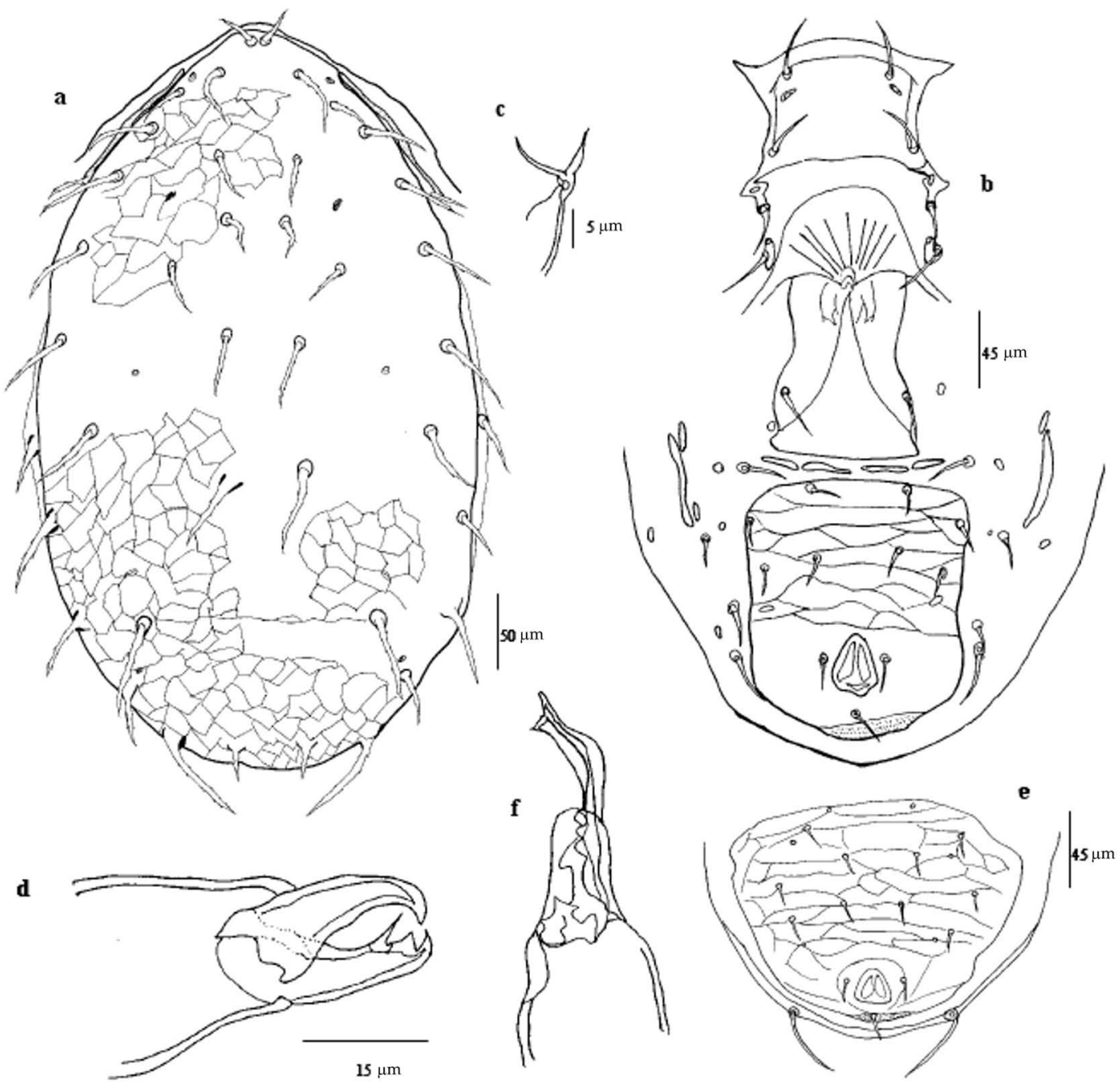

FIGURE 2: Neoseiulella aceri (Collyer). Female (syntype): a - dorsal shield; b - ventral shields; $\mathrm{c}$ - spermatheca; $\mathrm{d}$ - chelicera. Male (syntype): e - ventrianal shield; $\mathrm{f}$ - spermatodactyl.

97 long and 138 wide, distinctly reticulated and with five pairs of preanal setae and three pairs of poroids. Spermatodactyl with a terminal foot, and with a non-enlarged toe. This description is based on one male syntype.

Previous reports - N. aceri is only known from the West-Palaearctic and Nearctic areas. However, its occurrence in the Nearctic area (three records) might be due to an introduction. Countries from which this species is reported are: Azerbaijan (Abbasova 1972); Belgium (André 1986); Croatia (Tixier et al. 2010); Czech Republic (Kabicek 2003; Kabicek and Rehakova 2004; Kabicek 2005, 2010;); England (Collyer 1957); Finland (Tuovinen and Rokx 1991; Tuovinen 1993); France (Chant and Yoshida-Shaul 1989); Germany (Balder et al. 1999); Hungary (Szabo 1980; Ripka 1998, 2006); Italy (Ragusa and Paoletti 1985; Duso et al. 1993, 2004); Moldova (Beglyarov and Malov 1977); Norway (Karg and Edland 1987); Sweden (Steephs et al. 1993); Turkey (Cobanoglu 1996, 2000); Ukraine (Livshitz and Kuznetsov 1972; Akimov et al. 2007; Kolodochka and Omeri 2007; Kolodochka 2009); USA (Chant 1959b; Chant and 
Yoshida-Shaul 1989; Congdon 2002).

Neoseiulella aceri was collected from a wide range of plant supports: Acer campestre L., A. macrophyllum Pursh, A. platanoides L., A. pseudoplatanus L., Acer sp. (Aceraceae); Aesculus hippocastanum L. (Hippocastanaceae); Alnus incana (L.) Moench, Carpinus betulus L., Corylus avellana L. (Betulaceae); Juglans regia L. (Juglandaceae); Juniperus sabina L. (Cupressaceae); Morus alba L. (Moraceae); Prunus (Cerasus) sp., Prunus armeniaca L., Prunus sp., Rubus sp. (Rosaceae); Quercus ilex L. (Fagaceae); Trifolium pratense L. (Fabaceae); Zelkova sp. (Ulmaceae).

\section{Neoseiulella squamiger (Wainstein) (Figure 3)}

Typhlodromus squamiger Wainstein 1960: 689-690; Chant and Yoshida-Shaul 1989: 1013. Typhlodromus (Nesbitteius) squamiger (Wainstein) Arutunjan 1970: 19. Typhloctonus squamiger (Wainstein) Wainstein 1973: 176; Chaudhri et al. 1974, 231; Kolodochka 1974a: 27; Arutunjan 1977: 55; Kolodochka 1978: 50-51; Denmark and Rather 1984: 173-174; Moraes et al. 1986: 233. Pegodromus squamiger (Wainstein) Athias-Henriot and Fauvel 1981: 74. Neoseiulella (Typhloctona) squamiger (Wainstein) Denmark and Rather 1996: 61-62. Neoseiulella squamiger (Wainstein) Moraes et al. 2004: 291; Chant and McMurtry 2007: 147.

\section{Adult female (Figure $3 \mathrm{a}-\mathrm{d}$ )}

Dorsal shield (Figure 3a) - Dorsal shield distinctly reticulated throughout: 342 long, 184 (at level of s4) and 210 (at level of Z1). Five pairs of small solenostomes on the dorsal shield: gd1, gd2, $\operatorname{gd} 6, \operatorname{gd} 8$, and $\mathrm{gd} 9$ and no poroid visible. Sub-lateral setae $\mathrm{r} 3$ on the lateral margin and R1 on the dorsal shield. Dorsal shield bearing 20 pairs of setae (R1 on dorsal shield) all serrated: j1 14; j3 20; j4 17; j5 16; j6 21; J2 29; J5 13; z2 20; z3 25; z4 28; z5 15; Z1 28; Z4 35; Z5 42; s4 29; s6 30; S2 34; S4 27; S5 17; sublateral setae r3 20 and R1 20. Peritreme extending anteriorly to the level of $j 3$.

Ventral shields (Figure 3b) - Sternal shield 37 long and 53 wide (at level of ST2), smooth with three pairs of setae (ST1, ST2 and ST3) and two pairs of poroids (posterior to ST1; anterior to ST3). ST3 on an elongate projection of the sternal shield. A pair of metasternal setae (ST4) on separate platelets with a pair of small poroids. Genital shield 130 long and 60 wide (at level of ST5), smooth. Four elongate platelets or sigilla between genital and ventrianal shields. One pair of poroids close to the genital shield (ST 5) and 3 pairs of poroids around the genital shield. Ventrianal shield subquadrateshaped 103 long and 86 wide (at level of ZV2), distinctly reticulated, with four pairs of preanal setae (JV1, JV2, JV3 and ZV2) and a pair of solenostomes $g v 3$ posterior to JV3. Four pairs of caudoventral setae (ZV1, ZV3, JV4 and JV5) on the integument surrounding the ventrianal shield. JV5 17 long, smooth. Primary metapodal plate or inguinal sigillum 30 long and 3 wide.

Spermatheca (Figure 3c) - Cervix 4 long, cupshaped, with an enlarged atrium.

Chelicera (Figure 3d) - Two teeth and a pilus dentilis on the fixed digit. Movable digit 25 long, is edentate.

Legs - Measurements of legs: leg I 227; leg II 209; leg III 211; leg IV 239. Seven setae (2-2/0, 2/0$1)$ on the genu II. No macroseta on legs.

Material examined - The female holotype deposited in the ASU, Institute of Zoology, Academy of Sciences, Kiev, Ukraine.

Adult male (Figure 3e, f) Described by Denmark and Rather $(1984,1996)$.

Dorsal shield chaetotaxy is similar to the female. Ventrianal shield 103 long and 142 wide, distinctly reticulated and with five pairs of preanal setae and three pairs of poroids. Spermatodactyl with a terminal foot, and a slightly enlarged toe.

This description is based on one of the male specimens of our collection (Montpellier SupAgro collection, UMR CBGP), collected in Kiev (Ukraine) on Norway maple (Acer platanoides L.).

Previous reports - N. squamiger is only known from the West-Palearctic area. Countries from which this species is reported are: Armenia (Arutunjan 1970, 1971); Croatia (Tixier et al. 2010); Greece (Papadoulis and Emmanouel 1990); Hungary (Bozai 1996, 1997; Ripka 1998, 2006); Moldova (Wainstein 1960, 1973); Ukraine (Kolodochka 1973, 
Kanouh M. et al.

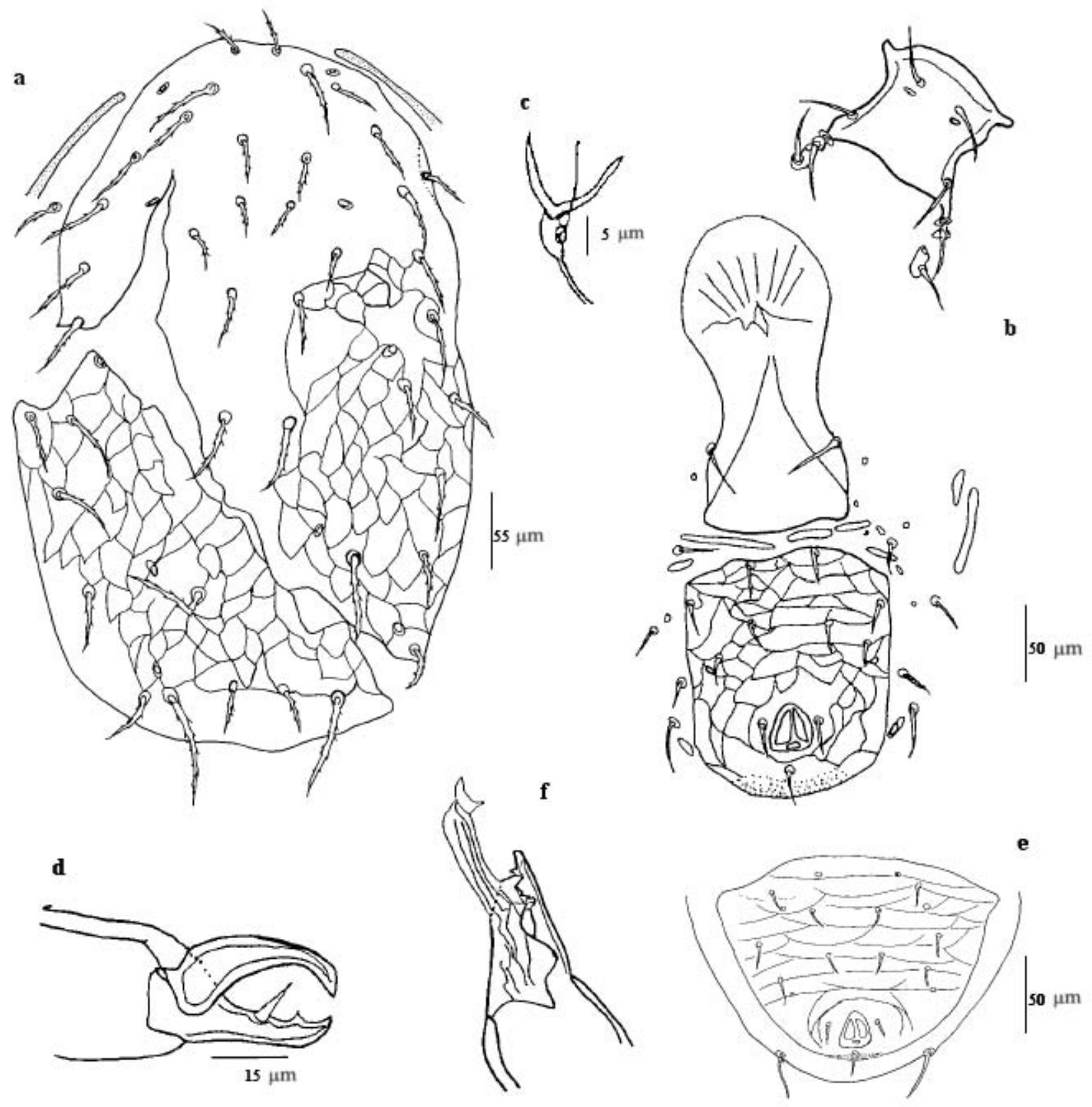

FIGURE 3: Neoseiulella squamiger (Wainstein). Female (holotype): a - dorsal shield; b - ventral shields; c - spermatheca; d - chelicera. Male (collection): e - ventrianal shield; f - spermatodactyl. 
1974b, 1978). Plant supports on which N. squamiger was collected are: Acer campestre, A. platanoides, Acer sp. (Aceraceae); Carpinus betulus, Corylus avellana, Ostrya carpinifolia Scopoli (Betulaceae); Cornus sp. (Cornaceae); Fraxinus ornus L. (Oleaceae); J. regia (Juglandaceae); Picea sp. (Pinaceae); Prunus (Cerasus) sp., Prunus sp. (Rosaceae).

\section{Neoseiulella aceris (Lehman) (Figure 4)}

Heteroseiulus aceris Lehman 1982: 236, 283. Neoseiulella aceris (Lehman) Moraes et al. 2004: 291; Chant and McMurtry 2007: 147.

\section{Adult female (Figure $4 \mathrm{a}-\mathrm{d}$ )}

Dorsal shield (Figure 4a) - Dorsal shield distinctly reticulated throughout: length 318 , width 180 (at level of s4) and 210 (at level of Z1). One pair of solenostomes gd 9 on the dorsal shield; other solenostomes, if present, not discernible because of the bad conditions of the specimen examined. No poroid visible. Sub-lateral setae $\mathrm{r} 3$ on the lateral margin, R1 on the dorsal shield. Dorsal shield bearing 20 pairs of setae (R1 on dorsal shield), serrated: j1 17; j3 25; j4 18; j5 18; j6 23; J2 36; J5 13; z2 19; z3 25; z4 29; z5 18; Z1 32; Z4 35; Z5 41; s4 32; s6 33; S2 35; S4 28; S5 17; sub-lateral setae r3 21 and R1 23. Peritreme extending anteriorly to the level of $j 3$.

Ventral shields (Figure 4b) - Sternal shield 40 long and 61 wide (at level of ST2), smooth, with three pairs of setae (ST1, ST2 and ST3) and two pairs of poroids (posterior to ST1; anterior to ST3). ST3 inserted on an elongate projection of the sternal shield. A pair of metasternal setae (ST4) inserted on separate platelets with a pair of small poroids. Genital shield 132 long and 54 wide (at level of ST5), smooth. Four elongate platelets or genital sigilla between genital and ventrianal shields. One pair of poroids close to the genital shield (ST 5) and 1 pair of poroids around the genital shield. Ventrianal shield subquadrate-shaped, 97 long and 82 wide (at level of ZV2), reticulated, with four pairs of preanal setae (JV1, JV2, JV3 and ZV2) and a pair of solenostomes gv3 posterior to JV3. Four pairs of caudoventral setae (ZV1, ZV3, JV4 and JV5) on the integument surrounding the ventrianal shield. JV5
15 long, smooth. Primary metapodal plate or inguinal sigillum 33 long and 2 wide.

Spermatheca (Figure 4c) - Cervix 4 long, cupshaped, with an enlarged atrium.

Chelicera (Figure 4d) - Two teeth and a pilus dentilis on the fixed digit. Movable digit 27 long, edentate.

Legs - Measurements of legs: leg I 245; leg II 214; leg III 211; leg IV 270. Seven setae (2-2/0, 2/01 ) on the genu II. No macroseta on legs.

Material examined - The female holotype deposited in the collection of the Florida, Department of Agriculture and Consumer Services, USA.

Adult maleDescribed by Lehman (1982). It has been impossible to borrow the male type specimen of this species.

Previous reports: N. aceris is only known from Pennsylvania (USA; Nearctic area). Plant supports on which this species was collected are: A. platanoides (Aceraceae); Aesculus hippocastanum (Hippocastanaceae); Ilex crenata 'rotundifolia' Thunb. (Aquifoliaceae); Juniperus virginiana L. (Cupressaceae); Pinus sylvestris L., Tsuga canadensis (L.) Carrière (Pinaceae); Taxus umbraculifera (Siebold ex Endl.) Ravenscroft var. hicksii (Hort. ex Rehder) Spjut (Taxaceae).

The examination of the type materials of $N$. aceri, N. squamiger and N. aceris shows similar measurements. However, N. aceri differs from both $N$. squamiger and $N$. aceris by the position of the sub-lateral seta R1. Recent molecular experiments (Kanouh et al. 2010) showed that the position of sub-lateral seta (R1) is not a valid diagnostic criteria to distinguish between these species and that $N$. squamiger and $N$. aceri are synonyms (Kanouh et al. 2010). This agrees with the conclusions of Chant and Yoshida-Shaul (1989) and Kolodochka (1986). On the other hand, only one pair of solenostomes (gd9) is observed on N. aceris, whereas five pairs (gd1, gd2, gd6, gd8, gd9) are observed on N. aceri and N. squamiger. Lehman (1982) drew three pairs of solenostomes ( $g d 2, \operatorname{gd} 6, \operatorname{gd} 8)$ that we did not observe on the specimen examined. As some authors have shown the importance of such characters for species differentiation (Chant and Yoshida- 


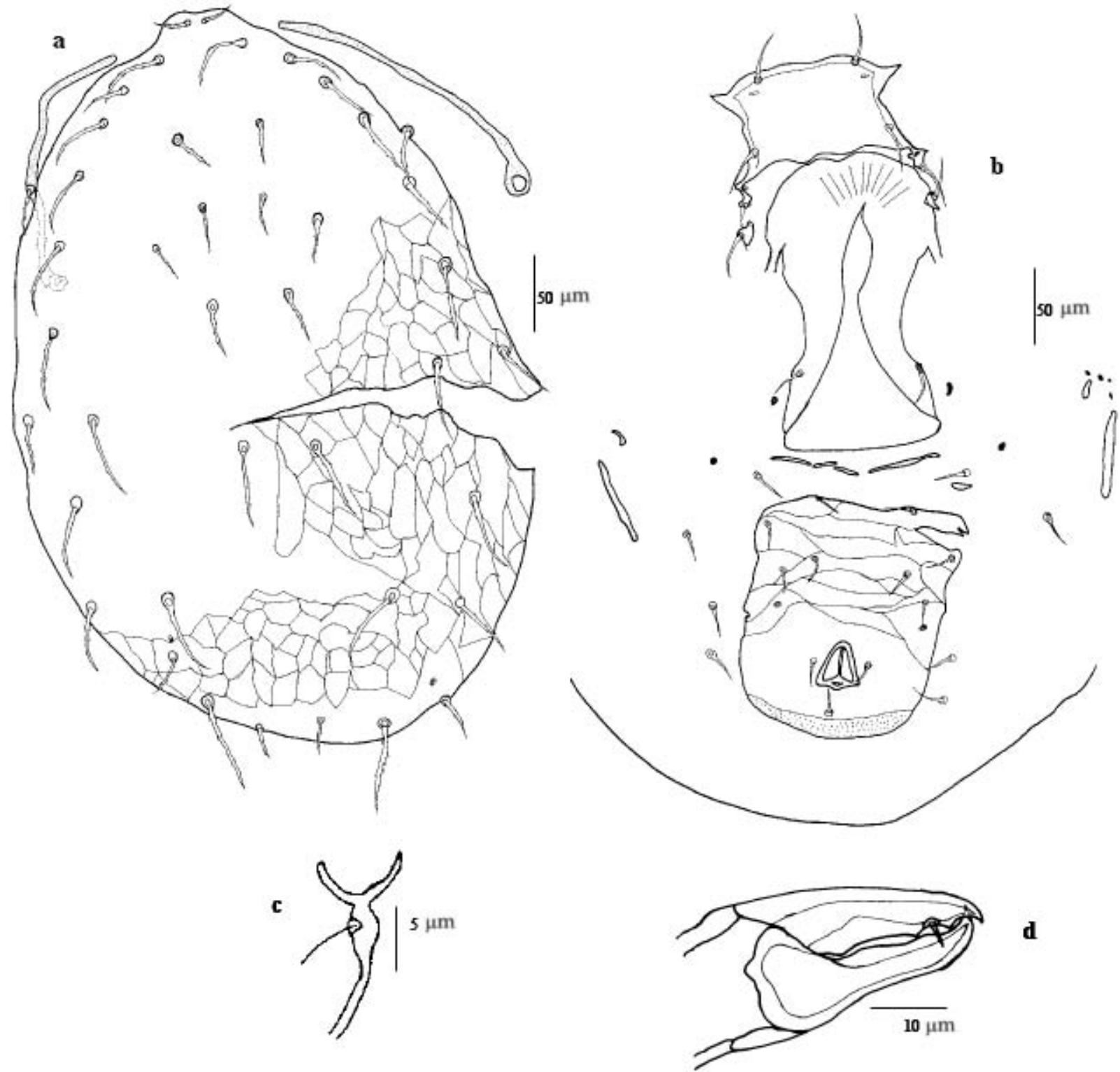

FIGURE 4: Neoseiulella aceris (Lehman). Female (holotype): a - dorsal shield; b - ventral shields; c - spermatheca; $\mathrm{d}$ - chelicera.

Shaul 1987; Ragusa and Tsolakis 1994; Tixier et al. 2006a, b), but as we do not know if this reliability is universal for species diagnostic, the synonymy of $N$. aceris and N. aceri / N. squamiger is still questioned. Examination of other female paratypes of $N$. aceris, as well as molecular analyses or cross breedings, would thus be required.
We thus consider that $N$. aceri is a senior synonym of $N$. squamiger, and we propose, at this time, that $N$. aceris as a provisional junior synonym of $N$. aceri. 
(ii). Neoseiulella tiliarum (Oudemans) and N. formosa (Wainstein)

Neoseiulella tiliarum was suggested as a senior synonym of N. formosa by Chant (1959b). Hirschman (1962) then considered these two species as valid. Denmark and Rather (1984) mentionned N. tiliarum in their revision of the genus Typhloctonus, but not N. formosa. Then, based on a morphlogical comparaison of type materials, Kolodochka (1986), Chant and Yoshida-Shaul (1989), Denmark and Rather (1996) and Kolodochka (2009) concluded that these two species are synonyms.

\section{Neoseiulella tiliarum (Oudemans) (Figure 5)}

Typhlodromus tiliarum Oudemans 1930: 51-52; Chant 1958: 622. Typhlodromus (Typhlodromus) tiliarum (Oudemans) Chant 1959: 65. Typhloctonus tiliarum (Oudemans) Muma 1961: 299; Denmark and Rather 1984: 165; Kolodochka 1986: 26-27; Moraes et al. 1986: 233; Kolodochka 2009: 485-486. Typhlodromus (Nesbitteius) tiliarum (Oudemans) Wainstein 1962: 23. Seiulus tiliarum Abbasova 1972: 21; Karg 1982: 205; Karg and Edland 1987: 387. Seiulus (Typhloctonus) tiliarum (Oudemans) Beglyarov 1981: 19. Neoseiulella (Typhloctona) tiliarum (Oudemans) Denmark and Rather 1996: 58-59. Neoseiulella tiliarum (Oudemans) Chant and McMurtry 1994: 248; Moraes et al. 2004: 296; Chant and McMurtry 2007: 147.

\section{Adult female (Figure $5 \mathrm{a}-\mathrm{d}$ )}

Dorsal shield (Figure 5a) - Dorsal shield distinctly reticulated throughout: length 350; width 164 (at level of s4) and 182 (at level of Z1). Five pairs of large circular solenostomes: gd1, gd2, gd6, gd8, and gd9. No poroid visible. Sub-lateral setae (r3 and R1) on the lateral margin. Dorsal shield bearing 19 pairs of setae, all smooth except Z4 and Z5 slightly serrated: j1 20; j3 30; j4 19; j5 21; j6 20; J2 26; J5 7; z2 25; z3 31; z4 32; z5 20; Z1 26; Z4 38; Z5 44; s4 34; s6 36; S2 40; S4 35; S5 18; sub-lateral setae r3 29 and R1 21. Peritreme extending anteriorly to the level of $z 4$.

Ventral shields (Figure 5b) - Sternal shield 82 long and 84 wide (at level of ST2), smooth with two pairs of setae (ST1 and ST2) and two pairs of poroids. ST3 on a separate platelet close to the sternal shield. A pair of metasternal setae (ST4) on separate platelets with a pair of small poroids. Genital shield 123 long and 62 wide (at level of ST5), smooth. Four elongate platelets or genital sigilla folded under the genital shield and between genital and ventrianal shields. One pair of poroids close to the genital shield (ST 5) and 1 pair of poroids around the genital shield. Ventrianal shield rectangular-shaped, 103 long and 60 wide (at level of ZV2), slightly reticulated, with four pairs of preanal setae (JV1, JV2, JV3 and ZV2) and without solenostome $g v 3$. Four pairs of caudoventral setae (ZV1, ZV3, JV4 and JV5) on the integument surrounding the ventrianal shield. JV5 26 long, smooth. Primary metapodal plate or inguinal sigillum 28 long and 3 wide.

Spermatheca (Figure 5c) - Cervix 14 long, elongated and cup-shaped.

Chelicera (Figure 5d) - One tooth and a pilus dentilis on the fixed digit. Movable digit 27 long, unidentate.

Legs - Measurements of legs: leg I 274; leg II 222; leg III 219; leg IV 281. Eight setae (2-2/1, 2/0-1) on the genu II. No macroseta on legs.

Material examined - The female holotype deposited in the Rijksmuseum van Natuurlijke Historie, Leiden, the Netherlands. As this specimen was in bad conditions, the leg chaetotaxy and lengths were observed on one specimen of our collection (Montpellier SupAgro, UMR CBGP), collected in Valleraugues (Gard, South of France) on small leaved linden (Tilia cordata Miller).

Adult male (Figure 5e, f) Described by Livshitz and Kuznetsov (1972) and Denmark and Rather (1984, 1996). Dorsal shield chaetotaxy similar to the female, but the sub-lateral seta R1 on the dorsal shield. Ventrianal shield 104 long and 131 wide, distinctly reticulated and bearing five pairs of preanal setae and three pairs of poroids. Spermatodactyl Lshaped with a terminal foot and a toe slightly enlarged. This description is based on a specimen of our collection (Montpellier SupAgro, UMR CBGP), collected in Valleraugues (Gard, South of France) on T. cordata. 


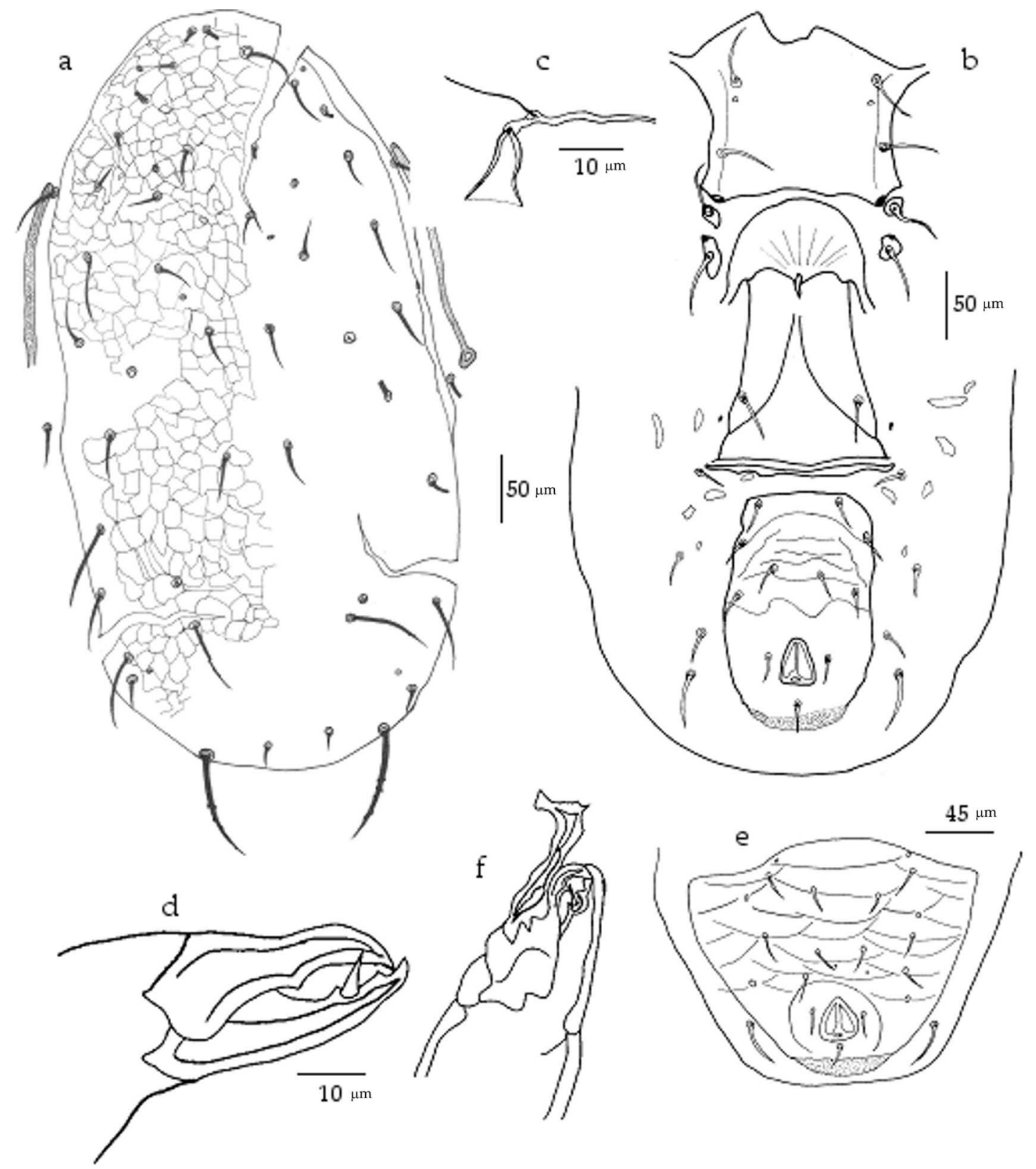

FIGURE 5: Neoseiulella tiliarum (Oudemans). Female (holotype): a - dorsal shield; b-ventral shields; c-spermatheca; $d$ - chelicera. Male (collection): e - ventrianal shield; $\mathrm{f}$ - spermatodactyl.

Previous reports $-N$. tiliarum is only known from the West- Palaearctic and Nearctic areas. However, its occurrence in the Nearctic area (15 reports in Canada and three in USA) might be due to introductions. The three reports in Massachusetts (USA) were on insects: Graphiphora haruspica (Grote) and Spaelotis clandestine (Harris) (Noctuidae, Lepi- doptera) (Treat 1975). Countries from which this species is reported are: Algeria (Athias-Henriot, 1958b); Austria (Bohm 1960; Ragusa and Ragusa 1997); Azerbaijan (Abbasova 1972); Canada (Nesbitt 1951; Herbert 1952; Chant et al. 1974); Croatia (Tixier et al. 2010); Czech Republic (Kabicek 2003; Kabicek and Rehakova 2004; Kabicek 2008, 
2010); Denmark (Hansen and Johnsen 1986); England (Nesbitt 1951; Chant 1955, 1956; Collyer 1956); France (Gunthart 1957, 1960; Rambier 1974; Kreiter and Brian 1987; Kreiter et al. 2000; Tixier et al. 2000; Arnault et al. 2008); Georgia (Samsoniya 1977); Germany (Oudemans 1930; Dosse 1956a, b, 1957; Westerboer and Bernhard 1963; Thill 1964; Karg 1970, 1971, 1972, 1975); Greece (Swirski and Ragusa 1976; Ragusa and Tsolakis 1998); Hungary (Kropczyńska and Jenser 1968; Bozai 1980; Dellei and Szendrey 1991; Sarospataki et al. 1992; Bream and Bozai 1995; Bozai 1996, 1997; Ripka 1998, 2006); Iran (Daneshvar 1987); Italy (Gunthart 1957, 1960; Coiutti 1993; Duso et al. 1993; Michelatti et al. 1994; Nicotina and Cioffi 1998 ; Duso et al. 2004); Moldova (Beglyarov and Malov 1977); Montenegro (Mijuskovic and Tomasvic 1975); Netherlands (Nesbitt 1951; Van de Vrie and Fluiter 1958; Van de Vrie 1963, 1972; Miedema 1987); Norway (Karg and Edland 1987); Poland (Wiackowski and Suski 1963; Boczek 1964; Dabrowski 1968; Dabrowski 1970; Skorupska 1981; Chant and Yoshida-Shaul 1989; Jaworski 2000; Kropczyńska et al. 2009); Russia (Beglyarov 1962); Slovak Republic (Praslicka and Bartekova 2008; Praslicka et al. 2009); Spain (Chant and Yoshida-Shaul 1989; Villaronga and GarciaMari 1988, 1992; Minarro et al. 2005); Switzerland (Gunthart 1957, 1960; Genini et al. 1983; Klay 1987); Tunisia (Kreiter et al. 2002); Turkey (Swirski and Amitai 1982; Düzgüneş and Kiliç 1983; Cobanoglu 1991, 1992, 1996, 2000); Ukraine (Akimov and Kolodochka 1970; Livshitz and Kuznetsov 1972; Beglyarov and Malov 1977; Kolodochka and Omeri 2007; Kolodochka 2009; Omeri 2009); USA (Treat 1975).

Neoseiulella tiliarum was collected on a wide range of plant supports: A. campestre, Acer sp. (Aceraceae); Actinidia deliciosa (Chev.) Liang and Ferguson (Actinidiaceae); A. hippocastanum (Hippocastanaceae); Agrimonia sp., Malus baccata (L.) Borkh, M. pumila Miller, Malus sp., Mespilus sp., P. armeniaca, P. cerasifera Ehrh, P. (Cerasus) avium (L.) L., P. domestica L., Prunus sp., P. spinosa L., Pyrus aucuparia L., P. communis L., Rosa sp., Rubus sp. (Rosaceae); Alnus sp., Carpinus betulus, Corylus avellana, Corylus sp. (Betulaceae); Castanea sativa Miller,
Fagus sylvatica L., Quercus sp. (Fagaceae); Cercis canadensis L. (Fabaceae); Citrus sp. (Rutaceae); Cornus sanguinea L., Cornus sp. (Cornaceae); Ficus carica L. (Moraceae); Frangula alnus Miller (Rhamnaceae); Fraxinus angustifolia Vahl, Fraxinus sp., Olea sp. (Oleaceae); Dittrichia viscosa (L.) Greuter (Asteraceae); Juglans regia (Juglandaceae); Pteridium aquilinum (L.) Kuhn (Hypolepidaceae); Ribes nigrum L., Ribes sp. (Grossulariaceae); Tilia americana L., T. cordata Miller, T. miqueliana Maxim., T. platyphyllos Scopoli, Tilia sp. (Tiliaceae); Ulmus campestris L., $U$. laevis Pallas, U. pumila L., U. scabra (Miller), Ulmus sp., U. suberosa Moench, Zelkova carpinifolia (Pall.) Dippel., Zelkova sp. (Ulmaceae); Urtica dioica L. (Urticaceae); Vitis sp., V. vinifera L. (Vitaceae).

\section{Neoseiulella formosa (Wainstein) (Figure 6)}

Typhlodromus formosus Wainstein 1958: 206; Abbasova 1966: 186. Typhlodromus (Seiulus) formosus (Wainstein) Ehara 1966: 16. Typhlodromus (Nesbitteius) formosus (Wainstein) Arutunjan 1970: 19. Typhloctonus formosus (Wainstein) Kolodochka 1974a: 26-27; Rivnay and Swirski 1980: 183. Neoseiulella formosa (Wainstein) Moraes et al. 2004: 297; Chant and McMurtry 2007: 147.

Adult female (Figure $6 \mathrm{a}-\mathrm{d}$ )

Dorsal shield (Figure 6a) - Dorsal shield distinctly reticulated throughout: length 336; width 163 (at level of s4) and 180 (at level of Z1). Five pairs of large circular solenostomes: gd1, gd2, gd6, gd8, and gd9. No poroid visible. Sub-lateral setae (r3 and R1) on the lateral margin. Dorsal shield bearing 19 pairs of setae, all smooth except Z4 and Z5 slightly serrated: j1 19; j3 30; j4 19; j5 20; j6 18; J2 26; J5 11; z2 22; z3 28; z4 31; z5 17; Z1 33; Z4 38; Z5 44; s4 34; s6 34; S2 39; S4 35; S5 19; sub-lateral setae r3 28 and R1 21. Peritreme extending anteriorly to the level of $\mathrm{z} 4$.

Ventral shields (Figure 6b) - Sternal shield 66 long and 65 wide (at level of ST2), smooth with three pairs of setae (ST1, ST2 and ST3) and two pairs of poroids. ST3 on an elongate projection of the sternal shield. A pair of metasternal setae (ST4) on separate platelets with a pair of small poroids. Genital shield 117 long and 62 wide (at level of 
ST5), smooth. Four elongate platelets or genital sigilla folded under the genital shield and situated between genital and ventrianal shields. One pair of poroids close to the genital shield (ST 5) and 3 pairs of poroids around the genital shield. Ventrianal shield rectangular-shaped, 102 long and 66 wide (at level of ZV2), lightly reticulated, with four pairs of preanal setae (JV1, JV2, JV3 and ZV2) and without solenostome $g v 3$. Four pairs of caudoventral setae (ZV1, ZV3, JV4 and JV5) on the integument surrounding the ventrianal shield. JV5 24 long, smooth. Primary metapodal plate or inguinal sigillum 31 long and 3 wide.

Spermatheca (Figure 6c) - Cervix 13 long, elongated and cup-shaped.

Chelicera (Figure 6d) - One tooth and a pilus dentilis on the fixed digit. Movable digit 26 long, bearing one tooth.

Legs - Measurements of legs: leg I 271; leg II 219; leg III 211; leg IV 275. Eight setae (2-2/1, 2/0-1) on the genu II. No macroseta on legs.

Material examined - The female lectotype deposited in the ASU, Institute of Zoology, Academy of Sciences, Kiev, Ukraine.

Adult male (Figure 6e, f) Dorsal shield chaetotaxy similar to the female, but sub-lateral seta R1 on the dorsal shield. Ventrianal shield 99 long and 139 wide, distinctly reticulated and bearing five pairs of preanal setae and four pairs of poroids. Spermatodactyl L-shaped with a terminal foot and a toe enlarged. This description is based on one of the paralectotype specimens (deposited in the ASU, Ukraine).

Previous reports - N. formosa is only known from the West-Palaearctic area. Countries from which this species is reported are: Armenia (Arutunjan 1970, 1971); Caucasus region (Abbasova 1966); Georgia (Wainstein 1958; Samsoniya 1972; Wainstein and Vartapetov 1973); Hungary (Bozai 1996, 1997; Ripka 1998, 2006); Moldova (Wainstein 1973); Ukraine (Wainstein 1958; Kolodochka 1974b, 1978). Plants on which N. formosa was reported are: A. campestre, Acer sp. (Aceraceae); Cydonia sp., Malus sp., Mespilus germanica L., Mespilus sp., P. armeniaca, P. cerasifera, P. (Cerasus) avium, Prunus sp.,
P. spinosa, Pyrus sp., Rosa sp., Rubus sp., Sorbus sp. (Rosaceae); Alnus sp., C. avellana, Corylus sp. (Betulaceae); Cornus sp. (Cornaceae); Ficus carica L. (Moraceae); Juglans regia (Juglandaceae); Phaseolus sp. (Fabaceae); Q. cerris L., Quercus sp. (Fagaceae); U. laevis, U. scabra, Ulmus sp. (Ulmaceae).

The examination of the type materials of both $N$. tiliarum and $N$. formosa shows that except for the position of sternal setae ST3 (on/off the sternal shield), all other morphological characters and measurements are similar. Furthermore, morphological and molecular analyses (Kanouh et al. 2010) showed that the position of seta ST3 is not a reliable diagnostic character and thus that $N$. tiliarum is a senior synonym of $N$. formosa. These results agree with the conclusions of Kolodochka (1986), Chant and Yoshida-Shaul (1989) and Denmark and Rather (1996).

(iii). Neoseiulella tuberculata (Wainstein), N. sexapori (Karg and Edland) and N. arutunjani (Kuznetsov)

Karg and Edland (1987) differentiated N. sexapori and $N$. tuberculata by the following characters: the shape of the ventrianal shield, the length of the peritreme, the surface of the dorsal shield and the number and the shape of dorsal solenostomes. Chant and Yoshida-Shaul (1989) synonymised N. sexapori and N. tuberculata. In 1996, Denmark and Rather did not mention N. sexapori in their revision. Kuznetsov (1984) then described $N$. arutunjani, similar to $N$. tuberculata but lacking the caudoventral seta JV4. However, N. arutunjani was not included in revisions of the genus Neoseiulella carried out by Chant and Yoshida-Shaul (1989) and Denmark and Rather (1996). Kolodochka (2009) discussed the presence of JV4 on N. arutunjani, and then synonymised this species with $N$. tuberculata.

\section{Neoseiulella tuberculata (Wainstein) (Figure 7)}

Typhlodromus tuberculatus Wainstein 1958: 205206. Wainstein 1961: 160; Hirschmann 1962: 12; Abbasova 1966: 186; Chant and Yoshida-Shaul 1989: 1014-1015. Typhlodromus (Seiulus) tuberculatus (Wainstein) Ehara 1966 : 17. Typhloctonus (Typhloctonus) tuberculatus (Wainstein) Wainstein 1973: 


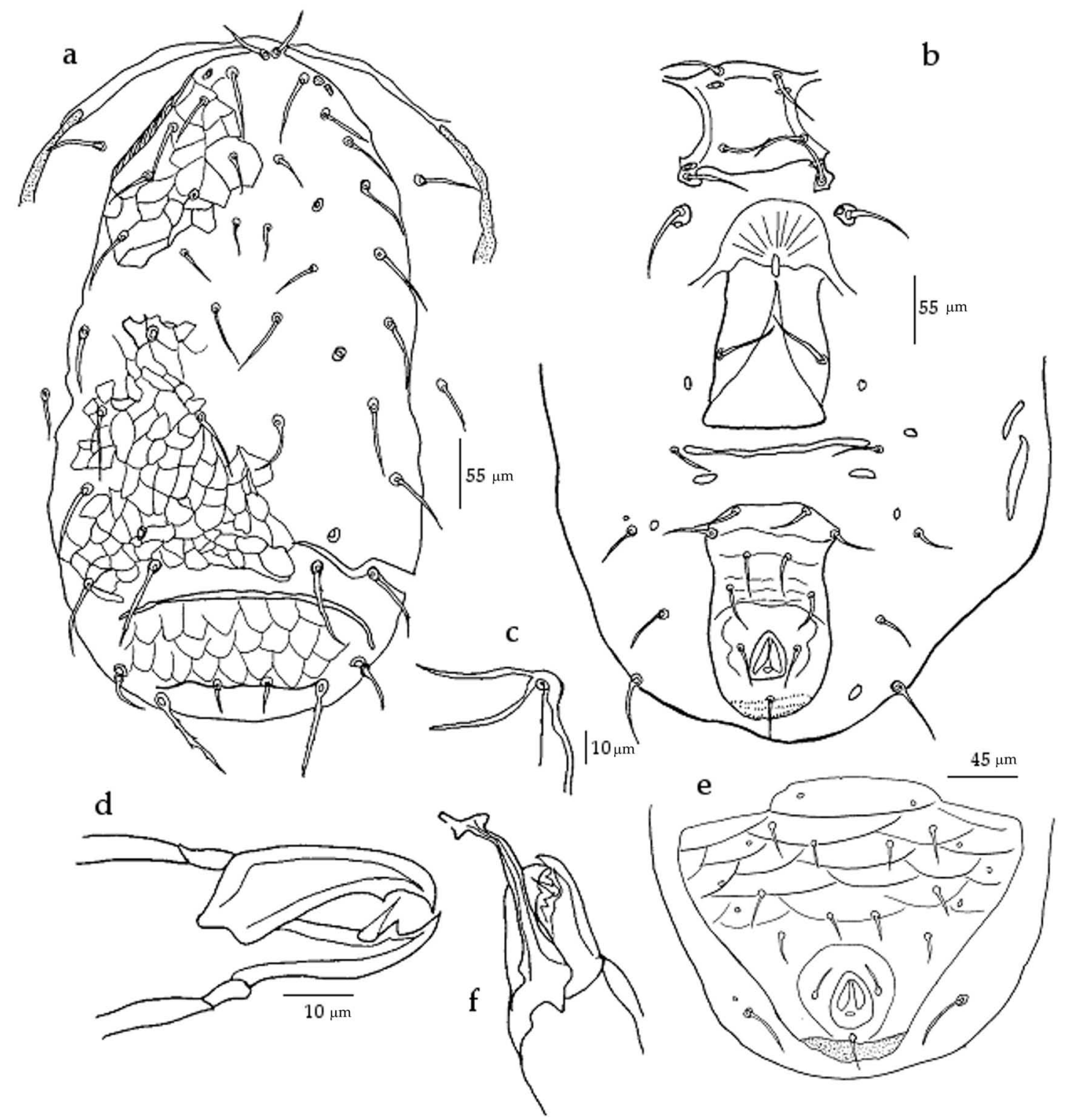

FIgURE 6: Neoseiulella formosa (Wainstein). Female (lectotype): a - dorsal shield; b - ventral shields; c - spermatheca; $\mathrm{d}$ - chelicera. Male (collection): e - ventrianal shield; $\mathrm{f}$ - spermatodactyl.

176. Typhloctonus tuberculatus (Wainstein) Arutunjan 1977: 55; Denmark and Rather 1984: 175-176; Moraes et al. 1986: 235; Kolodochka 2009: 488490. Seiulus tuberculatus (Wainstein) Beglyarov and Malov 1977: 6. Seiulus (Typhloctonus) tuberculatus (Wainstein) Beglyarov 1981: 19. Neoseiulella (Typhloctona) tuberculata (Wainstein) Denmark and Rather 1996: 62-63. Neoseiulella tuberculata (Wainstein) Moraes et al. 2004 : 297; Chant and McMurtry
2007: 147.

\section{Adult female (Figure $7 \mathrm{a}-\mathrm{d}$ )}

Dorsal shield (Figure 7a) - Dorsal shield heavily reticulated throughout: length 380 (370 - 390); width 197 (194 - 200) (at level of s4), 242 (238 - 246) (at level of Z1). Three pairs of solenostomes: gd2, gd6, and gd9 (gd5 is present on the specimen designated as lectotype by Kolodochka [2009] but not on the specimens presently examined or the other 
specimens designated as paralectotypes). Our examination of six specimens of this species collected on Acer platanoides in Massif Central (France) also showed that gd5 is absent. Five pairs of poroids. Sub-lateral setae ( $\mathrm{r} 3$ and R1) on the lateral margin. Dorsal shield bearing 19 pairs of setae, all dorsal and sub-lateral setae smooth: j1 19 (17 - 20); j3 25 (24 - 25); j4 12 (11 - 13); j5 14 (13 - 15); j6 20 (1920); J2 25 (23 - 27); J5 13 (12 - 13); z2 15 (14 - 16); z3 25 (23 - 27); z4 27; z5 16 (15 - 16); Z1 22 (21 - 22); Z4 29 (27 - 30); Z5 44 (42 - 46); s4 27; s6 25 (23 27); S2 26 (25 - 26); S4 24 (23 - 24); S5 19 (17 - 20); sub-lateral setae r3 $20(19-20)$ and R1 $19(17-20)$. Peritreme extending anteriorly to the level of $j 3$ or between j1-j3.

Ventral shields (Figure $7 b$ ) - Sternal shield (in poor conditions in the specimens examined) 60 (58 - 62) long and 59 (58 - 60) wide (at level of ST2), smooth with two pairs of setae (ST1 and ST2) and two pairs of small poroids. Third and fourth pairs of sternal setae (ST3, ST4) on separate platelets. A pair of small poroids accompanying ST4. Genital shield $124(120-128)$ long and $65(64-65)$ wide (at level of ST5), smooth. Four elongate platelets or genital sigilla between genital and ventrianal shields. One pair of poroids close to the genital shield (ST 5) and 4 pairs of poroids around the genital shield. Ventrianal shield subquadrate-shaped $114(110$ - 117) long and 98 (95 - 100) wide (at level of ZV2), lightly reticulated throughout, with four pairs of preanal setae (JV1, JV2, JV3 and ZV2), and a pair of circular solenostomes gv3 posteromediad to JV3. Four pairs of caudoventral setae (ZV1, ZV3, JV4 and JV5) on the integument surrounding the ventrianal shield. JV5 17 (15 - 18) long, smooth. Primary metapodal plate or inguinal sigillum $35(33-36)$ long and 5 (4 -5) wide.

Spermatheca (Figure 7c) - Cervix $4(3-4)$ long, shallowly cup-shaped.

Chelicera (Figure 7d) - Five teeth and a pilus dentilis on the fixed digit. The movable digit 35 (33 -36) long, bidentate.

Legs - Measurements of legs: leg I 268 (266 269); leg II 235 (233 - 237); leg III $233(231$ - 234); leg IV $290(289-291)$. Seven setae $(2-2 / 0,2 / 0-1)$ on the genu II. No macroseta on legs.
Material examined - A female syntype, designated now as paralectotype by Kolodochka (2009), and two other female paralectotype, deposited in the ASU, Institute of Zoology, Academy of Sciences, Kiev, Ukraine.

\section{Adult male}

Unknown from the type materials. However, it has been reported on maple (Acer pseudoplatanus) in Kremenets region, Ternopol district (Ukraine), collected and described, for the first time, by Kolodochka (2009).

Previous reports $-N$. tuberculata is only known from the West-Palaearctic area. Countries from which this species is reported are: Caucasus region (Abbasova 1966), Croatia (Tixier et al. 2010), Georgia (Wainstein 1958), Greece (Papadoulis and Emmanouel 1997), Moldova (Wainstein 1973), Norway (Chant and Yoshida-Shaul 1989), and Ukraine (Kolodochka 1981, 2009). Plants on which N. tuberculata was reported are: A. pseudoplatanus, Acer sp., A. steveni Pojark. (Aceraceae); A. hippocastanum (Hippocastanaceae); Artemisia sp. (Asteraceae); $C y$ donia sp., P. armeniaca, Prunus (cerasus) sp.; Rubus sp. (Rosaceae); J. regia (Juglandaceae); Ribes sp. (Grossulariaceae); Zelkova sp. (Ulmaceae). This species was recently collected in the Massif Central (France), on A. platanoides.

\section{Neoseiulella sexapori (Karg and Edland) (Figure 8)}

Seiulus sexapori Karg and Edland 1987: 388-389; Karg 1991: 27. Neoseiulella sexapori (Karg and Edland) Moraes et al. 2004: 297; Chant and McMurtry 2007: 147.

Adult female (Figure 8a-d) Dorsal shield (Figure 8a) - Dorsal shield heavily reticulated throughout: length 330 (320 - 340); width 179 (177 - 181) (at level of s4), $222(220-224)$ (at level of Z1). Four pairs of solenostomes: $\operatorname{gd} 2, \operatorname{gd} 5, \operatorname{gd} 6$, and gd9. Poroid not visible. Sub-lateral setae ( $\mathrm{r} 3$ and $\mathrm{R} 1$ ) on the lateral margin. The dorsal shield bearing 19 pairs of setae, all dorsal and sub-lateral setae smooth and on tubercles, except for $\mathrm{Z} 5$ which is slightly serrated: $\mathrm{j} 1$ 16 (15 - 17); j3 25 (23 - 27); j4 14 (13 - 15); j5 14 (13 - 14); j6 19 (18 - 20); J2 23 (21 - 24); J5 11 (10 - 11); 

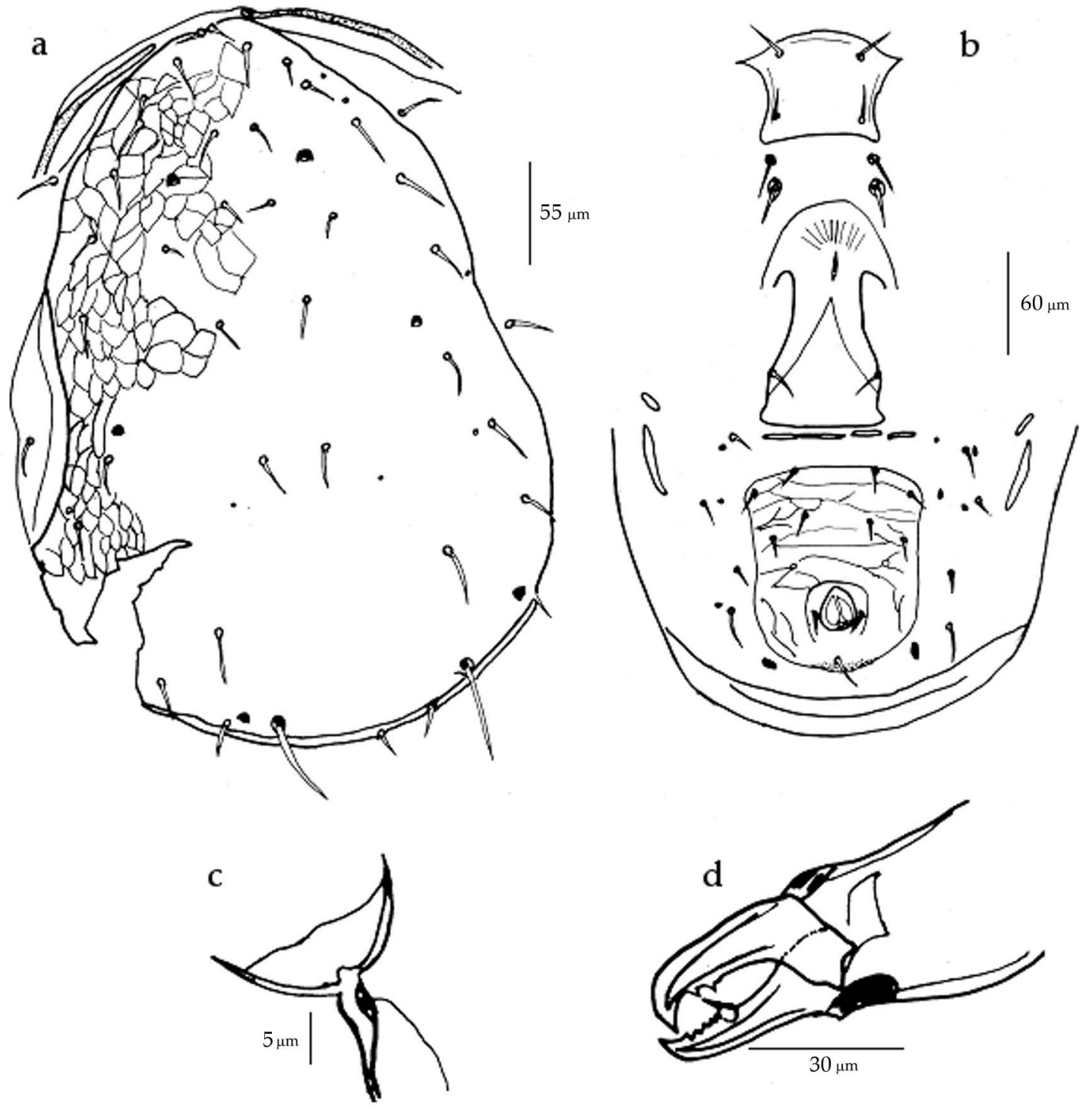

FIGURE 7: Neoseiulella tuberculata (Wainstein). Female (syntype): a - dorsal shield; b - ventral shields; c - spermatheca; d - chelicera.

z2 17 (16 - 17); z3 25 (22 - 27); z4 24 (23 - 25); z5 15 (14 - 15); Z1 22 (21 - 22); Z4 28 (27 - 28); Z5 41 $(40-42) ;$ s4 26 (25 - 27); s6 25 (24 - 26); S2 24 (23 25); S4 22 (20 - 23); S5 17 (16 - 18); sub-lateral setae r3 20 (19-21) and R1 $15(14-16)$. Presence of few visible muscles marks (sigilles) on the dorsal shield. Peritreme extending anteriorly to the level between z2-j3.

Ventral shields (Figure 8b) - Sternal shield 53 $(48-59)$ long and $59(57-61)$ wide (at level of ST2), smooth with two pairs of setae (ST1 and ST2) and two pairs of small poroids. The third and fourth pairs of sternal setae (ST3, ST4) on separate platelets. A pair of small poroids accompanying ST4. Genital shield, $124(122-126)$ long and 59 (55 - 63) wide (at level of ST5), smooth. Four elongate platelets or genital sigilla between genital and ventrianal shields. One pair of poroids close to the genital shield (ST 5) and 4 pairs of poroids around the genital shield. Ventrianal shield subquadrateshaped, $103(101-105)$ long and $83(80-85)$ wide (at level of ZV2), distinctly reticulated throughout, 

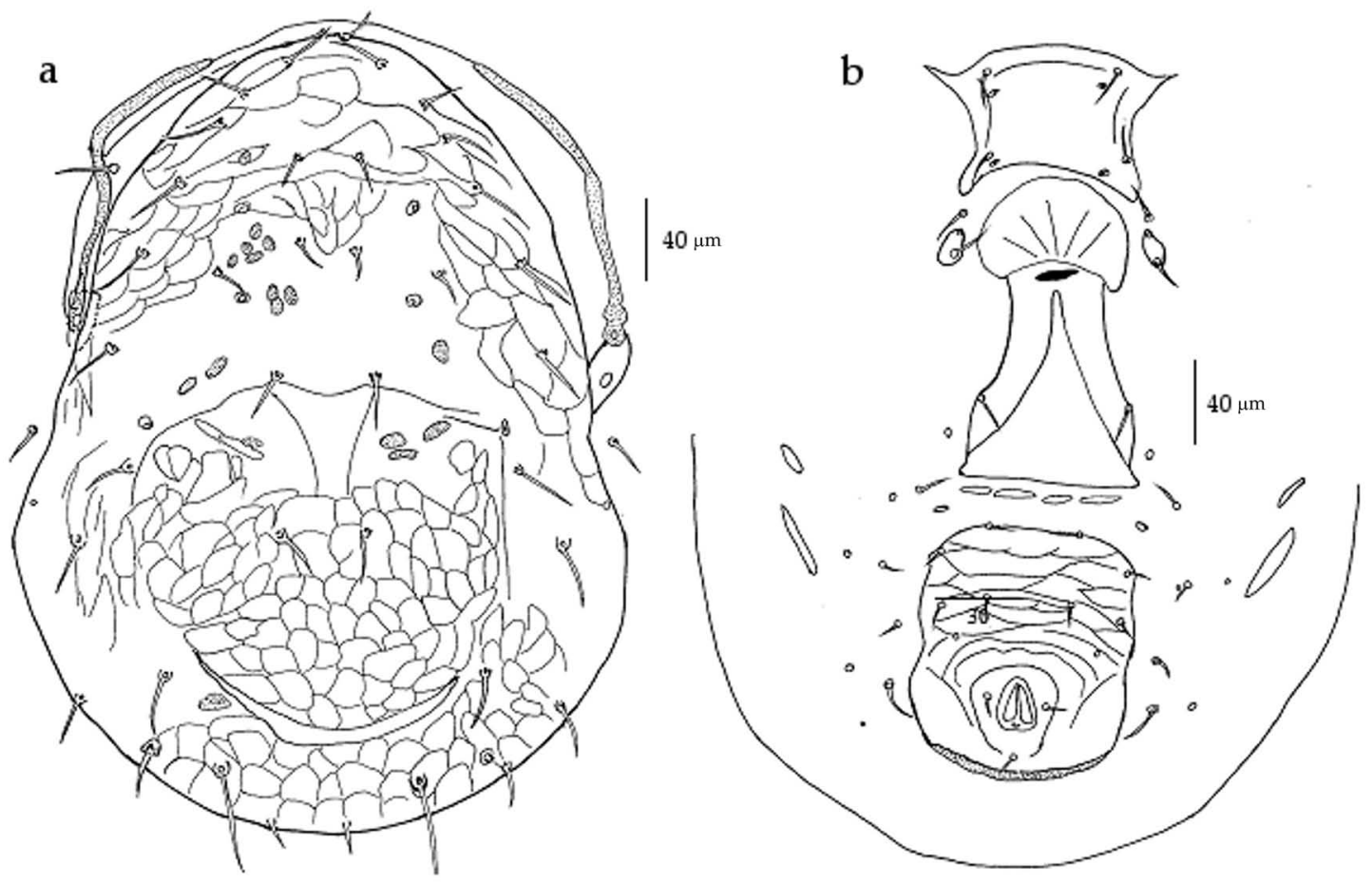

C

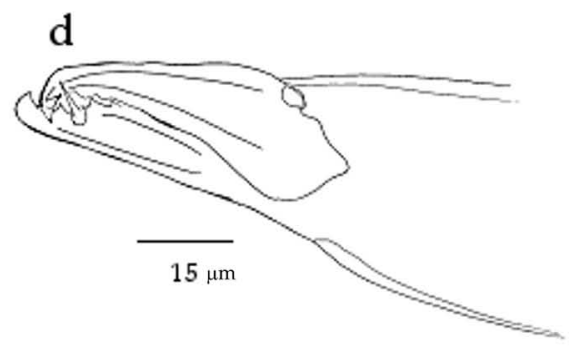

FIGURE 8: Neoseiulella sexapori (Karg and Edland). Female (holotype): $\mathrm{a}$ - dorsal shield; $\mathrm{b}$ - ventral shields; $\mathrm{c}$ - spermatheca; $\mathrm{d}$ - chelicera.

with four pairs of preanal setae (JV1, JV2, JV3 and $\mathrm{ZV} 2$ ), and a pair of circular solenostomes gv3 posteromediad to JV3. Four pairs of caudoventral setae (ZV1, ZV3, JV4 and JV5) on the integument surrounding the ventrianal shield. JV5 $15(13-17)$ long, smooth. Dimensions of the primary metapodal plate or inguinal sigillum $34(33-33)$ long and 4 wide.

Spermatheca (Figure 8c) - Cervix $4(3-4)$ long, cup-shaped.

Chelicera (Figure 8d) - Three teeth and a pilus dentilis on the fixed digit. Movable digit $27(26-27)$ long, bidentate.

Legs - Measurements of legs: leg I 261 (252 -
270); leg II 215 (200 - 229); leg III 215 (210 - 219); leg IV $288(285-291)$. Seven setae $(2-2 / 0,2 / 0-1)$ on the genu II. All legs much shorter than the dorsal shield and without macroseta.

Material examined - The female holotype and three female paratypes deposited in the Museum für Naturkunde, Arthropod collection, Berlin, Germany.

\section{Adult male}

The male of this species is unknown.

Previous reports - N. sexapori is only known from Norway on Rubus fruticosus L. (Rosaceae). 


\section{Neoseiulella arutunjani (Kuznetsov) (Figure 9)}

Seiulus (Typhloctonus) arutunjani Kuznetsov 1984: 54-57. Neoseiulella arutunjani (Kuznetsov) Chant and McMurtry 1994: 248; Moraes et al. 2004: 292; Chant and McMurtry 2007: 147.

Adult female (Figure 9a-d)

Dorsal shield (Figure 9a) - Dorsal shield heavily reticulated throughout: length 313; width 155 (at level of s4), 160 (at level of Z1). Four pairs of large solenostomes: gd2, gd5, gd6, and gd9. No poroid visible. Sub-lateral seta $\mathrm{r} 3$ on the dorsal shield. The other sub-lateral seta R1 on the lateral margin. Dorsal shield bearing 20 pairs of setae, all dorsal and sub-lateral setae smooth, except Z5 slightly serrated: j1 13; j3 19; j4 12; j5 12; j6 19; J2 20; J5 10; z2 12; z3 19; z4 20; z5 13; Z1 20; Z4 24; Z5 38; s4 22; s6 20; S2 22; S4 20; S5 16; sub-lateral setae r3 13 and R1 24. Peritreme extending anteriorly to the level between z2-j3.

Ventral shields (Figure 9b) - Sternal shield 63 long and 51 wide (at level of ST2), smooth with two pairs of setae (ST1 and ST2) and two pairs of poroids. The third and fourth pairs of sternal setae (ST3, ST4) on separate platelets. A pair of small poroids accompanying ST4. Genital shield 105 long and 49 wide (at level of ST5), smooth. Four elongate platelets or genital sigilla between genital and ventrianal shields. One pair of poroids close to the genital shield (ST 5) and 3 pairs of poroids around the genital shield. Ventrianal shield subquadrateshape, 110 long and 78 wide (at level of ZV2), distinctly reticulated throughout, with four pairs of preanal setae (JV1, JV2, JV3 and ZV2), with a pair of circular solenostomes gv3 posteromediad to JV3. Four pairs of caudoventral setae (ZV1, ZV3, JV4 and JV5) on the integument surrounding the ventrianal shield. NB: one seta of the JV4 pair is present (reported absent on the original description) supporting Kolodochka (2009). JV5 13 long, smooth. Primary metapodal plate or inguinal sigillum 35 long and 4 wide.

Spermatheca (Figure 9c) - Cervix short, 4 long, shallowly cup-shaped.
Chelicera (Figure 9d) - Seven teeth and a pilus dentilis on the fixed digit. Movable digit 29 long, bidentate.

Legs - Measurements of legs: leg I 248; leg II 213; leg III 213; leg IV 283. Seven setae (2-2/0, 2/0$1)$ on the genu II. No macroseta on legs.

Material examined - The female holotype deposited in the collection of Nikita State Botanic Garden, Yalta, Crimea, Ukraine. This material was examined in the ASU, Institute of Zoology, Academy of Sciences, Kiev, Ukraine.

\section{Adult male}

The male of this species is unknown.

Previous reports - N. arutunjani is only known from Ukraine, on Artemisia sp. (Asteraceae).

Remarks - It is noteworthy that in the original description, two females mounted on one slide were mentioned. Kolodochka (2009) showed that only one female actually belonged to this species. The other female was Paraseiulus incognitus Wainstein and Arutunjan. Our examination of these two females supports Kolodochka's observations.

The present examination of the type materials of these three latter species could emphasize the following conclusions:

Neoseiulella tuberculata does not differ from $N$. sexapori in setal and body measurements. Even if the shape of the spermatheca of these two species is slightly different (cup-shaped cervix in N. sexapori and a disc-shaped [shallowly cup-shaped] cervix in $N$. tuberculata), these two types of shapes are very close and such differences could be simply due to specimen mounting artefacts. The pair of solenostomes gd5 is observed on the four examined specimens of $N$. sexapori, and only on one of the three type specimens of $N$. tuberculata. At last, we observe other differences not mentioned by Chant and Yoshida-Shaul (1989): all dorsal setae are arising from tubercles in $N$. sexapori but not in $N$. tuberculata; the peritreme is shorter (at level between z2-j3) for $N$. sexapori than for $N$. tuberculata (at level of $\mathrm{j} 1$ or between $\mathrm{j} 1-\mathrm{j} 3$ ); the number of teeth on the fixed digit is different (three for N. sexapori, five for N. tuberculata); the ventrianal shield is heavily reticulated in $N$. sexapori, and lightly in N. tuberculata. As some 

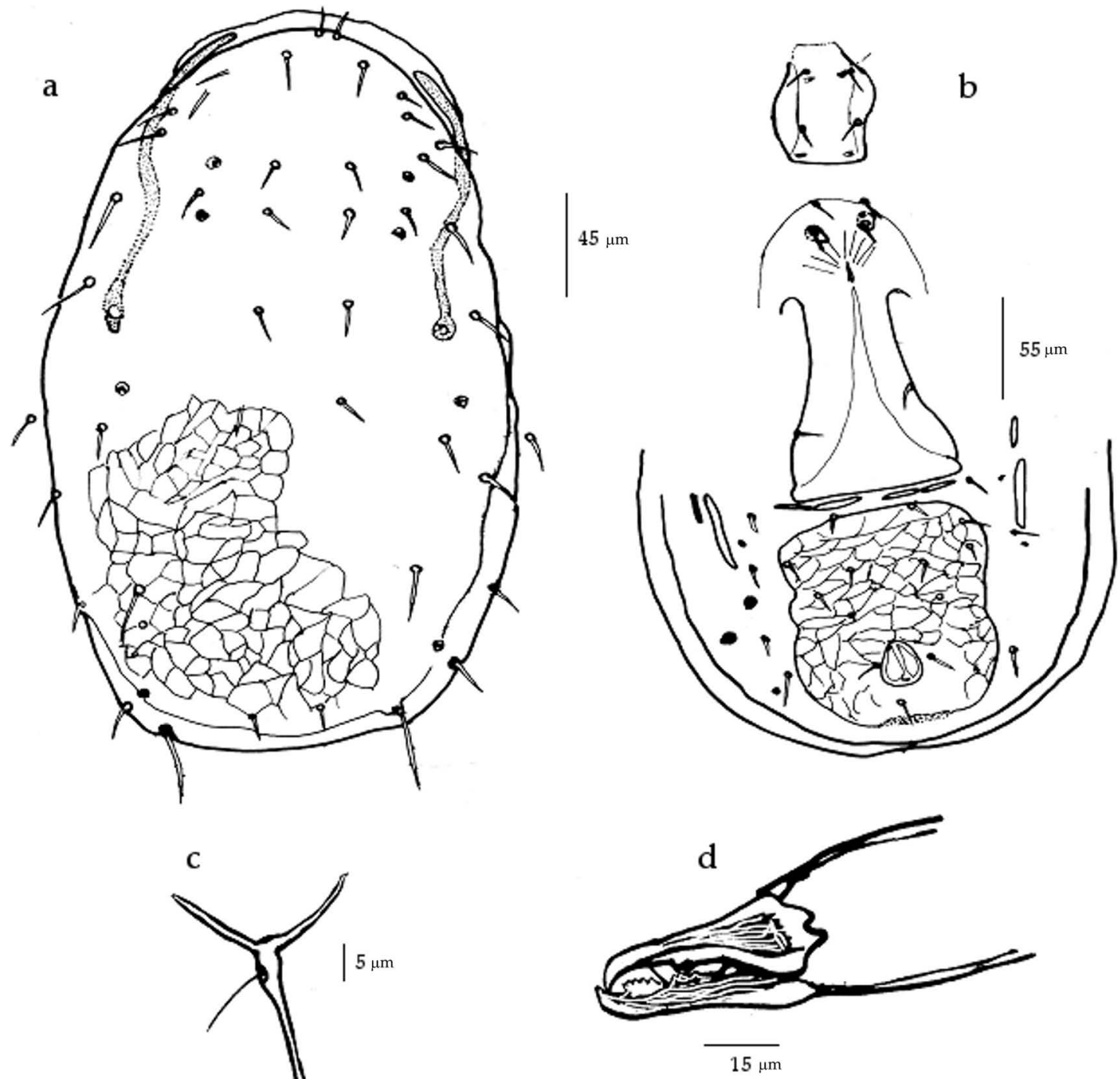

FIGURE 9: Neoseiulella arutunjani (Kuznetsov). Female (holotype): a - dorsal shield; b - ventral shields; $\mathrm{c}$ - spermatheca; $\mathrm{d}$ - chelicera.

authors have already shown the importance of such morphological characters for species differentiation (Chant and McMurtry 1994; Tixier et al. 2006a, b; Chant and McMurtry 2007; Okassa et al. 2009), we conclude that $N$. tuberculata and $N$. sexapori seem to be separate specific entities. These results agree with the conclusions of Karg and Edland (1987), but not with Chant and Yoshida-Shaul (1989).

Small differences in setal and body measurements are observed between $N$. tuberculata and $N$. arutunjani. According to intraspecific variations already observed within the family Phytoseiidae for continued characters, these differences seem to be too tiny for separating $N$. tuberculata from $N$. arutunjani. However, other differences are observed: the peritreme is shorter in $N$. arutunjani (reaching between z2-j3) than in $N$. tuberculata (reaching j1 or between $j 1-j 3$ ); the ventrianal shield is heavily reticulated on $N$. arutunjani, and lightly on $N$. tuberculata; fixed digit of chelicera bear seven teeth on $N$. arutunjani, and five on $N$. tuberculata; sub-lateral seta $\mathrm{r} 3$ is inserted on the dorsal shield on $N$. arutunjani and on lateral margin on N. tuberculata. However, as the position of sub-lateral seta (R1) was de- 
montrasted to be a non reliable diagnostic character to differentiate between $N$. aceri and $N$. squamiger (Kanouh et al. 2010), the position of $r 3$ could be also assumed to be a non reliable diagnostic character as well. Though, the other morphological differences between $N$. tuberculata and $N$. arutunjani seem sufficiently discriminant to conclude that these two species are not synonyms. These results do not agree with the conclusion of Kolodochka (2009).

Small differences in setal and body measurements are observed between $N$. arutunjani and $N$. sexapori. However, all dorsal setae are arising from tubercles on N. sexapori, but not on N. arutunjani; the number of teeth on the fixed digit is different (three on $N$. sexapori, seven on N. arutunjani); spermatheca has a cup-shaped cervix in N. sexapori, but a discshaped (shallowly cup-shaped) cervix in N. arutunjani. These morphological differences between $N$. sexapori and $N$. arutunjani seem also sufficiently discriminant to conclude that these two species are not synonyms.

It seems thus that $N$. tuberculata, $N$. arutunjani and $N$. sexapori present sufficiently different characters to support their specific validity. These conclusions did not agree with Chant and Yoshida-Shaul (1989) and Kolodochka (2009).

(iv). Neoseiulella vollsella (Chaudhri, Akbar and Rasool), N. transitans (Gupta) and N. prunus

(Denmark and Rather)

Denmark and Rather (1984) differentiated N. prunus from $N$. vollsella by the length of both dorsal setae $j 3$ and S4. Then, Chant and Yoshida-Shaul (1989) considered N. prunus a junior synonymy of N. transitans, and N. vollsella a provisional senior synonym to these two latter species. Denmark and Rather (1996) supported this conclusion.

\section{Neoseiulella transitans (Gupta) (Figure 10)}

Typhlodromus transitans Gupta 1981: 40-41; Chant and Yoshida-Shaul 1989: 1016-1017. Typhlodromus (Typhloctonus) transitans (Gupta) Gupta 1985: 404. Typhloctonus transitans (Gupta) Moraes et al. 1986: 235. Neoseiulella transitans (Gupta) Chant and McMurtry 1994: 248; Moraes et al. 2004: 298; Chant and McMurtry 2007: 147. Neoseiulella (Typhloctona) transitans (Gupta) Denmark and Rather 1996: 67-69. Amblydromella (Aphanoseia) transitans (Gupta) Denmark and Welbourn 2002: 309.

Adult female (Figure 10a - e)

Dorsal shield (Figure 10a) - Dorsal shield heavily reticulated: length 327 (320 - 334); width 187 (185 - 189) (at level of s4) and 171 (169 - 173) (at level of Z1). Three pairs of solenostomes: gd2, gd8, and gd9. No poroid visible. Sub-lateral setae ( $\mathrm{r} 3$ and R1) on the lateral margin. Dorsal shield bearing 19 pairs of setae, all smooth except Z4 and Z5 which are slightly serrated; Z5 knobbed: j1 18 (17 - 19); j3 25 (24 - 26); j4 16 (15 - 17); j5 17 (16 - 17); j6 20 (18 22); J2 24 (23 - 25); J5 10 (9 - 10); z2 19 (18 - 20); z3 25 (24 - 26); z4 24 (22 - 26); z5 18 (17 - 19); Z1 22 (21 - 23); Z4 31 (29 - 33); Z5 46 (42 - 50); s4 27 (25 - 29); s6 27 (26 - 28); S2 31 (30 - 31); S4 30 (29 - 30); S5 23 (22 - 23); sub-lateral setae r3 25 (24 - 26) and R1 22 $(21-22)$. Peritreme extending anteriorly to the level of $\mathrm{j} 1$.

Ventral shields (Figure 10b) - Sternal shield 71 $(67-75)$ long and $69(67-71)$ wide (at level of ST2), smooth with three pairs of setae (ST1, ST2 and ST3) and two pairs of poroids. A pair of metasternal setae (ST4) on separate platelets accompanied by a pair of small poroids. Genital shield 110 (108 -111) long and 67 wide (at level of ST5), is smooth. Four elongate platelets or genital sigilla separating genital and ventrianal shields folded under the genital shield. One pair of poroids close to the genital shield (ST 5) and 3 pairs of poroids around the genital shield. Ventrianal shield much longer than wide, with distinct waist, $103(96-108)$ long and 68 (66 - 70) wide (at level of ZV2), smooth, with four pairs of preanal setae (JV1, JV2, JV3 and ZV2), and a pair of small circular solenostomes gv3 posteromediad to JV2. Four pairs of caudoventral setae (ZV1, ZV3, JV4 and JV5) on the integument surrounding the ventrianal shield. JV5 38 (36 - 40) long, smooth. Primary metapodal plate or inguinal sigillum 24 (22 -25) long and $4(3-4)$ wide.

Spermatheca (Figure 10c) - Cervix 15 (12 - 17) long, cup-shaped.

Chelicera (Figure 10d) - Two large teeth, a ridge of $6(5-6)$ small teeth, and a pilus dentilis on the 


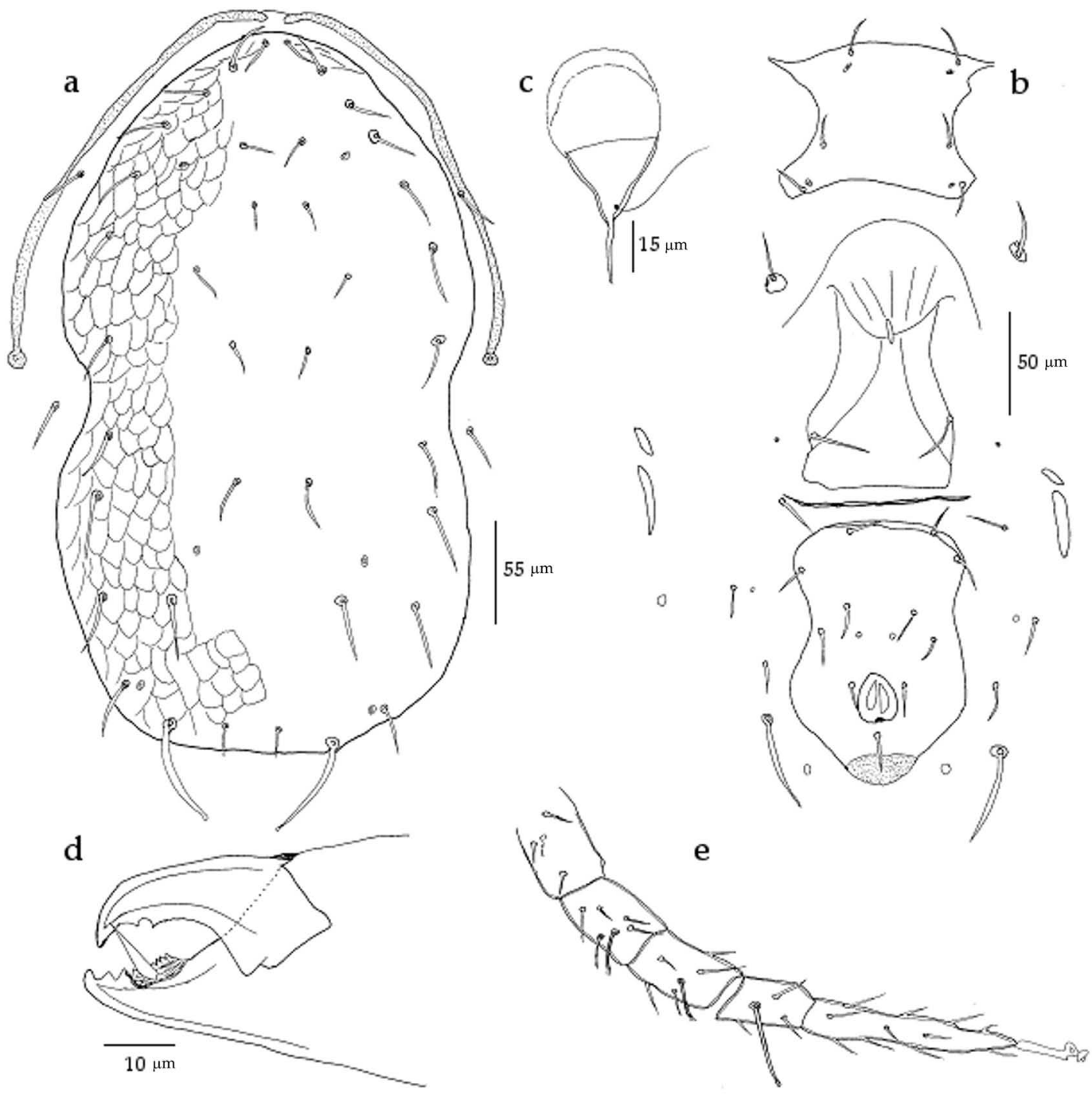

FIGURE 10: Neoseiulella transitans (Gupta). Female (holotype): a - dorsal shield; b - ventral shields; c - spermatheca; $d$ - chelicera; e - leg IV.

fixed digit. Movable digit 23 (21 - 25) long, bidentate.

Legs (Figure 10e) - Measurements of legs: leg I 275 (270 - 280); leg II 246 (242 - 250); leg III 244 (240 - 248); leg IV 303 (300 - 306). Seven setae (2-2/0, 2/0-1) on the genu II. Three knobbed macrosetae, 21 (20 - 21), $18(17-18)$ and 33 (30 - 36) long, on genu, tibia and basitarsus IV, respectively.

Material examined - The female holotype and two female paratypes deposited in the collection of the Zoological Survey of India (ZSI), Kolkata, India.
Adult male

The male of this species is unknown.

Previous reports $-N$. transitans is only known from the Oriental area, from Jammu and Kashmir (India), on Pyrus communis L. (Rosaceae), and Morus sp. (Moraceae).

\section{Neoseiulella prunus (Denmark and Rather) (Figure 11)}

Typhloctonus prunus Denmark and Rather 1984: 172173; Moraes et al. 1986: 233. Neoseiulella prunus 


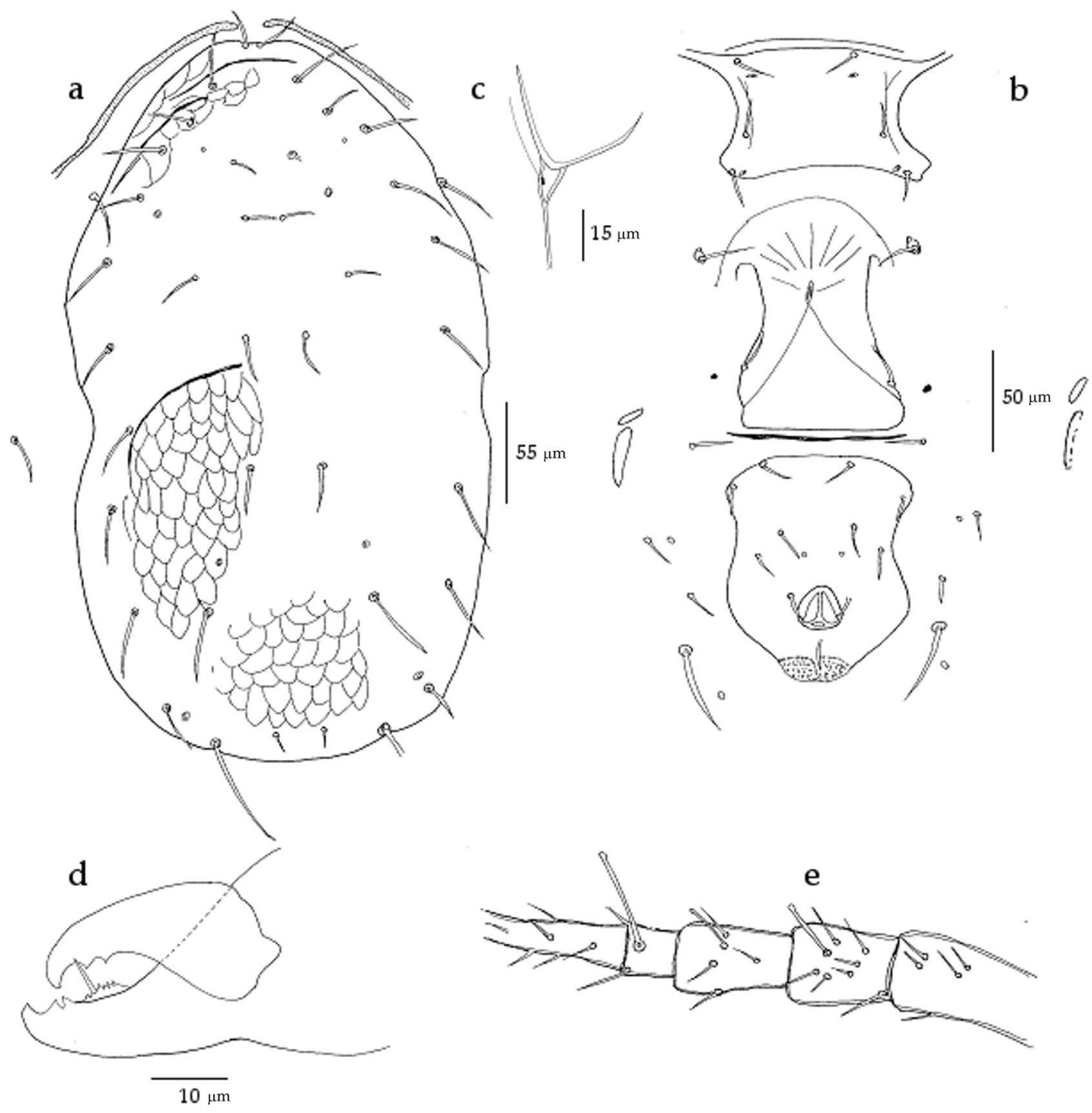

FIGURE 11: Neoseiulella prunus (Denmark and Rather). Female (paratype): a - dorsal shield; $\mathrm{b}$ - ventral shields; $\mathrm{c}$ - spermatheca; $\mathrm{d}$ chelicera; e - leg IV.

(Denmark and Rather) Moraes et al. 2004: 298; Chant and McMurtry 2007: 147.

\section{Adult female (Figure 11a - e)}

Dorsal shield (Figure 11a) — Dorsal shield heavily reticulated: length 339; width 183 (at level of s4) and 169 (at level of Z1). Three pairs of solenostomes on the dorsal shield: $\operatorname{gd} 2, \operatorname{gd} 8$, and $\operatorname{gd} 9$. One pair of poroids. Sub-lateral setae (r3 and R1) on the lateral margin. Dorsal shield bearing 19 pairs of setae, all smooth except Z4 and Z5 slightly serrated; Z5 knobbed: j1 16; j3 25; j4 17; j5 19; j6 19; J2 24; J5 9; z2
19; z3 24; z4 22; z5 19; Z1 25; Z4 28; Z5 44; s4 25; s6 27; S2 30; S4 32; S5 25; sub-lateral setae r3 25 and R1 22. Peritreme extending anteriorly to the level of $\mathrm{j} 1$.

Ventral shields (Figure 11b) - Sternal shield 73 long and 68 wide (at level of ST2), smooth with three pairs of setae (ST1, ST2 and ST3) and two pairs of poroids. A pair of metasternal setae (ST4) on separate platelets accompanied by a pair of small poroids. Genital shield 100 long and 64 wide (at level of ST5), smooth. Elongate platelets or genital sigilla separating genital and ventrianal shields 
folded under the genital shield. One pair of poroids close to the genital shield (ST 5) and 2 pairs of poroids around the genital shield. Ventrianal shield much longer than wide, with a distinct waist, 100 long and 67 wide (at level of ZV2), smooth, with four pairs of preanal setae (JV1, JV2, JV3 and ZV2), and a pair of small circular solenostomes gv3 posteromediad to JV2. Four pairs of caudoventral setae (ZV1, ZV3, JV4 and JV5) on the integument surrounding the ventrianal shield. JV5 40 long, smooth. Primary metapodal plate or inguinal sigillum 22 long and 3 wide.

Spermatheca (Figure 11c) - Cervix 16 long, cupshaped.

Chelicera (Figure 11d) - Two teeth, a ridge of six denticles and a pilus dentilis on the fixed digit. Movable digit 22 long, bidentate.

Legs (Figure 11e) - Measurements of legs: leg I 267; leg II 238; leg III 238; leg IV 298. Seven setae (2$2 / 0,2 / 0-1)$ on the genu II. Three knobbed macrosetae, 19, 18 and 32 long, on genu, tibia and basitarsus $\mathrm{IV}$, respectively.

Material examined - A female paratype deposited in the collection of the Department of Zoology, University of Kashmir, Srinagar.

Adult male: The male of this species is unknown.

Previous reports $-N$. prunus is only known from the Oriental area, from Jammu and Kashmir (India), on Prunus armeniaca L. (Rosaceae).

No difference in all the morphological characters considered was found between $N$. transitans and $N$. prunus. Consequently, we consider that $N$. prunus is a junior synonym of $N$. transitans. Denmark (personal comm. 2010) confirmed this conclusion. As we were not able to borrow the type materials of $N$. vollsella, an attentive examination of the original description of this latter species was conducted. No morphological difference was observed between $N$. vollsella, N. transitans and N. prunus. Moreover, the geographical distributions of these three species are very close. Thus, we support the suggestion of Chant and Yoshida-Shaul (1989) concerning the synonymy of these three species.

\section{(v). Neoseiulella manukae (Collyer) and N. glenfieldensis (Schicha)}

Denmark and Rather (1996) considered these two species to be synonyms. Schicha (1980) and Chant and Yoshida-Shaul (1989) differentiated N. manukae from $N$. glenfieldensis by several idiosomal seta measurements (ex. j4, z2, z4, s4, and Z5).

\section{Neoseiulella manukae (Collyer) (Figure 12)}

Typhlodromus manukae Collyer 1964: 637-638; Schicha 1980: 16-18; Collyer 1982: 190; Schicha 1987: 140-143; Chant and Yoshida-Shaul 1989: 1034-1036. Neoseiulella manukae (Collyer) Moraes et al. 1986: 201; Moraes et al. 2004: 294; Chant and McMurtry 2007: 147. Neoseiulella (Neoseiulella) manukae (Collyer) Denmark and Rather 1996: 55-56.

\section{Adult female (Figure 12a - e)}

Dorsal shield (Figure 12a) - Dorsal shield smooth: length $440(439-440)$; width $226(225$ - 226) (at level of s4), 224 (223 - 224) (at level of Z1), with five pairs of solenostomes: gd2, gd4, gd5, gd6, and gd9. three pairs of poroids. Sub-lateral setae ( $\mathrm{r} 3$ and R1) on the lateral margin. Dorsal shield bearing 19 pairs of setae, all smooth except Z5 which is slightly serrated: j1 34 (33 - 34); j3 46 (45 - 46); j4 15 (14 - 15); j5 14; j6 16; J2 16; J5 14; z2 17; z3 30 (29 - 30); z4 31 (30 - 31); z5 15; Z1 15; Z4 55; Z5 134 (133 - 134); s4 36 (35 - 36); s6 25 (24 - 25); S2 28; S4 17; S5 21; sublateral setae $\mathrm{r} 320$ and R1 17. Peritreme extending anteriorly to the level of $\mathrm{j} 1$.

Ventral shields (Figure 12b) - Sternal shield 92 (91 - 92) long and $88(86-89)$ wide (at level of ST2), smooth with three pairs of setae (ST1, ST2 and ST3) and two pairs of poroids. A pair of metasternal setae (ST4) on separate platelets accompanied by a pair of small poroids. Genital shield 133 (132 - 133) long and 74 (73 - 74) wide (at level of ST5), smooth. Elongate platelets or genital sigilla separating genital and ventrianal shields folded under the genital shield. One pair of poroids close to the genital shield (ST 5) and 4 pairs of poroids around the genital shield. Ventrianal shield longer than wide, 143 $(142-143)$ long and $110(109-110)$ wide (at level of ZV2), smooth, with three pairs of preanal setae (JV1, 


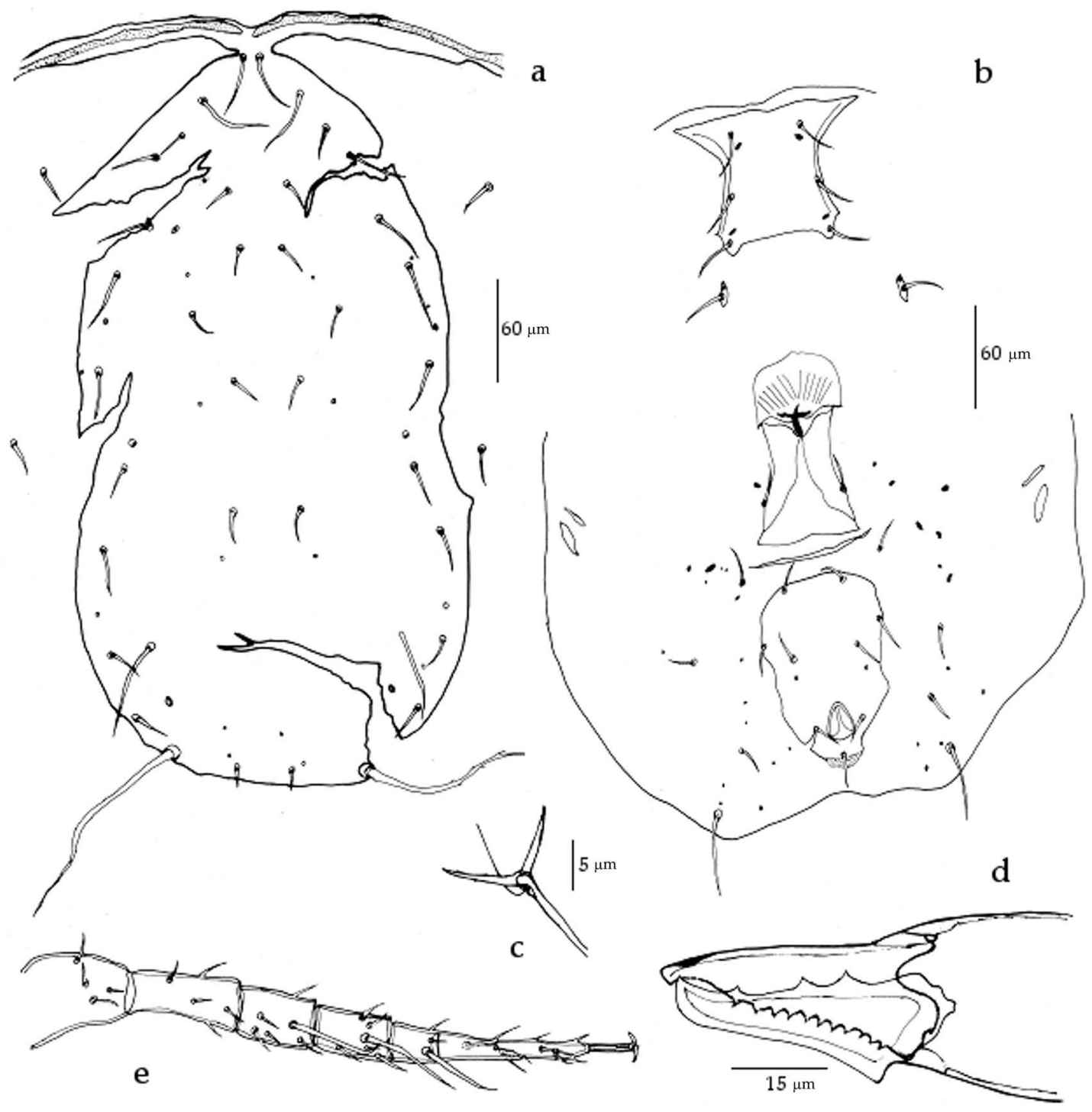

FIGURE 12: Neoseiulella manukae (Collyer). Female (lectotype): a - dorsal shield; b - ventral shields; c - spermatheca; $\mathrm{d}$ - chelicera; e leg IV.

JV2 and ZV2; JV3 absent), and a pair of small circular solenostomes gv3. Four pairs of caudoventral setae (ZV1, ZV3, JV4 and JV5) on the integument surrounding the ventrianal shield. JV5 $50(49-50)$ long, smooth. Primary metapodal plate or inguinal sigillum $23(22-23)$ long and 7 wide.

Spermatheca (Figure 12c) - Cervix 5 long, cupshaped.

Chelicera (Figure 12d) - Eleven teeth and a pilus dentilis on the fixed digit. Movable digit $33(32-33)$ long, bearing three teeth.

Legs (Figure 12e) - Measurements of legs: leg I 396 (395 - 396); leg II 330 (329 - 330); leg III 345 (344 - 346); leg IV 437 (436 - 437). Seven setae (2-2/0, 2/0-1) on the genu II. Two macrosetae, $41(40-41)$ and $32(31-32)$ long, on genu and tibia III, respectively. Three other macrosetae, 81, 67 and 50 long, on genu, tibia and basitarsus IV, respectively.

Material examined - The female lectotype and one female paralectotype deposited in the BMNH, 
the British Museum of Natural History, Cromwell Road, London, UK.

Adult male The male of this species is unknown.

Previous reports - N. manukae is only known from the Australasian area. The type specimens were collected at Waitakeres, near Auckland, New Zealand, on Leptospermum scoparium J.R. Forst. and G. Forst. (Myrtaceae) (Collyer 1964). This species has been also found on $L$. ericoides A. Rich. at Awanui Inlet, New Zealand (Collyer 1982); and on Eucalyptus parivolia Cambage (Myrtaceae) in New South Wales, Australia (Schicha 1987).

\section{Neoseiulella glenfieldensis (Schicha) (Figure 13)}

Typhlodromus glenfieldensis Schicha 1980: 18; Schicha, 1987: 140-142; Chant and Yoshida-Shaul 1989: 1034-1037. Neoseiulella glenfieldensis (Schicha) Moraes et al. 1986: 201; Moraes et al. 2004: 294; Chant and McMurtry 2007: 147.

\section{Adult female (Figure 13a-e)}

Dorsal shield (Figure 13a) - Dorsal shield smooth: length 418 (415 - 421); width 231 (230 - 232) (at level of s4), 240 (238 - 242) (at level of Z1), with five pairs of solenostomes: $\operatorname{gd} 2$, gd4, gd5, gd6, and gd9. Four pairs of poroids. Sub - lateral setae (r3 and R1) on the lateral margin. Dorsal shield bearing 19 pairs of setae, all smooth, except Z5 which is slightly serrated: j1 35 (34 - 36); j3 40; j4 11; j5 14 (13 - 14); j6 15 (14 - 16); J2 18 (17 - 18); J5 12 (11 - 12); z2 16; z3 25 (23 - 26); z4 21 (20 - 21); z5 14 (13 - 14); Z1 16 (15 - 16); Z4 52 (50 - 53); Z5 171 (166 - 176); s4 28 (27 - 28); s6 19; S2 22 (21 - 23); S4 18; S5 20 (19 - 20); sub - lateral setae r3 19 and R1 18 (17 - 18). Presence of few visible muscles marks (sigilles) on the dorsal shield. Peritreme extending anteriorly to the level of $\mathrm{j} 1$.

Ventral shields (Figure 13b) - Sternal shield 93 (91 - 95) long and $92(91-93)$ wide (at level of ST2), smooth with three pairs of setae (ST1, ST2 and ST3) and two pairs of poroids. A pair of metasternal setae (ST4) on separate platelets accompanied by a pair of small poroids. Genital shield $141(140-141)$ long and 83 (82 - 83) wide (at level of ST5), smooth. Four elongate platelets or genital sigilla separating genital and ventrianal shields folded under the genital shield. One pair of poroids close to the genital shield (ST 5) and 4 pairs of poroids around the genital shield. Ventrianal shield longer than wide, 133 (132 - 133) long and $112(111$ - 112) wide (at level of ZV2), smooth, with three pairs of preanal setae (JV1, JV2 and ZV2; JV3 absent), and a pair of small circular solenostomes gv3. Four pairs of caudoventral setae (ZV1, ZV3, JV4 and JV5) on the integument surrounding the ventrianal shield. JV5 50 (49 - 50) long, smooth. Primary metapodal plate or inguinal sigillum $23(22-23)$ long and 7 wide.

Spermatheca (Figure 13c) - Cervix 5 long, cupshaped.

Chelicera (Figure 13d) - Twelve teeth and a pilus dentilis on the fixed digit. The movable digit, $40(39-40)$ long, bearing three teeth.

Legs (Figure 13e) - Measurements of legs: leg I 391 (387 - 395); leg II 371 (368 - 374); leg III 349 (344 - 354); leg IV 462 (460 - 463). Seven setae (2-2/0, $2 / 0-1)$ on the genu II. Two macrosetae 39 (37 - 40) and 32 (31 - 32) long, on genu and tibia III, respectively. Three other macrosetae, 72 (69 - 75), 68 (66 69), 54 (53 - 55) long, on genu, tibia and basitarsus $\mathrm{IV}$, respectively.

Material examined - The female holotype and one female paratype deposited in NSW Department of Primary Industries, Agricultural Scientific Collections Unit (Acarology), Orange Agricultural Institute, Australia.

Adult male

Described by Schicha (1980). We were not able to borrow the male type specimen of this species.

Previous reports - N. glenfieldensis is only known from Australia (New South Wales). Plants on which this species was collected are: Citrus sp. (Rutaceae); Malus domestica Borkh (Rosaceae) and Quercus sp. (Fagaceae).

The present examination of the type materials of N. manukae and N. glenfieldensis shows two main differences. The first one concerns the dentition of the fixed digit (11 teeth in N. manukae; 12-13 teeth in N. glenfieldensis). However, Schicha (1980) mentioned that $N$. glenfieldensis has 11-13 teeth on the fixed digit; we do not thus consider this difference 


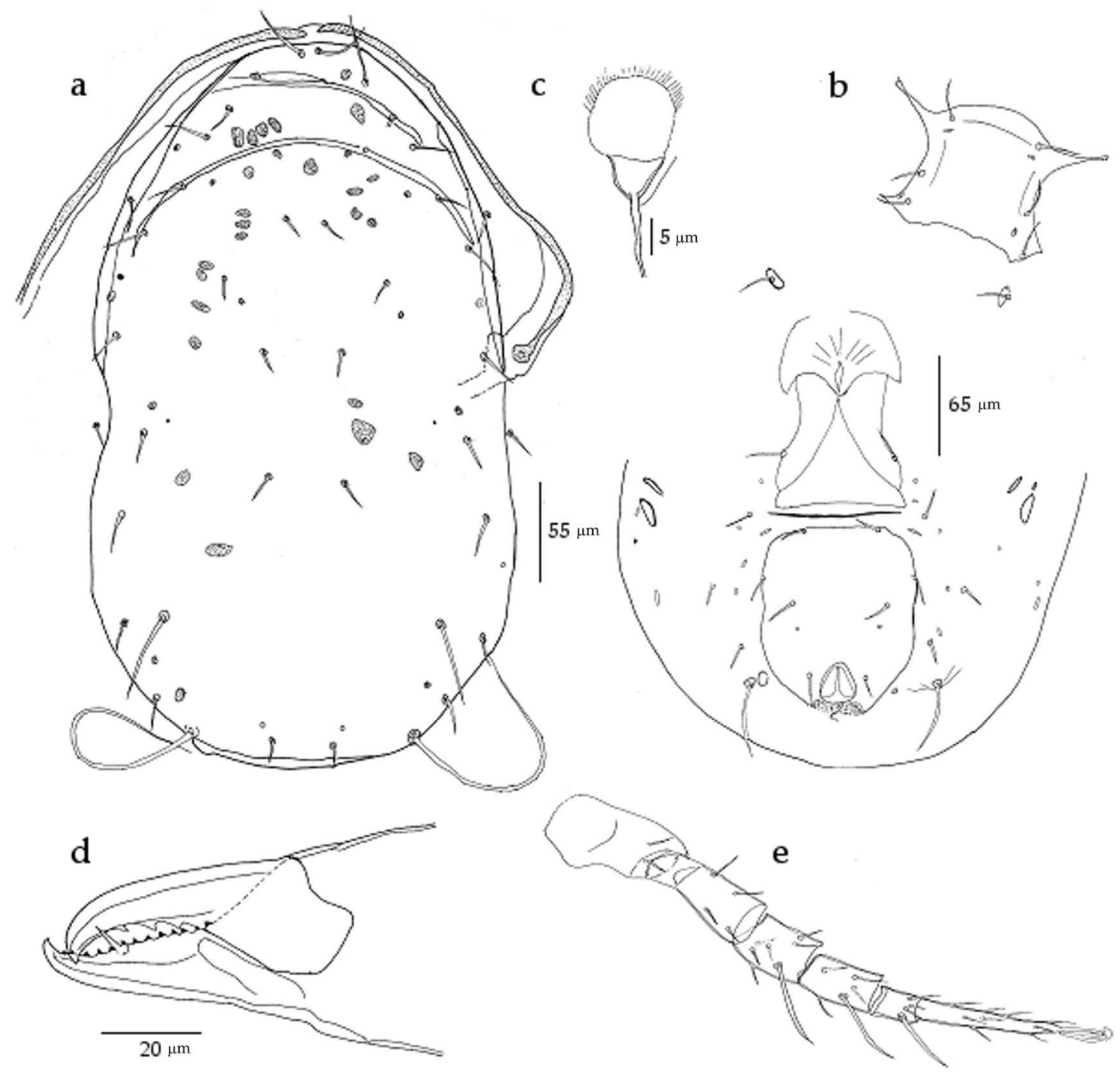

FIGURE 13: Neoseiulella glenfieldensis (Schicha). Female (holotype): a - dorsal shield; b - ventral shields; $\mathrm{c}$-spermatheca; $\mathrm{d}$ - chelicera; $\mathrm{e}$ $-\operatorname{leg}$ IV.

to be significant. The second difference relates to the length of the seta Z5 (Z5 134 on N. manukae; Z5 171 on $N$. glenfieldensis). Even if this difference is quite high, high intraspecific vatiations have been previously observed for idiosomal seta lengths in the family Phytoseiidae (Tixier et al. 2003, 2008). Furthermore, it would be the unique diagnostic characters to separate these two species. We thus propose that $N$. manukae is a senior synonym of $N$. glenfieldensis, in accordance with the conclusions of Denmark and Rather (1996), but not with those of Schicha (1980) and Chant and Yoshida-Shaul (1989). However, an examination of other female paratype specimens of both species and/or molecular studies would be useful to determine the reliability of the length of $Z 5$ for species diagnosis.

\section{Are there new cases of synonymies within the genus Neoseiulella?}

The examination of the type materials allows to highlight similarities between two species, and thus we propose a new synonymy within this genus: Neoseiulella nesbitti (Womersley) and N. armidalensis (Schicha and Elshafie). These two species were considered in the previous revisions as two differ- 
ent entities (Chant and Yoshida-Shaul 1989; Denmark and Rather 1996). Schicha and Elshafie (1980) when describing $N$. armidalensis have noted the similarity with $N$. nesbitti but stated that these species differ in the presence/absence of JV3 (present on N. armidalensis, absent on N. nesbitti). However, Chant and Yoshida-Shaul (1989) showed the absence of JV3 on the holotype specimens of these two species, but distinguished them by the presence of macrosetae on leg IV (one macroseta on N. nesbitti; three macrosetae on N. armidalensis), and the occurrence of pilus dentilis on the fixed digit (present on N. nesbitti; absent on N. armidalensis).

\section{Neoseiulella nesbitti (Womersley) (Figure 14)}

Typhlodromus nesbitti Womersley 1954: 179-180; Hirschmann 1962: 12; Narayanan and Ghai 1963: 541; Prasad 1974: 174; Schicha 1978: 5-7; Schicha 1987: 132-133; Chant and Yoshida-Shaul 1989: 10431044. Typhlodromus (Typhlodromus) nesbitti (Womersley) Chant 1959: 65-66. Neoseiulella nesbitti (Womersley) Muma 1961: 295; Moraes et al. 1986: 201; Chant and McMurtry 1994: 249; Moraes et al. 2004: 294; Chant and McMurtry 2007: 147. Typhlodromus (Nesbittieus) nesbitti (Womersley) Wainstein 1962: 23. Typhlodromus (Seiulus) nesbitti (Womersley) Ehara 1966: 16-17. Typhloctonus (Neoseiulellus) nesbitti (Womersley) Wainstein 1977: 1415. Typhlodromus (Typhloctonus) nesbitti (Womersley) Gupta 1985: 403-404. Neoseiulella (Neoseiulella) nesbitti (Womersley) Denmark and Rather 1996: 46-48.

textitAdult female (Figure 14a - e)

Dorsal shield (Figure 14a) - Dorsal shield lightly reticulated: length 399; width 228 (at level of s4) and 233 (at level of Z1). Five pairs of solenostomes : gd2, gd4, gd5, gd6, and gd9. No poroid visible. Sub-lateral setae ( $\mathrm{r} 3$ and $\mathrm{R} 1$ ) on the lateral margin. Dorsal shield bearing 19 pairs of setae, all smooth, except Z4 and Z5 which are slightly serrated: j1 25; j3 27; j4 18; j5 19; j6 20; J2 21; J5 12; z2 19; z3 28; z4 28; z5 18; Z1 20; Z4 38; Z5 57; s4 26; s6 27; S2 31; S4 25; S5 23; sub-lateral setae r3 21 and R1 20. Peritreme extending anteriorly to the level of j1.
Ventral shields (Figure 14b) - Sternal shield 86 long and 82 wide (at level of ST2), smooth with three pairs of setae (ST1, ST2 and ST3) and two pairs of poroids. A pair of metasternal setae (ST4) on separate platelets accompanied by a pair of small poroids. Genital shield 126 long and 73 wide (at level of ST5), smooth. Four elongate platelets or genital sigilla separating genital and ventrianal shields folded under the genital shield. One pair of poroids close to the genital shield (ST 5) and 2 pairs of poroids around the genital shield. Ventrianal shield much longer than wide, 144 long and 110 wide (at level of ZV2), smooth, with three pairs of preanal setae (JV1, JV2 and ZV2; JV3 absent), with a pair of small circular solenostomes gv3 posterior to JV2. Four pairs of caudoventral setae (ZV1, ZV3, JV4 and JV5, JV3 absent) on the integument surrounding the ventrianal shield. JV5 41 long, smooth. Primary metapodal plate or inguinal sigillum 28 long and 7 wide.

Spermatheca (Figure 14c) - Cervix 6 long, shallowly cup-shaped.

Chelicera (Figure 14d) - Nine teeth and a pilus dentilis on the fixed digit. Movable digit 35 long, bearing three teeth.

Legs (Figure 14e) - Measurements of legs: leg I 353; leg II 322; leg III 302; leg IV 395. Seven setae (2$2 / 0,2 / 0-1)$ on the genu II. Three pointed macrosetae, 31, 33 and 49 long, on genu, tibia and basitarsus IV, respectively.

Material examined - The female holotype deposited in the South Australian Museum, Adelaide, Australia.

\section{Adult male}

Described by Schicha (1978). We were not able to borrow the male type specimens of this species.

Previous reports - The type specimens of $N$. nesbitti were collected from Australia (New South Wales) on Medicago arborea L. (Fabaceae). This species was reported from two biogeographical areas: Australasian and Oriental areas. Countries in which N. nesbitti was recorded are: Australia (New South Wales) (Womersley 1954; Schicha 1975; Wainstein 1977; Schicha 1978). Australia (Tasmania) (Schicha 1987); India (Delhi) (Narayanan and 


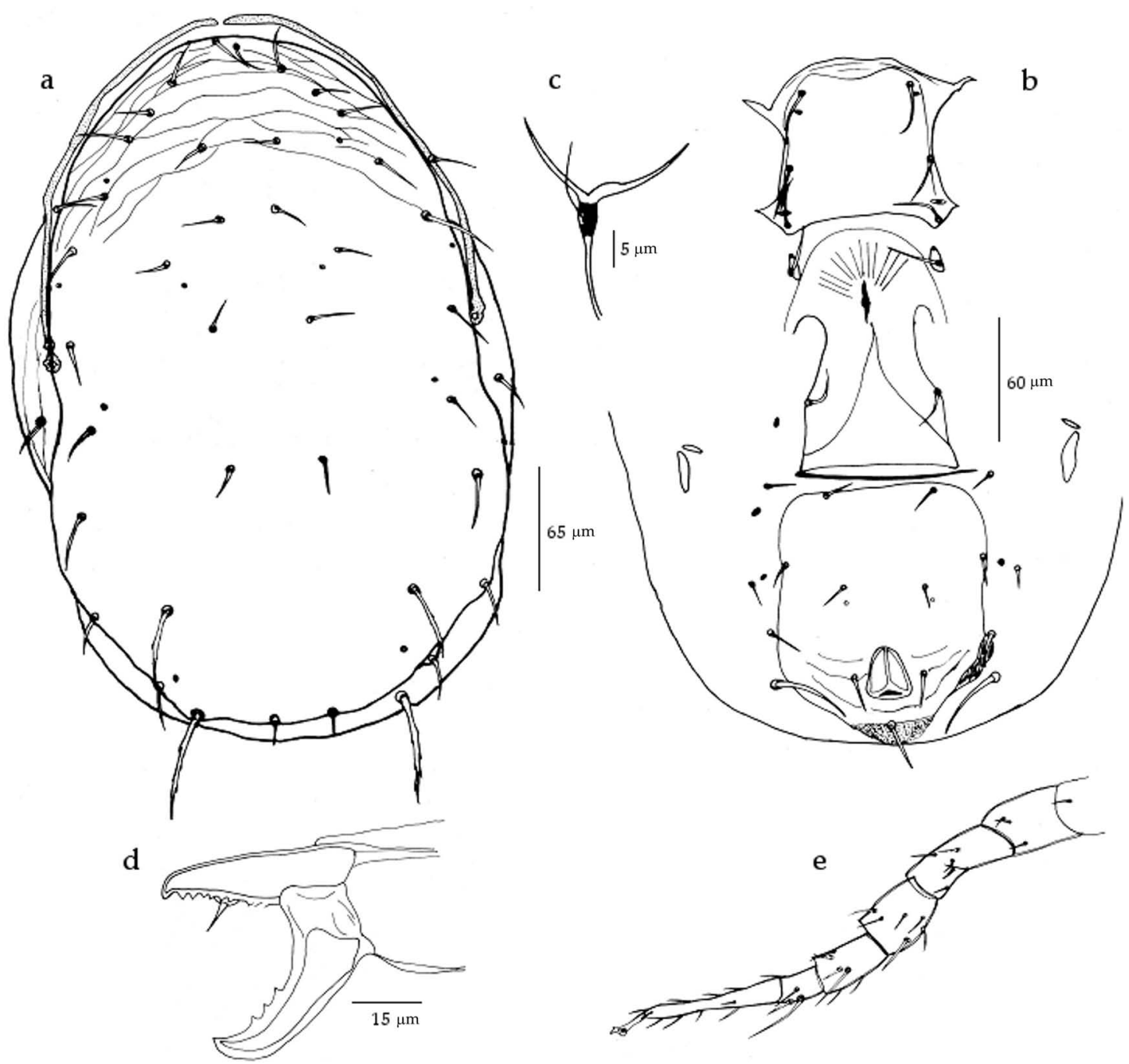

FIGURE 14: Neoseiulella nesbitti (Womersley). Female (holotype): a - dorsal shield; b - ventral shields; $\mathrm{c}$ - spermatheca; $\mathrm{d}$ - chelicera; $\mathrm{e}-$ leg IV.

Ghai 1961). Plants on which this species was collected are: Actinidia chinensis Planch. (Actinidiaceae); Banksia integrifolia L.f. (Proteaceae); Eucalyptus parivolia (Myrtaceae); Casuarina sp. (Casuarinaceae); Hydrangea macrophylla (Thunb.) Ser. (Hydrangeaceae); Malus domestica (Rosaceae); Mangifera indica L. (Anacardiaceae).

\section{Neoseiulella armidalensis (Schicha and Elshafie) (Figure 15)}

Typhlodromus armidalensis Schicha and Elshafie 1980: 36; Schicha 1987: 140; Chant and Yoshida-Shaul 1989: 1042. Neoseiulella armidalensis (Schicha and
Elshafie) Moraes et al. 1986: 201; Moraes et al. 2004: 291; Chant and McMurtry 2007: 147. Neoseiulella (Typhloctona) armidalensis (Schicha and Elshafie) Denmark and Rather 1996: 57.

\section{Adult female (Figure 15a-e)}

Dorsal shield (Figure 15a) - Dorsal shield smooth: length 416; width 214 (at level of s4) and 223 (at level of Z1). Five pairs of solenostomes: gd2, gd4, gd5, gd6, and gd9. No poroid visible. Sublateral setae (r3 and R1) on the lateral margin. Dorsal shield bearing 19 pairs of setae, all smooth, except Z5 which is slightly serrated. Lateral setae S4 and $\mathrm{S} 5$ on small tubercles in the specimen exam- 


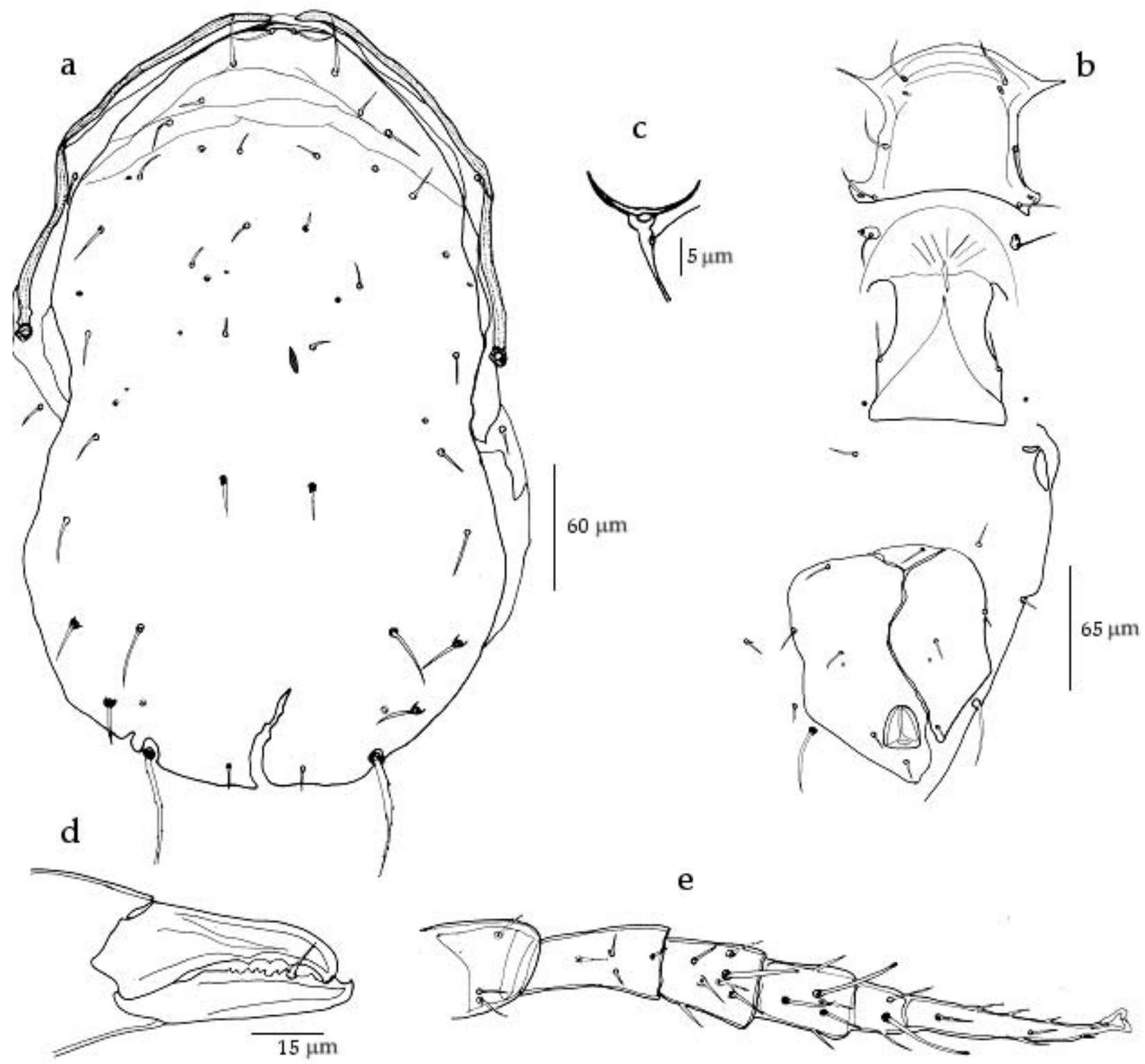

FIGURE 15: Neoseiulella armidalensis (Schicha and Elshafie). Female (paratype): a - dorsal shield; b - ventral shields; $\mathrm{c}$ - spermatheca; $\mathrm{d}$ chelicera; e - leg IV.

ined: j1 22; j3 28; j4 13; j5 10; j6 12; J2 broken in the specimen examined (Chant and Yoshida-Shaul [1989] and Denmark and Rather [1996] mentioned J2 15); J5 11; z2 14; z3 21; z4 18; z5 10; Z1 16; Z4 33; Z5 65; s4 22; s6 17; S2 23; S4 22; S5 22; r3 14 and R1 15. Peritreme extending anteriorly to the level of $j 1$.

Ventral shields (Figure 15b) — Sternal shield 90 long and 83 wide (at level of ST2), smooth, with three pairs of setae (ST1, ST2 and ST3) and two pairs of poroids. A pair of metasternal setae (ST4) on separate platelets accompanied by a pair of small poroids. Genital shield 125 long and 73 wide (at level of ST5), smooth. Four elongate platelets or genital sigilla separating the genital and ventrianal shields not discernible on the specimen examined. One pair of poroids close to the genital shield (ST 5) and no poroid visible around the genital shield. Ventrianal shield (in poor conditions in the speci- 
men examined) 134 long and 117 wide (at level of ZV2), smooth, with three pairs of preanal setae (JV1, JV2 and ZV2; JV3 absent) and a pair of small circular solenostomes gv3 posterior to JV2. Four pairs of caudoventral setae (ZV1, ZV3, JV4 and JV5) on the integument surrounding the ventrianal shield. JV5 42 long, smooth. Primary metapodal plate or inguinal sigillum 24 long and 7 wide.

Spermatheca (Figure 15c) - Cervix 7 long, cupshaped.

Chelicera (Figure 15d) — Eight or nine teeth and pilus dentilis on the fixed digit. Movable digit 35 long, bearing three teeth. Chant and Yoshida-Shaul (1989) mentioned that the pilus dentilis is not visible whereas Schicha $(1980,1987)$ and Denmark and Rather (1996) drew the pilus dentilis.

Legs (Figure 15e) - Measurements of legs: leg I 390; leg II 315; leg III 305; leg IV 408. Seven setae (2$2 / 0,2 / 0-1)$ on the genu II. Three knobbed macrosetae, 37, 45 and 47 long, on genu, tibia and basitarsus $\mathrm{IV}$, respectively.

Material examined - One female paratype specimen (deposited in NSW Department of Primary Industries, Agricultural Scientific Collections Unit (Acarology), Orange Agricultural Institute, Australia.

\section{Adult male}

The male of this species is unknown.

Previous reports $-N$. armidalensis is only known from New South Wales (Australia), on Malus sp. (Rosaceae) and Eucalyptus sp. (Myrtaceae).

The present examination of the type materials of $N$. nesbitti and N. armidalensis shows that JV3 is absent; the fixed digit has a pilus dentilis, and that leg IV bears three macrosetae for the two species. Moreover, no difference in setal and body measurements between these two species is observed. We thus propose that $N$. nesbitti is a senior synonym of $N$. armidalensis. This conclusion does not agree with those of Chant and Yoshida-Shaul (1989) and Denmark and Rather (1996). The unique difference we observe between $N$. nesbitti and N. armidalensis is the nature of macrosetae on leg IV (pointed on $N$. nesbitti, knobbed on $N$. armidalensis). Further experiments would be consequently interesting to carry out in order to determine the reliabilty of such a difference for species diagnosis.

From these latter considerations, we thus include 37 valid species in the genus Neoseiulella: $N$. aceri (Collyer) (senior synonym of $N$. squamiger [Wainstein], and provisionally of $N$. aceris [Lehman]); N. arinoi Moraza, Peña-Estevez and Ferragut; $N$. arutunjani (Kuznetsov); N. ashleyae (Chant and Yoshida-Shaul); N. canariensis Ferragut and Pena-Estevez; N. carmeli (Rivnay and Swirski); N. cassiniae (Collyer); N. celtis (Denmark and Rather); $N$. compta (Corpuz-Raros) (suspected synonym of N. multispinosa [Tseng] [Chant and Yoshida-Shaul, 1989]); N. coreen Walter; N. corrugata (Schicha); N. cottieri (Collyer); N. crassipilis (Athias-Henriot and Fauvel); N. dachanti (Collyer); N. elaeocarpi (Schicha); N. elongata Ferragut and Pena-Estevez; N. elisae (Schicha and McMurtry), N. ferraguti Moraza and Pena-Estevez; N. litoralis (Swirski and Amitai); N. longiseta Moraza, Pena-Estevez and Ferragut; N. manukae (Collyer) (senior synonym of N. glenfieldensis [Schicha]); N. montforti (Rivnay and Swirski); N. myopori (Collyer); N. neoviniferae (Basha, Mahrous and Mostafa); N. nesbitti (Womersley) (senior synonym of $N$. armidalensis [Schicha and Elshafie]); N. novaezealandiae (Collyer); N. oleariae (Collyer); N. perforata (Athias-Henriot); N. runiacus (Kolodochka); N. spaini (Collyer); N. splendida Ferragut and Pena-Estevez; N. steeli (Shicha and McMurtry); N. steveni (Schicha); N. tiliarum (Oudemans) (senior synonym of $N$. formosa [Wainstein]); N. tuberculata (Wainstein); N. sexapori (Karg and Edland); N. transitans (Gupta) (senior synonym of $N$. prunus [Denmark and Rather], and provisionally a junior synonym of N. vollsella [Chaudhri, Akbar and Rasool] [Chant and Yoshida-Shaul 1989; Denmark and Rather 1996).

\section{Description of the other valid species of the genus Neoseiulella}

\section{Neoseiulella arinoi Moraza, Peña-Estévez and Ferragut (Figure 16)}

Neoseiulella arinoi Moraza, Peña-Estévez and Ferragut 2005: 109-112; Moraza and Peña-Estevez 2006: 59; Chant and McMurtry 2007: 147. 


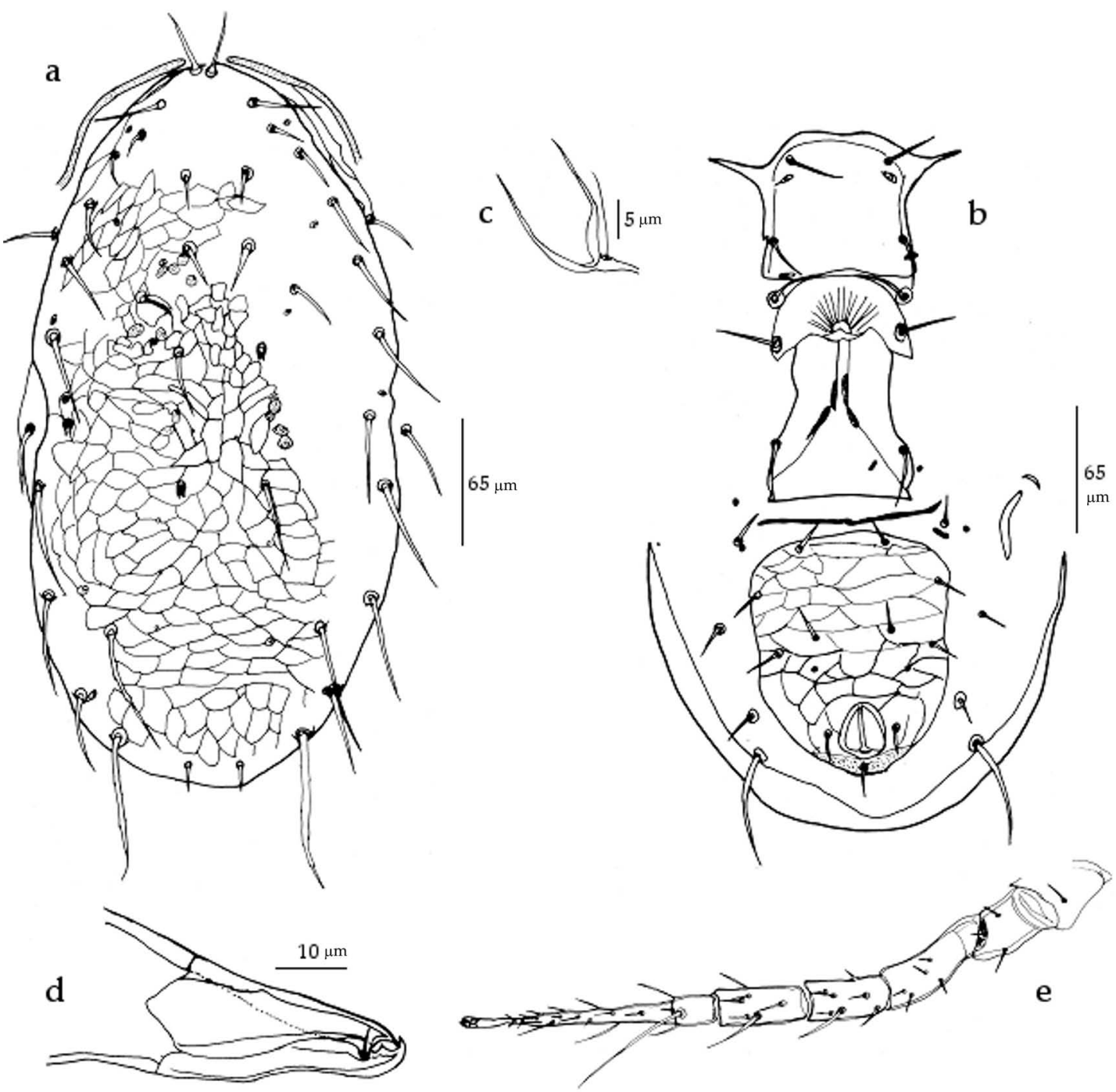

FIGURE 16: Neoseiulella arinoi Moraza, Peña-Estévez and Ferragut. Female (paratype): a - dorsal shield; b - ventral shields; c - spermatheca; $\mathrm{d}$ - chelicera; e - leg IV.

\section{Adult female (Figure 16a-e)}

Dorsal shield (Figure 16a) - Dorsal shield distinctly reticulated throughout: length 409; width 191 (at level of s4) and 202 (at level of Z1). Seven pairs of solenostomes: gd1, gd2, gd4, gd5, gd6, $\operatorname{gd} 8$, and gd9. No poroid visible. Sub-lateral setae (r3 and R1) inserted on the lateral margin. Dorsal shield bearing 19 pairs of setae, all smooth, except for Z4 and Z5 slightly serrated. Lateral setae on small tubercles: j1 34; j3 37; j4 18; j5 20; j6 36; J2 49; J5 12; z2 18; z3 30; z4 42; z5 24; Z1 46; Z4 75; Z5 80; s4 41; s6 52; S2 63; S4 60; S5 47; sub-lateral setae r3 41 and R1 41. Presence of few visible muscles marks (sigilles) on the dorsal shield. Peritreme extending anteriorly to the level of $j 1$.

Ventral shields (Figure 16b) — Sternal shield 75 long and 78 wide (at level of ST2), smooth, with two pairs of setae (ST1 and ST2) and two pairs of poroids. ST3 and ST4 on separate platelets, and a pair of small poroids accompanying ST4. Genital shield 122 long and 74 wide (at level of ST5), smooth. Four elongate platelets or genital sigilla separating genital and ventrianal shields folded under the genital shield. One pair of poroids close 
to the genital shield (ST 5) and 1 pair of poroids around the genital shield. Ventrianal shield longer than wide, 141 long and 110 wide (at level of ZV2), faintly striate, with four pairs of preanal setae (JV1, JV2, JV3 and ZV2) and a pair of circular solenostomes gv3 posteromediad to JV3. Four pairs of caudoventral setae (ZV1, ZV3, JV4 and JV5) on the integument surrounding the ventrianal shield. JV5 62 long, smooth. Dimensions of the primary metapodal plate or inguinal sigillum 37 long and 5 wide.

Spermatheca (Figure 16c) - Cervix 4 long, Ushaped.

Chelicera (Figure 16d) - Two teeth and a pilus dentilis on the fixed digit. Movable digit 33 long, unidentate.

Legs (Figure 16e) - Measurements of legs: leg I 373; leg II 345; leg III 328; leg IV 416. Seven setae (2$2 / 0,2 / 0-1)$ on the genu II. One pointed macroseta, 82 long, on the basitarsus IV. On the specimen examined, two other macrosetae, 30 and 36, on genu and tibia IV, respectively. Even if Moraza et al. (2005) draw three macrosetae on the leg IV, they only mentioned in the text, the presence of one macroseta on this leg (on basitarsus).

Material examined - A female paratype deposited in Museum of Zoology of University of Navarra, Spain.

\section{Adult male}

Described by Moraza et al. (2005). We were not able to borrow the male type specimen of this species.

Previous reports $-N$. arinoi is only known from the Canary Islands. It was collected from lichens on dead log, from soil of "lapilli" and litter of Ficus carica (Moraceae), Castanea sativa (Fagaceae) and Echium virescens D. C. (Boraginaceae) (Moraza et al. 2005).

\section{Neoseiulella ashleyae (Chant and Yoshida-Shaul) (Figure 17)}

Typhlodromus oleariae sensu Schicha $(1987,187$, plate 92), non sensu Collyer (1982). Typhlodromus ashleyae Chant and Yoshida-Shaul 1989: 1039-1041. Neoseiulella (Neoseiulella) ashleyae (Chant and YoshidaShaul) Denmark and Rather 1996: 51. Neoseiulella ashleyae (Chant and Yoshida-Shaul) Moraes et al. 2004: 292; Chant and McMurtry 2007: 147.

\section{Adult female (Figure 17a - e)}

Dorsal shield (Figure 17a) - Dorsal shield smooth: length 464 (458 - 469); width 302 (299 304) (at level of s4) and $285(280-290)$ (at level of Z1). Six pairs of small solenostomes: gd2, gd4, gd5, gd6, gd8 and gd9. Four pairs of poroids. In the original description of this species, Chant and YoshidaShaul (1989) noted the presence of only five pairs of solenostomes (gd2, gd4, gd5, gd6, and gd9). However, on their drawings a large pair of solenostomes corresponding to the position of gd8 (according to Athias-Henriot [1975] and Swirski et al. [1998]) is present. We observed this pair of solenostomes on the four type specimens examined, we thus considered that gd 8 is present and that $N$. ashleyae bears six solenostomes on the dorsal shield.

Sub-lateral setae ( $\mathrm{r} 3$ and R1) on the lateral margin. Dorsal shield bearing 19 pairs of setae, all smooth, except Z5 slightly serrated: j1 35 (33 - 37); j3 53 (51 - 56); j4 17 (15 - 18); j5 13 (10 - 16); j6 20; J2 24 (21 - 27); J5 11 (10 - 11); z2 18 (16 - 20); z3 48 (45 - 50); z4 26 (25 - 27); z5 11 (10 - 11); Z1 28 (26 - 29); Z4 61 (59 - 62); Z5 91 (88 - 94); s4 51 (49 - 53); s6 38 (36 - 39); S2 51 (50 - 52); S4 31 (28 - 33); S5 27 (26 - 27); sub-lateral setae r3 24 (20 - 28) and R1 22 (19 -24). Peritreme extending anteriorly to the level of j1.

Ventral shields (Figure 17b) — Sternal shield 93 (91 - 94) long and $101(98-103)$ wide (at level of ST2), smooth, with three pairs of setae (ST1, ST2 and ST3) and two pairs of poroids. A pair of metasternal setae (ST4) on separate platelets accompanied by a pair of small poroids. Genital shield 147 long, 78 wide (at level of ST5), smooth. Four elongate platelets or genital sigilla between genital and ventrianal shields. One pair of poroids close to the genital shield (ST 5) and 4 pairs of poroids around the genital shield. Ventrianal shield subtriangularshaped, 152 (147 - 156) long and $128(122-133)$ wide (at level of ZV2), smooth, with three pairs of preanal setae (JV1, JV2 and ZV2; JV3 absent) and a pair of small solenostomes gv3 posterior to JV2. Four pairs of caudoventral setae (ZV1, ZV3, JV4 and JV5) on the integument surrounding the ven- 

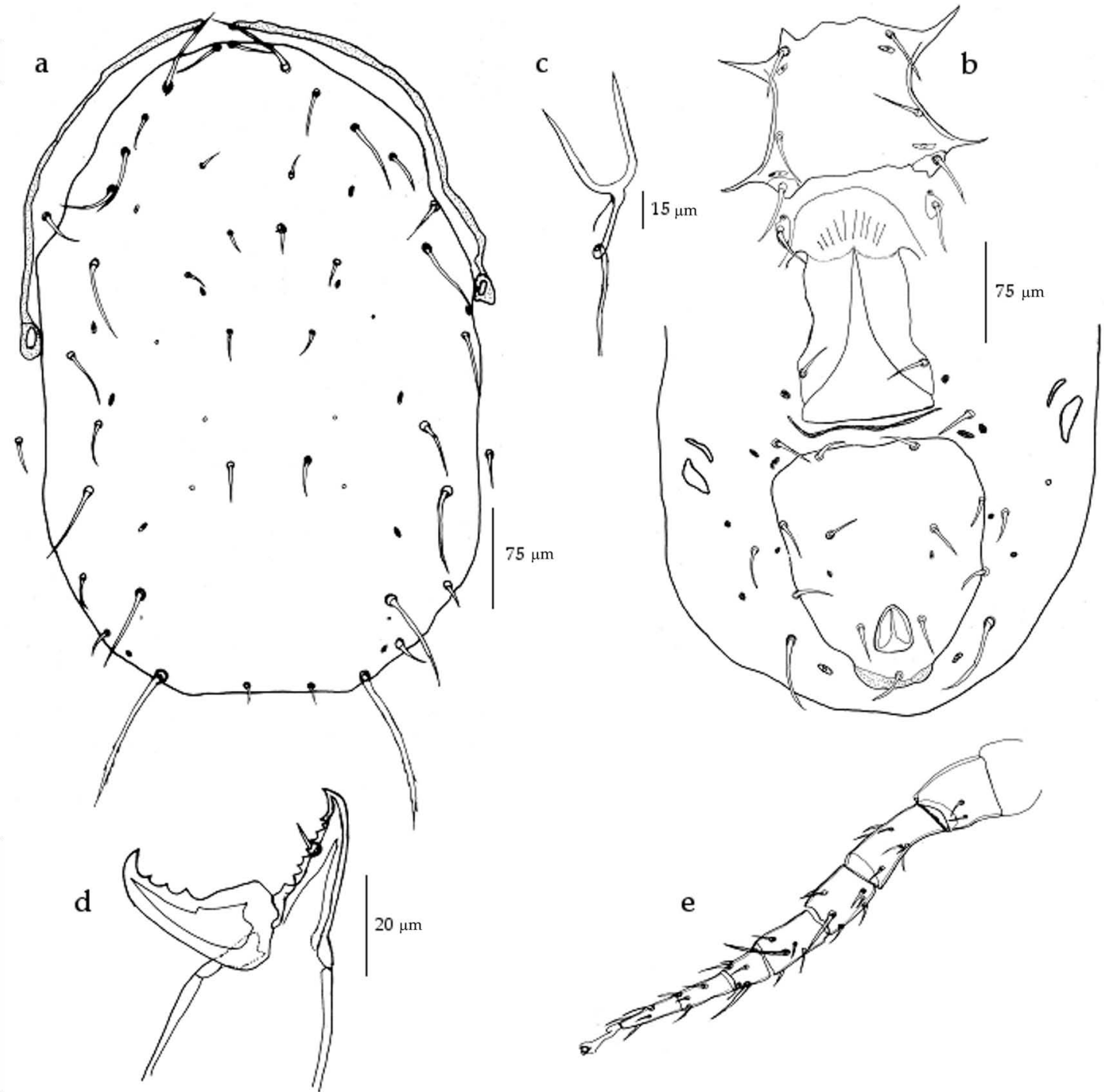

FIGURE 17: Neoseiulella ashleyae (Chant and Yoshida-Shaul). Female (holotype): a - dorsal shield; $\mathrm{b}$ - ventral shields; $\mathrm{c}$ - spermatheca; $\mathrm{d}$ - chelicera; e - leg IV.

trianal shield. JV5 $46(41-51)$ long, smooth. Primary metapodal plate or inguinal sigillum $26(24-$ 28) long and $8(6-9)$ wide.

Spermatheca (Figure 17c) - Cervix $14(12-16)$ long, thick and U-shaped.

Chelicera (Figure 17d) - Nine teeth and a pilus dentilis on the fixed digit. Movable digit $42(39-44)$ long, bears three teeth.

Legs (Figure 17e) - Measurements of legs: leg I 435 (430 - 440); leg II 388 (386 - 390); leg III 364 (361 - 366); leg IV 441 (436-445). Seven setae (2-2/0,
2/0-1) on the genu II. One macroseta (28 long) on the genu III. Three other macrosetae, $42(39-45), 42$ $(40-44)$ and $34(32-35)$ long, on genu, tibia and basitarsus IV, respectively.

Material examined - The female holotype and three female paratypes deposited in the Canadian National Collection, Department of Zoology, University of Toronto, Toronto, Canada. A specimen of this species labeled as Typhlodromus oleariae (Schicha 1987) (deposited in the New Zealand Arthropod Collection [NZAC], Landcare Research, Auckland, New Zealand) was also presently examined. Our 
examination of this specimen shows that, as stated by Chant and Yoshida-Shaul (1989), it belongs to $N$. ashleyae, but not to $N$. oleariae.

\section{Adult male}

The male of this species is unknown.

Previous reports $-N$. ashleyae is only known from New Zealand (Nelson Province) (Chant and Yoshida-Shaul 1989). Plants on which this species was collected are: Elaeocarpus hookerianus Raoul (Elaeocarpaceae), Citrus sp. (Rutaceae), Nothofagus menziesii (Hook.f.) Oerst. (Nothofagaceae) and Pinus uncinata Ramond ex D. C. (Pinaceae).

\section{Neoseiulella canariensis Ferragut and Peña-Estevez (Figure 18)}

Neoseiulella canariensis Ferragut and Peña-Estevez 2003: 159-161; Moraes et al. 2004: 292; Moraza and Peña-Estevez 2006: 59; Chant and McMurtry 2007: 147.

\section{Adult female (Figure 18a - e)}

Dorsal shield (Figure 18a) - Dorsal shield smooth: length 364 (342 - 385); width 185 (174 195) (at level of s4) and 209 (183 - 235) (at level of Z1). Seven pairs of small solenostomes on the dorsal shield: gd1, gd2, gd4, gd5, gd6, gd8 and gd9. Five pairs of poroids. Sub-lateral setae (r3 and R1) on the lateral margin. Dorsal shield bearing 19 pairs of setae, all smooth, thick, and rising up tubercles, except J5, Z4 and Z5 slightly serrated: j1 28 (26-30); j3 42; j4 21 (19 - 23); j5 20 (20 - 22); j6 32 (30 - 33); J2 37 (35 - 39); J5 32 (31 - 33); z2 22 (20 - 23); z3 40 (38 - 42); z4 29 (27 - 31); z5 21 (19 - 23); Z1 35 (32 - 38); Z4 61 (59 - 62); Z5 90 (88 - 91); s4 47 (43 - 50); s6 46 (44 - 48); S2 51 (48 - 53); S4 41 (34 - 47); S5 30 (28 31); sub-lateral setae r3 30 (28 - 32) and R1 31 (28 33). Presence of few visible muscles marks (sigilles) on the dorsal shield. Peritreme extending anteriorly to the level of $j 1$.

Ventral shields (Figure 18b) - Sternal shield 61 (50 - 71) long and 60 (47 - 73) wide (at level of ST2), smooth with two pairs of setae (ST1 and ST2) and two pairs of poroids. ST3 and the metasternal setae (ST4) on separate platelets, with a pair of small poroids with ST4. Genital shield $110(90-129)$ long,
$54(48-60)$ wide (at level of ST5), smooth. Three elongate platelets or genital sigilla situated between genital and ventrianal shields. One pair of poroids close to the genital shield (ST 5) and 4 pairs of poroids around the genital shield. Ventrianal shield subtriangular-shaped, $102(85-118)$ long and 77 $(60-84)$ wide (at level of ZV2), smooth or faintly striate, with four pairs of preanal setae (JV1, JV2, JV3 and ZV2) and a pair of small solenostomes gv3 posteromediad to JV3. Four pairs of caudoventral setae (ZV1, ZV3, JV4 and JV5) on the integument surrounding the ventrianal shield. JV5 $34(30-38)$ long, smooth. Primary metapodal plate or inguinal sigillum $25(21-29)$ long and $6(5-7)$ wide.

Spermatheca (Figure 18c) - Cervix 4 (3-5) long, U-shaped, flaring towards vesicle.

Chelicera (Figure 18d) - Six teeth and a pilus dentilis on the fixed digit. Movable digit 26 long, bidentate.

Legs (Figure 18e) - Measurements of legs: leg I 374 (365 - 383); leg II 310 (301 - 320); leg III 297 (286 - 308); leg IV 415 (404 - 425). Seven setae (2-2/0, $2 / 0-1)$ on the genu II. Three pointed macrosetae 33 $(31-34), 31(30-32)$ and $55(51-59)$ long on genu, tibia and basitarsus IV, respectively.

Material examined - Three female paratypes deposited in the Department of Agroforestal Ecosystems, Universidad Politécnica de Valencia, Spain.

\section{Adult male (Figure 18f, g)}

Dorsal shield slightly reticulated and chaetotaxy similar to the female. Sub-lateral seta R1 on the dorsal shield. Ventrianal shield 118 long and 150 wide, slightly reticulated and bearing 7 pairs of preanal setae and 4 pairs of poroids. Spermatodactyl L-shaped. This description is based on a male paratype specimen.

Previous reports $-N$. canariensis is only known from the Canary Islands (Ferragut and PeñaEstevez 2003, 2007). It was collected on various plants belonging to 15 botanical families: Ageratina adenophora (Spreng.) King and H. Rob, Andryala pinnatifida Ait., Argyranthemum frutescens (L.) Sch.Bip., Argyranthemum gracile Webb ex Sch.Bip., Carlina salicifolia (L.fil.) Cav., Cynara cardunculus L., 


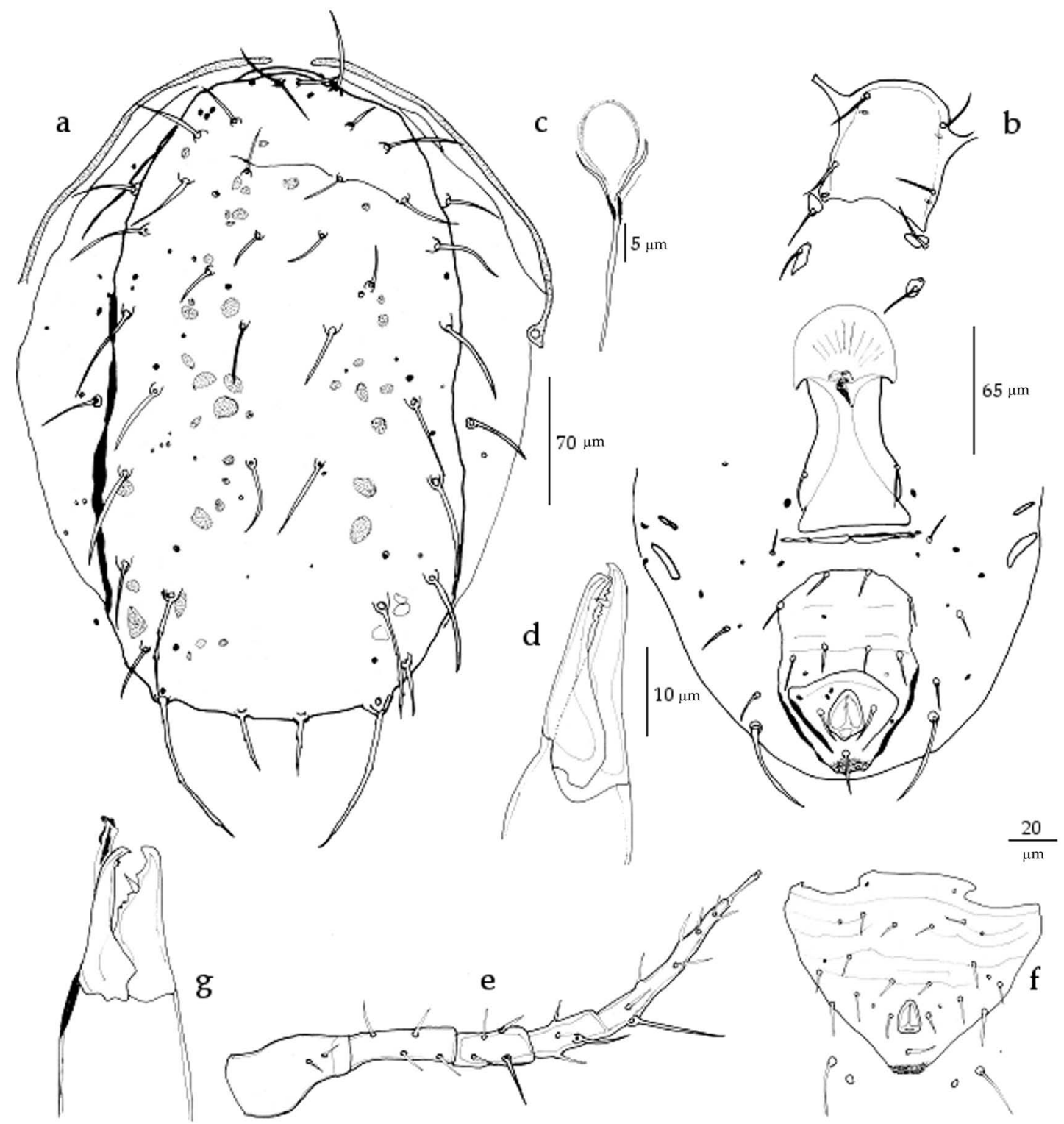

FIGURE 18: Neoseiulella canariensis Ferragut and Peña-Estevez. Female (holotype): a - dorsal shield; b - ventral shields; $\mathrm{c}$ - spermatheca; $\mathrm{d}$ - chelicera; $\mathrm{e}$ - leg IV. Male (paratype): $\mathrm{f}$ - ventrianal shield; $\mathrm{g}$ - spermatodactyl.

Gonospermum gomerae Bolle., Senecio tussilaginis (L'Hér.) (Asteraceae); Bencomia caudata (Aiton) Webb and Berthel. (Rosaceae); Bosea yervamora L. (Amaranthaceae); Calamintha sylvatica Bromf., Cedronella canariensis (L.) Webb and Berthel., Lavandula buchii Webb (Lamiaceae); Chamaecytisus prolifer (L.f.) Link, Teline microphylla (DC.) Gibbes and Dingw., Teline gomerae (Gibbs and Dingw.) Kunkle (Fabaceae); Convolvulus sp. (Convolvulaceae);
Crambe pritzelii Bolle, Crambe strigosa L'Hér. (Cruciferae); Echium acanthocarpum Svent., Echium sp. (Boraginaceae); Erica arborea L., Erica scoparia L. (Ericaceae); Geranium canariensis L. (Geraniaceae); Gesnouinia arborea (L.f.) Gaudich.(Urticaceae); Laurus novocanariensis Rivas Mart. Rivas Mart., Lousã, Fern. Prieto, E.Díaz, J.C. Costa and C. Aguiar (Lauraceae); Scrophularia smithii Hornem (Scrophulariaceae); Viburnum rigidum Vent. (Caprifoliaceae); Vi- 

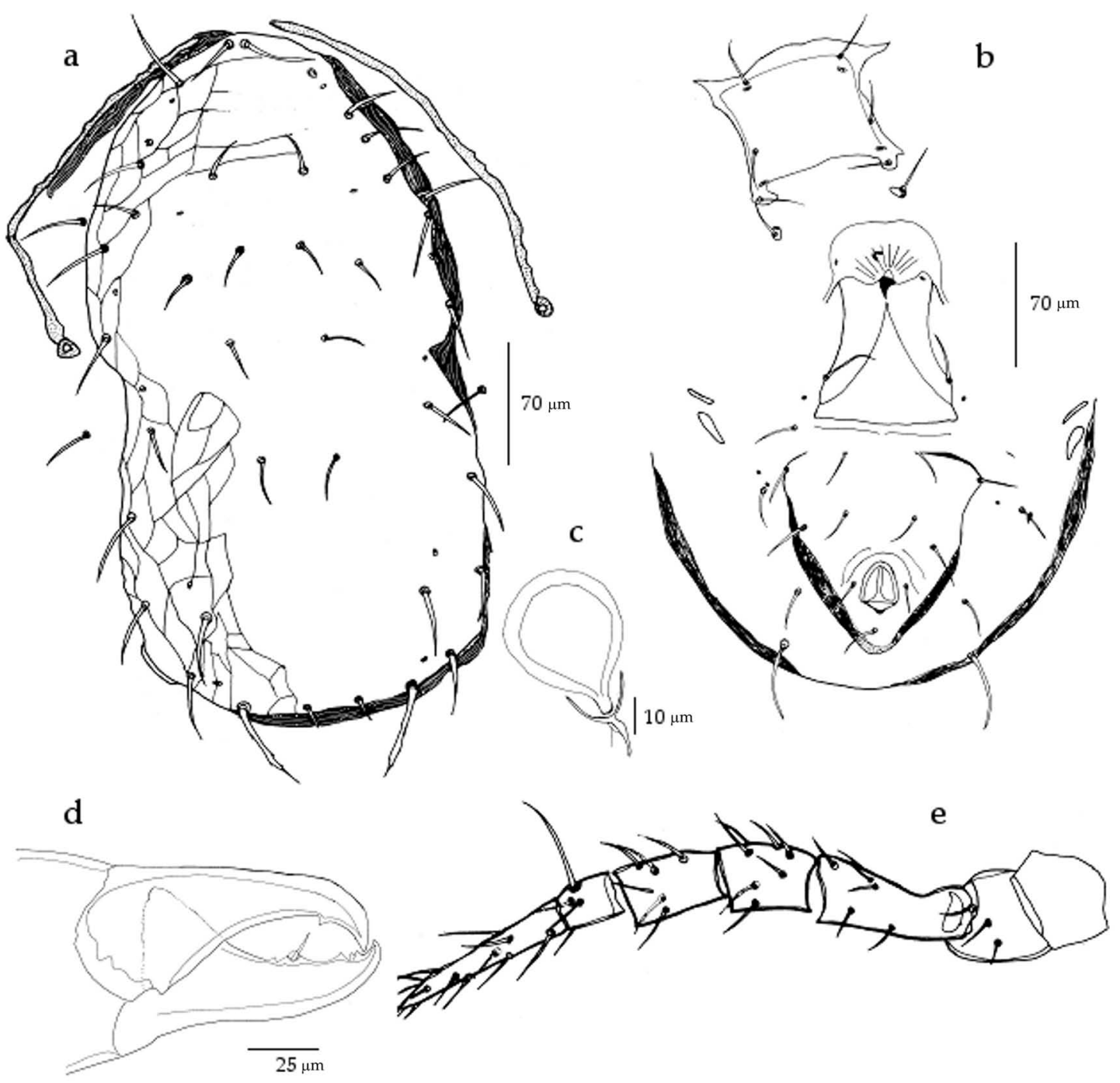

FIgURE 19: Neoseiulella carmeli (Rivnay and Swirski). Female (paratype): a - dorsal shield; b - ventral shields; c - spermatheca; d chelicera; e - leg IV.

ola riviniana $\mathrm{Rchb.} \mathrm{(Violaceae).}$

\section{Neoseiulella carmeli (Rivnay and Swirski)} (Figure 19)

Typhloctonus carmeli Rivnay and Swirski 1980: 177179; Denmark and Rather 1984: 167; Moraes et al. 1986: 232. Typhlodromus carmeli (Rivnay and Swirski) Chant and Yoshida-Shaul 1989: 1020. Neoseiulella (Typhloctona) carmeli (Rivnay and Swirski) Denmark and Rather 1996: 65-66. Neoseiulella carmeli (Rivnay and Swirski) Swirski and Amitai 1997b: 37; Swirski et al. 1998: 115; Moraes et al. 2004: 292; Chant and McMurtry 2007: 147.

Adult female (Figure 19a - e)

Dorsal shield (Figure 19a) - Dorsal shield slightly reticulated along the lateral area: length 409; width 204 (at level of s4) and 188 (at level of Z1). Six pairs of solenostomes on the dorsal shield: $\operatorname{gd} 1, \operatorname{gd} 2, \operatorname{gd} 4, \operatorname{gd} 6, \operatorname{gd} 8$ and $g d 9$. No poroid visible. Sub-lateral setae (r3 and R1) on the lateral margin. Dorsal shield bearing 19 pairs of setae, all smooth except Z5 slightly serrated: j1 38; j3 47; j4 24 (22 25); j5 22; j6 24; J2 28; J5 12; z2 26; z3 33 (31 - 35); z4 
25; z5 24; Z1 27; Z4 42; Z5 55; s4 38 (36 - 39); s6 37; S2 39 (37 - 40); S4 35 (33 - 36); S5 38; sub-lateral setae r3 35 and R1 30. Peritreme extending anteriorly to the level of $\mathrm{j} 1$.

Ventral shields (Figure 19b) - Sternal shield 87 long and 90 wide (at level of ST2), smooth with three pairs of setae (ST1, ST2 and ST3) and two pairs of poroids. A pair of metasternal setae (ST4) on separate platelets accompanied by a pair of small circular poroids. Genital shield 134 long and 87 wide (at level of ST5), smooth. Platelets or genital sigilla separating between genital and ventrianal shields not discernible. One pair of poroids close to the genital shield (ST 5) and 1 pair of poroids around the genital shield. Ventrianal shield subtriangularshaped, lightly longer than wide, 142 long and 136 wide (at level of ZV2), smooth, with four pairs of preanal setae (JV1, JV2, JV3 and ZV2) and without solenostome $g v 3$. Four pairs of caudoventral setae (ZV1, ZV3, JV4 and JV5) on the integument surrounding the ventrianal shield. JV5 54 (50 - 58) long, smooth. Primary metapodal plate or inguinal sigillum 25 long and 7 wide.

Spermatheca (Figure 19c) - Cervix 12 long, Ushaped.

Chelicera (Figure 19d) - Three or four teeth and a pilus dentilis on the fixed digit. Movable digit 55 long, unidentate.

Legs (Figure 19e) - Measurements of legs: leg I 412; leg II 357 (353 - 360); leg III 370 (361 - 378); leg IV 467. Six setae $(1-2 / 0,2 / 0-1)$ on the genu II. One macroseta $58(56-59)$ long, on the basitarsus IV.

Material examined - Three female paratypes deposited in the Division of Entomology, Agricultural Research Organization, Bet Dagan, Israel.

\section{Adult male}

The male of this species is unknown.

Previous reports - N. carmeli is only known from Israel (Rivnay and Swirski 1980; Swirski and Amitai 1997b; Swirski et al. 1998). Plants on which this species was collected are: Quercus calliprinos Webb (Fagaceae); Phillyrea latifolia L. (Oleaceae); Salvia sp. (Lamiaceae); and Styrax officinalis L. (Styracaceae).

\section{Neoseiulella cassiniae (Collyer) (Figure 20)}

Typhlodromus cassiniae Collyer 1982: 189; Chant and Yoshida-Shaul 1989: 1024-1026. Typhloctonus cassiniae (Collyer) Denmark and Rather 1984: 171; Moraes et al. 1986: 232. Neoseiulella (Typhloctona) cassiniae (Collyer) Denmark and Rather 1996: 70. Neoseiulella cassiniae (Collyer) Moraes et al. 2004: 292; Chant and McMurtry 2007: 147.

Adult female (Figure 20a-e)

Dorsal shield (Figure 20a) - Dorsal shield slightly reticulated throughout: length 473; width 235 (at level of s4) and 260 (at level of Z1). Six pairs of solenostomes on the dorsal shield: $\operatorname{gd} 1, \mathrm{gd} 2, \mathrm{gd} 4$, gd5, gd6 and gd9. No poroid visible. Sub-lateral setae (r3 and R1) on the lateral margin. Dorsal shield bearing 19 pairs of setae all smooth: j1 20; j3 20; j4 11; j5 11; j6 12; J2 broken in the specimen examined (Denmark and Rather [1984, 1996] mentioned J2 11); J5 11; z2 11; z3 15; z4 14; z5 9; Z1 14; Z4 broken on the specimen examined (Denmark and Rather [1984, 1996] mentioned Z4 27); Z5 39; s4 20; s6 21; S2 19; S4 14; S5 14; sub-lateral setae r3 19 and R1 18. Peritreme extending anteriorly to the level between j1-j3.

Ventral shields (Figure 20b) - Sternal shield 71 long and 76 wide (at level of ST2), smooth with two pairs of setae (ST1 and ST2) and two pairs of poroids. ST3 and ST4 on separate platelets and a pair of small poroids accompanying ST4. Genital shield 167 long and 87 wide (at level of ST5), smooth. Four elongate platelets or genital sigilla between genital shield and ventrianal shields. One pair of poroids close to the genital shield (ST 5) and 2 pairs of poroids around the genital shield. Ventrianal shield subtriangular-shaped, 157 long and 131 wide (at level of ZV2), smooth, with four pairs of preanal setae (JV1, JV2, JV3 and ZV2) and without solenostome $g v 3$. Four pairs of caudoventral setae (ZV1, ZV3, JV4 and JV5) on the integument surrounding the ventrianal shield. JV5 36 long, smooth. Primary metapodal plate or inguinal sigillum 34 long and 7 wide. 


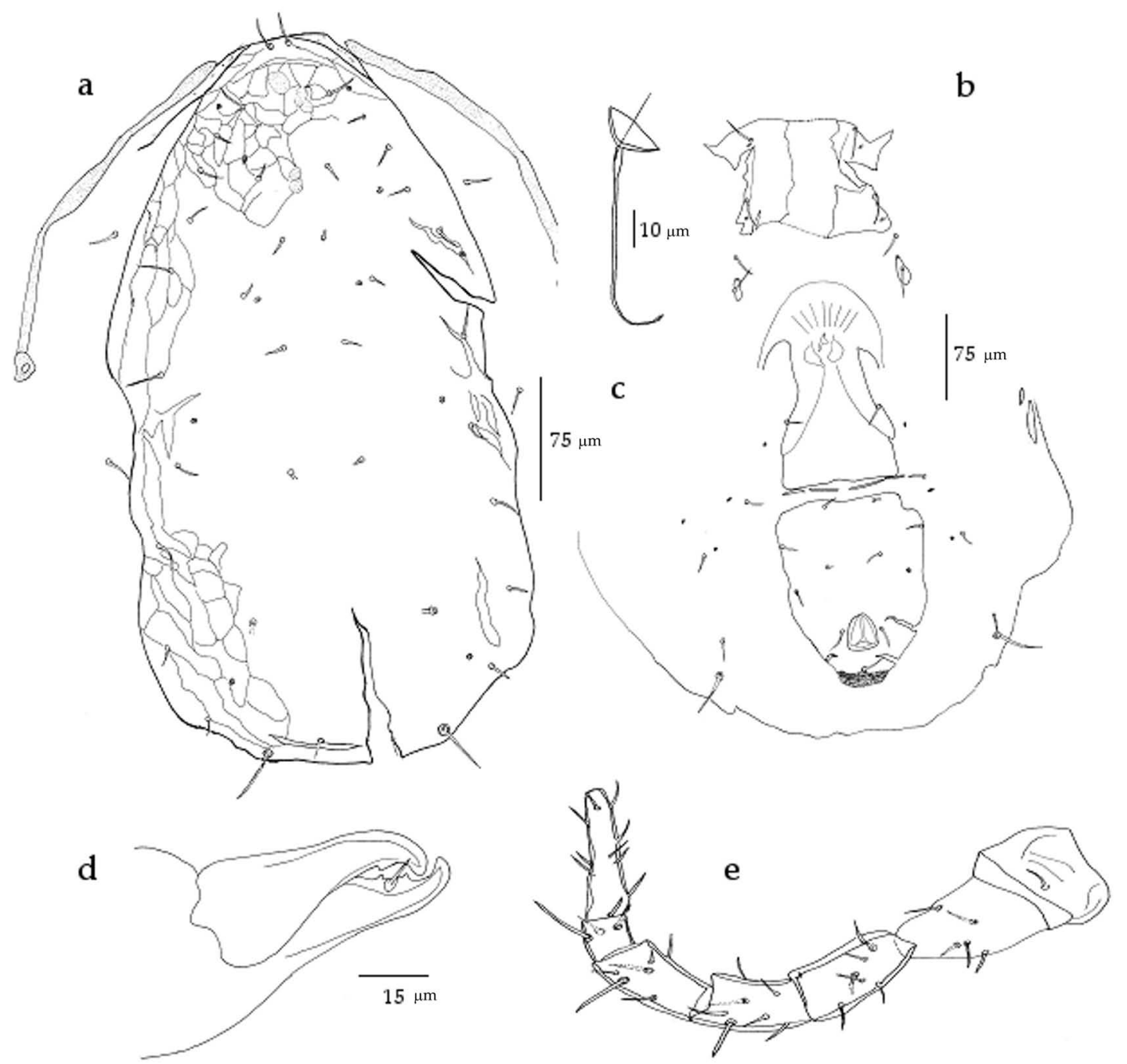

FIGURE 20: Neoseiulella cassiniae (Collyer). Female (paratype): a - dorsal shield; b - ventral shields; c - spermatheca; $\mathrm{d}$ - chelicera; $\mathrm{e}$ - leg IV.

Spermatheca (Figure 20c) - Cervix 8 long, cupshaped.

Chelicera (Figure 20d) - Two teeth and a pilus dentilis on the fixed digit. Movable digit 37 long, unidentate.

Legs (Figure 20e) - Measurements of legs: leg I 391; leg II 323; leg III 337; leg IV 417. Eight setae $(2-2 / 1,2 / 0-1)$ on the genu II. Three macrosetae, 25,30 and 32 long, on genu, tibia and basitarsus IV, respectively.
Material examined - The female holotype deposited in the New Zealand Arthropod Collection (NZAC), Landcare Research, Auckland, New Zealand.

\section{Adult male}

The adult of this species is unknown.

Previous reports $-N$. cassiniae is only known from New Zealand, on Cassinia sp. (Asteraceae) and Hebe sp. (Plantaginaceae). 


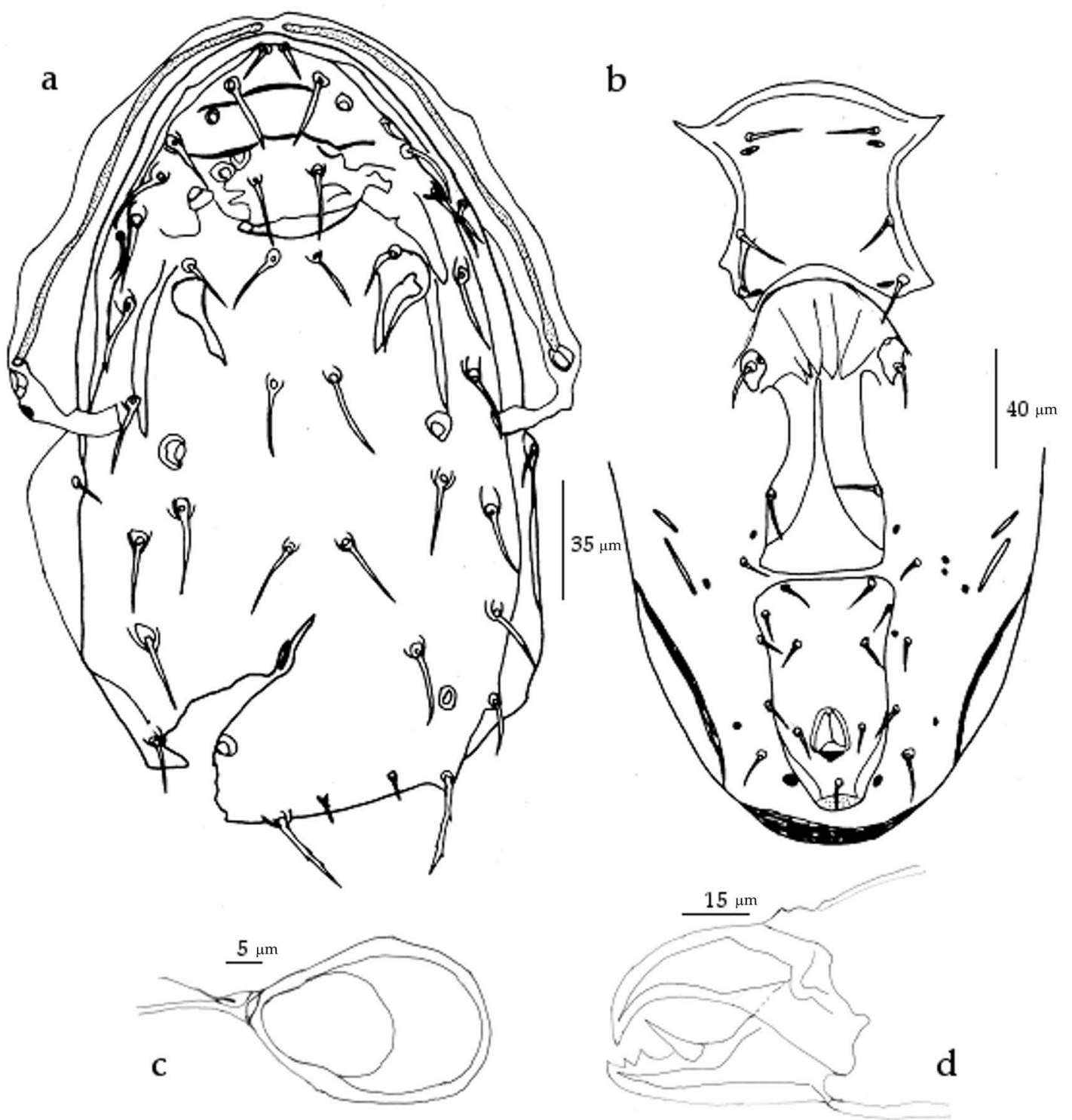

FIGURE 21: Neoseiulella coreen Walter. Female (holotype): a - dorsal shield; b - ventral shields; $\mathrm{c}$ - spermatheca; $\mathrm{d}$ - chelicera.

\section{Neoseiulella coreen Walter \\ (Figure 21)}

Neoseiulella coreen Walter 1997: 336-337. Neoseiulella coreen Walter, Moraes et al. 2004: 292; Chant and McMurtry 2007: 147.

Adult female (Figure $21 \mathrm{a}-\mathrm{d}$ )

Dorsal shield (Figure 21a) - Dorsal shield is smooth: length 266 (261 - 270); width 132 (129 - 135) (at level of s4), 145 (139-150) (at level of Z1). Tuber- culous ornements covering the lateral areas of the dorsal shield. Three pairs of large circular solenostomes (gd1, gd6, and gd9) and one pair of small and crescent-shaped solenostomes ( $\mathrm{gd} 8$ ) on the dorsal shield. No poroid visible. Sub-lateral setae (r3 and R1) on the lateral margin. Dorsal shield bearing 19 pairs of setae all smooth and rising to tubercles, except Z5 slightly serrated: j1 16 (12 - 20); j3 22 (20 24); j4 24 (23 - 25); j5 29 (28 - 30); j6 30 (28 - 31); J2 28 
(26 - 30); J5 9 (8 - 10); z2 18; z3 25 (23 - 26); z4 25 (24 - 26); z5 16 (15 - 17); Z1 31 (30 - 32); Z4 25 (24 - 26); Z5 31 (30 - 32); s4 23; s6 29; S2 30 (29 - 31); S4 24 (22 - 25); S5 20 (19 - 21); sub-lateral setae r3 22 (21 - 23) and R1 14 (12-15). Peritreme extending anteriorly to the level of $\mathrm{j} 1$.

Ventral shields (Figure 21b) - Sternal shield weakly sclerotized, 58 (54 - 62) long and 56 (55 57) wide (at level of ST2), smooth with three pairs of setae (ST1, ST2 and ST3) and two pairs of small poroids. A pair of metasternal setae (ST4) inserted on separate platelets accompanied by a pair of small poroids. Genital shield 95 (93 - 96) long and 39 (35 -42) wide (at level of ST5), smooth. Four elongate platelets or genital sigilla separating genital and ventrianal shields folded under the genital shield. One pair of poroids close to the genital shield (ST $5)$ and 4 pairs of poroids around the genital shield. Ventrianal shield $79(74-83)$ long and $47(44-49)$ wide (at level of ZV2), smooth, with three pairs of preanal setae (JV1, JV2 and ZV2; JV3 absent), and without solenostome $g v 3$. Four pairs of caudoventral setae (ZV1, ZV3, JV4 and JV5) on the integument surrounding the ventrianal shield. JV5 14 (13 -15) long, smooth. Primary metapodal plate or inguinal sigillum 19 long and $2(1.5$ - 2) wide.

Spermatheca (Figure 21c) - Cervix $4(3-4)$ long, U-shaped.

Chelicera (Figure 21d) - Two teeth and a pilus dentilis on the fixed digit. Movable digit $24(23-25)$ long, edentate.

Legs - Measurements of legs: leg I 270 (268 272); leg II 205 (195 - 215); leg III 191 (188 - 194); leg IV 271 (268 - 274). Eight setae (2-2/1, 2/0-1) observed on the genu II. No macroseta on legs.

This species is easily distinghuished from the other species in the genus Neoseiulella by the tuberculous ornements on the dorsal shield, and by the small size and the shape of the ventrianal shield, which is narrowly vase-shaped.

Material examined - The female holotype and five female paratypes deposited in the UQIC, Department of Entomology, University of Queensland, St Lucia, Australia.

Adult male
Described by Walter (1997). We were not able to borrow any male type specimens of this species.

Previous reports - N. coreen is only known from Queensland (Australia) on rainforest trees.

\section{Neoseiulella corrugata (Schicha) (Figure 22)}

Typhlodromus corrugatus Schicha 1983: 120; Schicha 1987: 141-144; Chant and Yoshida-Shaul 1989: 10391040. Seiulus corrugatus (Schicha) Moraes et al. 1986: 230. Neoseiulella (Neoseiulella) corrugata (Schicha) Denmark and Rather 1996: 50. Neoseiulella corrugata (Schicha) Moraes et al. 2004 : 293; Chant and McMurtry 2007: 147.

\section{Adult female (Figure $22 \mathrm{a}-\mathrm{e}$ )}

Dorsal shield (Figure 22a) - Dorsal shield smooth: length 409; width 247 (at level of s4), 240 (at level of Z1) and 272 (at level of S2). Four pairs of solenostomes on the dorsal shield: $\mathrm{gd} 2, \mathrm{gd} 4, \mathrm{gd} 6$ and gd9. No poroid visible. Sub-lateral setae (r3 and R1) on the lateral margin. Dorsal shield bearing 19 pairs of setae, all except $\mathrm{j} 1$ on tubercles. All dorsal and sub-lateral setae smooth, except $Z 4$ and Z5 distinctly serrated: j1 29; j3 40; j4 28; j5 26; j6 30; J2 35; J5 12; z2 25; z3 37; z4 37; z5 24; Z1 37; Z4 66; Z5 117; s4 42; s6 40; S2 48; S4 36; S5 29; sub-lateral setae r3 23 and R1 22. Peritreme extending anteriorly to the level of $\mathrm{j} 1$.

Ventral shields (Figure 22b) - Sternal shield 80 long and 92 wide (at level of ST2), smooth with three pairs of setae (ST1, ST2 and ST3) and two pairs of poroids. A pair of metasternal setae (ST4) inserted on separate platelets accompanied by a pair of small poroids. Genital shield 126 long and 83 wide (at level of ST5), smooth. Four elongate platelets or genital sigilla separating genital and ventrianal shields folded under the genital shield. One pair of poroids close to the genital shield (ST 5) and 3 pairs of poroids around the genital shield. Ventrianal shield 148 long and 120 wide (at level of ZV2), smooth, with three pairs of preanal setae (JV1, JV2 and ZV2; JV3 absent), with a pair of circular solenostomes $g v 3$. Four pairs of caudoventral setae (ZV1, ZV3, JV4 and JV5) on the integument surrounding the ventrianal shield. JV5 53 long, 


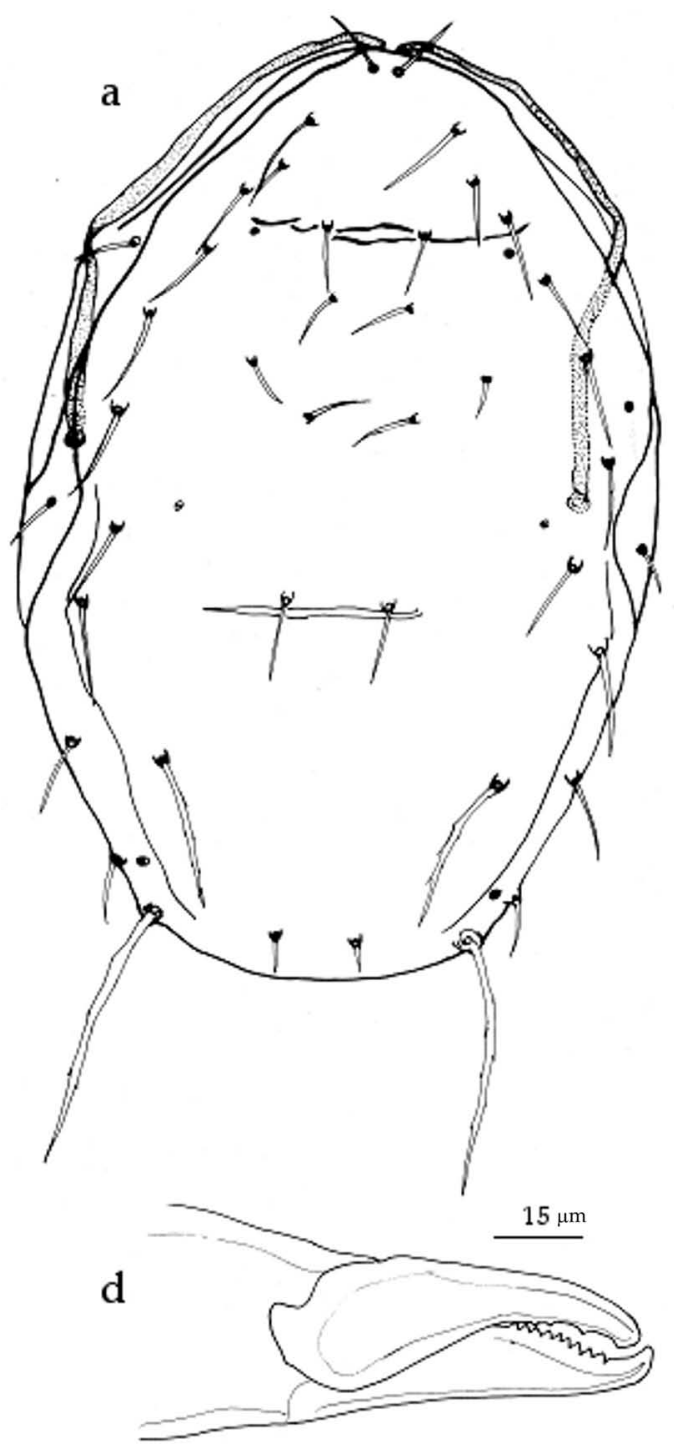

b
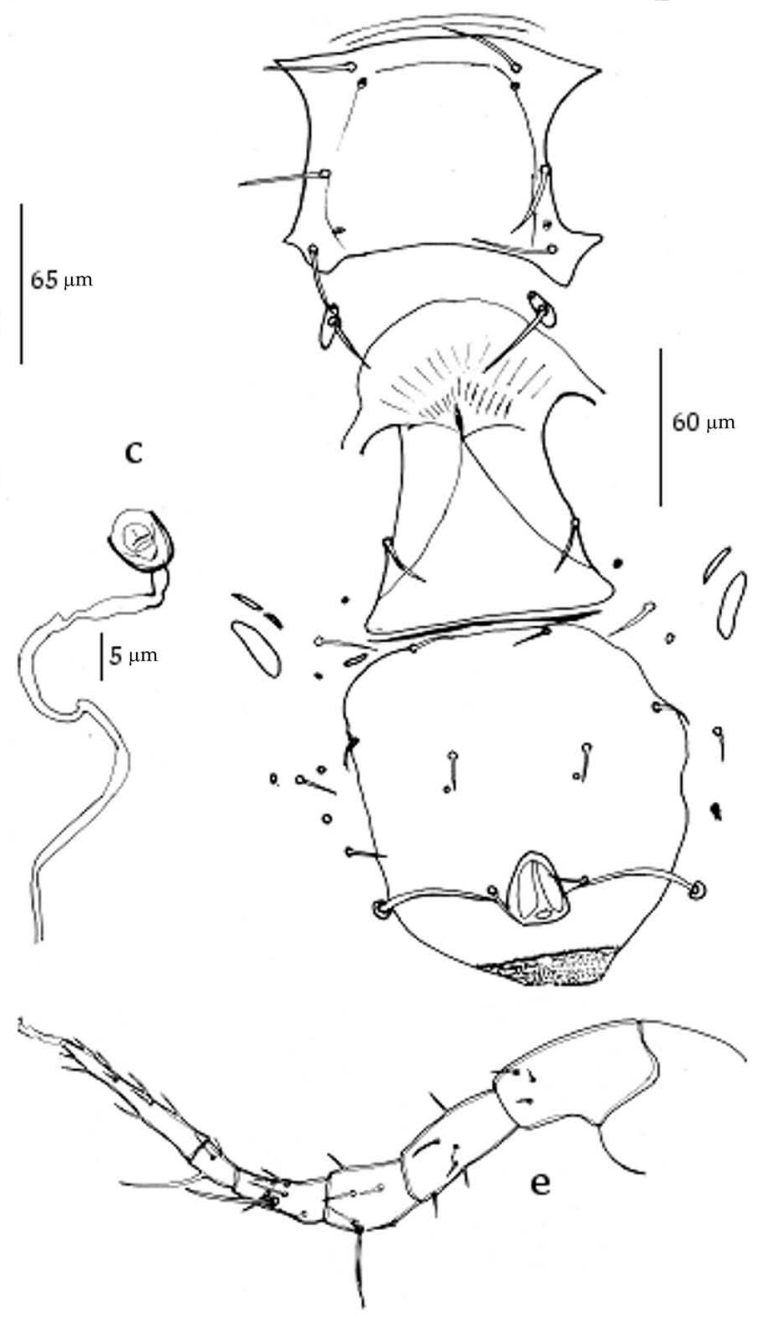

FIGURE 22: Neoseiulella corrugata (Schicha). Female (holotype): a - dorsal shield; b - ventral shields; c - spermatheca; d - chelicera; e leg IV.

smooth. Primary metapodal plate or inguinal sigillum 29 long and 8 wide.

Spermatheca (Figure 22c) - Cervix 6 long, Ushaped.

Chelicera (Figure 22d) - Nine teeth, without pilus dentilis, on the fixed digit. Movable digit 33 long, bearing three teeth.

Legs (Figure 22e) - Measurements of legs: leg I 443; leg II 351; leg III 361; leg IV 456. Seven setae $(2-2 / 0,2 / 0-1)$ on the genu II. One macroseta (32 long) on the genu III. Three other macrosetae, 47, 55 and 52 long, on genu, tibia and basitarsus IV, respectively.

Material examined - The female holotype deposited in NSW Department of Primary Industries, Agricultural Scientific Collections Unit (Acarology), Orange Agricultural Institute, Australia.

Adult male

The male of this species is unknown. 


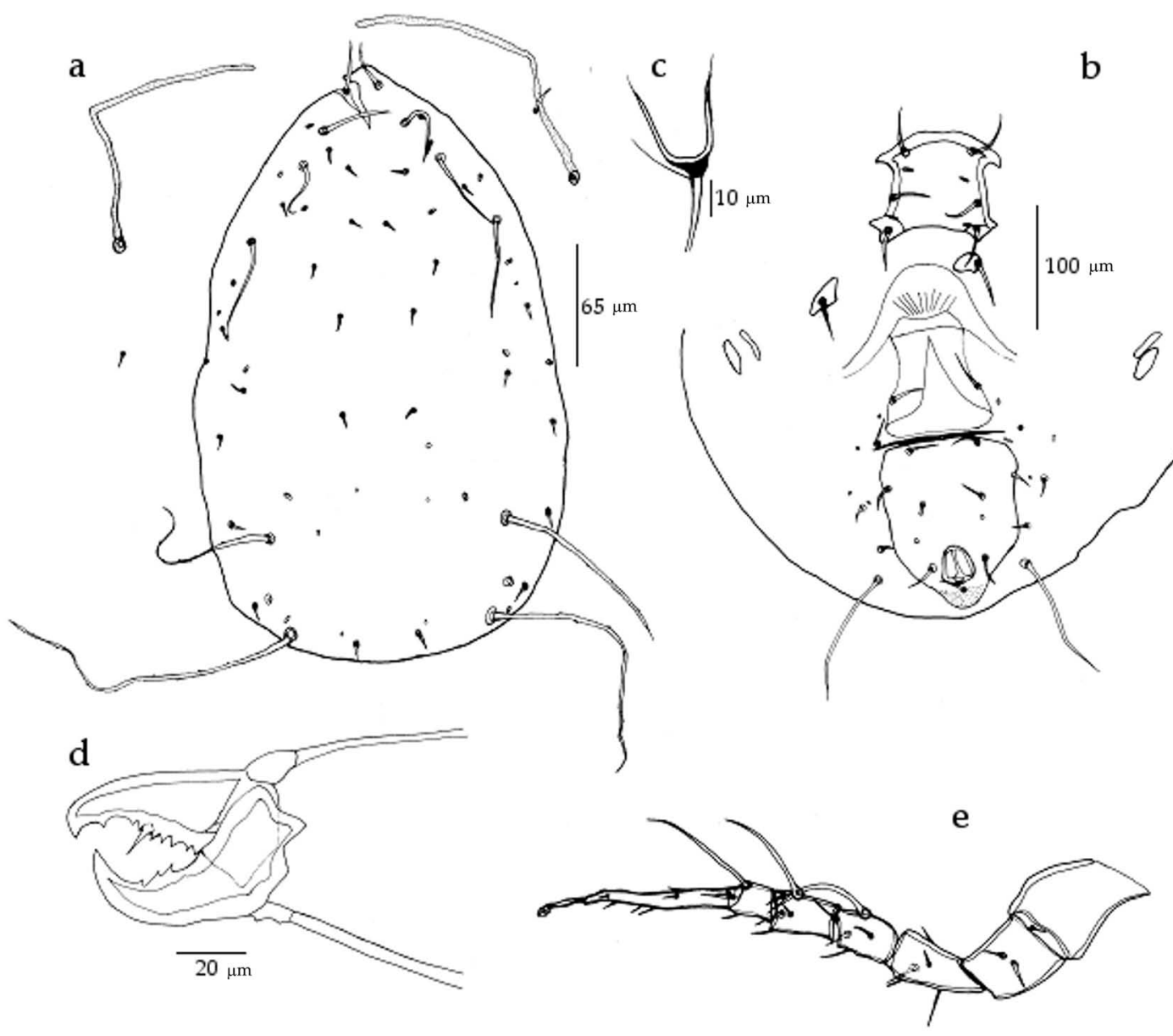

FIGURE 23: Neoseiulella cottieri (Collyer). Female (lectotype): a - dorsal shield; b - ventral shields; c - spermatheca; d - chelicera; e - leg IV.

Previous reports - N. corrugata is only known from Australia on Malus domestica (Rosaceae).

\section{Neoseiulella cottieri (Collyer) (Figure 23)}

Typhlodromus cottieri Collyer 1964: 640-641; Schicha 1980: 20-22; Collyer 1982: 189-190; Schicha 1987: 138-140; Chant and Yoshida-Shaul 1989: 1029-1032. Typhloctonus (Tasmanidromus) cottieri (Collyer) Wainstein 1977: 1415. Neoseiulella (Neoseiulella) cottieri (Collyer) Denmark and Rather 1996: 53. Neoseiulella cottieri (Collyer) Moraes et al. 1986: 248; Chant and McMurtry 1994: 248; Moraes et al. 2004: 293; Chant and McMurtry 2007: 147.

Adult female (Figure 23a-e)
Dorsal shield (Figure 23a) - Dorsal shield smooth: length 385; width 215 (at level of s4) and 255 (at level of Z1). Six pairs of solenostomes observed: gd1, gd2, gd4, gd6, gd8 and gd9. Four pairs of poroids. Sub-lateral setae (r3 and R1) on the lateral margin. Dorsal shield bearing 19 pairs of setae, all smooth except for Z4 and Z5 which are slightly serrated: j1 29; j3 43; j4 5; j5 6; j6 9; J2 8; J5 11; z2 6; z3 48; z4 7; z5 6; Z1 6; Z4 121; Z5 232; s4 67; s6 7; S2 9; S4 10; S5 11; sub-lateral setae r3 15 and R1 12. Peritreme extending anteriorly to the level of $\mathrm{j} 1$.

Ventral shields (Figure 23b) — Sternal shield 77 long and 70 wide (at level of ST2), smooth with three pairs of setae (ST1, ST2 and ST3) and two pairs of poroids. A pair of metasternal setae (ST4) on separate platelets accompanied by a pair of small 
poroids. Genital shield 120 long and 68 wide (at level of ST5), smooth. Four elongate platelets or genital sigilla situated between genital and ventrianal shields. One pair of poroids close to the genital shield (ST 5) and 2 pairs of poroids around the genital shield. Ventrianal shield, longer than wide 124 long and 101 wide (at level of ZV2), smooth, with three pairs of preanal setae (JV1, JV2 and ZV2; JV3 absent), with a pair of circular solenostomes gv3 posterior to JV2. Four pairs of caudoventral setae (ZV1, ZV3, JV4 and JV5) inserted on the integument surrounding the ventrianal shield. JV5 93 long, smooth. Primary metapodal plate or inguinal sigillum 25 long and 7 wide.

Spermatheca (Figure 23c) - Cervix 11 long, Ushaped.

Chelicera (Figure 23d) - Eight teeth and a pilus dentilis on the fixed digit. Movable digit 30 long, bearing three teeth.

Legs (Figure 23e) - Measurements of legs: leg I 403; leg II 318; leg III 313; leg IV 427. Seven setae $(2-2 / 0,2 / 0-1)$ on the genu II. One pointed macroseta (38 long) on the genu III. Three other pointed macrosetae, 82, 65 and 77 long, on genu, tibia and basitarsus IV, respectively.

This species is easily distinguished from all other species of this genus by the lengths of Z4 (121) and Z5 (232).

Material examined - The female lectotype deposited in the BMNH, the British Museum of Natural History, Cromwell Road, London, UK.

\section{Adult male}

Described by Collyer (1964) and Schicha (1980). We were not able to borrow the male type specimens of this species.

Previous reports - The type specimens of $N$. cottieri were collected from New Zealand on thistle (Asteraceae). This species is only known from the Australasian area: Australia (Wainstein 1977; Schicha 1980, 1987) and New Zealand (Collyer 1964, 1982). Plants on which this species was collected are: Astelia sp. (Asteliaceae); Cassiniae sp. (Asteraceae); Fragaria $x$ ananassa Duchesne, Malus domestica (Rosaceae); Hebe sp. (Plantaginaceae); Hu- mulus lupulus L. (Cannabaceae); Trifolium repens $\mathrm{L}$. (Fabaceae) and on moss samples.

\section{Neoseiulella crassipilis (Athias-Henriot and Fauvel) (Figure 24)}

Pegodromus crassipilis Athias-Henriot and Fauvel 1981: 72-73; Ragusa 2006: $3 . \quad$ Typhlodromus crassipilis (Athias-Henriot and Fauvel) Chant and Yoshida-Shaul 1989: 1011-1013. Neoseiulella crassipilis (Athias-Henriot and Fauvel) Moraes et al. 2004: 293; Chant and McMurtry 2007: 147.

Adult female (Figure24 a-d)

Dorsal shield (Figure 24a) - Dorsal shield heavily reticulated throughout: length 454; width 248 (at level of s4) and 290 (286 - 294) (at level of Z1). Five pairs of solenostomes: gd1, gd2, gd6, gd8, and gd9. No poroid visible. The presence of gd1 was stated by Athias-Henriot and Fauvel (1981), but not by Chant and Yoshida-Shaul (1989). Sub-lateral setae (r3 and R1) on the dorsal shield. Dorsal shield bearing 21 pairs of setae, all are thick and serrated: j1 35 (34 - 36); j3 51 (50 - 52); j4 39 (37 - 40); j5 37 (34 - 39); j6 50 (49 - 50); J2 63 (62 - 64); J5 17 (16 - 17); z2 35 (34 - 35); z3 45 (44 - 45); z4 62 (59 - 65); z5 30 (28 - 31); Z1 65 (64 - 65); Z4 73 (71 - 75); Z5 67 (65 - 68); s4 57 (56 - 58); s6 58 (57 - 58); S2 68 (65 - 71); S4 75 (72 - 77); S5 39 (37 - 40); sub-lateral setae r3 49 (44 - 54) and R1 44 (40 - 47). Peritreme extending anteriorly to the level of $\mathrm{j} 1$.

Ventral shields (Figure 24b) - Sternal shield 47 (45 - 48) long and $79(78-80)$ wide (at level of ST2), smooth with distinct striation on the lateral areas, with two pairs of setae (ST1 and ST2) and two pairs of poroids. ST3 and ST4 on separate platelets. A pair of small poroids accompanies ST4. Genital shield 143 (141 - 145) long and 82 wide (at level of ST5), distinctly reticulated along. Four platelets or sigillla separate between genital and ventrianal shields. No pair of poroids visible close to the genital shield (ST 5) and 2 pairs of poroids around the genital shield. Ventrianal shield subquadrateshaped, $160(158$ - 162) long and 168 (163 - 172) wide (at level of ZV2), strongly reticulated, with four pairs of preanal setae (JV1, JV2, JV3 and ZV2) and a pair of solenostomes $g v 3$ posterormediad to 


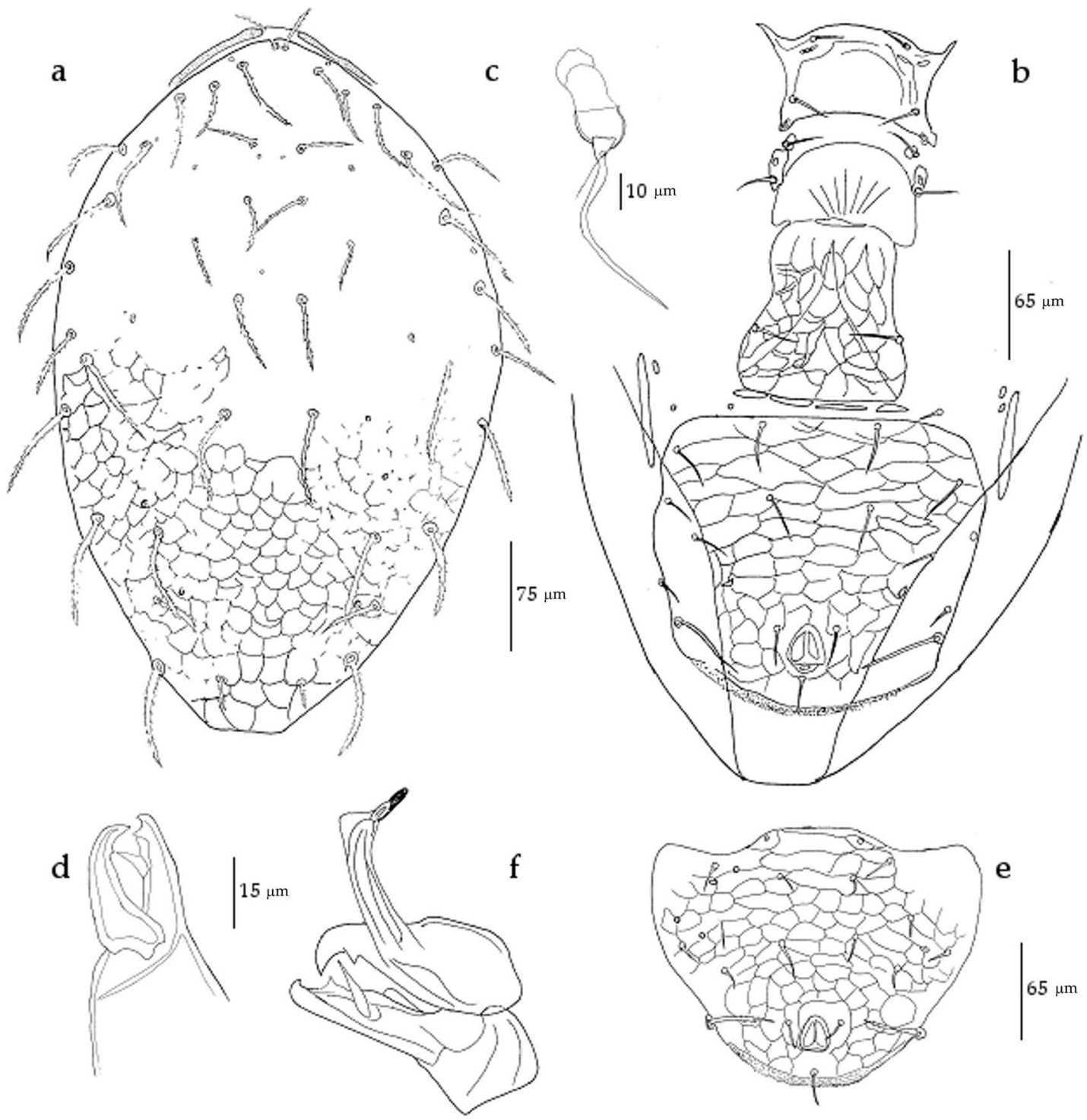

FIGURE 24: Neoseiulella crassipilis (Athias-Henriot and Fauvel). Female (paratype): a - dorsal shield; b - ventral shields; c - spermatheca; $\mathrm{d}$ - chelicera. Male (paratype): e - ventrianal shield; $\mathrm{f}$ - spermatodactyl.

JV3. Four pairs of caudoventral setae (ZV1, ZV3, JV4 and JV5) on the integument surrounding the ventrianal shield. JV5 44 (42 - 45) long, serrated. Primary metapodal plate or inguinal sigillum 65 (63 -66) long and 5 wide. This plate much longer than those of all the species of this genus.

Spermatheca (Figure 24c) - Cervix 13 long, cupshaped.

Chelicera (Figure 24d) - One large tooth and a pilus dentilis on the fixed digit. The movable digit,
30 long, unidentate.

Legs - Measurements of legs: leg I 316 (313 319); leg II 293 (287 - 298); leg III 300 (293 - 307); leg IV 385 (383 - 387). Eight setae (2-2/1, 2/0-1) on the genu II. No macroseta on legs.

This species is easily distinguished from the other species of the genus by the shape of the ventrianal shield and the reticulation of the genital shield.

Material examined - Three female paratypes deposited in Montpellier SupAgro, UMR CBGP, 
Campus International de Baillarguet, CS 30016, 34988 Montferrier-sur-Lez, France).

\section{Adult male (Figure 24e, f)}

Dorsal shield chaetotaxy similar to the female. Ventrianal shield 152 long and 196 wide, distinctly reticulated, bearing six pairs of preanal setae with four or five pairs of poroids. Spermatodactyl L-shaped. This description is based on a male paratype specimen.

Previous reports $-N$. crassipilis is only known from the West-Palaearctic area. Countries from which this species was reported are: France (AthiasHenriot and Fauvel 1981; Viollier and Fauvel 1984) and Greece (Ragusa and Tsolakis 1998; Ragusa 2006). It was collected on Pyrus amygdaliformis Vill. and Pyrus sp. (Rosaceae).

\section{Neoseiulella dachanti (Collyer) (Figure 25)}

Typhlodromus dachanti Collyer 1964: 638-640. Schicha 1980: 22-24; Collyer 1982: 189; Schicha 1987: 139, 141; Chant and Yoshida-Shaul 1989: 1032-1034. Neoseiulella (Neoseiulella) dachanti (Collyer) Denmark and Rather 1996: 54-55. Neoseiulella dachanti (Collyer) Moraes et al. 1986: 201; Moraes et al. 2004 : 293; Chant and McMurtry 2007: 147.

\section{Adult female (Figure 25a - e)}

Dorsal shield (Figure 25a) - Dorsal shield smooth: length 394; width 225 (at level of s4), 226 (at level of Z1). Four pairs of solenostomes: gd2, gd4, gd6, and gd9. Four pairs of poroids. Sub-lateral setae ( $\mathrm{r} 3$ and R1) on the lateral margin. Dorsal shield bearing 19 pairs of setae, all dorsal and sub-lateral setae smooth, except Z5 slightly serrated: j1 27; j3 41; j4 7; j5 8; j6 12; J2 13; J5 7; z2 11; z3 39; z4 13; z5 8; Z1 13; Z4 48; Z5 111 (106 - 115); s4 42; s6 17; S2 23; S4 12; S5 10; r3 14 and R1 15. Presence of few visible muscles marks (sigilles) on the dorsal shield. Peritreme extending anteriorly to the level of $\mathrm{j} 1$.

Ventral shields (Figure 25b) - Sternal shield 83 long and 80 wide (at level of ST2), smooth with three pairs of setae (ST1, ST2 and ST3) and two pairs of poroids. A pair of metasternal setae (ST4) on separate platelets accompanied by a pair of small poroids. Genital shield 104 long and 68 wide (at level of ST5), smooth. Four elongate platelets or genital sigilla separating genital and ventrianal shields folded under genital shield. One pair of poroids close to the genital shield (ST 5) and 3 pairs of poroids around the genital shield. Ventrianal shield 121 long and 88 wide (at level of ZV2), smooth, with three pairs of preanal setae (JV1, JV2 and ZV2; JV3 absent), with a pair of large solenostomes $g v 3$ posterior to JV2. Four pairs of caudoventral setae (ZV1, ZV3, JV4 and JV5) on the integument surrounding the ventrianal shield. JV5 39 long, smooth. Primary metapodal plate or inguinal sigillum 20 long and 6 wide.

Spermatheca (Figure 25c) - Cervix 3 long, shallowly cup-shaped.

Chelicera (Figure 25d) - Twelve teeth, without pilus dentilis, on the fixed digit. Movable digit, 35 long, bearing three teeth.

Legs (Figure 25e) - Measurements of legs: leg I 372; leg II 323 (318 - 328); leg III 323 (318 - 328); leg IV 395 (391-400). Seven setae $(2-2 / 0,2 / 0-1)$ on the genu II. Two macrosetae, 30 and 27 long, on genu and the tibia III, respectively. Three other macrosetae, 46,48 and 48 long, on genu, tibia and basitarsus IV, respectively.

Material examined - The female lectotype deposited in the BMNH, the British Museum of Natural History, Cromwell Road, London, UK.

\section{Adult male}

Described by Collyer (1964) and Schicha (1980). We were not able to borrow the male type specimen of this species.

Previous reports - The type specimens of $N$. dachanti were collected at Waitakeres, near Auckland, New Zealand, on "native bush". This species is only known from the Australasian area: New Zealand (Collyer 1964, 1982) and Australia (Schicha 1987). Plant supports on which this species was reported are: Brachyglottis repanda J. R. and G. Forst. (Asteraceae); Coprosma sp. (Rubiaceae); Cytisus sp. (Fabaceae); Elaeocarpus dentatus (G. R. and G. Forster) Vahl (Elaeocarpaceae); Erica sp. (Ericaceae); Melicytus ramiflorus G. R. and G. Forster (Violaceae); Nothofagus sp. (Nothofagaceae); Nothopanax sp., Pseudopanax sp. (Araliaceae); Podocarpus sp. 


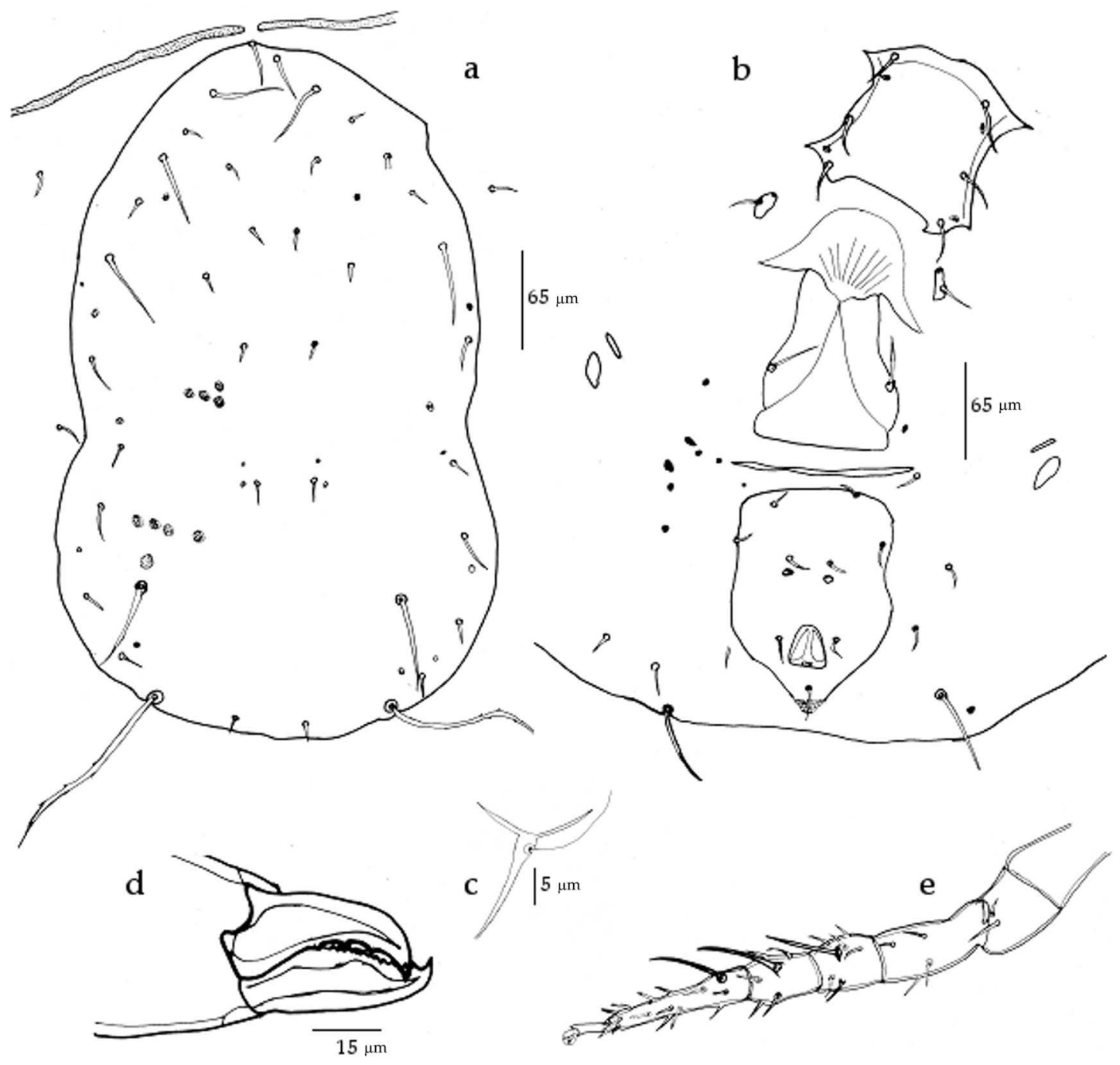

FIGURE 25: Neoseiulella dachanti (Collyer). Female (lectotype): a - dorsal shield; b - ventral shields; c - spermatheca; $d$ - chelicera; e - leg IV.

(Podocarpaceae); Eucalyptus sp. (Myrtaceae); Rubus sp. (Rosaceae) and tree ferns.

\section{Neoseiulella elaeocarpi (Schicha) (Figure 26)}

Typhlodromus elaeocarpi Schicha, in Schicha and O'Dowd 1993: 304-305. Neoseiulella (Neoseiulella) elaeocarpi (Schicha) Denmark and Rather 1996: 49. Neoseiulella elaeocarpi (Schicha) Moraes et al. 2004 : 293; Chant and McMurtry 2007: 147.

Adult female (Figure 26a - e)
Dorsal shield (Figure 26a) - Dorsal shield heavily reticulated throughout: length 356; width 201 (at level of s4) and 226 (at level of Z1). Six pairs of solenostomes on the dorsal shield: $\operatorname{gd} 1, \operatorname{gd} 4, \operatorname{gd} 5$, gd6, gd8, and gd9. One pair of poroids. Sublateral setae (r3 and R1) on the lateral margin. Dorsal shield bearing 19 pairs of setae, all smooth except for Z4 (slightly serrated) and Z5 (distinctly serrated), and on tubercles: j1 18; j3 20; j4 16; j5 16; j6 18; J2 22; J5 9; z2 16; z3 20; z4 20; z5 17; Z1 21; Z4 25; Z5 42; s4 19; s6 21; S2 22; S4 23; S5 25; sub-lateral setae r3 18 and R1 18. Peritreme extending anteriorly to the level $\mathrm{j} 1$. 


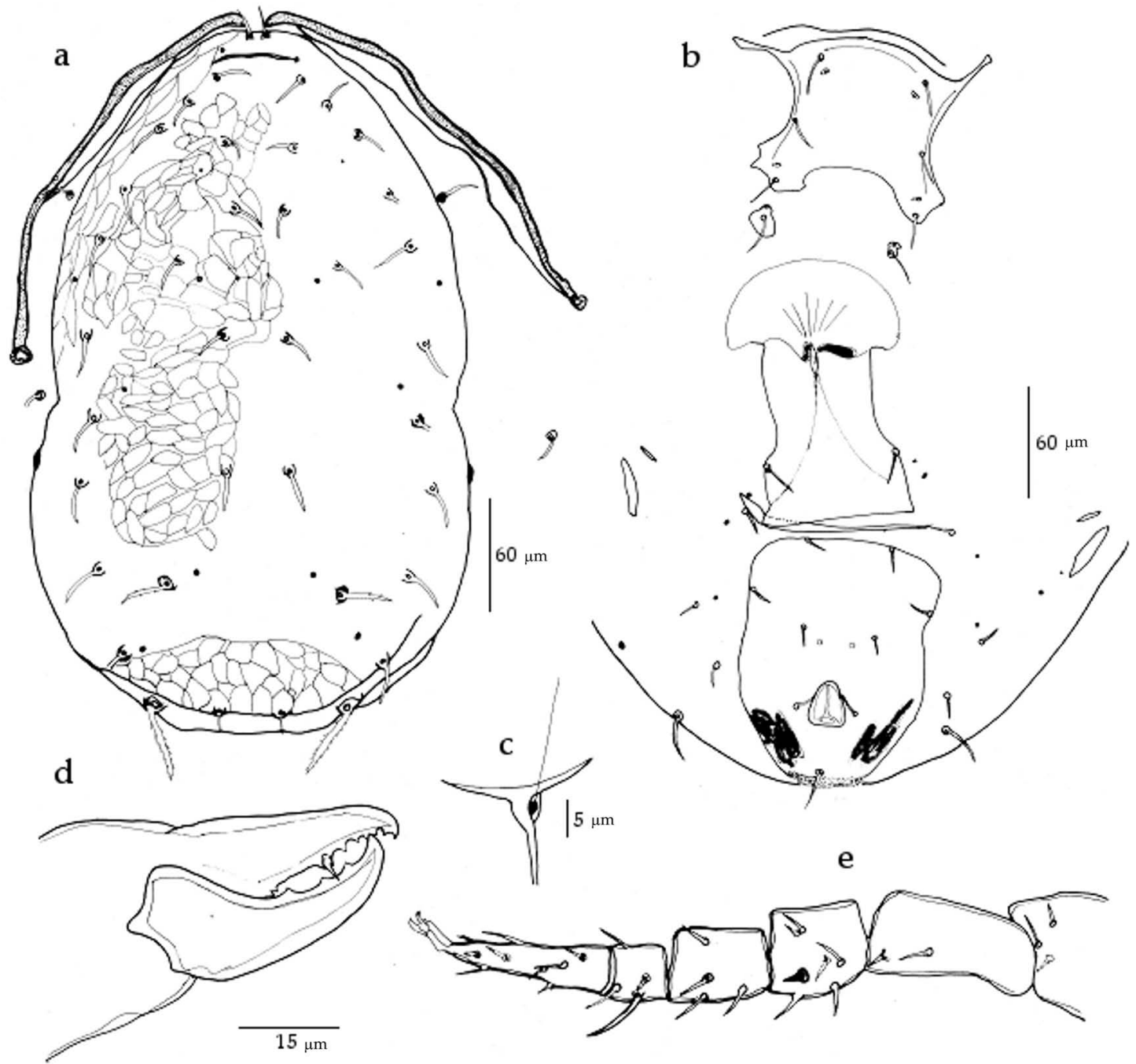

FIGURE 26: Neoseiulella elaeocarpi (Schicha). Female (holotype): a - dorsal shield; b - ventral shields; c - spermatheca; d - chelicera; e leg IV.

Ventral shields (Figure 26b) — Sternal shield 67 long and 72 wide (at level of ST2), smooth, with three pairs of setae (ST1, ST2 and ST3) and two pairs of poroids. The metasternal setae (ST4) on separate platelets accompanied by a pair of small poroids. Genital shield 128 long and 67 wide (at level of ST5), smooth. Four elongate platelets or genital sigilla separating genital and ventrianal shields folded under genital shield. One pair of poroids close to the genital shield (ST 5) and 3 pairs of poroids around the genital shield. Ventrianal shield subgquadrateshaped, 122 long and 92 wide (at level of ZV2), smooth, with three pairs of preanal setae (JV1, JV2 and ZV2; JV3 absent) and a pair of large solenostomes $g v 3$ posteromediad to JV2. Four pairs of caudoventral setae (ZV1, ZV3, JV4 and JV5) on the integument surrounding the ventrianal shield. JV5 22 long, smooth. Primary metapodal plate or inguinal sigillum 30 long and 6 wide.

Spermatheca (Figure 26c) - Cervix 4 long, shallowly cup-shaped.

Chelicera (Figure 26d) - Seven or eight teeth and a pilus dentilis on the fixed digit. Movable digit 31 long, bearing three teeth.

Legs (Figure 26e) - Measurements of legs: leg 
I 299; leg II 270; leg III 264; leg IV 332. Seven setae $(2-2 / 0,2 / 0-1)$ on the genu II. Two thick and short macrosetae, 6 and 22 long, on genu and basitarsus IV, respectively.

Material examined - The female holotype deposited in NSW Department of Primary Industries, Agricultural Scientific Collections Unit (Acarology), Orange Agricultural Institute, Australia.

\section{Adult male}

The male of this species is unknown.

Previous reports - N. elaeocarpi is only known from Queensland (Australia), on Elaeocarpus coorangooloo J. Bailey and C. White (Elaeocarpaceae).

\section{Neoseiulella elongata Ferragut and Peña-Estevez (Figure 27)}

Neoseiulella elongata Ferragut and Peña-Estevez 2003: 164; Moraes et al. 2004: 293; Moraza and PeñaEstevez 2006: 58; Chant and McMurtry 2007: 147.

Adult female (Figure 27a - e)

Dorsal shield (Figure 27a) - Dorsal shield heavily reticulated: length 394; width 175 (at level of s4), 178 (at level of Z1), with four pairs of solenostomes: gd2, gd6, gd8, and gd9. Four pairs of poroids. Sublateral setae (r3 and R1) on the lateral margin. Dorsal shield bearing 19 pairs of setae, all smooth: j1 20; j3 16; j4 12; j5 11; j6 14; J2 16; J5 11; z2 14; z3 16; z4 16; z5 11; Z1 20; Z4 23; Z5 29; s4 17; s6 19; S2 20; S4 21; S5 19; sub-lateral setae r3 23 and R1 24. Presence of few visible muscles marks (sigilles) on the dorsal shield. Peritreme extending anteriorly to the level of z2. It is noteworthy that the peritreme differs from the ones of the other species of the genus Neoseiulella as its anterior surface is striate.

Ventral shields (Figure 27b) - Sternal shield 83 long and 73 wide (at level of ST2), smooth, with two pairs of setae (ST1 and ST2) and two pairs of small poroids. Two other pairs of sternal setae (ST3, ST4) on separate platelets. A pair of small poroids accompanies ST4. Genital shield 140 long and 66 wide (at level of ST5), smooth. Four elongate platelets or genital sigilla separating genital and ventrianal shields folded under genital shield. One pair of poroids close to the genital shield (ST 5) and 4 pairs of poroids around the genital shield. Ventrianal shield subtriangular-shaped, 134 long and 93 wide (at level of ZV2), lightly reticulated, with four pairs of preanal setae (JV1, JV2, JV3 and ZV2), and without solenostome gv3. Four pairs of caudoventral setae (ZV1, ZV3, JV4 and JV5) on the integument surrounding the ventrianal shield. JV5 20 long, smooth. Primary metapodal plate or inguinal sigillum 42 long and 4 wide.

Spermatheca (Figure 27c) - Cervix 5 long, shallowly cup-shaped.

Chelicera (Figure 27d) - One tooth and a pilus dentilis on the fixed digit. Movable digit 44 long, unidentate.

Legs (Figure 27e) - Measurements of legs: leg I 335; leg II 281; leg III 275; leg IV 356. Seven setae (2$2 / 0,2 / 0-1)$ on the genu II. One macroseta, 61 long, on the basitarsus IV.

Material examined - A female paratype deposited in the Department of Agroforestal Ecosystems, Universidad Politécnica of Valencia, Spain.

Adult male

The adult of this species is unknown.

Previous reports $-N$. elongata is only known from the Canary Islands on Pinus canariensis C. Sm. (Pinaceae).

\section{Neoseiulella ferraguti Moraza and Peña-Estevez (Figure 28)}

Neoseiulella ferraguti Moraza and Peña-Estevez 2006: 56-58.

\section{Adult female (Figure 28a - e)}

Dorsal shield (Figure 28a) - Dorsal shield smooth: length 365; width 226 (at level of s4), 264 (at level of Z1), with seven pairs of solenostomes: gd1, gd2, gd4, gd5, gd6, gd8, and gd9. Seven pairs of poroids. Sub-lateral setae (r3 and R1) on the lateral margin. Dorsal shield bearing 19 pairs of setae, all smooth except $Z 4$ and $Z 5$ which are slightly serrated: j1 28; j3 49; j4 31; j5 32; j6 38; J2 34; J5 19; z2 15; z3 54; z4 47; z5 29; Z1 34; Z4 77; Z5 94; s4 62; s6 64; S2 71; S4 54; S5 33; sub-lateral setae r3 28 and R1 35. Most dorsal setae of opisthosomal area (S2, S4, S5, 


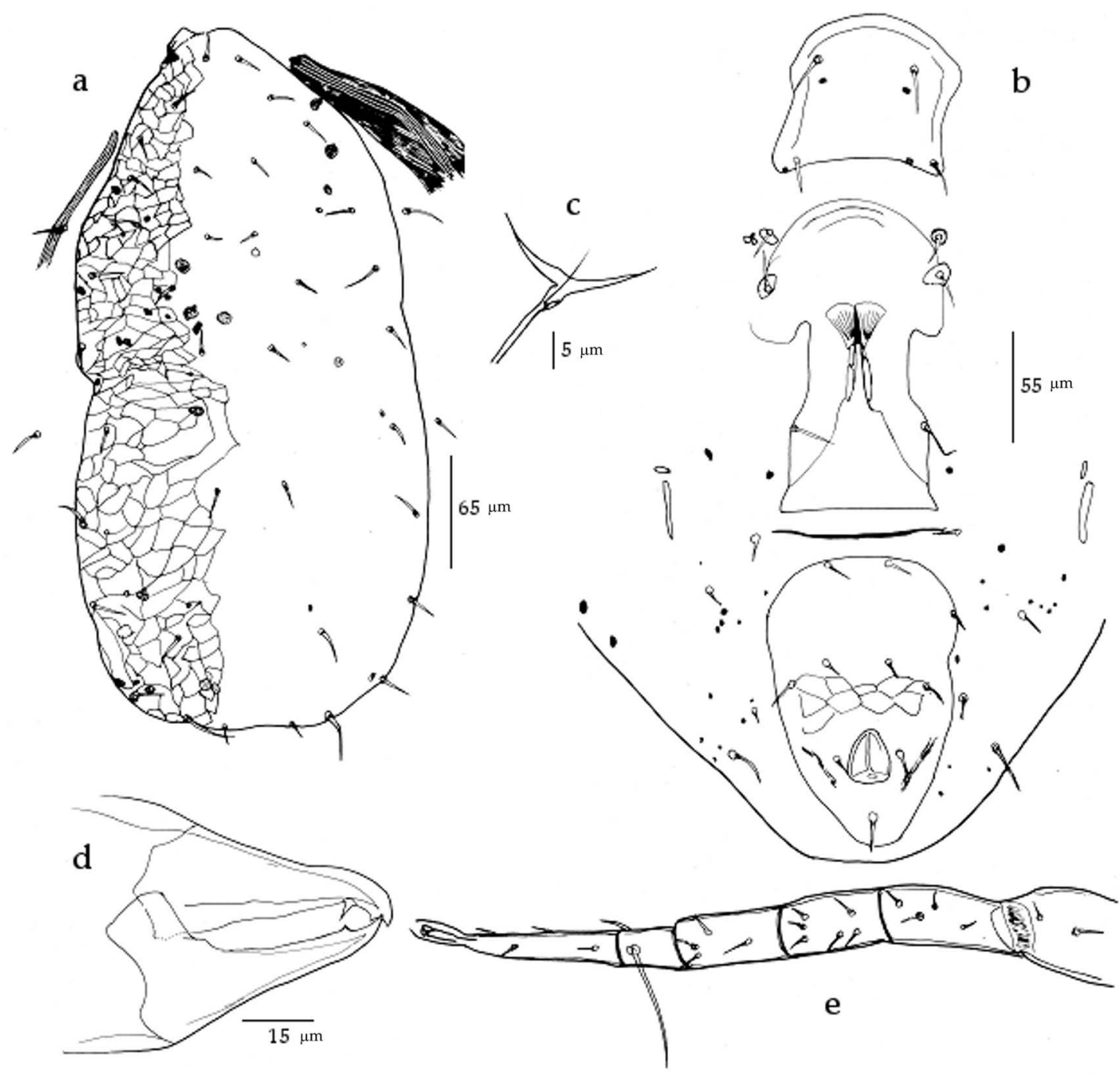

FIgURE 27: Neoseiulella elongata Ferragut and Peña-Estevez. Female (paratype): a - dorsal shield; b - ventral shields; c - spermatheca; $d$ - chelicera; e - leg IV.

Z4, Z5, and J5) on tubercles. Peritreme extending anteriorly to the level of $j 1$.

Ventral shields (Figure 28 b) - Sternal shield 67 long and 68 wide (at level of ST2), smooth, with two pairs of setae (ST1 and ST2) and two pairs of distinct poroids. ST3 and ST4 on separate platelets. A pair of small poroids accompanies ST4. Genital shield 130 long and 66 wide (at level of ST5), smooth. Four elongate platelets or genital sigilla separating genital and ventrianal shields folded under genital shield. One pair of poroids close to the genital shield (ST 5) and 3 pairs of poroids around the genital shield. Ventrianal shield subtriangularshaped, 127 long and 112 wide (at level of ZV2), faintly striate, with four pairs of preanal setae (JV1, JV2, JV3 and ZV2), and a pair of large and circular solenostomes gv3 posteromediad to JV3. Four pairs of caudoventral setae (ZV1, ZV3, JV4 and JV5) on the integument surrounding the ventrianal shield. JV5 66 long, lightly serrated. Primary metapodal plate or inguinal sigillum 22 long and 11 wide.

Spermatheca (Figure 28c) - Cervix 4 long, Ushaped.

Chelicera (Figure 28d) - Seven teeth and a pilus 


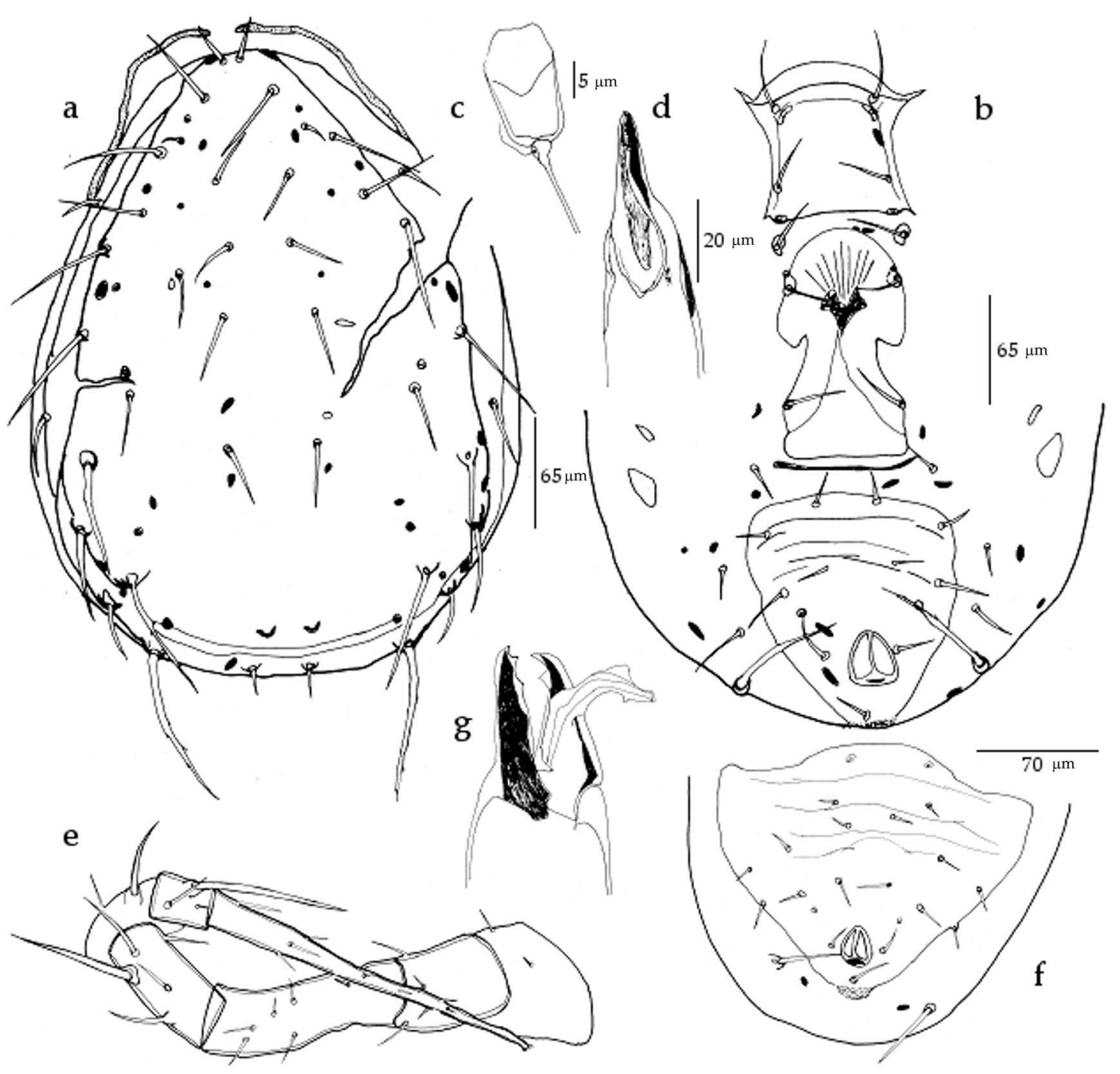

FIgURE 28: Neoseiulella ferraguti Moraza and Peña-Estevez. Female (holotype): a - dorsal shield; b - ventral shields; c - spermatheca; $d$ - chelicera; e - leg IV. Male (paratype): f - ventrianal shield; g - spermatodactyl.

dentilis on the fixed digit. Movable digit 37 long, bidentate.

Legs (Figure 28e) - Measurements of legs: leg I 422; leg II 313; leg III 314; leg IV 362. Eight setae $(2-2 / 1,2 / 0-1)$ on the genu II. One macroseta (not reported on the original description), 33 long, on the genu III. Three other pointed macrosetae, 54, 34, 67 long, on genu, tibia and basitarsus IV, respectively.

Material examined - The female holotype deposited in Museum of Zoology of University of Navarra (MZUNAV), Spain.

Adult male (Figure 28f, g)
Male specimen of this species similar to but smaller than the female. Moraza and Peña-Estevez (2006) described the male of N. ferraguti. However, these authors did not give a complete setal and body measurements. We thus present a complete description of this male.

Dorsal shield - Dorsal shield chaetotaxy similar to the female, with smooth surface: length 322; width 163 (at level of s4), 200 (at level of Z1), with seven pairs of solenostomes: gd1, gd2, gd4, gd5, gd6, gd8, and gd9. Dorsal shield bearing 21 pairs of setae (sub-lateral setae, r3 and R1 on the dorsal 
shield). All dorsal setae smooth, except Z5 which is slightly serrated: j1 29; j3 36; j4 22; j5 22; j6 25; J2 25; J5 13; z2 11; z3 43; z4 33; z5 24; Z1 25; Z4 55; Z5 68; s4 49; s6 48; S2 50; S4 39; S5 29; sub-lateral setae r3 23 and R1 32. Peritreme extending anteriorly to the level of $\mathrm{j} 1$.

Ventral shields (Figure 28f) - Sternogenital shield is smooth. Ventrianal shield 135 long and 170 wide, lightly reticulated, bearing seven pairs of preanal setae with two pairs of poroids. Caudoventral seta JV5 42 long, smooth, on the integument surrounding the ventrianal shield.

Chelicera (Figure 28g) - Two teeth and a pilus dentilis on the fixed digit. Movable digit 31 long, unidentate. Spermatodactyl L-shaped.

Legs - Measurements of legs: leg I 375; leg II 306; leg III 283; leg IV 355. Three macrosetae, 35, 35 and 50 long, on genu, tibia, and basitarsus IV, respectively.

The male specimen of this species is different from the female by the position of both sub-lateral setae ( $\mathrm{r} 3$ and R1) (on dorsal shield on the male; on lateral margin on the female), and the number of solenostomes on the ventrianal shield (two pairs on the male; one pair on the female).

Material examined - A male paratype specimen.

Previous reports $-N$. ferraguti is only known from Tenerife (Canary Islands). It was reported from lichens on dead log, and from soil and litter of Cheirolophus canariensis var. subexpinnatus (Burch.) A. Hansen and Sunding (Asteraceae).

\section{Neoseiulella litoralis (Swirski and Amitai) (Figure 29)}

Typhloctonus litoralis Swirski and Amitai 1984: 73-76. Neoseiulella (Typhloctona) litoralis (Swirski and Amitai) Denmark and Rather 1996: 71-72. Neoseiulella litoralis (Swirski and Amitai) 1997b: 37; Moraes et al. 2004: 294; Chant and McMurtry 2007: 147.

\section{Adult female (Figure 29a - e)}

Dorsal shield (Figure 29a) — Dorsal shield heavily reticulate: length 393 (383 - 403); width 184 (178 -190) (at level of s4), 197 (188 - 205) (at level of Z1), with six pairs of solenostomes: gd1, gd2, gd5, gd6, $\operatorname{gd} 8$, and gd9. One pair of poroids. Sub-lateral setae (r3 and R1) on the lateral margin. Dorsal shield bearing 19 pairs of setae all smooth (in one paratype specimen, Z5 is slightly serrated): j1 $23(21-24) ; j 3$ 24 (22 - 26); j4 15 (13 - 17); j5 13 (11 - 14); j6 15 (14 16); J2 18 (17 - 18); J5 14; z2 13 (11 - 15); z3 22 (20 24); z4 18 (17 - 19); z5 14 (12 - 15); Z1 19 (18 - 20); Z4 50 (48 - 51); Z5 63 (60 - 66); s4 20 (19 - 21); s6 28 (26 - 30); S2 37 (35 - 38); S4 29 (26 - 31); S5 29 (26 - 31); sub-lateral setae r3 23 and R1 $23(20-25)$. Peritreme extending anteriorly to the level of $j 3$ or between $z 2$ $-\mathrm{j} 3$.

Ventral shields (Figure 29b) - Sternal shield 59 (55 - 63) long and 69 wide (at level of ST2), smooth, with two pairs of setae (ST1 and ST2) and two pairs of poroids. The third and fourth pairs of sternal setae (ST3, ST4) on separate platelets and a pair of small poroids accompanying ST4. Genital shield $130(122$ - 137) long and $67(66-68)$ wide (at level of ST5), smooth. Four elongate platelets or genital sigilla separating genital and ventrianal shields folded under the genital shield. No pair of poroids close to the genital shield (ST 5) and 1 pair of poroids around the genital shield. Ventrianal shield subtriangular-shaped with conspicuous waist, much longer than wide, $140(137$ - 143) long and 98 (92 - 104) wide (at level of ZV2), reticulate with four pairs of preanal setae (JV1, JV2, JV3 and $\mathrm{ZV} 2$ ), and without solenostome gv3. Four pairs of caudoventral setae (ZV1, ZV3, JV4 and JV5) on the integument surrounding the ventrianal shield. JV5 45 (37 - 52) long, smooth. Primary metapodal plate or inguinal sigillum $41(37-44)$ long and 5 wide.

Spermatheca (Figure 29c) - Cervix 4 long, Ushaped.

Chelicera (Figure 29d) - Two teeth and a pilus dentilis on the fixed digit. Movable digit 37 (36-38) long, unidentate.

Legs (Figure 29e) - Measurements of legs: leg I 338 (331 - 344); leg II 299 (295 - 303); leg III 296 (292 - 300); leg IV 395 (386 - 404). Seven setae (2-2/0, $2 / 0-1$ ) on the genu II. One pointed macroseta 41 (36 -45) long, on the basitarsus IV.

Material examined - Three female paratypes 


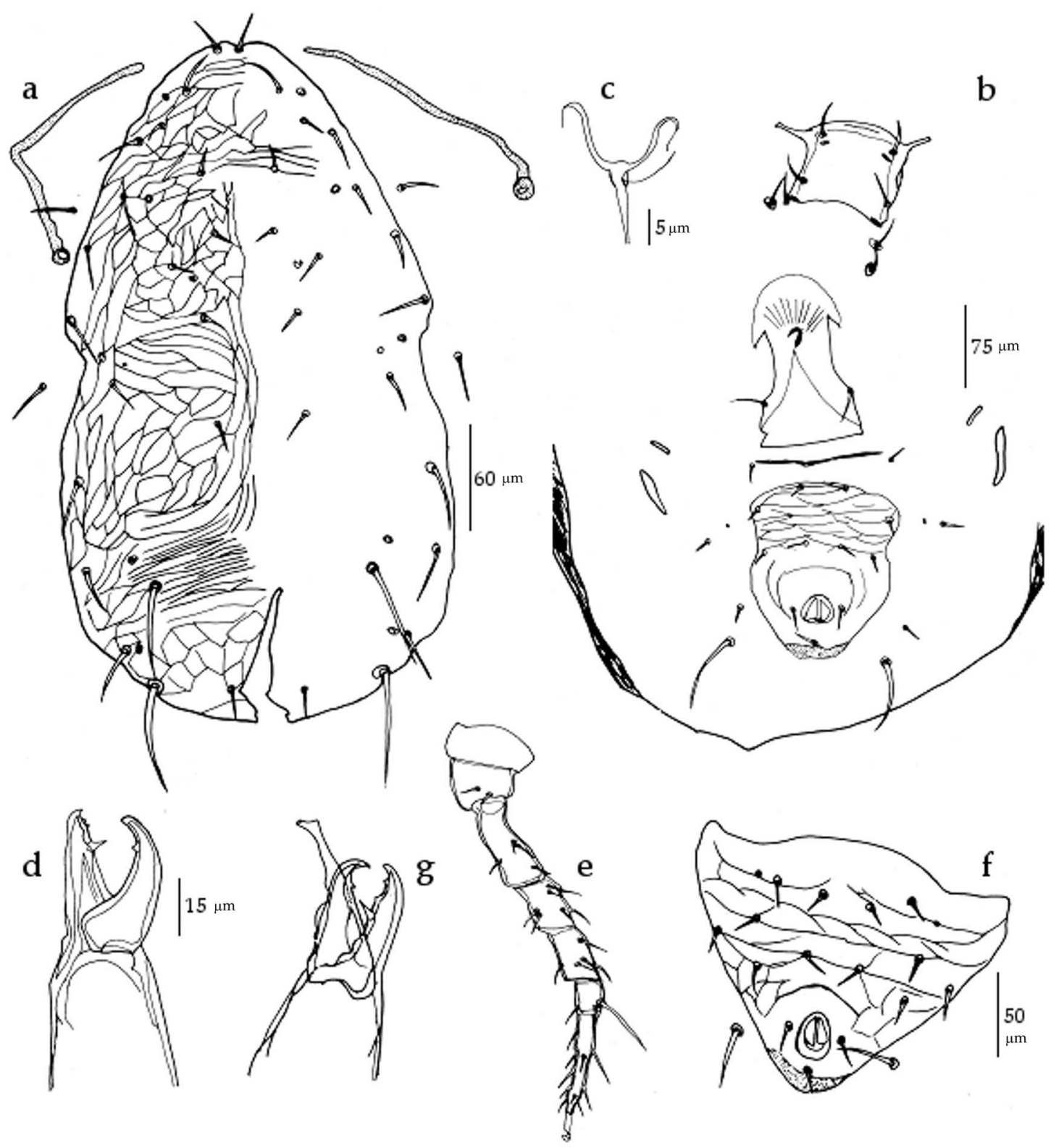

FIGURE 29: Neoseiulella litoralis (Swirski and Amitai). Female (paratype): a - dorsal shield; b - ventral shields; $\mathrm{c}$ - spermatheca; $\mathrm{d}$ chelicera; e - leg IV. Male (paratype): $\mathrm{f}$ - ventrianal shield; g - spermatodactyl.

deposited in the Division of Entomology, Agricultural Research Organization, Bet Dagan, Israel.

Adult male (Figure 29f, g)

Dorsal shield chaetotaxy similar to but smaller than the female. Sub-lateral seta R1 inserted on the dorsal shield (different from the female, on which R1 on lateral margin). Six pairs of solenostomes on the dorsal shield. Ventrianal shield 124 long and 142 wide, distinctly reticulated, bearing six pairs of preanal setae and a pair of poroids. Spermatodactyl L-shaped. This description is based on a paratype specimen.

Previous reports $-N$. litoralis is only known from the West- Palaearctic area. Countries from which this species was reported are: Israel (Swirski and Amitai 1984; Klein et al. 1994); Spain (Fer- 
ragut et al. 2008). Plant supports on which this species was collected are: Ammophila arenaria (L.) Link (Poaceae); Achillea maritima (L.) Ehrend and Y.P.Guo, Artemisia monosperma Delile, Limbarda crithmoides (L.) Dumort (Asteraceae); Crucianella maritima L. (Rubiaceae); Echiohilon fruticosum Desf. (Boraginaceae); Lotus creticus L., Retama raetam (Forssk.) Webb. (Fabaceae); Oenothera drummondi Hook (Onagraceae); Polygonum equisetiforme Sibth and Sm. (Polygonaceae); Scrophularia syriaca A.D.C. (Scrophulariaceae); Vitis vinifera subsp. sylvestris (C.C.Gmel.) Hegi (Vitaceae).

This species was recently collected in Villeneuve-lès-Maguelone (Hérault, Mediterranean Coast) on red swampfire (Salicornia rubra Nelson) and sea purslane (Halimione portulacoides (L.) Aellen (Amaranthaceae) (Kanouh et al. 2010).

\section{Neoseiulella longiseta Moraza, Peña-Estevez and Ferragut (Figure 30)}

Neoseiulella longiseta Moraza, Peña-Estévez and Ferragut 2005: 107-111; Moraza and Peña-Estevez 2006: 59; Chant and McMurtry 2007: 147.

Adult female (Figure 30a-e)

Dorsal shield (Figure 30a) - Dorsal shield faintly striate: length 405 (401 - 408); width 202 (196 - 207) (at level of s4), 238 (234 - 242) (at level of Z1), with seven pairs of solenostomes: $\mathrm{gd} 1, \mathrm{gd} 2, \mathrm{gd} 4$, gd5, gd6, gd8, and gd9. No poroid visible. Sublateral setae (r3 and R1) on the lateral margin. Dorsal shield bearing 19 pairs of setae, all smooth, except Z4 and Z5 serrated. Most lateral setae on tubercles: j1 31; j3 41 (37 - 45); j4 12 (10 - 14); j5 16 (15 - 16); j6 26 (25 - 26); J2 16 (15 - 16); J5 14 (13 - 15); z2 10; z3 46 (41 - 51); z4 25 (23 - 27); z5 15 (14 - 15); Z1 15; Z4 88 (84 - 91); Z5 117 (116 - 118); s4 67 (63 $70)$; s6 71 (70 - 72); S2 75 (73 - 76); S4 63 (62 - 63); S5 45 (41 - 48); sub-lateral setae r3 24 (23 - 25) and R1 34 (33 - 35). Presence of few visible muscles marks (sigilles) on the dorsal shield. Peritreme extending anteriorly to the level of $\mathrm{j} 1$.

Ventral shields (Figure $30 \mathrm{~b}$ ) - Sternal shield 75 (74-76) long and 75 (74-76) wide (at level of ST2), smooth, with two pairs of setae (ST1 and ST2) and poroids. ST3 and ST4 on separate platelets with a pair of small poroids accompanying ST4. Genital shield 140 long and $75(73$ - 76) wide (at level of ST5), smooth. Four elongate platelets or genital sigilla separating genital and ventrianal shields folded under the genital shield. No pair of poroids close to the genital shield (ST 5) and 2 pairs of poroids around the genital shield. Ventrianal shield subcircular-shaped, reticulate with four pairs of preanal setae (JV1, JV2, JV3 and ZV2), and a pair of large and circular solenostomes gv3 posteromediad to JV3. Length 136 (135 - 137); wide 129 (127 - 130) (at level of ZV2), 142 (137 - 147) (at level of JV3), 99 (97 - 101) (al level of anus). Four pairs of caudoventral setae (ZV1, ZV3, JV4 and JV5) on the integument surrounding the ventrianal shield. JV5 $83(80-85)$ long, smooth. Primary metapodal plate or inguinal sigillum $26(24-28)$ long and $8(6-7)$ wide.

Spermatheca (Figure 30c) - Cervix 5(4-6) long, U-shaped.

Chelicera (Figure 30d) - Six teeth and a pilus dentilis on the fixed digit. Movable digit 46 (42 48) long, bidentate.

Legs (Figure 30e) - Measurements of legs: leg I 401; leg II 306 (287 - 325); leg III 313 (300 - 325); leg IV $438(430-445)$. Eight setae $(2-2 / 1,2 / 0-1)$ on the genu II. Three pointed macrosetae, $63(62-64), 49$ $(40-58)$ and $76(72-78)$ long, on the genu, tibia and basitarsus IV, respectively.

Material examined - Two female paratypes deposited in Museum of Zoology of University of Navarra, Spain.

\section{Adult male}

Described by Moraza et al. (2005). We were not able to borrow the male type specimen of this species.

Previous reports - N. longiseta is only known from the Canary Islands. It was collected from dry soil, moss and litter under the following plants: Aeonium sp., Monanthes sp. (Crassulaceae), Asplenium sp. (Aspleniaceae), Juniperus turbinata Guss. (Cupressaceae), Cistus monspeliensis L. (Cistaceae), and from lichens (Moraza et al. 2005). 


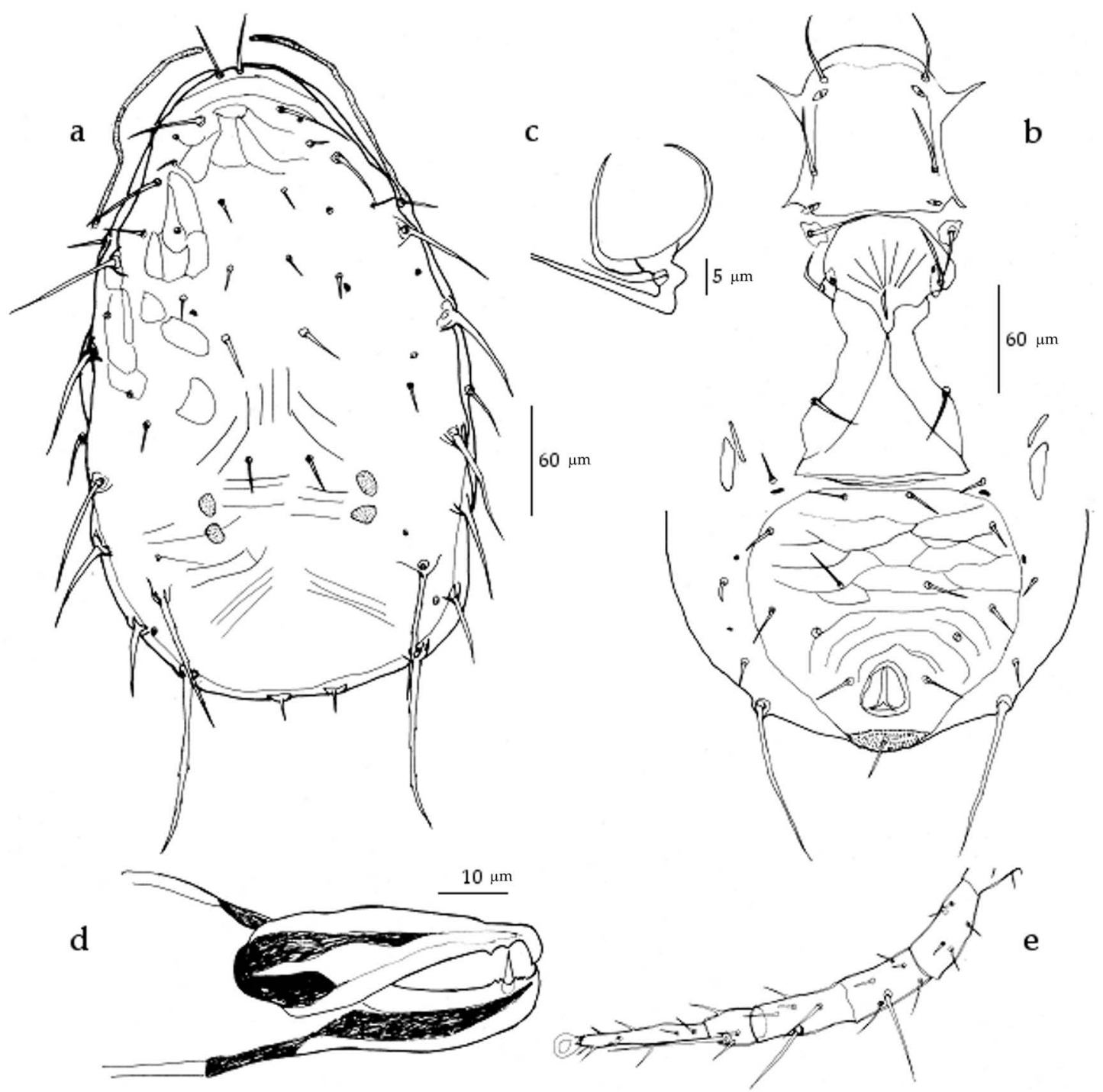

FIgURE 30: Neoseiulella longiseta Moraza, Peña-Estevez and Ferragut. Female (paratype): a - dorsal shield; b - ventral shields; c spermatheca; d - chelicera; e - leg IV.

\section{Neoseiulella montforti (Rivnay and Swirski) (Figure 31)}

Typhloctonus montforti Rivnay and Swirski 1980: 179-182; Swirski and Amitai 1984: 77; Denmark and Rather 1984: 169-170; Moraes et al. 1986: 233. Typhlodromus montforti (Rivnay and Swirski) Chant and Yoshida-Shaul 1989: 1020-1023. Neoseiulella montforti (Rivnay and Swirski) Swirski and Amitai 1997b: 37; Moraes et al. 2004: 294; Chant and McMurtry 2007: 147. Neoseiulella (Typhloctona) montforti (Rivnay and Swirski) Denmark and Rather 1996: 66-
68.

Adult female (Figure 31a - d)

Dorsal shield (Figure 31a) - Dorsal shield heavily reticulate: length 383 (381 - 384); width 193 (191 - 194) (at level of s4), 196 (194 - 197) (at level of Z1), with six pairs of solenostomes: gd1, gd2, gd4, gd6, gd8, and gd9. No poroid visible. Sub-lateral setae ( $\mathrm{r} 3$ and R1) on the lateral margin. Dorsal shield bearing 19 pairs of setae. On one of specimens examined, one seta of the $\mathrm{J} 1$ pair is present. All dorsal and sub-lateral setae smooth, except Z5 serrated: j1 

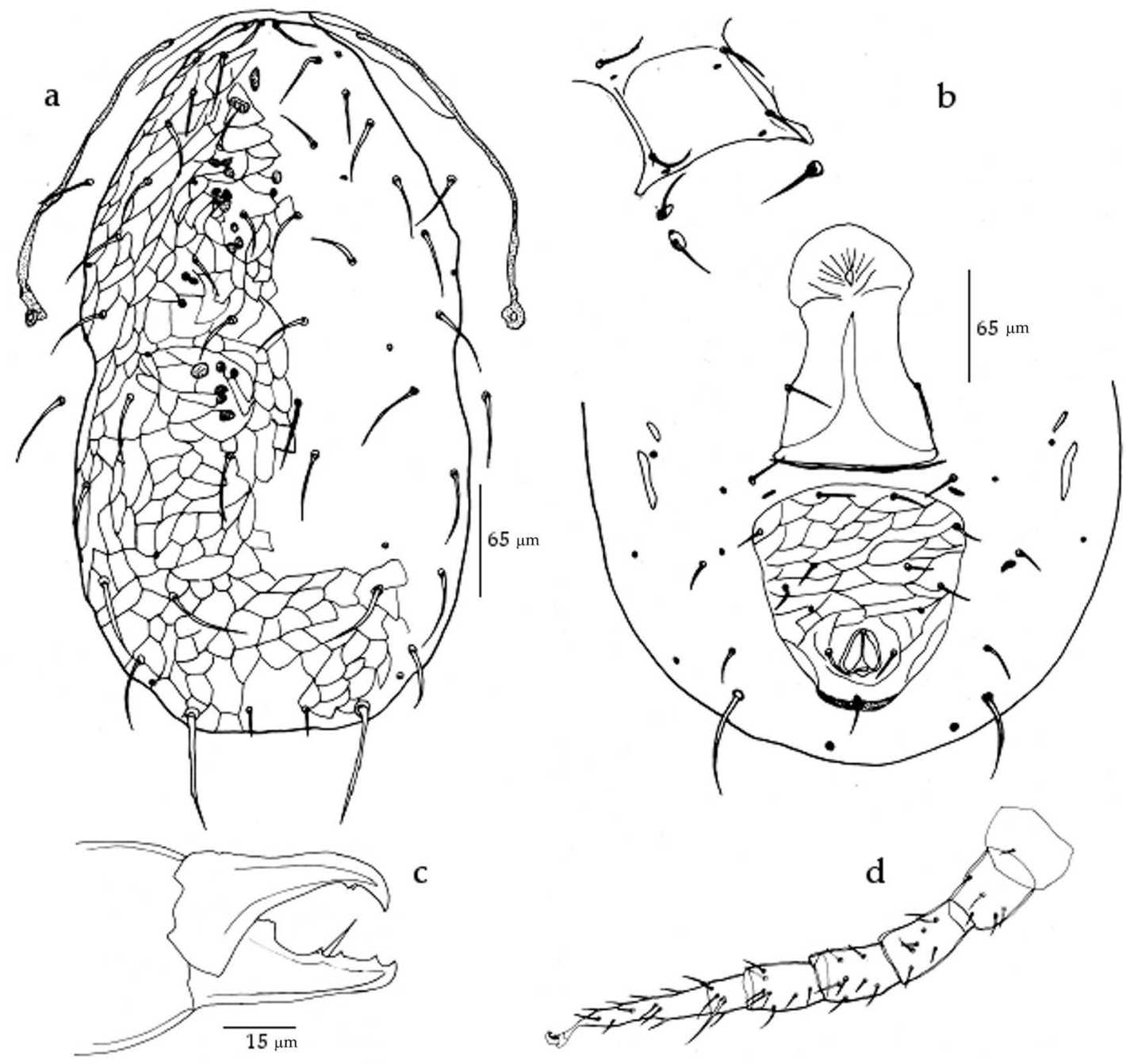

FIGURE 31: Neoseiulella montforti (Rivnay and Swirski). Female (paratype): a - dorsal shield; b - ventral shields; c - chelicera; d - leg IV.

30 (28 - 31); j3 36 (34 - 37); j4 25 (23 - 26); j5 23 (22 24); j6 31 (30-31); J1 36; J2: 37 (36 - 37); J5 13 (12 13); z2 24 (22 - 25); z3 32 (31 - 32); z4 34 (33 - 34); z5 23; Z1 41 (39 - 43); Z4 48 (46 - 50); Z5 58 (56 - 59); s4 38 (37 - 39); s6 43; S2 45 (43 - 46); S4 43 (41 - 45); S5 40 (38 - 41); sub-lateral setae r3 35 (33 - 36) and R1 $41(39-42)$. Presence of few visible muscles marks (sigilles) on the dorsal shield. Peritreme extending anteriorly to the level of $j 3$ or between $\mathrm{j} 1-\mathrm{j} 3$.

Ventral shields (Figure 31b) — Sternal shield weakly sclerotized, $74(73-74)$ long and 80 wide (at level of ST2), smooth, with two pairs of setae (ST1 and ST2) and two pairs of poroids. ST3 and ST4 on separate platelets with a pair of small poroids ac- companying ST4. Genital shield 150 long and 76 (74 - 78) wide (at level of ST5), smooth. Four elongate platelets or genital sigilla separating genital and ventrianal shields folded under the genital shield. One pair of poroids close to the genital shield (ST 5) and 4 pairs of poroids around the genital shield. Ventrianal shield subtriangular-shaped, 133 (131 135) long and 116 (112 - 119) wide (at level of ZV2), reticulate with four pairs of preanal setae (JV1, JV2, JV3 and ZV2), and a pair of small circular solenostomes gv3 posteromediad to JV3. Four pairs of caudoventral setae (ZV1, ZV3, JV4 and JV5) on the integument surrounding the ventrianal shield. JV5 52 $(51-53)$ long, is smooth. Primary metapodal plate 
or inguinal sigillum $38(35-40)$ long and $5(4-6)$ wide.

Spermatheca - Spermatheca not discernible in the two type specimens examined. Rivnay and Swirski (1980) mentioned that the cervix has a Ushaped type.

Chelicera (Figure 31c) - Two or three teeth and a pilus dentilis on the fixed digit. Movable digit 39 $(38-40)$ long, bears one or two teeth.

Legs (Figure 31d) - Measurements of legs: leg I 357 (350 - 363); leg II 302 (297 - 307); leg III 312 (302 - 321); leg IV 422 (411 - 432). Seven setae (2-2/0, $2 / 0-1)$ on the genu II. One macroseta, $38(34-41)$ long, on the basitarsus IV.

Material examined - Two female paratypes deposited in the Division of Entomology, Agricultural Research Organization, Bet Dagan, Israel.

\section{Adult male}

The male of this species is unknown.

Previous reports $-N$. montforti is only known from Israel (Swirski and Amitai 1984; Swirski and Amitai 1997a). The type specimens were collected at Monfort (Western Galilee, Israel) on Quercus calliprinos (Fagaceae). It has since been reported on Artemisia monosperma, Limbarda crithmoides (Asteraceae); at Haifa (Western Carmel) on Q. calliprinos; and on Platanus orientalis L. (Platanaceae).

\section{Neoseiulella myopori (Collyer) (Figure 32)}

Typhlodromus myopori Collyer 1982: 190; Chant and Yoshida-Shaul 1989: 1028-1029. Typhloctonus myopori (Collyer) Denmark and Rather 1984: 168-169; Moraes et al. 1986: 233. Neoseiulella (Typhloctona) myopori (Collyer) Denmark and Rather 1996: 63-65. Neoseiulella myopori (Collyer) Moraes et al. 2004: 294; Chant and McMurtry 2007: 147.

\section{Adult female (Figure 32a - e)}

Dorsal shield (Figure 32a) - Dorsal shield smooth, except for the lateral area slightly reticulated: length 462 (456 - 467); width $266(242-269)$ (at level of s4) and $259(258-260)$ (at level of Z1). Five pairs of solenostomes on the dorsal shield: gd1, gd2, gd4, gd6, and gd9. No poroid visible. Sublateral setae ( $\mathrm{r} 3$ and $\mathrm{R} 1$ ) on the lateral margin. The dorsal shield bearing 19 pairs of setae, all smooth, except Z5 slightly serrated. On the specimen examined, one seta of the J1 pair is present; this pair of setae is absent in the other type specimens examined of this species: j1 $36(35-37)$; j3 $52(47-56)$; j4 13 (12 - 13); j5 11 (10 - 12); j6 14 (12 - 16); J1 16; J2 18; J5 14; z2 17 (16 - 18); z3 32 (27 - 37); z4 29 (2632); z5 11 (10 - 11); Z1 18 (17 - 18); Z4 46 (45 - 47); Z5 112; s4 34 (33 - 34); s6 24 (23 - 24); S2 23 (21 - 24); S4 19 (17 - 20); S5 17 (16 - 18); sub-lateral setae r3 21 (21 - 22) and R1 $18(17$ - 19). Peritreme extending anteriorly to the level of $\mathrm{j} 1$.

Ventral shields (Figure 32b) - Sternal shield 87 (86 - 88) long and 97 (95-98) wide (at level of ST2), smooth, with three pairs of setae (ST1, ST2 and ST3) and two pairs of poroids. A pair of metasternal setae (ST4) on separate platelets accompanied by a pair of small poroids. Genital shield $151(149-153)$ long and 86 (85 - 86) wide (at level of ST5), smooth. Four elongate platelets or genital sigilla separating the genital and ventrianal shields not discernible on the specimen examined. One pair of poroids close to the genital shield (ST 5) and 4 pairs of poroids around the genital shield. Ventrianal shield 153 (150 - 155) long and $117(110$ - 124) wide (at level of ZV2), smooth, with four pairs of preanal setae (JV1, JV2, JV3 and ZV2) and a pair of small circular solenostomes gv3 posterior to JV2. Four pairs of caudoventral setae (ZV1, ZV3, JV4 and JV5) on the integument surrounding the ventrianal shield. JV5 37 (33 - 40) long, smooth. Primary metapodal plate or inguinal sigillum $33(32-33)$ long and $8(7-8)$ wide.

Spermatheca (Figure 32c) - Cervix $10(9-10)$ long, cup-shaped.

Chelicera (Figure 32d) - Eight teeth and a pilus dentilis on the fixed digit. Movable digit 38 (36-39) long, unidentate.

Legs (Figure 32e) - Measurements of legs: leg I 369 (397 - 427); leg II 389 (368 - 403); leg III 387 $(378$ - 396); leg IV $488(464-512)$. Eight setae (2$2 / 1,2 / 0-1$ ) on the genu II. Three macrosetae, 34,32 and 28 long, on the genu, tibia and basitarsus III, respectively. Three other macrosetae, $74(70-78), 68$ 


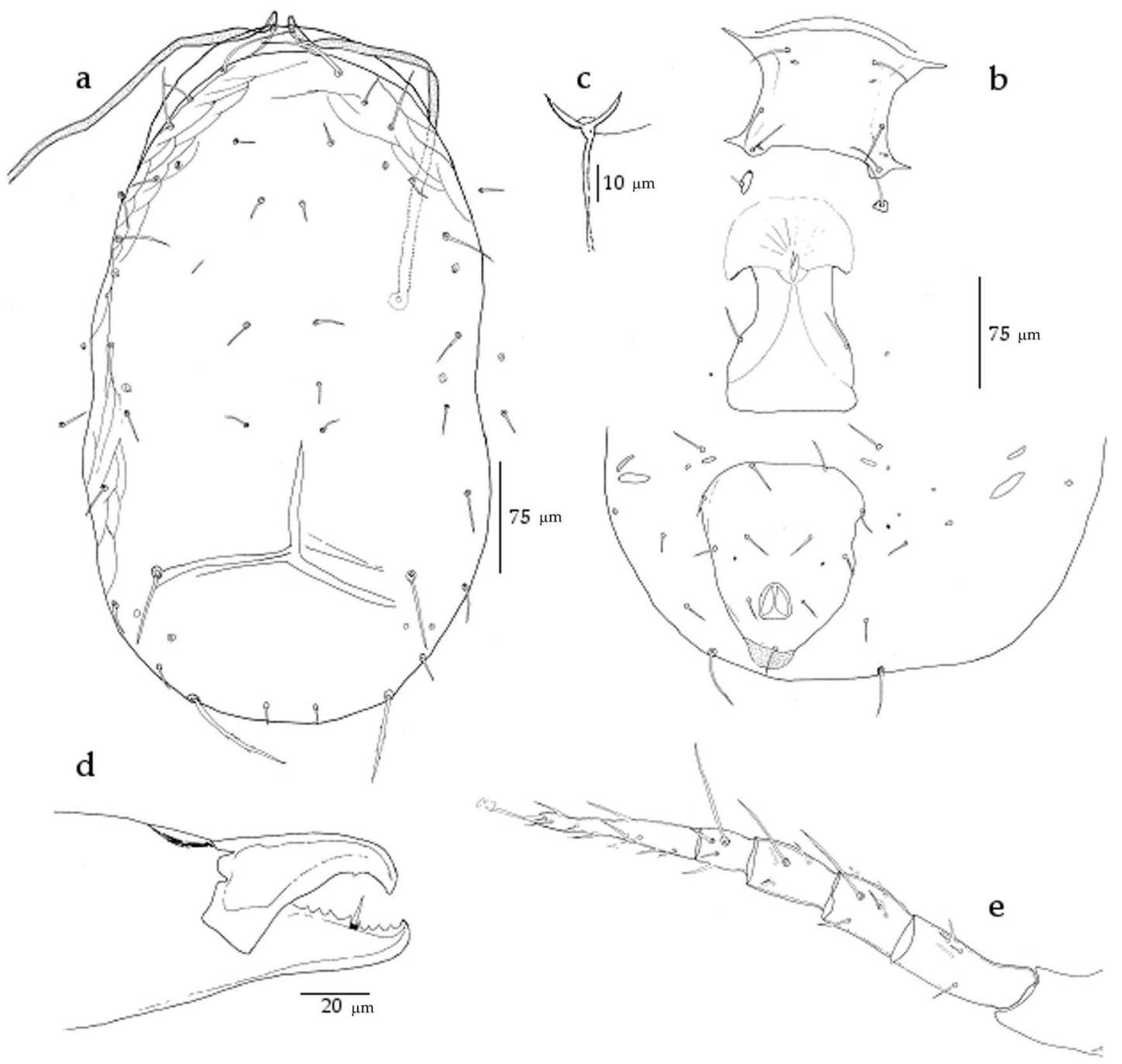

FIGURE 32: Neoseiulella myopori (Collyer). Female (paratype): a - dorsal shield; b - ventral shields; c - spermatheca; d - chelicera; e - leg IV.

$(60-76)$ and $71(65-77)$ long, on the genu, tibia and basitarsus IV, respectively.

Material examined - Two female paratypes deposited in the New Zealand Arthropod Collection (NZAC), Landcare Research, Auckland, New Zealand.

\section{Adult male}

The male of this species is unknown.

Previous reports - N. myopori is only known from New Zealand. The female holotype and six female paratypes were collected on Myoporum laetum G. Forst. (Myoporaceae) at Clifton Coast, South of
Napier. One additional report (1 female and a deutonymph), excluded from the type series, was from Dun Mountain (Nelson Province), on Holocarpus bidwillii (Hook. f.ex T.Kirk.) Quinn (Podocarpaceae) (Collyer 1982).

\section{Neoseiulella neoviniferae Basha, Mahrous and Mostafa}

(Figure 33)

Neoseiulella grapevini Basha et al., Chant and McMurtry 2007: 147.

Adult female (Figure 33a-d) 


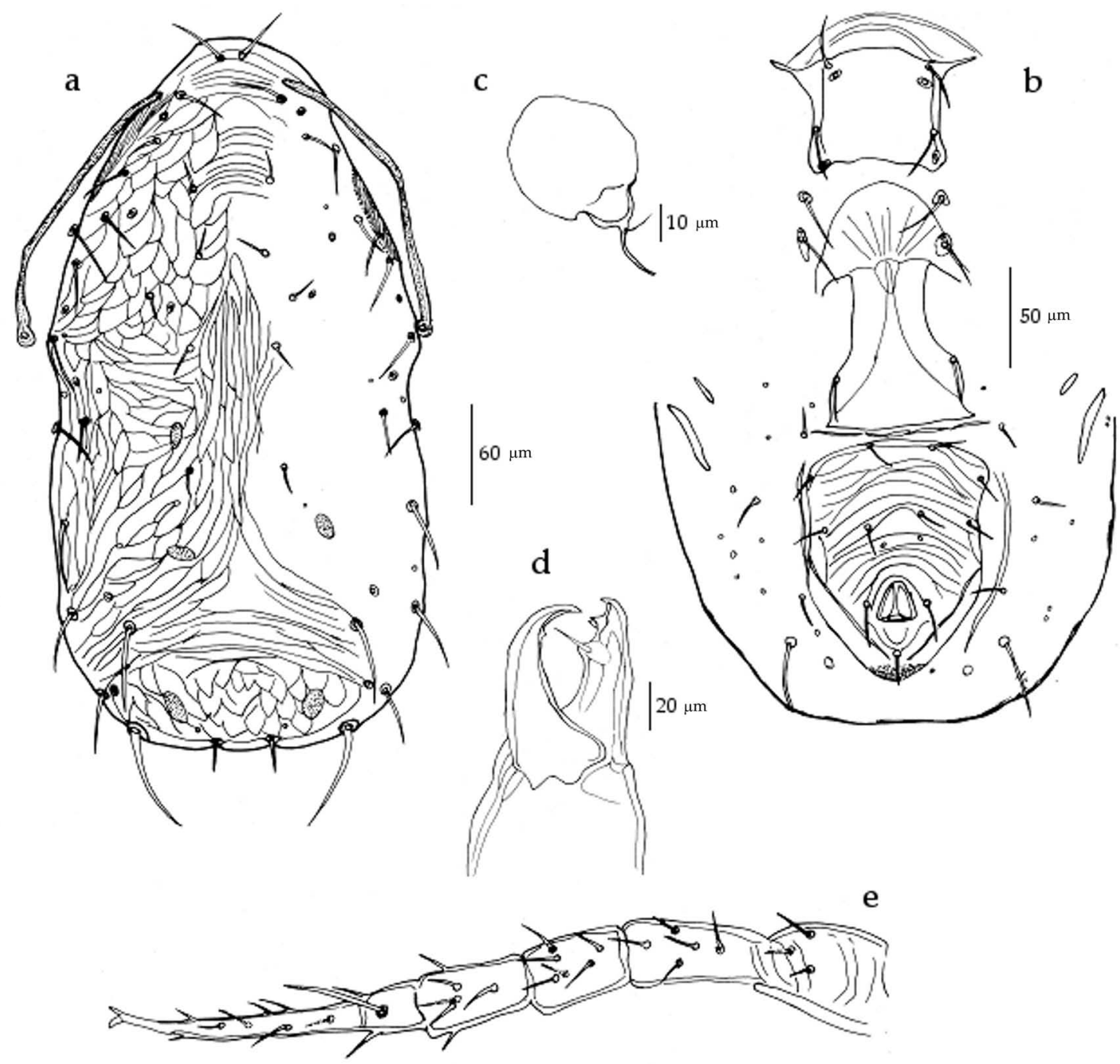

FIGURE 33: Neoseiulella neoviniferae Basha, Mahrous and Mostafa. Female (paratype): a - dorsal shield; $\mathrm{b}$ - ventral shields; $\mathrm{c}$ - spermatheca; d - chelicera; e - leg IV.

Dorsal shield (Figure 33a) - Dorsal shield distinctly reticulated throughout: length 386 (381 390), width 175 (171 - 178) (at level of s4) and 191 (187 - 195) (at level of Z1). Seven pairs of large solenostomes on the dorsal shield: gd1, gd2, gd4, gd5, gd6, gd8, and gd9. Five pairs of poroids. Sublateral setae ( $\mathrm{r} 3$ and $\mathrm{R} 1)$ on the lateral margin. Like us, Basha et al. (2004) noted the presence of seven pairs of solenostomes. However, on their drawings gd4 is absent (present on the specimens examined). Dorsal shield bearing 19 pairs of setae, all smooth: j1 23 (21 - 25); j3 24 (22 - 26); j4 14 (12 - 15); j5 12 (10 - 13); j6 16 (15 - 17); J2 15 (14 - 15); J5 15 (14 -
15); z2 10 (9 - 11); z3 24 (22 - 25); z4 19 (17 - 20); z5 14 (13 - 15); Z1 17 (16 - 17); Z4 47 (44 - 49); Z5 62 (59 - 64); s4 23 (22 - 24); s6 26 (25 - 27); S2 35 (34 36); S4 33 (31 - 35); S5 28 ( 26 - 30); sub-lateral setae r3 $28(26-30)$ and R1 $25(23-27)$. Presence of few visible muscles marks (sigilles) on the dorsal shield. Peritreme extending anteriorly to the level of $j 3$.

Ventral shields (Figure 33b) - Sternal shield 62 $(60-63)$ long and $67(66-67)$ wide (at level of ST2), is smooth with two pairs of setae (ST1 and ST2) and two pairs of poroids. ST3 and ST4 on separate platelets. A pair of small poroids accompany- 
ing ST4. Genital shield 128 (125 - 131) long and 66 $(64-67)$ wide (at level of ST5), smooth. Four elongate platelets or genital sigilla between genital and ventrianal shields. One pair of poroids close to the genital shield (ST 5) and 4 pairs of poroids around the genital shield. Ventrianal shield subtriangularshaped, 130 (125 - 134) long and 98 (95 - 101) wide (at level of ZV2), distinctly reticulated, with four pairs of preanal setae (JV1, JV2, JV3 and ZV2) and a pair of solenostomes gv3 posterior to JV2. Four pairs of caudoventral setae (ZV1, ZV3, JV4 and JV5) on the integument surrounding the ventrianal shield. JV5 48 (46 - 50) long, smooth. Primary metapodal plate or inguinal sigillum $39(38-40)$ long and $5(4-6)$ wide.

Spermatheca (Figure 33c) - Cervix 4 (3-4) long, cup-shaped.

Chelicera (Figure 33d) - Two large teeth and a pilus dentilis on the fixed digit. Movable digit 38 (36 -39) long, unidentate. Basha et al. (2004) mentioned that the fixed digit bears three teeth.

Legs (Figure 33e) - Measurements of legs: leg I 341 (333 - 349); leg II 286 (285 - 286); leg III 285 (284 - 286); leg IV 381 (369 - 393). Seven setae (2$2 / 0,2 / 0-1)$ on the genu II. One macroseta 42 (37 47) long, on the basitarsus IV.

Material examined - Four female paratypes deposited in the collection of Plant Protection Department, Faculty of Agriculture, Zagazig University, Egypt.

\section{Adult male}

The male of this species is unknown.

Previous reports - N. neoviniferae is only known from Al-Sharkia Governorate, El-Khattara District (Egypt) on Vitis vinifera L. (Vitaceae).

Remarks - N. neoviniferae is similar to N. montforti but differs by the presence/ absence of gd5 (present on $N$. neoviniferae; absent on $N$. montforti), the shape of the spermatheca (c-shaped on $N$. neoviniferae; U-shaped on N. montforti) and measurements of some dorsal setae (j6, J2, z2, Z1 and R1).

\section{Neoseiulella novaezealandiae (Collyer) (Figure 34)}

Typhlodromus novaezealandiae Collyer 1964: 635-637; Schicha 1980: 24-26; Collyer 1982: 188-189; Schicha 1987: 136-137; Chant and Yoshida-Shaul 1989: 10321035. Neoseiulella novaezealandiae (Collyer) Moraes et al. 1986: 202; Moraes et al. 2004: 295; Chant and McMurtry 2007: 147. Neoseiulella (Neoseiulella) novaezealandiae (Collyer) Denmark and Rather 1996: 48-49.

\section{Adult female (Figure $34 \mathrm{a}-\mathrm{e}$ )}

Dorsal shield (Figure 34a) - Dorsal shield heavily reticulated: length 400; width 235 (at level of s4), 231 (at level of Z1), and 262 (at level of S2). Five pairs of solenostomes on the dorsal shield: $g d 2$, gd4, gd5, gd6, and gd9. One pair of poroids. Chant and Yoshida-Shaul (1989) draw and mentioned only four pairs of solenostomes (gd5 absent). However, the present examination of type material shows the presence of gd5, like in the drawings of Schicha (1987). Sub-lateral setae ( $\mathrm{r} 3$ and R1) on the lateral margin. Dorsal shield bearing 19 pairs of setae, all smooth, except Z4 and Z5 serrated: j1 24; j3 27; j4 17; j5 15; j6 18; J2 21; J5 12; z2 17; z3 24; z4 23; z5 17; Z1 22; Z4 40; Z5 59; s4 24; s6 22; S2 25; S4 23; S5 21; sublateral setae r3 21 and R1 17. Presence of very few visible muscles marks (sigilles) on the dorsal shield. Peritreme extending anteriorly to the level of $\mathrm{j} 1$.

Ventral shields (Figure 34b) - Sternal shield 85 long and 84 wide (at level of ST2), smooth, with three pairs of setae (ST1, ST2 and ST3) and two pairs of poroids. A pair of metasternal setae (ST4) on separate platelets accompanied by a pair of small poroids. Genital shield 121 long and 74 wide (at level of ST5), smooth. Four elongate platelets or genital sigilla separating genital and ventrianal shields not discernible in the specimen examined. No pair of poroids close to the genital shield (ST 5) and 2 pairs of poroids around the genital shield. Ventrianal shield 139 long and 110 wide (at level of ZV2), smooth, with three pairs of preanal setae (JV1, JV2 and ZV2; JV3 absent) and a pair of large solenostomes gv3 mediad to JV2. Four pairs of caudoventral setae (ZV1, ZV3, JV4 and JV5) on the integument surrounding the ventrianal shield. JV5 35 


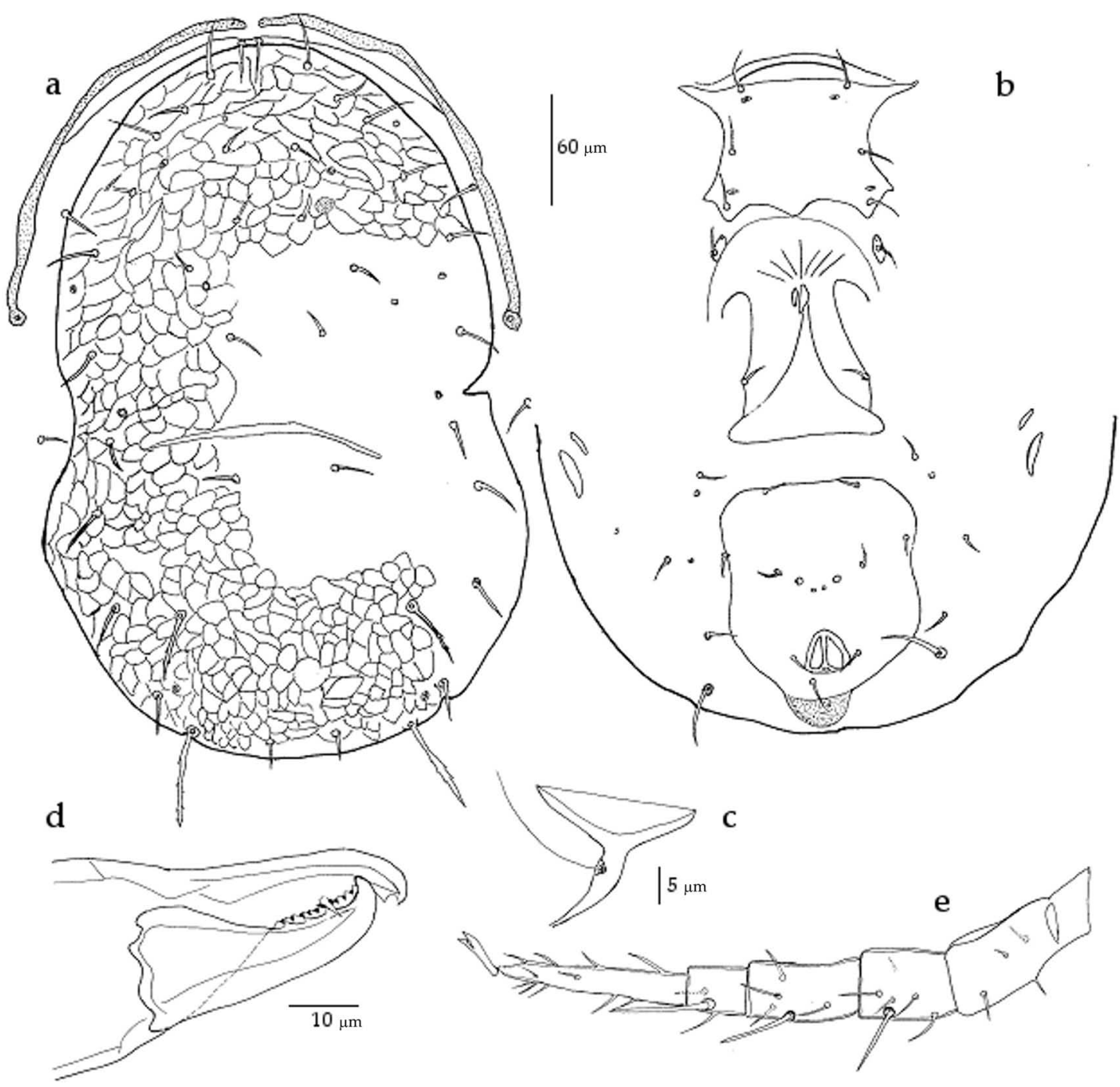

FIGURE 34: Neoseiulella novaezealandiae (Collyer). Female (paratype): a - dorsal shield; b - ventral shields; $\mathrm{c}$ - spermatheca; $\mathrm{d}$ - chelicera; e- leg IV.

long, smooth. Primary metapodal plate or inguinal sigillum 30 long and 8 wide.

Spermatheca (Figure 34c) - Cervix 5 long, shallowly cup-shaped.

Chelicera (Figure 34d) - Nine teeth and a pilus dentilis on the fixed digit. Movable digit 33 (32-34) long, bearing three teeth.

Legs (Figure 34e) - Measurements of legs: leg I 320; leg II 286; leg III 286; leg IV 391.. Seven setae (2$2 / 0,2 / 0-1)$ on the genu II. Three thick and pointed macrosetae, 30, 33 and 45 long, on the genu, tibia and basitarsus IV, respectively.
Material examined - One female paralectotype deposited in the New Zealand Arthropod Collection (NZAC), Landcare Research, Auckland, New Zealand.

\section{Adult male}

Described by Collyer (1964) and Schicha (1980) and Denmark and Rather (1996). We were not able to borrow male type specimens of this species.

Previous reports $-N$. novaezealandiae is only known from the Australasian area. The type specimens (30 females and 5 males) were collected at Kawau Island (New Zealand), on Metrosideros ex- 
celsa Gaertn (Myrtaceae). Collyer (1964, 1982,) reported that this species is distributed throughout New Zealand, on a wide range of native plants. Additional collections of this species have been reported from New South Wales and Queensland (Australia) (Schicha 1987; Walter 1999). Plants on which this species was collected are: Brachyglottis repanda (Asteraceae); Pseudopanax sp. (Araliaceae); Callicoma serratifolia Andrews (Cunoniaceae); Elaeocarpus dentatus (Elaeocarpaceae); Nothofagus sp., Quercus sp., Sophora tetraptera J.F.Mill. (Fagaceae); Eucalyptus sp., Leptospermum scoparium (Myrtaceae); Tacsonia mollissima Kunth, Passiflora sp. (Passifloraceae); Dacrydium cupressinum Sol. ex Lamb., Podocarpus sp. (Podocarpaceae); Eriobotrya sp., Malus domestica, Pyrus communis (Rosaceae); Elatostema rugosum A.Cunn. (Urticaceae); Lantana camara L., Vitex lucens T. Kirk (Verbenaceae).

Remarks - N. novaezealandiae is very similar to $N$. nesbitti in setal and body measurements. However, differences are observed for the ornementation of dorsal shield (lightly reticulated on N. nesbitti, heavily reticulated on $N$. novaezealandiae) and the position and size of prenanal solenostomes (small and posterior to JV2 in N. nesbitti, large and mediad to JV2 in N. novaezealandiae). As several authors have showed the importance of such characters for species identification (Shicha 1980; Chant and McMurtry 1994; Swirski et al. 1998; Chant and McMurtry 2007; Okassa et al. 2009), we consider that these two species are separate specific entities.

\section{Neoseiulella oleariae (Collyer) (Figure 35)}

Typhlodromus oleariae Collyer 1982: 190-191; Schicha 1987: 137-138; Chant and Yoshida-Shaul 1989: $1035-$ 1039. Amblydromella oleariae (Collyer) Moraes et al. 1986: 168-169. Neoseiulella (Neoseiulella) oleariae (Collyer) Denmark and Rather 1996: 52-53. Neoseiulella oleariae (Collyer) Moraes et al. 2004: 295; Chant and McMurtry 2007: 147.

Adult female (Figure 35a - e)

Dorsal shield (Figure 35a) - Dorsal shield smooth, except for the lateral area of the podosoma lightly reticulated: length $418(417$ - 418); width 258 (257 - 259) (at level of s4), 269 (at level of Z1), and
$280(279-280)$ (at the level of S2). Five pairs of solenostomes on the dorsal shield: gd2, gd4, gd5, gd6, and gd9. No poroid visible. Sub-lateral setae ( $\mathrm{r} 3$ and R1) on the lateral margin. Dorsal shield bearing 19 pairs of setae, all smooth, except $Z 4$ and Z5 slightly serrated: j1 38 (37 - 39); j3 56; j4 31 (30 31); j5 23 (22 - 23); j6 30 (29 - 30); J2 37 (35 - 39); J5 11 (10 - 11); z2 28; z3 50 (45 - 55); z4 38 (37 - 39); z5 11; Z1 46; Z4 87 (86 - 88); Z5 112 (110 - 113); s4 57 (55 58); s6 54 (51 - 56); S2 58 (57 - 59); S4 33 (32 - 34); S5 35 (33 - 36); sub-lateral setae r3 $40(38-42)$ and R1 31. Presence of few visible muscles marks (sigilles) on the dorsal shield. Peritreme extending anteriorly to the level of $j 1$.

Ventral shields (Figure 35b) - Sternal shield 92 long and 94 wide (at level of ST2), smooth, with three pairs of setae (ST1, ST2 and ST3) and two pairs of poroids. A pair of metasternal setae (ST4) on separate platelets accompanied by a pair of small poroids. Genital shield 121 (119 - 123) long and 76 wide (at level of ST5), smooth. Four elongate platelets or genital sigilla separating genital and ventrianal shields folded under the genital shield. One pair of poroids close to the genital shield (ST 5) and 4 pairs of poroids around the genital shield. Ventrianal shield $152(150$ - 153) long and 123 (121 124) wide (at level of $Z V 2$ ), smooth, with three pairs of preanal setae (JV1, JV2 and ZV2; JV3 absent) and a pair of small circular solenostomes gv3 posterior or posterolateral to JV2. Three pairs of caudoventral setae (ZV1, ZV3 and JV5, JV4 absent) on the integument surrounding the ventrianal shield. Absence of the caudoventral seta JV4 allows to easily distinguish this species from all the. JV5 $53(51-55)$ long, smooth. Primary metapodal plate or inguinal sigillum $35(34-35)$ long and $11(10-11)$ wide.

Spermatheca (Figure 35c) - Cervix $10(9-10)$ long, U-shaped.

Chelicera (Figure 35d) -1 Nine teeth and a pilus dentilis on the fixed digit. Movable digit 38 (36-39) long, bearing three teeth.

Legs (Figure 35e) - Measurements of legs: leg I 391 (387 - 395); leg II 334 (324 - 343); leg III 340 (331 - 348); leg IV 439. Seven setae (2-2/0, 2/0-1) on the genu II. Two macrosetae $34(34-35)$ and 33 (32 - 33) long on the genu and tibia III, respectively. 


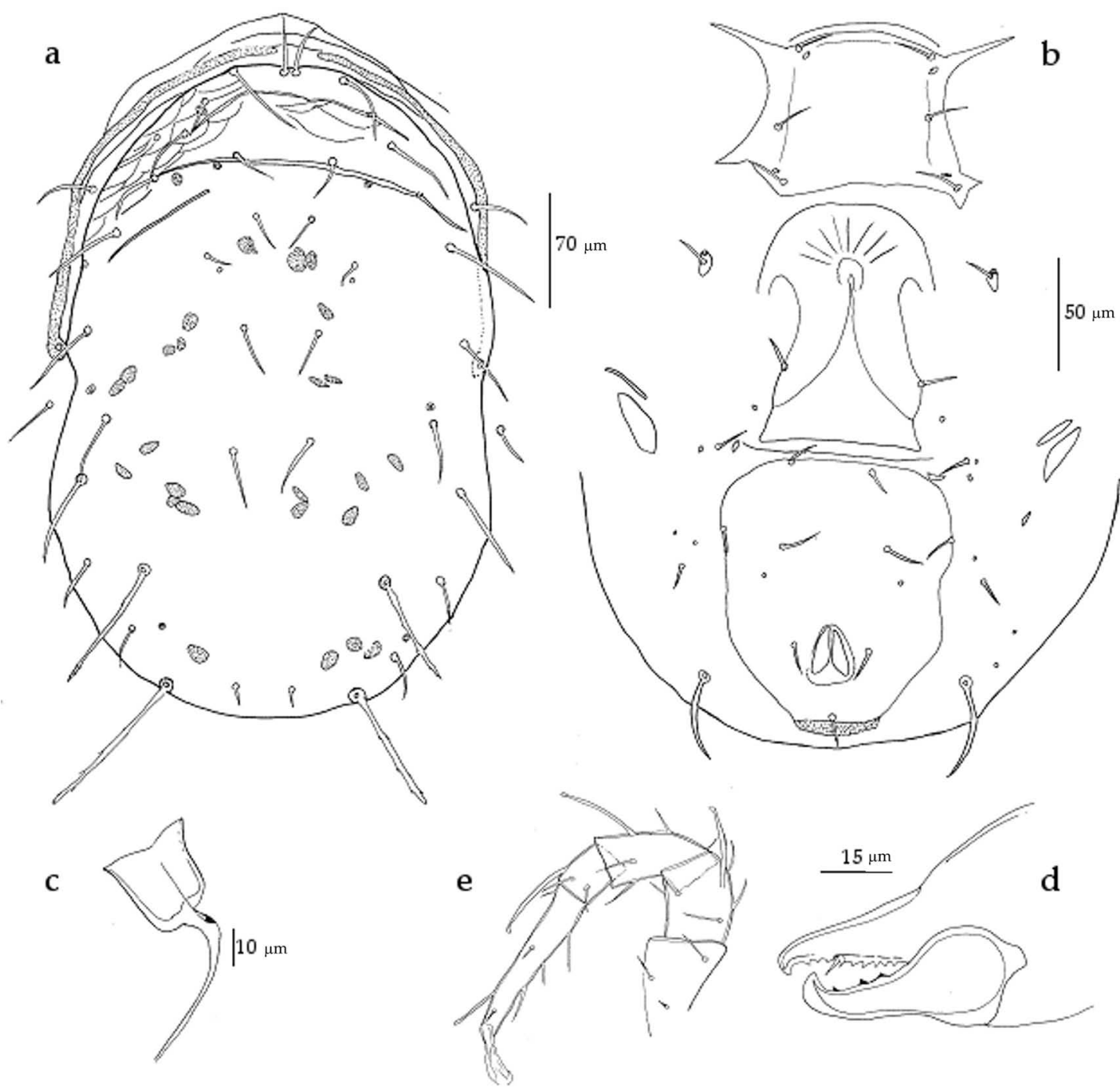

FIGURE 35: Neoseiulella oleariae (Collyer). Female (paratype): a - dorsal shield; b - ventral shields; $\mathrm{c}$ - spermatheca; $\mathrm{d}$ - chelicera; e - leg IV.

Three other knobbed macrosetae, 53 (52 - 54), 52 ( 50 - 54) and 54 (51 - 57) long, on the genu, tibia and basitarsus IV, respectively.

Material examined - Two female paratypes deposited in the New Zealand Arthropod Collection (NZAC), Landcare Research, Auckland, New Zealand.

\section{Adult male}

Described by Collyer (1982) and Denmark and Rather (1996). We were not able to borrow male type specimens of this species.

Previous reports $-N$. oleariae is only known from New Zealand. The female holotype and two paratype specimens ( 1 female and 1 male) of $N$. oleariae were collected on Olearia colensoi Moench. (Asteraceae) at Ruahine Range. Other paratype specimens ( 2 females and 1 male) were also collected on O. colensoi at Magister Ridge (Westland), Strachan Ridge (South Westland), and Pillans Pass (Manapouri). Other specimens (excluded from the type series) were collected from both North and South islands of New Zealand. Plants on which this species was collected are: Carmichaelia sp. (Fagaceae); Carpodetus serratus J.R. and G.Forst. (Car- 
podetaceae); Coprosma polymorpha W.R.B. Oliver (Rubiaceae); Dacrophyllum sp. (Podocarpaceae); Olearia lacunosa Moench. (Asteraceae); Pseudowintera axillaris J.R. and G.Forst. (Winteraceae); Vitex lucens Kirk (Verbenaceae).

\section{Neoseiulella perforata (Athias-Henriot) (Figure 36)}

Typhlodromus perforatus Athias-Henriot 1960: 72; Chant and Yoshida-Shaul 1989: 1018. Amblydromella perforata (Athias-Henriot) Moraes et al. 1986: 169. Typhloctonus perforatus (Athias-Henriot) McMurtry and Bounfour 1989: 15. Neoseiulella (Typhloctona) perforata (Athias-Henriot) Denmark and Rather 1996: 61. Amblydromella (Aphanoseia) perforata (Athias-Henriot) Denmark and Welbourn 2002: 308. Neoseiulella perforata (Athias-Henriot) Moraes et al. 2004: 295; Chant and McMurtry 2007: 147.

\section{Adult female (Figure 36a - e)}

Dorsal shield (Figure 36a) - Dorsal shield distinctly reticulated throughout: length 380; width 191 (at level of s4) and 182 (at level of Z1). Six pairs of circular solenostomes on the dorsal shield: gd1, gd2, gd5, gd6, gd8, and gd9. No poroid visible. Sub-lateral setae ( $\mathrm{r} 3$ and R1) on the lateral margin. Dorsal shield bearing 19 pairs of setae, all smooth, except Z5 slightly serrated: j1 $21(20-22)$; j3 21 (20 - 22); j4 13; j5 12 (11 - 13); j6 14 (13 - 14); J2 17 (14 19); J5 13; z2 13 (12 - 13); z3 20 (18 - 20); z4 21 (20 21); z5 13 (12 - 14); Z1 19 (17 - 20); Z4 34 (33 - 34); Z5 52 (50 - 53); s4 23 (22 - 23); s6 24 (21 - 26); S2 29 (27 - 30); S4 31 (29 - 33); S5 29 (27 - 30); sub-lateral setae r3 $24(23-25)$ and R1 $22(20-23)$. Peritreme extending anteriorly to the level of $j 3$ or between $z 2-$ j3.

Ventral shields (Figure 36b) - Sternal shield 68 long and 66 wide (at level of ST2), smooth, with two pairs of setae (ST1 and ST2) and two pairs of poroids. ST3 and ST4 on separate platelets and with a pair of small poroids accompanying ST4. Genital shield 128 long and 61 wide (at level of ST5), smooth. Platelets or genital sigilla separating between genital and ventrianal shields not discernible. One pair of poroids close to the genital shield (ST 5) and 3 pairs of poroids around the genital shield. Ventrianal shield 136 long and 108 (105
- 110) wide (at level of ZV2), distinctly reticulated throughout, with four pairs of preanal setae (JV1, JV2, JV3 and ZV2) and without solenostome gv3. Four pairs of caudoventral setae (ZV1, ZV3, JV4 and JV5) on the integument surrounding the ventrianal shield. JV5 46 (44-48) long, smooth. Primary metapodal plate or inguinal sigillum 31 long and 5 wide.

Spermatheca (Figure 36c) - Cervix 11 long, Ushaped.

Chelicera (Figure 36d) - One tooth and a pilus dentilis on the fixed digit. Movable digit $32(30-33)$ long, edentate.

Legs (Figure 36e) - Measurements of legs: leg I 328 (325 - 330); leg II 271 (266 - 275); leg III 270 (266 - 274); leg IV 362 (358 - 366). Eight setae (2$2 / 1,2 / 0-1)$ on the genu II. One pointed macroseta, 33 (32 - 33) long, on the basitarsus IV.

Material examined - Two female syntypes deposited in the Laboratoire de Zoologie, Muséum National d'Histoire Naturelle, Paris, France.

Adult male (Figure 36f, g)

Dorsal shield chaetotaxy similar to but smaller than the female. Ventrianal shield 114 (110-118) long and 138 (135-140) wide distinctly reticulated, bearing 6 pairs of preanal setae without solenostomes. Spermatodactyl L-shaped. This description is based on one male syntype specimen.

Previous reports - N. perforata is only known from the West-Palearctic area. Countries from which this species was reported are: Algeria (Athias-Henriot 1960), Morocco (Denmark and Bounfour 1989) and Spain (Chant and YoshidaShaul 1989). It was collected on various plants (13 botanical families): Adenostoma sp. (Rosaceae); Asparagus acutifolius L. (Liliaceae); Astericus maritimus L., Dittrichia graveolens (L.) Greuter, Dittrichia viscosa, Galactites tomentosa Moench, Pulicaria sicula (L.) Moris (Asteraceae); Beta vulgaris L. (Amaranthaceae); Cistus monspeliensis (Cistaceae); Daucus carota subsp. maximus (Desf.) Ball (Apiaceae); Fraxinus sp. (Oleaceae); Lotus creticus, Ononis alba subsp. monophylla (Desf.) Murb., Trifolium pratense (Fabaceae); Plantago lagopus L. (Plantaginaceae); Ricinus communis (L.) (Euphorbiaceae); Ridolfia sege- 


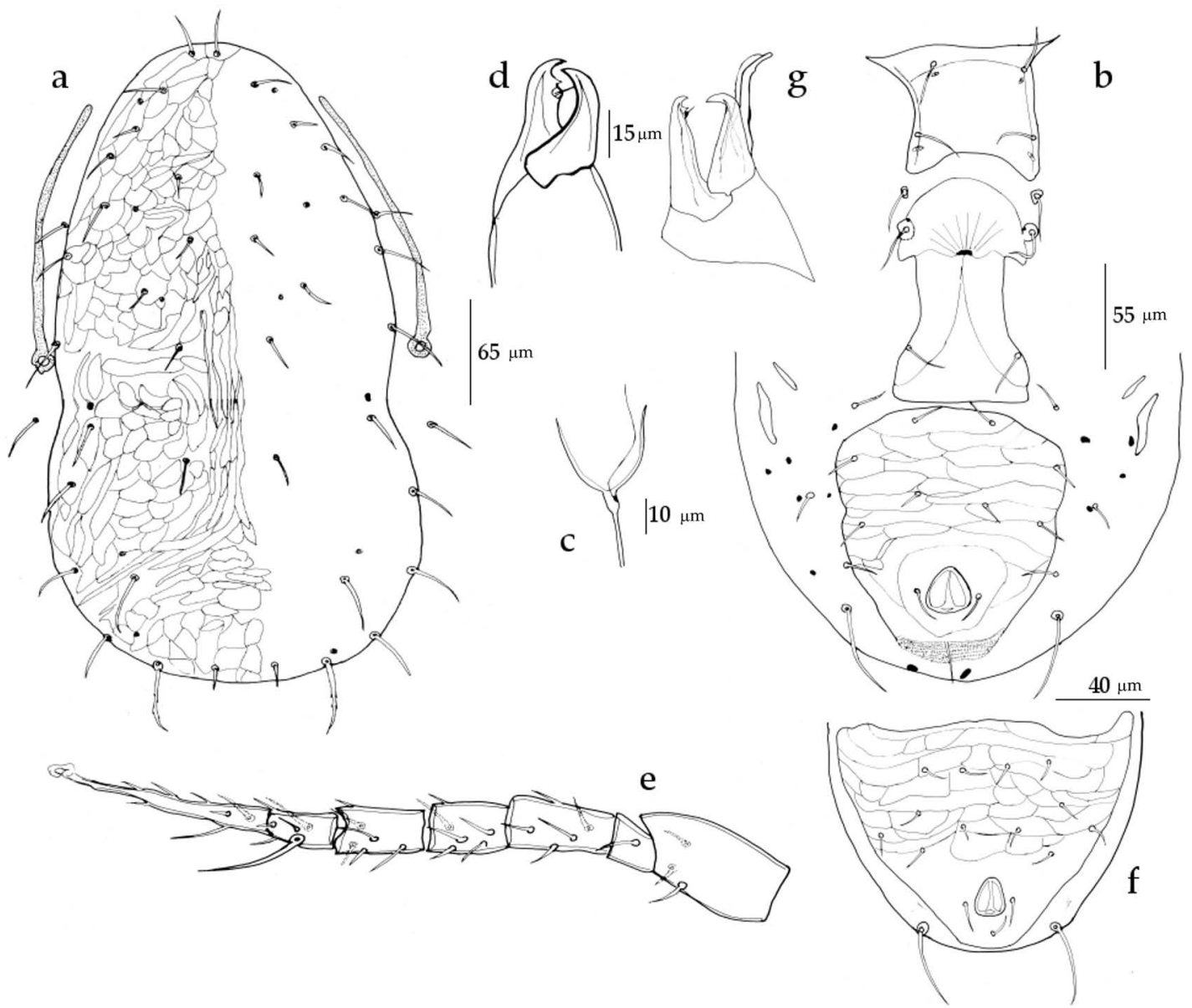

FIGURE 36: Neoseiulella perforata (Athias-Henriot). Female (syntype): a - dorsal shield; b - ventral shields; $\mathrm{c}$ - spermatheca; $\mathrm{d}$ - chelicera; e - leg IV. Male (syntype): $\mathrm{f}$ - ventrianal shield; g - spermatodactyl.

tum (L.) Moris (Ericaceae); Stachys ocymastrum (L.) Briq. (Lamiaceae); Verbascum sinuatum L. (Scrophulariaceae).

\section{Neoseiulella runiacus (Kolodochka) (Figure 37)}

Typhloctonus runiacus Kolodochka 1980: 64-65; Denmark and Rather 1984: 75-76; Moraes et al. 1986: 233; Kolodochka 2009: 488-489. Typhlodromus runiacus (Kolodochka) Chant and Yoshida-Shaul 1989: 1015-1017. Neoseiulella (Typhloctona) runiaca (Kolodochka) Denmark and Rather 1996: 63-64. Neoseiulella runiaca (Kolodochka) Moraes et al. 2004: 295; Chant and McMurtry 2007: 147.

Adult female (Figure 37a-d)
Dorsal shield (Figure 37a) - Dorsal shield heavily reticulated throughout: length 382; width 220 (at level of s4), 271 (at level of Z1). Four pairs of large solenostomes on the dorsal shield: gd2, gd5, gd6, and gd9. No poroid visible. Sub-lateral setae (r3 and R1) on the lateral margin. Dorsal shield bearing 19 pairs of setae, all smooth, except J5 and Z5 serrated. Most dorsal setae thick and on tubercles: j1 18; j3 23; j4 18; j5 18; j6 28; J2 32; J5 17; z2 17; z3 26; z4 25; z5 20; Z1 30; Z4 39; Z5 44; s4 27; s6 28; S2 31; S4 26; S5 24; sub-lateral setae r3 22 and R1 15. Peritreme extending anteriorly to the level of $\mathrm{j} 1$.

Ventral shields (Figure 37b) - Sternal shield 51 long and 64 wide (at level of ST2), smooth, with two pairs of setae (ST1 and ST2) and two pairs of poroids. ST3 and ST4 are inserted on separates 


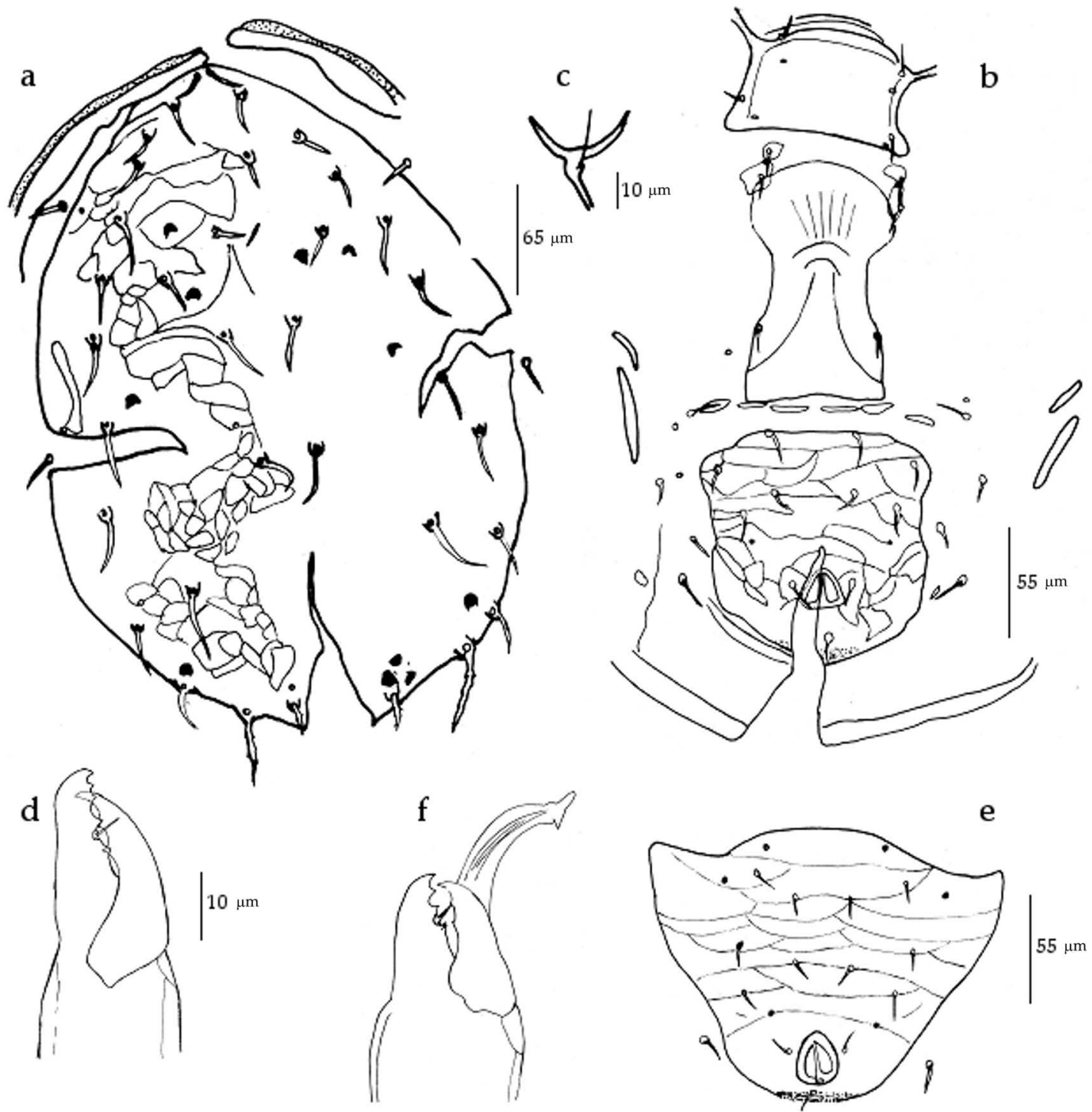

FIGURE 37: Neoseiulella runiacus (Kolodochka). Female (holotype): a - dorsal shield; b - ventral shields; $\mathrm{c}$ - spermatheca; $\mathrm{d}$ - chelicera. Male (paratype): $\mathrm{e}$ - ventrianal shield; $\mathrm{f}$ - spermatodactyl.

platelets and a pair of small poroids accompanying ST4. Genital shield 136 long and 67 wide (at level of ST5), smooth. Six elongate platelets or genital sigilla situated between genital and ventrianal shields. One pair of poroids close to the genital shield (ST 5) and 2 pairs of poroids around the genital shield. Ventrianal shield subquadrate-shaped, 110 long and 108 wide (at level of ZV2), distinctly reticulated, with four pairs of preanal setae (JV1, JV2, JV3 and ZV2) and a pair of circular solenostomes gv3 posterior to JV3. Four pairs of caudoven- tral setae (ZV1, ZV3, JV4 and JV5) on the integument surrounding the ventrianal shield. JV5 16 long, smooth. Primary metapodal plate or inguinal sigillum 45 long and 4 wide.

Spermatheca (Figure 37c) - Cervix 9 long, cupshaped.

Chelicera (Figure 37d) - Four teeth and a pilus dentilis on the fixed digit. Movable digit 23 long, bidentate.

Legs - Measurements of legs: leg I 250; leg II 
230; leg III 240; leg IV 300. Seven setae (2-2/0, 2/0$1)$ on the genu II. No macroseta on legs.

Material examined - The female holotype deposited in the ASU, Institute of Zoology, Academy of Sciences, Kiev, Ukraine.

\section{Adult male (Figure 37e-f)}

Dorsal shield similar to but smaller than female. Ventrianal shield 120 long and 142 wide, distinctly reticulated and bearing 5 pairs of preanal setae and three pair of poroids. Spermatodactyl L-shaped. This description is based on a paratype specimen.

Previous reports - The type specimens of $N$. runiacus were collected from Zakarpattia region (Ukraine) on Alnus viridis (Chaix) DC. (Betulaceae) and Fagus silvatica L. (Fagaceae) (Kolodochka 1980, 2009). Chant and Yoshida-Shaul (1989) indicated that a specimen originally identified as Typhlodromus aceri, collected in the Lake District (UK), was in fact $N$. runiacus.

Remarks $-N$. runiacus is similar to $N$. sexapori. Except for characteristics of dorsal setae (thick on $N$. runiacus; simple on $N$. sexapori), the nature of $\mathrm{J} 5$ (serrated on $N$. runiacus; smooth on $N$. sexapori), and the length of the peritreme (extending to the level of $\mathrm{j} 1$ on N. runiacus; extending to the level between z2-j3 on $N$. sexapori), all other morphological characters are similar. As several authors have already shown the importance of such characters for species differentiation (Athias-Henriot 1977; Chant and YoshidaShaul 1983; Chant and McMurtry 1994; Ragusa and Tsolakis 1998; Swirski et al. 1998; Chant and McMurtry 2007), we consider that N. runiacus and N. sexapori are two valid species.

\section{Neoseiulella spaini (Collyer) (Figure 38)}

Typhlodromus spaini Collyer 1982: 189; Schicha 1987: 134-135; Chant and Yoshida-Shaul 1989: 1024-1026. Neoseiulella (Typhloctona) spaini (Collyer) Denmark and Rather 1996: 73-74. Neoseiulella spaini (Collyer) Moraes et al. 1986: 202; Moraes et al. 2004: 295; Chant and McMurtry 2007: 147.

\section{Adult female (Figure 38a-d)}

Dorsal shield (Figure 38a) - Dorsal shield distinctly reticulated along the lateral area: length 412; width 209 (at level of s4) and 218 (at level of Z1). Six pairs of solenostomes on the dorsal shield: gd1, gd2, gd4, gd5, gd6, and gd9. One pair of poroids. Sub-lateral setae ( $\mathrm{r} 3$ and R1) on the lateral margin. Dorsal shield bearing 19 pairs of setae, all smooth, except Z5 slightly serrated: j1 25; j3 26; j4 11; j5 11; j6 15; J2 16; J5 12; z2 10; z3 16; z4 17; z5 11; Z1 15; Z4 31; Z5 48; s4 23; s6 23; S2 20; S4 17; S5 17; sublateral setae r3 20 and R1 16. Peritreme extending anteriorly to the level between $\mathrm{j} 1 \mathrm{j} 3$.

Ventral shields (Figure 38b) - Sternal shield 84 long and 91 wide (at level of ST2), smooth, with three pairs of setae (ST1, ST2 and ST3) and two pairs of poroids. Metasternal setae (ST4) inserted on separate platelets with a pair of small poroids. Genital shield 126 long and 72 wide (at level of ST5), smooth. Four elongate platelets or genital sigilla separating genital and ventrianal shields folded under the genital shield. One pair of poroids close to the genital shield (ST 5) and 3 pairs of poroids around the genital shield. Ventrianal shield subtriangular-shaped, 140 long and 118 wide (at level of ZV2), is smooth, with four pairs of preanal setae (JV1, JV2, JV3 and ZV2) and a pair of small and circular solenostomes gv3 posteromediad to JV3. Four pairs of caudoventral setae (ZV1, ZV3, JV4 and JV5) on the integument surrounding the ventrianal shield. JV5 44 long, smooth. Primary metapodal plate or inguinal sigillum 35 long and 8 wide.

Spermatheca (Figure 38c) - Cervix 8 long, cupshaped.

Chelicera (Figure 38d) - Five teeth and a pilus dentilis on the fixed digit. Movable digit 33 long, bidentate.

Legs (Figure 38e) - Measurements of legs: leg I 368; leg II 322; leg III 320; leg IV 412. Eight setae (2$2 / 1,2 / 0-1)$ on the genu II. Three knobbed macrosetae, 30, 28 and 54 long, on the genu, tibia and basitarsus IV, respectively.

Material examined - The female holotype deposited in the New Zealand Arthropod Collection (NZAC), Landcare Research, Auckland, New Zealand. 


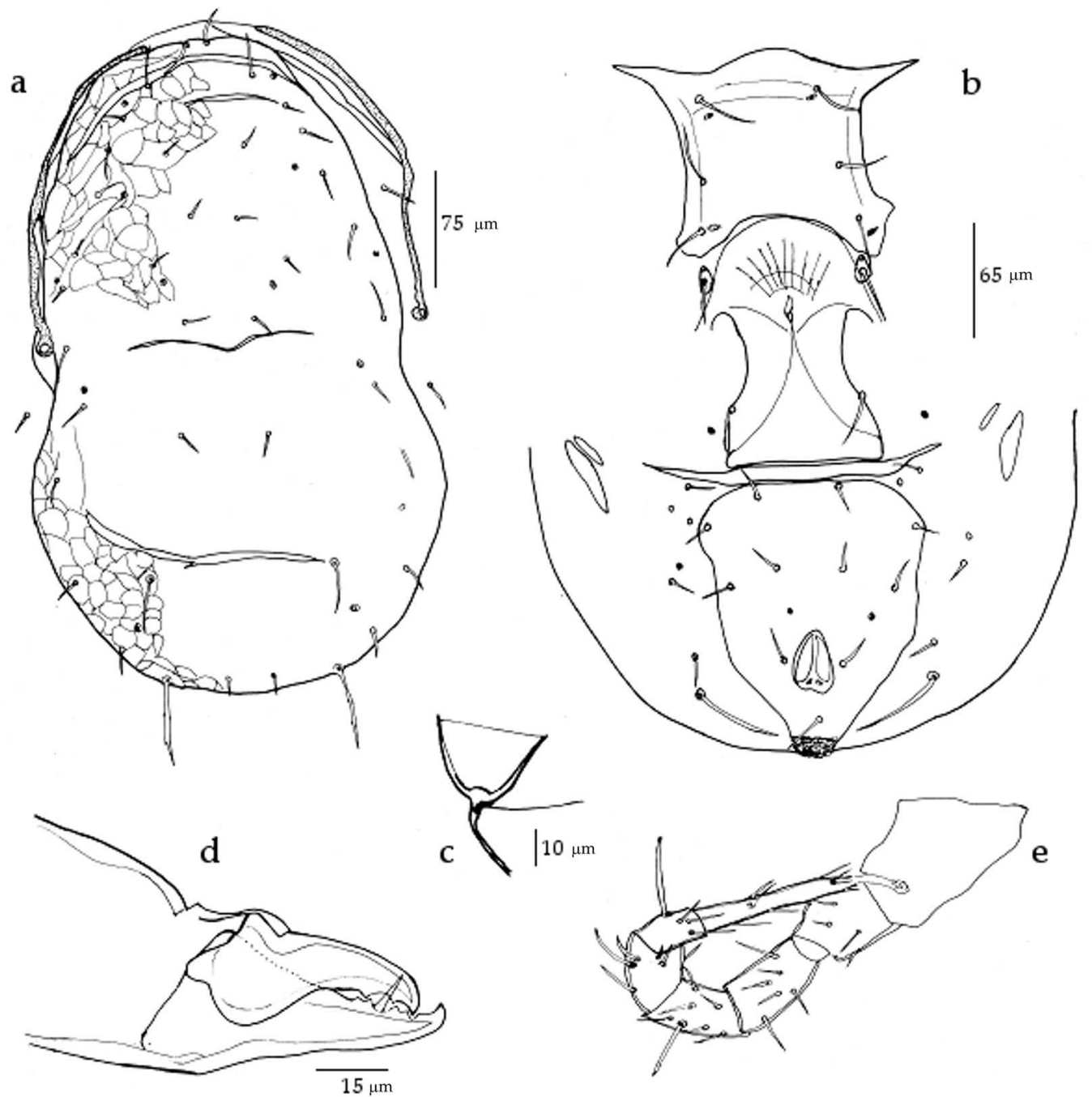

FIgURE 38: Neoseiulella spaini (Collyer). Female (holotype): a - dorsal shield; b - ventral shields; $\mathrm{c}$ - spermatheca; $\mathrm{d}$ - chelicera; $\mathrm{e}$ - leg IV.

Adult male

Described by Collyer (1982) and Denmark and Rather (1996). We were not able to borrow the male type specimen of this species.

Previous reports - N. spaini is only known from New Zealand (Collyer 1982; Schicha 1987). The female holotype, paratypes and other specimens of this species are reported on Olearia colensoi (Asteraceae) at Ruahine Range and Urewera National Park.

\section{Neoseiulella splendida Ferragut and Peña-Estevez \\ (Figure 39)}

Neoseiulella splendida Ferragut and Peña-Estevez 2003: 161-164; Moraes et al. 2004: 295; Moraza and Peña-Estevez 2006: 58; Chant and McMurtry 2007: 147.

Adult female (Figure 39a - e)

Dorsal shield (Figure 39a) - Dorsal shield heavily reticulated: length 361 (352 - 369); width 189 (181 - 196) (at level of s4) and 195 (193 - 197) (at level of Z1). Seven pairs of solenostomes on the dorsal shield: gd1, gd2, gd4, gd5, gd6, gd8, and gd9. Fer- 


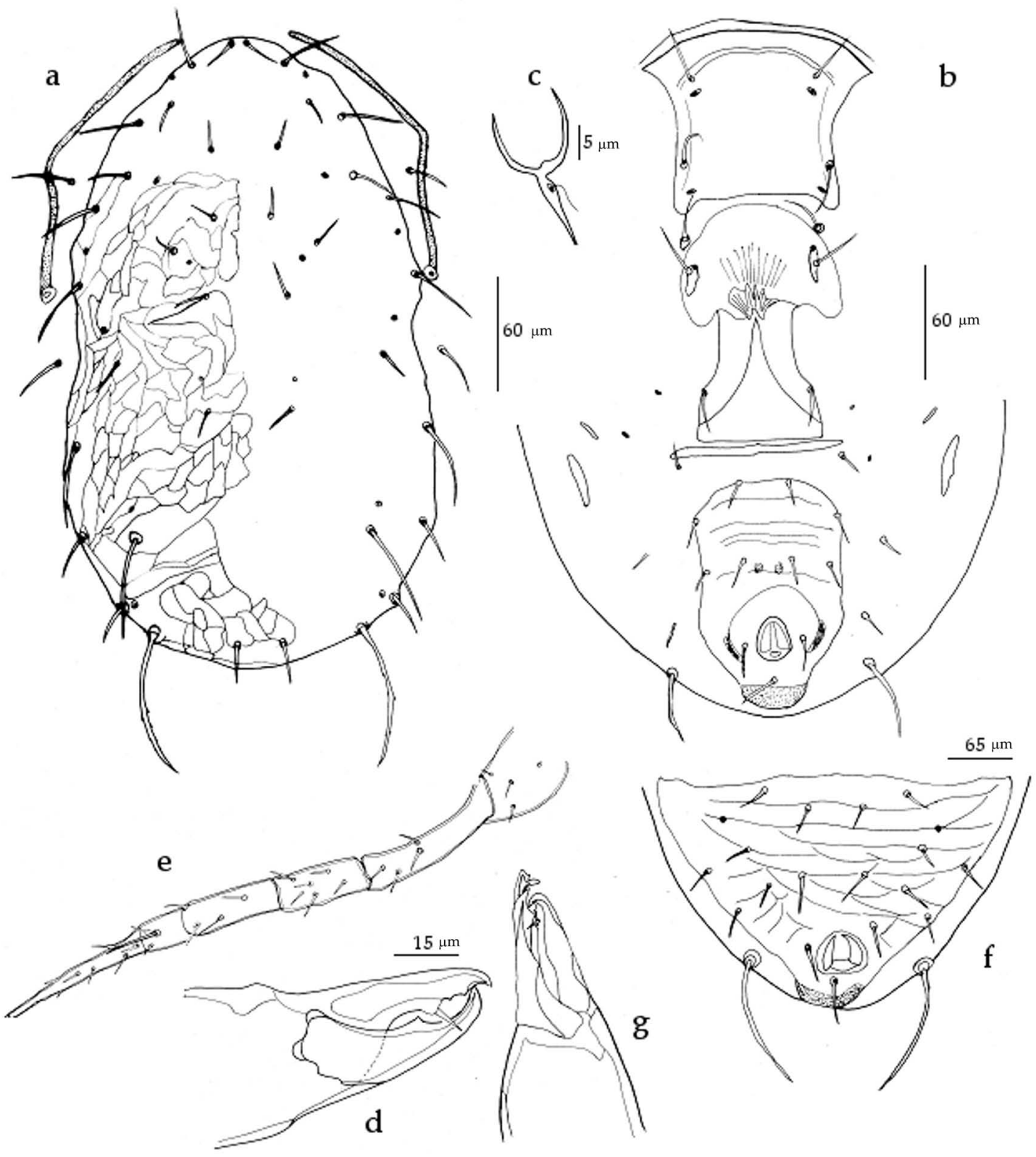

FIgURE 39: Neoseiulella splendida Ferragut and Peña-Estevez. Female (paratype): a - dorsal shield; b - ventral shields; c - spermatheca; $\mathrm{d}$ - chelicera; $\mathrm{e}$ - leg IV. Male (paratype): $\mathrm{f}$ - ventrianal shield; $\mathrm{g}$ - spermatodactyl.

ragut and Peña-Estevez (2003) noted the presence of only six pairs of solenostomes (gd1, gd2, gd5, gd6, gd8, and gd9). However, on their drawings a pair of solenostomes corresponding to the position of gd4 (according Athias-Henriot [1975] and Swirski et al. [1998]) is present. One pair of poroids. Sublateral setae (r3 and R1) on the lateral margin. Dorsal shield bearing 19 pairs of setae, all smooth ex- cept Z5 slightly serrated: j1 26 (23 - 28); j3 34 (32 35); j4 16; j5 16 (15 - 16); j6 18 (17 - 19); J2 19 (18 20); J5 17; z2 17 (16 - 17); z3 34 (33 - 35); z4 24; z5 16 (15 - 17); Z1 20 (19 - 20); Z4 62 (61 - 62); Z5 78; s4 34 (32 - 35); s6 40 (37 - 43); S2 41 (37 - 45); S4 27 (26 - 28); S5 26 (24 - 28); sub-lateral setae r3 30 (29-30) and R1 $27(25-29)$. Peritreme extending anteriorly to the level between $\mathrm{j} 1 \mathrm{-j} 3$. 
Ventral shields (Figure 39b) - Sternal shield 69 $(68-70)$ long and $69(68-70)$ wide (at level of ST2), smooth with two pairs of setae (ST1 and ST2) and two pairs of poroids. ST3 and ST4 on separate platelets and a pair of small poroids accompanying ST4. Genital shield 125 long, 68 wide (at level of ST5), smooth. Four elongate platelets or genital sigilla (folded in the specimen examined) between genital shield and ventrianal shields. One pair of poroids close to the genital shield (ST 5) and 1 pair of poroids around the genital shield. Ventrianal shield elongated with conspicuous waist, much longer than wide, 134 (124 - 143) long and $86(82-89)$ wide (at level of ZV2), faintly striate, with four pairs of preanal setae (JV1, JV2 JV3 and ZV2) and with a pair of circular solenostomes $g v 3$. Four pairs of caudoventral setae (ZV1, ZV3, JV4 and JV5) on the integument surrounding the ventrianal shield. JV5 $50(44-56)$ long, smooth. Primary metapodal plate or inguinal sigillum 31 (26$35)$ long and $6(5-7)$ wide.

Spermatheca (Figure 39c) - Cervix $4(3-4)$ long, U-shaped.

Chelicera (Figure 39d) - Two teeth and a pilus dentilis on the fixed digit. Movable digit 36 (34-38) long, unidentate.

Legs (Figure 39e) - Measurements of legs: leg I 332 (331 - 333); leg II 286 (279 - 292); leg III 284 (276 - 292); leg IV $392(383-401)$. Seven setae (2$2 / 0,2 / 0-1)$ on the genu II. One pointed macroseta, 47 (46-48) long, on the basitarsus IV.

Material examined - Four female paratypes deposited in the Department of Agroforestal Ecosystems, Universidad Politécnica de Valencia, Spain.

\section{Adult male (Figure 39f, g)}

Dorsal shield - dorsal shield similar to but smaller than the female. Sub-lateral seta R1 inserted on the dorsal shield (different from the female, on which R1 inserted on lateral margin). Ventrianal shield 140 long and 135 wide, distinctly reticulated, bearing seven pairs of preanal setae with a pair of poroids (Figure $39 \mathrm{f}$ ). Spermatodactyl Lshaped (Figure $39 \mathrm{~g}$ ). This description is based on a paratype specimen.
Previous reports $-N$. splendida is only known from Canary Islands. Plants on which this species was reported are: Argyranthemum lidii Humphries, A. escarrei (Svent.) Humphries, Cynara cardunculus, Nauplius stenophyllus (Link) Webb and Berth., Schizogyne glaberrima DC., Sonchus brachylobus Webb and Berthel (Asteraceae); Hypericum reflexum L.f. (Hypericaceae); Pennisetum setaceum (Forssk.) Chiov. (Poaceae); Suaeda vera J.F.Gmel., S. vermiculata Forssk. ex J.F.Gmel. (Chenopodiaceae).

Remarks - N. splendida is similar to N. litoralis. However these two species differ by the following characters: gd4 presence/ absence (present on $N$. splendida; absent on N. litoralis); j3, z3, Z4, Z5, s4, and s6 lengths; the length of the peritreme (extending between $\mathrm{j} 1-\mathrm{j} 3$ on $\mathrm{N}$. splendida; extending between z2-j3 on N. litoralis). Moreover, the males of these two species differ in the number of setae on the ventrianal shield (seven pairs on N. splendida, six on $N$. litoralis). These two species seem thus to be separate entities. However, further experiments would be useful in order to conclude on the reliability of these morphological characters in species identification.

\section{Neoseiulella steeli (Schicha and McMurtry) (Figure 40)}

Typhlodromus steeli Schicha and McMurtry 1986: 181-183; Schicha 1987: 133-134; Chant and YoshidaShaul 1989: 1029-1030. Neoseiulella (Typhloctona) steeli (Schicha and McMurtry) Denmark and Rather 1996: 74-75. Neoseiulella steeli (Schicha and McMurtry) Chant and McMurtry 1994: 248; Moraes et al. 2004: 295-296; Chant and McMurtry 2007: 147.

Adult female (Figure 40a-d)

Dorsal shield (Figure 40a) - Dorsal shield lightly reticulated along the lateral area: length 426; width 250 (at level of s4) and 246 (at level of Z1). Five pairs of solenostomes: $\mathrm{gd} 1, \mathrm{gd} 2, \mathrm{gd} 4, \mathrm{gd} 6$, and gd9. Three pairs of poroids. Sub-lateral setae (r3 and R1) on the lateral margin. Dorsal shield bearing 19 pairs of setae, all smooth, except for Z5 slightly serrated: j1 26; j3 36; j4 13; j5 11; j6 15; J2 16; J5 11; z2 13; z3 18; z4 18; z5 12; Z1 19; Z4 42; Z5 82; s4 21; s6 17; S2 17; S4 15; S5 16; sub-lateral setae r3 20 


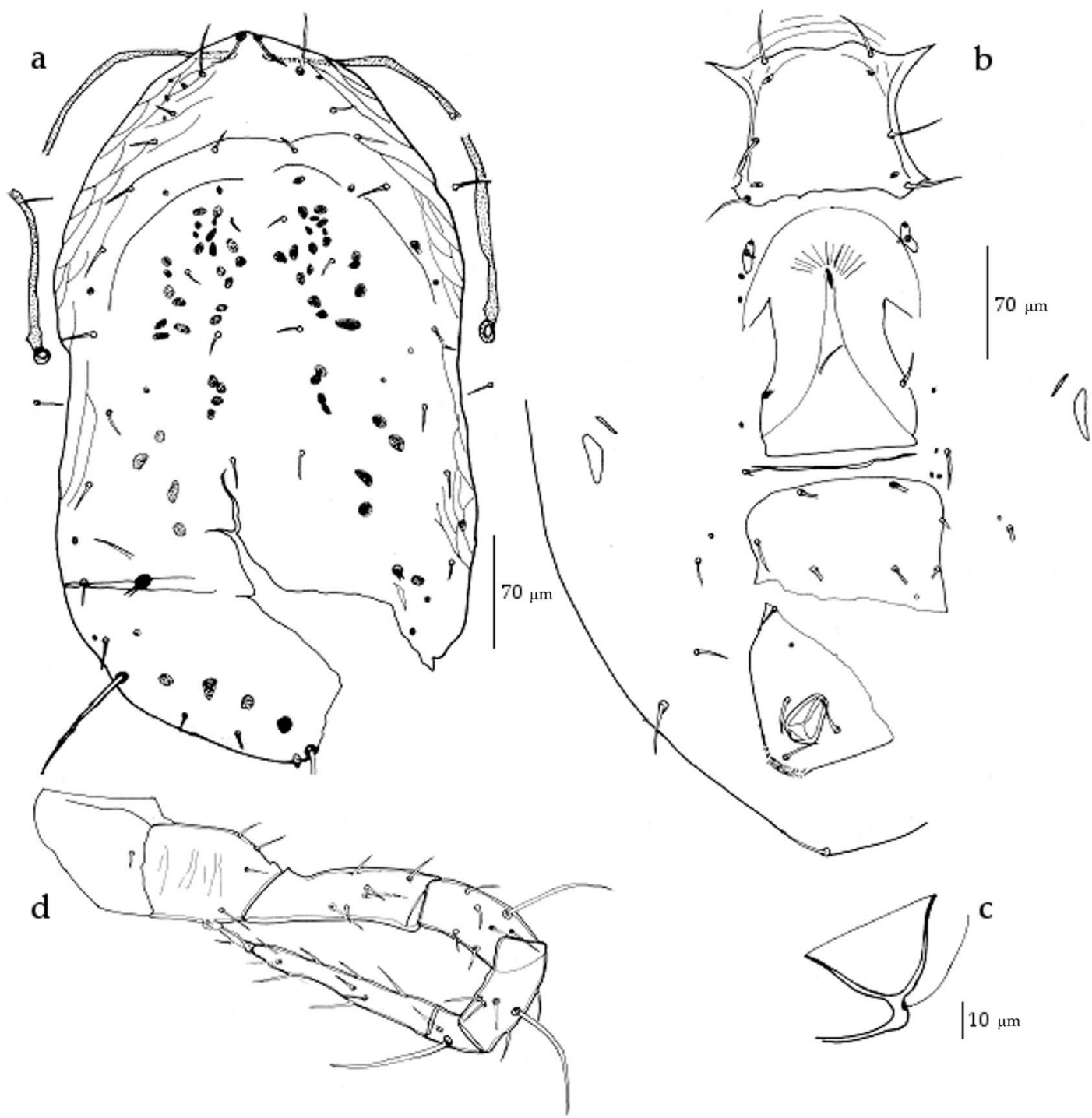

FIGURE 40: Neoseiulella steeli (Schicha and McMurtry). Female (holotype): a - dorsal shield; b - ventral shields; c - spermatheca; $\mathrm{d}$ - leg IV.

and R1 15. Presence of numerous small visible muscles marks (sigilles) on the dorsal shield. Peritreme extending anteriorly to the level of $j 1$.

Ventral shields (Figure 40b) - Sternal shield 82 long and 85 wide (at level of ST2), smooth, with three pairs of setae (ST1, ST2 and ST3) and two pairs of poroids. A pair of metasternal setae (ST4) on separate platelets accompanied by a pair of small poroids. Genital shield 139 long and 86 wide (at level of ST5), smooth. Four elongate platelets or genital sigilla separating genital and ventrianal shields folded under the genital shield. One pair of poroids close to the genital shield (ST 5) and 1 pair of poroids around the genital shield. Ventrianal shield subtriangular-shaped, 144 long and 113 wide (at level of ZV2), smooth, with four pairs of preanal setae (JV1, JV2, JV3 and ZV2) and a pair of small and circular solenostomes gv3 posteromediad to JV3. Four pairs of caudoventral setae (ZV1, ZV3, JV4 and JV5) on the integument surrounding the ventrianal shield. JV5 28 long, smooth. Primary metapodal plate or inguinal sigillum 30 long and 7 
wide.

Spermatheca (Figure 40c) - Cervix 9 long, cupshaped.

Chelicera - Dentition of the chelicera not discernible on the specimen examined. Schicha and McMurtry (1986) mentioned the presence of ten teeth and a pilus dentilis on the fixed digit of the chelicera, and of three teeth on the movable digit (32 long).

Legs (Figure 40d) - Measurements of legs: leg I 408; leg II 360; leg III 341; leg IV 444. Eight setae $(2-2 / 1,2 / 0-1)$ on the genu II. Two macrosetae, 31 and 30 long, on the genu and tibia III. Three other pointed macrosetae, 56, 64 and 55 long, are observed on the genu, tibia and basitarsus IV, respectively.

Material examined - The female holotype deposited in NSW Department of Primary Industries, Agricultural Scientific Collections Unit (Acarology), Orange Agricultural Institute, Australia.

\section{Adult male}

Described by Schicha and McMurtry (1986) and Denmark and Rather (1996). We were not able to borrow the male type specimen of this species.

Previous reports - N. steeli is only known from Stirling Range Parc National (Australia), on Eucalyptus sp. (Myrtaceae).

\section{Neoseiulella steveni (Schicha) (Figure 41)}

Typhlodromus steveni Schicha 1987: 135-136; Chant and Yoshida-Shaul 1989: 1026-1028. Neoseiulella (Typhloctona) steveni (Schicha) Denmark and Rather 1996: 64-66. Neoseiulella steveni (Schicha) Moraes et al. 2004: 296; Chant and McMurtry 2007: 147.

\section{Adult female (Figure 41a - e)}

Dorsal shield (Figure 41a) - Dorsal shield smooth, except for the lateral area of the podosoma lightly reticulated: length 359 (344-373); width 175 $(166-183)$ (at level of s4) and $190(183-197)$ (at level of Z1). Seven pairs of solenostomes: gd1, gd2, gd4, gd5, gd6, gd8, and gd9. No poroid visible. Sublateral setae ( $\mathrm{r} 3$ and $\mathrm{R} 1$ ) on the lateral margin. Dorsal shield bearing 19 pairs of setae, all smooth, except Z5 slightly serrated: j1 24 (34-24); j3 31 (31 -
32); j4 17 (15 - 18); j5 16 (15 - 17); j6 17 (16 - 18); J2 21 (20 - 22); J5 11 (10 - 12); z2 18 (16 - 19); z3 33 (30 35); z4 30 (29 - 30); z5 18 (17 - 18); Z1 20 (18 - 21); Z4 52 (50 - 53); Z5 74 (72 - 75); s4 38 (37 - 39); s6 43 (40 - 45); S2 46 (44 - 48); S4 25 (23 - 26); S5 25 (23 - 26); sub-lateral setae r3 $28(27-28)$ and R1 $20(19-21)$. Peritreme extending anteriorly to the level between j1-j3.

Ventral shields (Figure 41b) - Sternal shield 73 $(66-80)$ long and $77(75-79)$ wide (at level of ST2), smooth, with three pairs of setae (ST1, ST2 and ST3) and two pairs of poroids. A pair of metasternal setae (ST4) on separate platelets accompanied by a pair of small poroids. Genital shield 128 (124 - 131) long and $63(61$ - 65) wide (at level of ST5), smooth. Four elongate platelets or genital sigilla separating genital and ventrianal shields not discernible in the specimen examined. One pair of poroids close to the genital shield (ST 5) and 1 pair of poroids around the genital shield. Ventrianal shield 124 (121 - 126) long and 98 (94 - 101) wide (at level of ZV2), smooth to faintly striate, with four pairs of preanal setae (JV1, JV2, JV3 and ZV2) and without solenostome $g v 3$. Four pairs of caudoventral setae (ZV1, ZV3, JV4 and JV5) on the integument surrounding the ventrianal shield. JV5 49 (47 -51) long, smooth. Primary metapodal plate or inguinal sigillum $29(28-30)$ long and 5 wide. In a paratype specimen: secondary metapodal plate or inguinal sigillum 21 long and 3 wide.

Spermatheca (Figure 41c) - Cervix 4 long, Ushaped.

Chelicera (Figure 41d) - Six teeth and a pilus dentilis observed on the fixed digit. Movable digit $29(27$ - 31) long, bidentate.

Legs (Figure 41e) - Measurements of legs: leg I 369 (364 - 374); leg II 339 (328 - 350); leg III 298 (294 - 302); leg IV 434 (422 - 443). Eight setae (2-2/1, $2 / 0-1$ ) on the genu II. One pointed macroseta 48 (42 -54) long, on the basitarsus IV. 


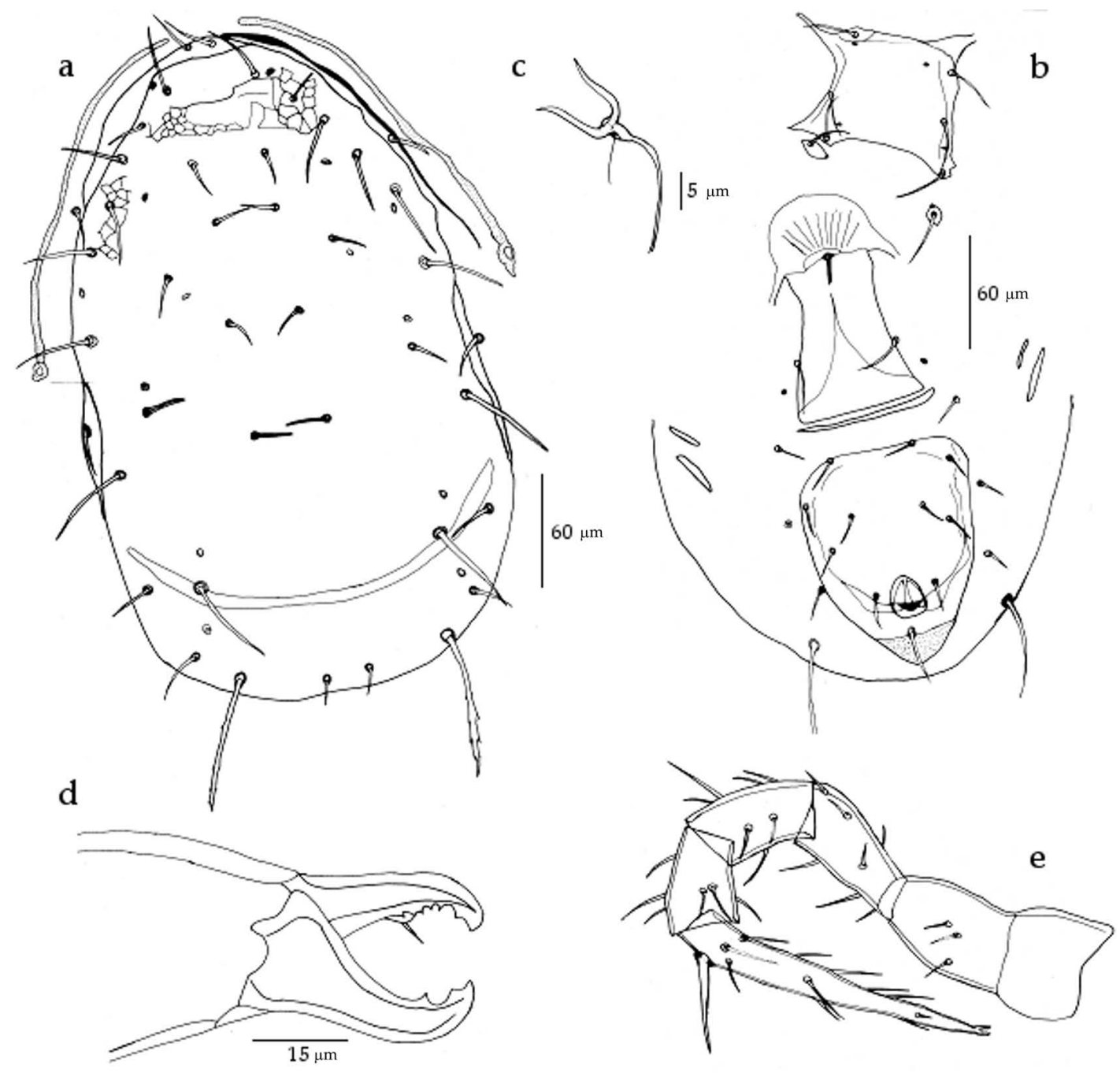

FIGURE 41: Neoseiulella steveni (Schicha). Female (holotype): a - dorsal shield; b - ventral shields; c - spermatheca; d - chelicera; e - leg IV.

Material examined - The female holotype and two female paratypes deposited in NSW Department of Primary Industries, Agricultural Scientific Collections Unit (Acarology), Orange Agricultural Institute, Australia.

\section{Adult male}

Described by Schicha (1987) and Denmark and Rather (1996). We were not able to borrow the male type specimens of this species.

Previous reports $-N$. steveni is only known from New South Wales (Australia), on Banksia sp. (Proteaceae).

\section{Key to adult females of the genus Neoseiulella Muma}

1. Ventrianal shield with three pairs of preanal setae (JV3 absent) ............................. 2 — Ventrianal shield with four pairs of preanal setae (JV3 present)...........................11

2(1). Caudoventral setae JV4 present ........... 3 - Caudoventral setae JV4 absent; dorsal shield with four pairs of solenostomes (gd2, gd4, gd5, gd6); spermatheca with U-shaped cervix; ventrianal shield with a pair of solenostomes; macrosetae 
on genu and tibia III, genu, tibia and basitarsus IV N. oleariae

3(2). Presence of solenostomes on the ventrianal shield (gv3), genu II with seven setae (2-2/0, 2/0-1)

— Absence of solenostomes on the ventrianal shield (gv3); genu II with eight setae (2-2/1, 2/0-1); legs without macrosetae; tuberculous ornaments with large glands cover the dorsal shield ........ coreen

4(3). Leg IV with three macrosetae, on genu, tibia and basitarsus ......................... 5

- Leg IV with two thick and short macrosetae, on genu and basitarsus, tibia IV without macroseta; all dorsal and sub-lateral setae inserted to tubercles; spermatheca with shallowly cup-shaped N. elaeocarpi

5(4). Dorsal shield with four pairs of solenostomes: gd2, gd4, gd6, gd9 (gd1, gd5, and gd8 absent); fixed digit without pilus dentilis . ...............6 - Dorsal shield with more than four pairs of solenostomes: $\operatorname{gd} 2, \operatorname{gd} 4, \operatorname{gd} 6$ and gd9 always present; gd1, gd5 and gd 8 present or absent ..... 7

6(5). Most dorsal setae inserted on tubercles; spermatheca with U-shaped cervix; fixed digit with nine teeth; leg III with one macroseta, on genu N. corrugata All dorsal setae not inserted on tubercles; spermatheca with shallowly cup-shaped cervix; fixed digit with twelve teeth; leg III with two macrosetae, on genu and tibia N. dachanti

7(5). Dorsal shield with six pairs of solenostomes . 8 — Dorsal shield with five pairs of solenostomes . . 9

8(7). gd1 present, gd5 absent, gd2, gd4, gd6, gd8, and gd9 present; Z4 and Z5 very long (120 $\mu \mathrm{m}$ and $230 \mu \mathrm{m}$ respectively), most of the other dorsal setae very short $(5-15 \mu \mathrm{m}$ long) ............... cottieri — gd1 absent, gd5 present, gd2, gd4, gd6,gd8, gd 9 present; Z4 and Z5 greatly shorter (about 60 and 90 $\mu \mathrm{m}$ respectively) .................. ashleyae
9(7). Leg III without macroseta . . . . . . . . . . . . . 10

- Leg III with macrosetae on genu and tibia N. manukae $=N$. glenfieldensis

10(9). Dorsal shield heavily reticulated; ventrianal shield with a large pair of solenostomes mediad to JV2 ................ nesbitti $=N$. armidalensis - Dorsal shield lightly reticulated; ventrianal shield with a small pair of solenotomes posterior to JV2 ....................... novaezealandiae

11(1). Absence of macroseta on the leg IV ..... 12 - Presence of at least one macroseta on the leg IV .......................................... 19

12(11). Seven setae on the genu II ........... 13

— Eight setae on the genu II .............. 18

13(12). One pair of solenostomes ( $\mathrm{gd} 8$ ) on the dor-

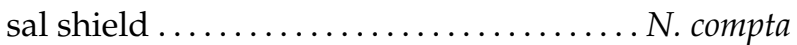
- More than one pair of solenostomes on the dorsal shield ................................. 14

14(13). Three pairs of solenostomes (gd2, gd6, gd9) on the dorsal shield ................. tuberculata - More than three pairs of solenostomes on the dorsal shield ........................... 15

15(14). Five solenostomes (gd1, gd2, gd6, gd8, gd9) on the dorsal shield .N. aceri $=N$. squamiger $=N$. aceris - Four solenostomes (gd2, gd5, gd6, gd9) on the dorsal shield ........................... 16

16(15). Peritreme reaching level of $\mathrm{j} 1 \ldots$.... runiacus - Peritreme reaching level between $\mathrm{j} 3$ and z2 . . 17

17(16). Dorsal setae arising from tubercles, three teeth on the fixed digit of the chelicerae. N. sexapori - Dorsal setae not arising from tubercles, seven teeth on the fixed digit of the chelicerae .N. arutunjani 
18(12). Dorsal shield setae long (i.e. $Z 4=73$; $\mathrm{Z} 5=67 ; \mathrm{S} 4=75$ ), peritreme reaching level of $\mathrm{j} 1$

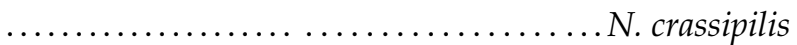
- Dorsal shield setae shorter (i.e. $Z 4=38 ; Z 5$ $=44 ; S 4=35)$, peritreme reaching level of $\mathrm{z} 4$ .N. tiliarum $=N$. formosa

19(11). One macroseta on the leg IV (on the basitar-

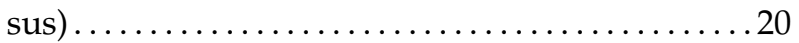

— Three macrosetae on the leg IV ...........29

20(19). Presence of solenostomes ( $g v 3)$ on the ventrianal shield ..........................21 - Absence of solenostomes ( $g v 3)$ on the ventrianal shield ............................23

21(20). One pair of solenostome on the dorsal shield (gd9), peritreme reaching level of $\mathrm{j} 1 \ldots \ldots .$. . . celtis - More than one pair of solenostomes on the dorsal shield, peritreme reaching level of $j 3 \ldots \ldots 22$

22(21). Six pairs of solenostomes on the dorsal shield (gd1, gd2, gd4, gd6, gd8, gd9), spermatheca with U-shaped cervix, setae on the dorsal shield longer (i.e. $\mathrm{R} 1=41, \mathrm{~S} 5=40, \mathrm{~s} 6=43, \mathrm{~s} 4=38, \mathrm{~J} 2=36$, $\mathrm{j} 6=31) \ldots \ldots \ldots \ldots \ldots \ldots \ldots \ldots \ldots \ldots \ldots \ldots \ldots \ldots$. montfort $i$ - Seven pairs of solenostomes on the dorsal shield (gd1, gd2, gd4, gd5, gd6, gd8, gd9), spermatheca with cup-shaped cervix, setae on the dorsal shield shorter (i.e. $\mathrm{R} 1=25, \mathrm{~S} 5=28, \mathrm{~s} 6=26, \mathrm{~s} 4=23, \mathrm{~J} 2=15$, $\mathrm{j} 6=16) \ldots \ldots \ldots \ldots \ldots \ldots \ldots \ldots \ldots \ldots \ldots \ldots$ neoviniferae

23(20). Six setae on the genu II ........... N. carmeli — More than six setae on the genu II ......... 24

24(23). Eight setae on the genu II . . . . . . . . . . 25 — Seven setae on the genu II ...............26

25(24). No tooth on the mobile digit of the chelicerae, one tooth on the fixed digit, six pairs of solenostomes on the dorsal shield (gd1, gd2, gd5, gd6, gd8, gd9), some setae shorter $(Z 4=34, Z 5=52$, $\mathrm{s} 6=26, \mathrm{~s} 2=29) \ldots \ldots \ldots \ldots \ldots \ldots \ldots \ldots \ldots \ldots$. perforata - Two teeth on the mobile digit of the chelicerae, six teeth on the fixed digit, seven pairs of solenos- tomes on the dorsal shield (gd1, gd2, gd4, gd5, gd6, $\operatorname{gd} 8, \mathrm{gd} 9)$, some setae longer $(Z 4=52, Z 5=74, \mathrm{~s} 6=$

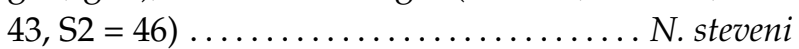

26(24). Four pairs of solenostomes on the dorsal shield (gd2, gd6, gd8, gd9), spermatheca with cupshaped cervix, one tooth on the fixed digit of the chelicerae ..................... elongata - More than four pairs of solenostomes on the dorsal shield, spermatheca with U-shaped cervix, two teeth on the fixed digit of the chelicerae . . . . . 27

27(26). Six pairs of solenostomes on the dorsal shield (gd1, gd2, gd5, gd6, gd8, gd9)..... litoralis - Seven pairs of solenostomes on the dorsal shield (gd1, gd2, gd4, gd5, gd6, gd8, gd9).....N. splendida

28(19). Absence of solenostomes ( $g v 3$ ) on the ventrianal shield ........................ cassiniae — Presence of solenostomes (gv3) on the ventrianal shield ............................29

29(28). Presence of at least one macroseta on the leg III .............................. 30

— Absence of macroseta on the leg III .........32

30(29). One macroseta on the leg III (on the genu), spermatheca with U-shaped cervix, seven pairs of solenostomes on the dorsal shield ( $g d 1, \operatorname{gd} 2, \operatorname{gd} 4$, gd5, gd6, gd8, gd9)................. ferraguti - More than one macroseta on the leg III, spermatheca with cup-shaped cervix, five pairs of solenostomes on the dorsal shield ............ 31

31(30). Three macrosetae on the leg III (genu, tibia, basitarsus), eight teeth on the fixed digit of the chelicerae, one tooth on the mobile digit, some setae longer (i.e. $\mathrm{z} 4=29, \mathrm{z} 3=32, \mathrm{j} 3=52$ ) $\ldots .$. . myopori - Two macrosetae on the leg III (genu, tibia), ten teeth on the fixed digit of the chelicerae, 3 teeth on the mobile digit, some setae shorter (i.e. $z 4=18, z 3$ $=18, \mathrm{j} 3=36) \ldots \ldots \ldots \ldots \ldots \ldots \ldots \ldots \ldots$. steeli

32(29). Eight setae on the genu II . . . . . . . . . . 33

— Seven setae on the genu II ................ 34 
33(32). Dorsal seta lengths shorter (i.e. $Z 4=31, Z 5$ $=48, \mathrm{~s} 4=23, \mathrm{~s} 6=26, \mathrm{~S} 2=20, \mathrm{~S} 4=17, \mathrm{~S} 5=17$ ), six pairs of solenostomes on the dorsal shield (gd1, gd2, gd4, gd5, gd6, gd9), spermatheca with cupshaped cervix.................... spaini - Dorsal seta lengths longer (i.e. $Z 4=88, Z 5=117$, $s 4=67, \mathrm{~s} 6=71, \mathrm{~S} 2=62, \mathrm{~S} 4=63, \mathrm{~S} 5=45)$, seven pairs of solenostomes on the dorsal shield ( $\mathrm{gd} 1, \mathrm{gd} 2, \mathrm{gd} 4$, gd5, gd6, gd8, gd9), spermatheca with U-shaped

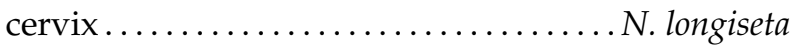

34(32). Three pairs of solenostomes on the dorsal shield ................................. 35 - Seven pairs of solenostomes on the dorsal shield

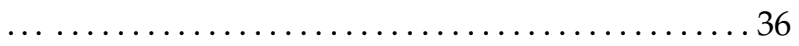

35(34). Presence of solenostomes gd2, gd8, gd9, spermatheca with cup-shaped cervix, some dorsal setae shorter (i.e. $\mathrm{Z} 1=22, \mathrm{Z} 4=31, \mathrm{~S} 2=31, \mathrm{~S} 4=$ $30, \mathrm{~S} 5=23, \mathrm{~J} 2=24)$

$\ldots \ldots \ldots \ldots \ldots$. vollsela $=N$. transitans $=N$. prunus - Presence of solenostomes gd5, gd8, gd9, spermatheca with U-shaped cervix, some dorsal setae longer (i.e. $\mathrm{Z} 1=43, \mathrm{Z} 4=60, \mathrm{~S} 2=62, \mathrm{~S} 4=55$, S5 =

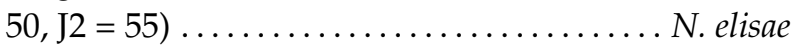

36(34). Two teeth on the mobile digit of the chelicerae, six teeth on the fixed digit, some different dorsal seta lengths (J5 = 32, S4 = 41, S5 = 30) N. canariensis - One tooth on the mobile digit of the chelicerae, two teeth on the fixed digit, some different dorsal seta lengths $(\mathrm{J} 5=12, \mathrm{~S} 4=61, \mathrm{~S} 5=47) \ldots . . N$. arinoi

\section{CONCLUSION}

The present paper provides a homogenous taxonomic revision of nearly the totality of the species belonging to the genus Neoseiulella with an identification key of the adult females of valid species. This revision allows to redefine this genus, excluding three species, including an additional species $T$. (A.) elisae and discussing six synonymies. Further experiments, especially cross-breedings and molecular analyses are required to determine the relia- bility of some morphological characters considered to be important by some authors to discriminate between species (ex. ornamentation of dorsal and ventral shields; presence of certain dorsal and ventral solenostomes; length of the peritreme; chelicera dentition; the position and size of preanal solenostomes). This paper also provides complete biogeographic data sets (distribution and host plants) of all the species of the genus Neoseiulella. Eighteen species are reported from the West-Palearctic area; two of them ( $N$. aceri and N. tiliarum) being also present in the Nearctic area; 15 species are reported from the Australasian area; one of them (N. nesbitti) being also present in the Oriental area. Three other species are reported from this latter area. These data associated to the ecological distribution (plant supports) could constitute the starting point for further analyses, especially biogeographic and phylogenetic analyses. The disjoint distribution of the species of the genus Neoseiulella questions actually the monophyly of this genus.

\section{ACKNOWLEDGEMENTS}

We wish to thank the following acarologists, entomologists, institutions and museums for their great help to obtain the type materials: Dr. Anne Baker (British Museum of Natural History, UK); Dr. Frédéric Beaulieu (Agriculture and Agri-Food Canada, Ontario, Canada); Dr A. Y. M. El-Laithy (Plant Protection Department, National Research Center, Dokki, Giza, Egypt); Dr. Francisco Ferragut (Instituto Agroforestal Mediterráneo, Universidad Politécnica de Valencia, Spain); Dr. David Hirst (the South Australian Museum, Adelaide, Australia); Dr. Mark Judson (the Laboratoire de Zoologie, Muséum National d'Histoire Naturelle, Paris, France); Dr. K. Karmakar (BCKV, Kalyani, West Bengal, India); Dr. S. K. Sanyal (the Zoological Survey of India, Kolkata, India); Dr Leonid A. Kolodochka (Institute of Zoology, Academy of Sciences, Kiev, Ukraine); Dr. Maria L. Moraza (Department of Zoology and Ecology, Faculty of Science, University of Navarra, Spain); Dr. Eric Palevsky (Deptartment of Entomology, Newe-Ya'ar Research Center, Israel); Dr Calvin W. Welbourn (Florida Department of Agriculture and Consumer 
Services, USA); Dr. Zhi-Qiang Zhang (Landcare Research, Auckland, New Zealand); the British Museum of Natural History (UK); the Canadian National Collection, Department of Zoology, University of Toronto (Canada); the Department of Entomology, University of Queensland (Australia); the Institute of Zoology, Academy of Sciences, Kiev (Ukraine); Laboratoire de Zoologie, Muséum National d'Histoire Naturelle, Paris, France; the Museum für Naturkunde, Arthropod collection, Berlin (Germany); the Museum of Zoology of University of Navarra (Spain); the New Zealand Arthropod Collection, Landcare Research, Auckland (New Zealand); the Rijksmuseum van Natuurlijke Histoire (The Netherlands). Special thanks to Dr Danuta K. Knihinicki (NSW Department of Primary Industries, Orange Agricultural Institute, Australia). We are also very grateful to the two anonymous reviewers for their valuable comments and suggestions which have improved the manuscript a lot.

\section{REFERENCES}

Abbasova E.D. 1966 - Study on predators of tetranychid mites of Bol'shom Caucasia (Phytoseiidae) - Materialy Sessii Zakavkazskogo Soveta po Koordinatsii Nauchno-Issledovatelískikh Rabot po Zashchite Rasteniy, Baku, Azerbaijan, 184-187.

Abbasova E.D. 1972 — Phytoseiid mites (Parasitiformes: Phytoseiidae) of Azerbaijan - Avtoreferat Dissertatsii na Soiskanie Uchenoy Stepeni Kandidata Biologicheskikh Nauk. Akadrmiya Nauk Azerbaydzhanskoy SSR, Institut Zoologii, Baku, 1-34.

Akimov I.A., Kolodochka L.H. 1970 - Phytoseiid mites (Gamasoidea, Phytoseiidae) of the Central SteppeForest UkrSSR which inhabit in colonies of Spider mites - Thesis of the II-nd Acarological council (Kiev, 1970), Ukraine. Naukova Dumka, Part I. 15-16.

Akimov I.A., Kolodochka L.A., Zhovnerchuk O.V., Omeri I.D., Samojlova T.P. 2007 - Species composition and ecological peculiarities of mites of the superfamily Tetranychoidea (Acariformes, Trombidiformes) and family Phytoseiidae (Parasitiformes, Gamasina), inhabiting plants in botanical gardens of Kyiv (Ukraine) — Vestn. Zool., 41: 521-534.

André H.M. 1986 - Notes on the ecology of corticolous epiphyte dwellers. 4. Actinedida (especially Tydeidae) and Gamasida (especially Phytoseiidae) - Acarologia, 27: 107-115.
Arutunjan E.S. 1970 - Phytoseiid mites (Phytoseiidae) on agricultural crops in the Armenian SSR - Akademii Nauk Armyanskoi SSR, Otdelenie Biologicheskikh Nauk, Dissertatsii na Soiskanie Uchenoi Stepeni Candidata Biologrcheskikh Nauk, Zooliya, Armenia, 97: 1-31.

Arutunjan E.S. 1971 - Confinement of phytoseiid mites to biotopes and their morphological adaptations Biolgicheskii Zhurnal Armenii, Akadrmiya Nauk Armyanskoi SSR, 24: 41-47.

Arutunjan E.S. 1977 - Identification manual of phytoseiid mites of agricultural crops of the Armenian SSR - Akademiya Nauk Armyanskoi SSR, Zoologicheskii Institut, Erevan, 1-177

Athias-Henriot C. 1958 - Phytoseiidae et Aceosejidae (Acarina: Gamasina) d'Algérie. II. Phytoseiidae. Clé des genres Amblyseius Berlese (Suite) et Seiulus Berlese — Bull. Soc. Hist. Natur. Afr. N., 49: 23-43.

Athias-Henriot C. 1960 - Phytoseiidae et Aceosejidae (Acarina: Gamasina) d'Algérie. IV. Genre Typhlodromus Scheuten, 1857 - Bull. Soc. Hist. Natur. Afr. N., 51: 62-107.

Athias-Henriot C. 1977 - Nouvelles notes sur les Amblyseiini. III. Sur le genre Cydnodromus : Redéfinition, composition (Parasitiformes, Phytoseiidae) - Entomophaga, 22: 61-73. doi:10.1007/BF02372991

Athias-Henriot C. 1975 - Nouvelles notes sur les Amblyseiini. II. Le relevé organotaxique de la face dorsale adulte (Gamasides protoadéniques, Phytoseiidae) Acarologia, 17(1): 20-29.

Athias-Henriot C., Fauvel. G. 1981 - Pegodromus crassipilis, n. g., n. sp., Typhlodromini nouveau du sud de la France (Parasitiformes: Phytoseiidae) - Intern. J. Acarol., 7: 71-74. doi:10.1080/01647958108683246

Balder H., Jäckel B., Pradel B. 1999 - Investigations on the existence of beneficial organisms on urban trees in Berlin - In Proc. Internatonal Symposium on Urban Tree Health., 496: 189-194.

Beglyarov G.A. 1962 - On the fauna of predaceous mites of the family Phytoseiidae in Krasnodar region - In: Zimina, L.S. and Shchepetilínikovoiy, V.A. (Eds.), Biologicheskiy Metod Bor'by s Vreditelyami i Boleznyami Cel'skokhozyaystvennykh kul'tur, 1: 198-203.

Beglyarov G.A. 1981 — Keys to the determination of phytoseiid mites of the USSR [in Russian] - Information Bulletin International Organization for Biological Control of Noxious Animals and Plants, East Palaearctic Section, Leningrad. 2: 1-97.

Beglyarov G.A., Malov N.A. 1977 — Predaceous phytoseiid mites (Phytoseiidae: Parasitiformes) of the fauna of Moldavia and north Bukovina (Report II) - Entomofagi v Zashchite Rasteniy. Vsesoyuznaya Ordena Lenina Akademiya Selískokhozyaystvennyukh Nauk Imeni V. I. Lenina. Kishinev, 3-11. 
Boczek J. 1964 - Studies on mites (Acarina) living on plants in Poland. IV - Bull. Acad. Pol. Sc., Série Sciences Biologiques, 12: 365-369 + 4 plates.

Bohm H. 1960 - Untersuchungen uber Spinnmilbenfeinde in Osterreich - Pflanzens; Ber., 25: 23-46.

Bozai J. 1980 - Data to the Phytoseiidae fauna of Hungary (Acari) - Fol. Entomol. Hungar., 41(33): 193194.

Bozai J. 1996 - Data to the knowledge of predaceous mites of Hungary (Acari: Phytoseiidae, Phytoseiinae) — Növényvédelem., 32: 521-525.

Bozai J. 1997 - Data to the fauna of predaceous mites of Hungary with the description of four new species (Acari: Phytoseiidae) - Fol. Entomol. Hungar., 58: 35-43.

Bream A.S., Bozai J. 1995 — Data to the knowledge about mite population on linden trees - Növényvédelem., 31(12): 585-588.

Chant D.A. 1955 - Notes on mites of the genus Typhlodromus Scheuten, 1857 (Acarina: Laelaptidae), with descriptions of the males of some species and the female of a new species - Can. Entomol.., 87(11): 496-503. doi:10.4039/Ent87496-11

Chant D.A. 1956 - Some mites of the subfamily Phytoseiinae (Acarina: Laelaptidae) from southeastern England, with descriptions of new species - Can. Entomol., 88: 26-37. doi:10.4039/Ent8826-1

Chant D.A. 1958 - Immature and adult stages of some British Phytoseiidae Berl., 1916 (Acarina) - J. Linn. Soc. London, Zool., 43: 599-643.

Chant D.A. 1959 - Phytoseiid mites (Acarina: Phytoseiidae). Part I. Bionomics of seven species in southeastern England. Part II. A taxonomic review of the family Phytoseiidae, with descriptions of thirty-eight new species - Can. Entomol., Supplement 12, 166 pp.

Chant D.A., McMurtry. J.A. 1994 - A review of the subfamilies Phytoseiinae and Typhlodrominae (Acari: Phytoseiidae) - Intern. J. Acarol., 20(4): 223-310. doi:10.1080/01647959408684022

Chant D.A.., McMurtry J.A. 2007 - Illustrated keys and diagnoses for the genera and subgenera of the Phytoseiidae of the world (Acari: Mesostigmata) - Michigan, Indira Publishing House, 220 pp.

Chant D.A., Yoshida-Shaul E. 1983 - A world review of the simplex species group in the genus Typhlodromus Scheuten (Acarina: Phytoseiidae) - Can. J. Zool., 61:1142-1151. doi:10.1139/z83-151

Chant D.A., Yoshida-Shaul. E. 1987 - A world review of the pyri species group in the genus Typhlodromus Scheuten (Acari: Phytoseiidae) - Can. J. Zool., 5(7): 1770-1804. doi:10.1139/z87-272
Chant D.A., Yoshida-Shaul. E. 1989 - A world review of the tiliarum species group in the genus Typhlodromus Scheuten (Acari: Phytoseiidae) - Can. J. Zool., 67(4): 1006-1046. doi:10.1139/z89-144

Chant D.A., Hansell R.I.C., Yoshida-Shaul E. 1974 - The genus Typhlodromus Scheuten (Acarina: Phytoseiidae) in Canada and Alaska - Can. J. Zool., 52: 1265-1291. doi:10.1139/z74-168

Chaudhri W.M., Akbar S., Rasool A. 1974 - Taxonomic studies of the mites belonging to the families Tenuipalpidae, Tetranychidae, Tuckerellidae, Caligonellidae, Stigmaeidae and Phytoseiidae - University of Agriculture Technical Bulletin, Lyallpur, Pakistan. 1: 204-233.

Cobanoglu S. 1991 - The distribution of phytoseiid species (Acari: Phytoseiidae) in important apple growing areas of Turkey - In: Dusbabek, F. and Bukva, V. (Eds.), Modern Acarology. Academia, Prague and SPB Academic Publishing bv, The Hague. 1: $565-570$

Cobanoglu S. 1992 (1991-1992) - An annotated list of mites on hazel of Turkey - Isr. J. Entomol.., 25-26: 35-40.

Cobanoglu S. 1996 - Typhloctonus Muma, 1961 (Acarina: Phytoseiidae) species, from the Thrace region of Turkey - Turk. J. Agric. Forest., 20: 353-357.

Coiutti C. 1993 - Phytoseiid mites on spontaneous and cultivated trees in the Friuli-Venezia Giulia region Frust. Entomol., 16(29): 65-77.

Collyer E. 1956 - Notes on the biology of some predacious mites on fruit trees in south-eastern England - Bull. Entomol. Res., 47(2): 205-214. doi:10.1017/S0007485300046654

Collyer E. 1957 - Two new species of the genus Typhlodromus Scheuten, 1857 (Acarina: Phytoseiidae) - Annu. Magaz. Natur. Hist., 12: 199-203. doi:10.1080/00222935708655947

Collyer E. 1964 - The occurrence of some mites of the family Phytoseiidae in New Zealand, and descriptions of seven new species - Acarologia, 6: 632-646.

Collyer E. 1982 - The Phytoseiidae of New Zealand (Acarina) 1. The genera Typhlodromus and Amblyseius keys and new species - New Zealand J. Zool., 9: 185206. doi:10.1080/03014223.1982.10423848

Congdon B.D. 2002 - The family Phytoseiidae (Acari) in western Washington State with descriptions of three new species - Intern. J. Acarol., 28(1): 3-27. doi:10.1080/01647950208684275

Dabrowski Z.T. 1968 - Studies on the toxicity of pesticides commonly used in the orchards in Poland on predatory mites (Phytoseiidae) - Roczniki Nauk Rolniczych., 93(A), 655-670. 
Dabrowski Z.T. 1970 — Density of spider mites (Tetranychidae) and predatory mites (Phytoseiidae) in apple orchards treated and not treated with pesticides Ekol. Polska, 18: 111-136.

Daneshvar H. 1987 - Some predatory mites from Iran, with descriptions of one new genus and six new species (Acari: Phytoseiidae, Ascidae) - Entomol. Phytopathol. Appl., 54 (1-2), 13-37.

Dellei A., Szendrey L. 1991 - The mite infestation of different grapevine varieties in the vineyards of Heves County - Novenyvedelem, 27(2): 55-61.

Denmark H.A., Rather A.Q. 1984 - Revision of the genus Typhloctonus Muma, 1961 (Acarina: Mesostigmata) - Intern. J. Acarol., 10: 163-177. doi:10.1080/01647958408683371

Denmark H.A., Rather A.Q. 1996 - Revision of the genus Neoseiulella Muma (Acari: Phytoseiidae) - Intern. J. Acarol., 22(1): 43-77. doi:10.1080/01647959608684080

Denmark H.A., Welbourn W.C. 2002 - Revision of the genera Amblydromella Muma and Anthoseius De Leon (Acari: Phytoseiidae) - Intern. J. Acarol., 28(4): 291316. doi:10.1080/01647950208684308

Dosse G. 1956a - Ueber die Bedeutung der Raubmilben innerhalb der Spinnmilbenbiozone auf Apfel. I. Grundsatzliches aus der Biologie rauberischer Milben — Mitt. Biol. Bund. Land- Forstwirschaft, 85: 40-44.

Dosse G. 1956b — Uber die Entwicklung einiger Raubmilben bei verschiedenen Nahrungstieren (Acarina: Phytoseiidae) — Pflanzens. Ber., 16(7/9): 122-136.

Dosse G. 1957 - Uber die phytophagen und rauberischen Milben im sudwestdeutschen Raum - Taguns. Deutsche Akad. Landwirt., 17: 9-29.

Duso C., Torresan L., Vettorazzo E. 1993 - La vegetazione spontanea come riserva di ausiliari: considerazioni sulla diffusione degli Acari fitoseidi (Acari Phytoseiidae) in un vigneto e sulle piante spontanee contigue - Boll. Zool. Agr. Bachic., Serie II, 25(2): 183203.

Duso C., Fontana P., Malagnini V. 2004 - Diversity and abundance of phytoseiid mites (Acari: Phytoseiidae) in vineyards and in the surrounding vegetation in northeastern Italy - Acarologia, 41: 31-47.

Düzgüneş Z., Kiliç S. 1983 - Determination of Phytoseiidae species in important apple growing areas of Turkey and studies on the effectiveness of the most important of them on Tetranychus viennensis Zacher Turk. J. Agric. Forest., 7: 193-205.

Ehara S. 1966 - A tentative catalogue of predatory mites of Phytoseiidae known from Asia, with descriptions of five new species from Japan — Mushi, 39: 9-30.

Ferragut F., Peña-Estevez M.A. 2003 - Phytoseiid mites of the Canary Islands (Acari: Phytoseiidae): 1. Gran
Canaria Island - Intern. J. Acarol., 29(2): 149-170. doi:10.1080/01647950308683654

Ferragut F., Peña-Estevez M.A. 2007 — Phytoseiid mites of the Canary Islands (Acari: Phytoseiidae). II. Tenerife and La Gomera islands - Graellsia, 63(2): 349-358.

Ferragut F., Gallardo A., Ocete R., Lopez M.A. 2008 - Natural predatory enemies of the erineum strain of Colomerus vitis (Pagenstecher) (Acari, Eriophyidae) found on wild grapevine populations from southern Spain (Andalusia) — Vitis, 47 (1): 51-54.

Genini M., Klay A., Delucchi V., Baillod M., Baumgartner J. 1983 - Les espèces de phytoseiides (Acarina: Phytoseiidae) dans les vergers de pommier en Suisse Mitt. Schweizer. Entomol. Gesellschaft., 56: 45-56.

Gunthart E. 1957 - Neues uber Auftreten und Bekampfung der Spinnmilben an Reben — Schweizer. Z. ObstWeinbau, 66: 231-236.

Gunthart E. 1960 - Uber das Auftreten von Spinnmilben (Tetranychidae) und Raubmilben (Phytoseiinae, Acari) in der Schweiz - Proceed. IV Internat. Cong. Crop Protection, Hamburg, 1957, 927-928.

Gupta S.K. 1981 — Phytoseiidae (Acari: Mesostigmata) from Jammu and Kashmir, India, with descriptions of five new species — Ind. J. Acarol., 5: 37-49.

Gupta S.K. 1985 - Plant mites of India - Zooogical Survey of India Handbook Series, Calcutta. 5: 1-520.

Hansen E.W., Johnsen S. 1986 - Predatory mites of the family Phytoseiidae in Denmark (Acarina, Gamasina) — Entomol. Meddelelser., 53(3): 137-142.

Herbert H.J. 1952 - Progress report on predacious mite investigations in Nova Scotia (Acarina, Phytoseiidae) - Ann. Rep. Entomol. Soc. Ontario, 83, 27-29.

Hirschmann W. 1962 - Gangystematik der Parasitiformes - Acarologie Schriftenreihe fur Vergleichende Milbenkunde, Hirschmann-Verlag, Furth/Bay. 5(5-6): $80 \mathrm{pp}+32$ plates.

Jaworski S. 2000 - Occurrence of phytoseiid mites (Acari: Phytoseiidae) on blackcurrant plantations and in surrounding vegetation in Southern Poland IOBC/WPRS Bull., 23(11): 57-62.

Kabicek J. 2003 - Broad leaf trees as reservoirs for phytoseiid mites (Acari: Phytoseiidae) — Plant Protec. Sci., 39: 65-69.

Kabicek J. 2005 - Intraleaf distribution of the phytoseiid mites (Acari, Phytoseiidae) on several species of wild broad leaf trees - Biologia, 60: 523-528.

Kabicek J. 2008 - Cohabitation and intraleaf distribution of phytoseiid mites (Acari, Phytoseiidae) on leaves of Corylus avellana — Plant Prot. Sci., 44(1): 32-36.

Kabicek J. 2010 - Scarceness of Phytoseiid Species cooccurrence (Acari: Phytoseiidae) on Leaflets of Juglans regia - Plant Protec. Sci., 46(2): 79-82. 
Kabicek J., Rehakova M. 2004 - Phytoseiid mite community on Aesculus hippocastanum in the parks - Acta Fytotech. Zootech., 7: 114-115.

Kanouh M., Tixier M.-S., Guichou S., Cheval B., Kreiter S. 2010 - Two synonymies within the genus Neoseiulella (Acari: Phytoseiidae): is the molecular evidence so evident? - Biol. J. Linn. Soc., 101: 323-344. doi:10.1111/j.1095-8312.2010.01516.x

Karg W. 1970 - Uber die Moglichkeiten von integrierten Pflanzenschutzmaßnahmen bei der Spinnmilbenbekämpfung im Obstbau - Nachrich. Deut. Pflanzen., 24(8): 166-171.

Karg W. 1971 - Untersuchungen uber die Acarofauna in Apfelanlagen im hinblick auf den ubergang von standardspritzprogrammen zu integrierten Behandlungsmaßnahmen - Archiv. Pflanzen., 7(4): 243-279. doi:10.1080/03235407109431783

Karg W. 1972 - Untersuchungen uber die Korrelation zwischen dominierenden Raubmilben arten und ihrer möglichen Beute in Apfelanlagen - Archiv. Pflanzen., B 8(1): 29-52.

Karg W. 1975 - Nützlingsschonende Spinnmilbenbekämpfung im Obstbau — Gartenbau, 22: 51-54.

Karg W. 1982 - Diagnostic and systematics of predatory mites of the family Phytoseiidae Berlese in orchards Zool. Jahr. Syst., 109: 188-210.

Karg W. 1983 - Systematische untersuchung der Gattungen und Untergattungen der Raubmilbenfamilie Phytoseiidae Berlese, 1916, mit der beschreibung von 8 neuen Arten - Mitt. Zool. Mus. Berlin, 59(2): 293328.

Karg W. 1991 — Die Raubmilbenarten der Phytoseiidae Berlese (Acarina) Mitteleuropas sowie angrenzender Gebiete - Zool. Jahr. Syst., 118(1): 1-64.

Karg W., Edland T. 1987 - Neue Raubmilbenarten der Phytoseiidae Berlese, 1916 - Deut. Entomol. Z., 34(45), 387-395.

Klay A. 1987 - Ecosysteme verger de pommier: enquete faunistique sur les phytoseiides et étude de leurs interactions avec l'acarien rouge Panonychus ulmi (Koch) en laboratoire - Doctorate Thesis Ecole Polytechnique Federale Zurich, Switzerland, 110 pp.

Klein Z., Kuslitzky W., Zarabi L. 1994 - List of Israeli mites (Acarina) - Ministry of Agriculture. Plant Protection and Inspection Services, Entomological Section. Bet Dagan, 51 pp.

Kolodochka L.A. 1973 - Predaceous phytoseiid mites (Parasitiformes: Phytoseiidae) from the forest steppe of the Ukrainian SSR. Part I. Species of the genus Amblyseius — Vest. Zool., (5): 78-81.

Kolodochka L.A. 1974a - The predaceous phytoseiid mites (Parasitiformes: Phytoseiidae) from the forest steppe of the Ukranian SSR. Part II. Species of the genera Kampimodromus, Paraseiulus, Typhlodromus, Typhloctonus, Anthoseius, Phytoseius - Vest. Zool., (1): 25-29.

Kolodochka L.A. 1974b - Predaceous phytoseiid mites (Parasitiformes, Phytoseiidae) from the forest steppe of the Ukrainian SSR. Part III. A key to genera and species — Vest. Zool., (3): 87-89.

Kolodochka L.A. 1978 - Handbook on identifying of plant inhabiting phytoseiid mites - Nauka Dumka, Kiev. 78 pp.

Kolodochka L.A. 1980 - New species of phytoseiid mites from the fauna of the USSR (Parasitiformes: Phytoseiidae) - Vest. Zool., (2), 64-70.

Kolodochka L.A. 1981 - New phytoseiid mites from Crimea (Parasitiformes: Phytoseiidae) - I. Vest. Zool., (1): 18-22.

Kolodochka L.A. 1986 - On taxonomic status of two Typhloctonus species (Parasitiformes, Phytoseiidae) Vest. Zool., (2): 26-34.

Kolodochka L.A. 2009 - A review of predaceous mites of the genus Typhloctonus Muma (Parasitiformes, Phytoseiidae) in Ukraine with the description of unknown male of T. tuberculatus — Vest. Zool., 43(6): 481-494.

Kolodochka L.A., Omeri I.D. 2007 — Species diversity and distribution of plant-inhabiting phytoseiid mites (Parasitiformes, Phytoseiidae) in Kaniv Reserve Vest. Zool., 41: 35-46.

Kostiainen T.S., Hoy M.A. 1996 - The Phytoseiidae as biological control agents of pest mites and insects. A bibliography - Monograph 17, Gainesville. University of Florida, Agricultural Experiment Station, Institute of Food and Agricultural Sciences, 355 pp.

Kreiter S., Auger P., Grissa K.L. Tixier M.-S., Chermiti B., Dali M. 2002 - Plant inhabiting mites (Acari: Prostigmata and Mesostigmata) of some Northern Tunisian crops - Acarologia, 42(4): 389-402.

Kreiter S., Brian F. 1987 - Les Phytoseiidae de la vigne en France : aspects faunistique, biogéographiques et agronomique - Proceed. Intern. Conf. Pests Agric., 6(3): 241-249.

Kreiter S., Tixier M.-S., Auger P., Muckensturm N., Sentenac G., Doublet B., Weber M. 2000 - Phytoseiid mites of vineyards in France (Acari: Phytoseiidae) Acarologia, 41(1-2): 77-96.

Kropczyńska D., Garnis J., Jaworski S., Sagan A., Krezlewicz M. 2009 - Drapiezne ozocze (Acari: Phytoseiidae) Ystepujace Na Roslinach W otoczeniu plnatacji krzewow jagodowych - Progress in Plant Protection/Postępy w Ochronie Roślin, 49 (3): 1047-1056.

Kropczyńska D., Jenser G. 1968 - Data to the knowledge of the Phytoseiidae in Hungarian orchards - Fol. Entomol. Hungar., 21: 321-323. 
Kuznetsov N.N. 1984 - New species of predacious mites of the family Phytoseiidae (Parasitiformes) in the USSR — Entomol. Obozrenie, 63(2): 384-397.

Lehman R.D. 1982 - Mites (Acari) of Pennsylvania conifers - Trans. Amer. Entomol. Soc., 108: 181-286.

Lindquist E.E. 1994 - Some observations on the chaetotaxy of the caudal body region of Gamasine mites (Acari: Mesostigmata), with a modified notation for some ventrocaudal body setae - Acarologia, 35 (4): 323-326.

Lindquist E.E.,, Evans G.O. 1965 - Taxonomic concepts in the Ascidae, with a modified setal nomenclature for the Idiosoma of the Gamasina (Acarina: Mesostigmata) - Mem. Entomol.Soc. Canada, 47: 1-64. doi:10.4039/entm9747fv

Livshitz I.Z., Kuznetsov N.N. 1972 - Phytoseiid mites from Crimea (Parasitiformes: Phytoseiidae) [in Russian] — In: Pests and diseases of fruit and ornamental plants. Proceed. All-Union V. I. Lenin Academy of Agricultural Science, The State Nikita Botanical Gardens, 61: 13-64.

McMurtry J.A., Bounfour M. 1989 - Phytoseiid mites of Morocco, with descriptions of two new species and notes on the genera Kuzinellus, Typhloctonus and Typhlodromus (Acari: Phytoseiidae) - Acarologia, 30(1): 13-24.

McMurtry J.A., Croft B.A. 1997 - Life-styles of phytoseiid mites and their roles in biological control - Annu. Rev. Entomol., 42: 291-321. doi:10.1146/annurev.ento.42.1.291

Michelatti G., Pinoggi G., Schreiber G., Mozzone G.C. 1994 - Esperienze di lotta razionale contro l'eriofide del nocciolo (Phytocoptella avellanae Nal.) condotte nell'arco di un quinquennio in Piemonte [in Italian] Acta Hort., 351: 575-581.

Miedema E. 1987 - Survey of phytoseiid mites (Acari: Phytoseiidae) in orchards and surrounding vegetation of northwestern Europe, especially in the Netherlands. Keys, descriptions and figures - Nether. J. Plant Pathol., 93(2): 1-64.

Mijuskovic M., Tomasevic B. 1975 - The mites on the citrus trees on the Yugoslav littoral - Society for Science and Art of Montenegro Monogs., Section of Natural Sciences, Montenegro. 1, 203 pp.

Minarro M., Barros R., Ferragut F., Dapena E. 2005 Fitoseidos en plantaciones frutales experimentales de arándano, avellano, castaño, cerezo, kiwi y manzano en Asturias superficie dedicada a otros cultivos frutales - Bol. San. Veg. Plagas. 31: 493-501.

Moraes G.J. de, McMurtry J.A., Denmark H.A. 1986 A catalog of the mite family Phytoseiidae. References to taxonomy, synonymy, distribution and habitat EMBRAPA-DDT, Brasilia. 353 pp.
Moraes G.J. de, McMurtry J.A., Denmark H.A., Campos C.B. $2004-$ A revised catalog of the mite family Phytoseiidae - Zootaxa, 434: 1-494.

Moraza M.L., Peña-Estevez M.A.. 2006 - A new species of Neoseiulella (Acari: Phytoseiidae) from the Macaronesian Region, Canary Islands - Zootaxa, 1366: 55-59.

Moraza M.L., Peña-Estevez M.A., Ferragut F.. 2005 Two new species of Neoseiulella Muma of the Canary Islands (Acari: Phytoseiidae) - Intern. J. Acarol., 31(2):107-112. doi:10.1080/01647950508683659

Muma M.H. 1961 - Sub-familes, genera, and species of Phytoseiidae (Acarina: Mesostigmata) - Flor. St. Mus. Bull., 5(7): 267-302.

Narayanan E.S., Ghai S. 1961 - Some new records of mites associated with malformation in mango trees in India - Proceed. $48^{\text {th }}$ Indian Science Congress, 502 pp.

Narayanan E.S., Ghai S. 1963 - Some new records and a new species of mites associated with malformation of mango trees in India - Proceed. National Institute Science India, 29(b): 535-546.

Nesbitt H.H.J. 1951 — A taxonomic study of the Phytoseiidae (Family Laelaptidae) predaceous upon Tetranychidae of economic importance - Zool. Verhand., 12: 64 pp.+ 32 plates.

Nicotina M., Cioffi E. 1998 - Distribution of phytoseiid mites (Acarina: Phytoseiidae) in hazelnut-growing areas in Campania - Redia, 81: 115-124.

Okassa M., Tixier M.-S., Cheval B., Kreiter S. 2009 Molecular and morphological evidence for a new species status within the genus Euseius (Acari: Phytoseiidae): consequences for taxonomy - Can. J. Zool., 87: 689-698. doi:10.1139/Z09-057

Oudemans A.C. 1930 - Acarologische Aanteekeningen. CI - Entomol. Berich., 8: 48-53.

Papadoulis G.T., Emmanouel N.G. 1990 - Phytoseiid mites of Greece: new records of species and description of the male and immature stages of Typhlodromus erymanthii Papadoulis and Emmanouel - Biol. GalloHellen., 17(1): 13-26.

Papadoulis G.T., Emmanouel N.G. 1997 - New records of phytoseiid mites from Greece, with a description of Typhlodromus krimbasi sp. nov. (Acarina: Phytoseiidae) - Acarologia, 38(1): 21-28.

Prasad V. 1974 - A catologue of mites of India - Indira Acarology Publishing House, Ludhiana, Punjab. 320 pp.

Praslicka J., Bartekova A. 2008 - Occurrence of predatory mites of the Phytoseiidae family on apple-trees in integrated and ecological orchards - Plant Prot. Sc., 44(2): 57-60. 
Praslicka J., Bartekova A., Schlarmannova J., Malina R. 2009 - Predatory mites of the Phytoseiidae family in integrated and ecological pest management systems in orchards in Slovakia — Biologia, 64(5): 959-961.

Pritchard A.E., Baker E.W. 1962 - Mites of the family Phytoseiidae from Central Africa, with remarks on genera of the world - Hilgardia, 33: 205-309.

Ragusa S. 2006 - Phytoseiid mites (Parasitiformes Phytoseiidae) of some Eptanissan Islands (Greece) — Redia, 89: 1-7.

Ragusa S., Paoletti M.G. 1985 - Phytoseiid mites (Parasitiformes, Phytoseiidae) of corn and soybean agroecosystems in the low-laying plain of Veneto (N-E Italy) — Redia, 68: 69-89.

Ragusa S., Ragusa E. 1997 — On Some Phytoseiid Mites (Parasitiformes, Phytoseiidae) from Styria (Austria) Mitt. Naturw. Ver. Steiermarkt, 127: 137-145.

Ragusa di Chiara S., Tsolakis H. 1994 - Revision of the genus Kampimodromus Nesbitt, 1951 (Parasitiformes, Phytoseiidae), with a description of a new species Acarologia, 35(4), 305-322.

Ragusa S., Tsolakis H. 1998 - Phytoseiid mites (Parasitiformes, Phytoseiidae) of Lesvos Island (Greece) with a description of a new species - Entomol. Hellen., 12: 55-64.

Rambier A. 1974 - Relations entre les acariens nuisibles et leurs ennemis naturels - In: Les organismes auxiliares en verger de pommiers - IOBC/WPRS Bull., 3: 107-109.

Ripka G. 1998 - New data to the knowledge on the phytoseiid fauna in Hungary (Acari: Mesostigmata) Acta Phytopathol. Entomol. Hung., 33: 395-405.

Ripka G. 2006 - Checklist of the Phytoseiidae of Hungary (Acari: Mesostigmata) — Folia Entomol., 67: 229260.

Rivnay T., Swirski E. 1980 - Four new species of phytoseiid mites (Acarina: Mesostigmata) from Israel Phytoparasitica, 8: 173-187.

Rowell H. J., Chant D.A., Hansell R.I.C. 1978 - The determination of setal homologies and setal patterns on the dorsal shield in the family Phytoseiidae (Acarina: Mesostigmata) - Can. Entomol., 110: 859-876. doi:10.4039/Ent110859-8

Samsoniya T.I. 1972 - Species composition of predatory mites (Parasitiformes: Phytoseiidae) on stonefruit plants in eastern Georgia - Bull. Acad. Sc. Georg. SSR, 65(1): 193-196.

Samsoniya T.I. 1977 - Zonal-vertical distribution of Phytoseiidae in eastern Georgia on pip fruit culture Bull. Acad. Sc. Georg. SSR, 87(1): 181-183.

Sarospataki G., Szendrey L., Mikulas J. 1992 — Raubmilben in der Weingärten von Ungarn - Med. Fac. Landbouww. Univ. Gent, 57: 965-967.
Schicha E. 1975 - Predacious mites (Acarina: Phytoseiidae) on sprayed apple trees at Bathurst (N.S.W.) - J. Austral. Entomol. Soc., 14: 217-219. doi:10.1111/j.1440-6055.1975.tb02029.x

Schicha E. 1978 - Typhlodromus nesbitti Womersly redescribed (Acari: Phytoseiidae) - Austral. Entomol. Mag., 5(1): 5-7.

Schicha E. 1980 - Two new species of phytoseiid mites from Australia and redescription of six from New Zealand and Japan - Gen. Appl. Entomol., 12: 1631.

Schicha E. 1983 - New species, new records, and redescriptions of phytoseiid mites from Australia, Tahiti, and the African region (Acari: Phytoseiidae) Intern. J. Entomol., 25(2-3): 103-126.

Schicha E. 1987 — Phytoseiidae of Australia and neighboring areas - Indira Publishing House, West Bloomfield, Michigan, USA, 187 pp.

Schicha E., Elshafie M. 1980 - Four new species of phytoseiid mites from Australia, and three species from America redescribed (Acari: Phytoseiidae) - J. Austral. Entomol. Soc., 19: 27-36. doi:10.1111/j.14406055.1980.tb00957.x

Schicha E., McMurtry J. 1986 - Two new and two known species of Typhlodromus Scheuten (Acari: Phytoseiidae) from Australia - J. Austral. Entomol. Soc., 25: 177-183. doi:10.1111/j.1440-6055.1986.tb01100.x

Schicha E., O'Dowd D. J. 1993 - New Australian species of Phytoseiidae (Acarina) from leaf domatia - J. Austral. Entomol. Soc., 32: 297-305. doi:10.1111/j.14406055.1993.tb00589.x

Steeghs N., Nedstam B., Lundqvist L. 1993 - Predatory mites of the family Phytoseiidae (Acari, Mesostigmata) from south Sweden - Entomol. Tidskrift, 114: 19-27.

Swirski E., Amitai S. 1982 - Notes on predacious mites (Acarina: Phytoseiidae) from Turkey, with description of the male of Phytoseius echinus Wainstein and Arutunjan - Israel J. Entomol., 16: 55-62.

Swirski E., Amitai S. 1984 - Notes on phytoseiid mites (Mesostigmata: Phytoseiidae) from the Mediterranean littoral zone of Israel, with a description of a new species of Typhloctonus — Israel J. Entomol., 18: 71-82.

Swirski E., Amitai S. 1997a - Notes on phytoseiid mites (Mesostigmata: Phytoseiidae) of Mt. Carmel (Israel), with descriptions of two new species - Israel J. Entomol., 31: 1-20.

Swirski E., Amitai S. 1997b - Annotated list of phytoseiid mites (Mesostigmata: Phytoseiidae) in Israel — Israel J. Entomol., 31: 21-46.

Swirski E., Ragusa S. 1976 - Notes on predacious mites of Greece, with a description of five new species 
(Mesostigmata: Phytoseiidae) - Phytoparasitica, 4: 101-122. doi:10.1007/BF02980341

Swirski E., Ragusa S., Tsolakis H. 1998 - Keys to the phytoseiid mites (Parasitiformes: Phytoseiidae) of Israel — Phytophaga, 8: 85-154.

Szabo P. 1980 - Faunisztikai vizsgalatok Toserdo atkain (Acari) — Fol. Entomol. Hung., 33(2): 377-378.

Thill H. 1964 - Beobachtungen an raubmilben auf Zwetschenbaumen - Entomophaga, 9: 239-242.

Tixier M.-S., Guichou S., Kreiter S. 2008 - Morphological variation in the biological control agent Neoseiulus californicus (McGregor) (Acari : Phytoseiidae): consequences for diagnostic reliability and synonymies Invert. Syst., 22: 453-469.

Tixier M.-S., Klaric V., Kreiter S., Duso C. 2010 - Phytoseiid Mite Species From Croatia, With Description of a New Species of the Genus Typhlodromus (Typhlodromus) - Entomol. Soc. Amer., 103(2): 165-180. doi:10.1603/AN09092

Tixier M.-S., Kreiter S., Auger P., Sentenac G., Salva G., Weber M. 2000 - Phytoseiidae mite species located in uncultivated areas surrounding vineyards in three French regions - Acarologia, 41(1-2): 127-140.

Tixier M.-S., Kreiter S, Cheval B., Auger P. 2003 - Morphometric variation between populations of Kampimodromus aberrans (Oudemans) (Acari:Phytoseiidae): implications for the taxonomy of the genus - Invert. Syst.,17(2): 349-358.

Tixier M.-S., Kreiter S., Ferragut F., Cheval B. 2006a — The suspected synonymy of Kampimodromus hmiminai and Kampimodromus adrianae (Acari: Phytoseiidae): morphological and molecular investigations - Can. J. Zool., 84(8): 1216-1222. doi:10.1139/z06-108

Tixier M.-S., Kreiter S., Barbar Z., Ragusa S., Cheval B. $2006 \mathrm{~b}$ - The status of two cryptic species: Typhlodromus exhilaratus Ragusa and Typhlodromus phialatus Athias-Henriot (Acari: Phytoseiidae): consequences for taxonomy - Zool. Scr., 35(2): 115-122. doi:10.1111/j.1463-6409.2006.00222.x

Treat A.E. 1975 - Mites of moths and butterflies Comstock Publishing Associates, Cornell Univ. Press, Ithaca, USA, 362 pp.

Tseng Y.H. 1975 — Systematics of the mite family Phytoseiidae from Taiwan, with a revised key to genera of the world (I) - J. Agric. Assoc. China, NS, 91: 45-68.

Tseng Y.H. 1983 - Further study on phytoseiid mites from Taiwan (Acarina: Mesostigmata) - Chin. J. Entomol., 3: 33-74.

Tuovinen T. 1993 - Identification and occurrence of phytoseiid mites (Gamasina: Phytoseiidae) in Finnish apple plantations and their surroundings - Entomol. Fenn., 4: 95-114.
Tuovinen T., Rokx J.A.H. 1991 — Phytoseiid mites (Acari: Phytoseiidae) on apple trees and in surrounding vegetation in southern Finland. Densities and species composition - Exp. Appl. Acarol., 12: 35-46. doi:10.1007/BF01204398

Van de Vrie M. 1963 - Observations on the ecology of predatory mites (Phytoseiidae) on fruit trees - Mitt. Schweizer. Entomol. Gesell., 36: 54-55.

Van de Vrie M. 1972 - Phytoseiid mites on tree crops, ornamental and wild plants in the Netherlands - Entomol. Berich., 32: 13-20.

Van de Vrie M., Fluiter H.J. de. 1958 - Some observations on the effect of insecticides and acaricides on the population of the European red spider mite (Metatetranychus ulmi Koch) and its principal predators in commercial orchards in the Netherlands - Proceed. $10^{\text {th }}$ Intern. Cong. Entomol., Montreal, Aug. 17-25, 1956, Canada. 4: 603-606.

Viollier B., Fauvel G. 1984 - Comparaison de la faune vivant sur 2 espèces de poiriers, Pirus amygdaliformis Vill. et $P$. communis $L$., en garrigue et dans un verger abandonné de la région de Montpellier [in French] Agronomie, 4(1): 11-18. doi:10.1051/agro:19840102

Wainstein B.A. 1958 - New species of mites of the genus Typhlodromus (Parasitiformes: Phytoseiidae) from Georgia - Soobsh. Akad. Nauk. Gruz. SSR, 21(2): 201-207.

Wainstein B.A. 1960 - New species and subspecies of the genus Typhlodromus Scheuten (Parasitiformes, Phytoseiidae) of the USSR fauna - Zool. Zh., 39: 683-690.

Wainstein B.A. 1961 - New species of mites of the genus Typhlodromus (Parasitiformes: Phytoseiidae) in Georgia - Tr. Instit. Zool. Akade. Nauk Gruz. SSR, 18: 153-162.

Wainstein B.A. 1962 - Révision du genre Typhlodromus Scheuten, 1857 et systematique de la famille des Phytoseiidae (Berlese 1916) (Acarina: Parasitiformes) Acarologia, 4: 5-30.

Wainstein B.A. 1973 - Predatory mites of the family Phytoseiidae (Parasitiformes) of the fauna of the Moldavian SSR — Fauna i Biologiya Nasekomykh Moldavii, Akademiya Nauk Moldavskoy SSR, Institut Zoologii, 12: 176-180.

Wainstein B.A. 1977 - A contribution to the fauna of the family Phytoseiidae (Parasitiformes) in Australia Zool. Zh., 56: 1413-1416.

Wainstein B.A., Vartapetov S.G. 1973 - Predatory mites of the family Phytoseiidae (Parasitiformes) of Adzharskaya ASSR - Akademiya Nauk Armyanskoy SSR, Biologicheskiy Zhurnal Armenii, 26(2): 102-105.

Walter D. E. 1997 - Notes on Australian Typhlodrominae (Acari: Mesostigmata: Phytoseiidae), with descriptions of two new species of Neoseiulella Muma from 
Tropical Rainforests in far northern Queensland Austral. J. Entomol., 36: 333-338. doi:10.1111/j.14406055.1997.tb01482.x

Walter D.E. 1999 - Cryptic inhabitants of a noxious weed: mites (Arachnida: Acari) on Lantana camara L. invading forests in Queensland - Austral. J. Entomol., 38: 197-200. doi:10.1046/j.14406055.1999.00101.x

Westerboer I., Bernhard F. 1963 - Die Familie Phytoseiidae Berlese 1916 - In: Stammer, H. (Ed.), Beitrage zur Systematik und Okologie mitteleuropaischer Acarina. Band II, Mesostigmata I. pp. 451-791.

Wiackowski S.K. Suski Z.W. 1963 - Preliminary investigations on the predacious mites (Acarina: Phytoseiidae) in Poland - Prace Instytutu Sadownictwa, 7: 233-237.

Womersley H. 1954 - Species of the subfamily Phytoseiinae (Acarina: Laelaptidae) from Australia - Austral.
J. Zool., 2: 169-191. doi:10.1071/ZO9540169

Wu W.N., Lan W.M. 1991 - A new species of the genus Iphiseius from Guangdong Province, China (Acari: Phytoseiidae) - Acta Zootax. Sin., 16(2): 191-193.

Zaher M.A. 1986 - Predaceous and nonphytophagous mites (Nile Valley and Delta) - Survey and ecological studies on phytophagous, predaceous and soil mites in Egypt. PL 480 Programme USA, Project EG-ARS30, Grant No. FG-EG-139, 567 pp.

\section{COPYRIGHT}

(co) EY-No-ND Kanouh M. et al. Acarologia is under free license. This open-access article is distributed under the terms of the Creative Commons-BY-NC-ND which permits unrestricted non-commercial use, distribution, and reproduction in any medium, provided the original author and source are credited. 